Universidad Nacional de La Plata

Facultad de Humanidades y Ciencias de la Educación

Doctorado en Letras

\title{
CULTURA LETRADA Y ETNICIDAD EN LOS MANUSCRITOS de Jacinto Ventura de Molina \\ (1817-1840)
}

Doctorando: Alejandro Gortázar

Directora: Dra. Teresa Basile La Plata, octubre de 2014 


\section{Cultura letrada y etnicidad en los manuscritos de Jacinto Ventura de Molina}

(1817-1840)

\section{Resumen}

El presente trabajo analiza la trayectoria como letrado de Jacinto Ventura de Molina (1766c.1841), un afrodescendiente libre que escribió cartas, memoriales, oraciones y documentos jurídicos sobre diversas materias durante la primera mitad del siglo XIX en Montevideo. Es tal vez el único caso de un escritor afrodescendiente en ese período en el Río de la Plata. El objetivo de este trabajo es proporcionar una descripción densa de su acción en un período de grandes transformaciones, ubicado entre fines del siglo XVIII y las primeras décadas del XIX, en el que cae la dominación colonial española, se dan las guerras por la independencia y se instituye el Estadonación. En tal sentido procuraré exhibir las tramas de significación que explican a Molina, el proceso de aculturación y alfabetización del que fue objeto, la red de relaciones que fue tejiendo en Montevideo, las dificultades de tomar la palabra en una sociedad racista, su lugar en la cultura letrada montevideana, las implicancias de escribir su propia historia y de asumir la representación colectiva de otros afrodescendientes.

En el primer capítulo "Jacinto Ventura de Molina en la ciudad letrada (1766-1837)" reconstruyo la trayectoria letrada de Molina desde la perspectiva del actor y a través de sus manuscritos contrastándola con otra documentación y con la bibliografía sobre el período. Como un ejercicio de microhistoria, a la manera de Carlo Ginzburg, pretendo estudiar a los letrados montevideanos, los modos de circulación de sus textos, la publicación, la educación formal e informal, las reglas de inclusión/exclusión del grupo a través de la perspectiva de un sujeto marginal que la historia dejó a un lado. En el segundo capítulo, "Cultura letrada y etnicidad en el siglo XIX rioplatense", discuto el concepto de ciudad letrada de Ángel Rama como modelo teórico para entender al letrado como sujeto y sus relaciones con el poder en América Latina. Propongo a su vez ciertos ajustes al modelo y su sustitución por el concepto de cultura letrada a partir de las distintas críticas que el texto ha recibido desde su publicación en 1984.

En los dos capítulos siguientes abordo dos aspectos específicos de los manuscritos. En el capítulo "Escribir «yo»: mimesis y autobiografía", analizo el resultado de asumir la palabra escrita y construir un "yo" a partir de la experiencia de ser un hombre negro en una sociedad racista, la importancia de la mimesis con la cultura de los blancos como estrategia básica para construir un yo y las implicancias de este dispositivo mimético en el caso de Molina (Ramos, 1996). Este capítulo se complementa con una perspectiva comparada sobre las autobiografías de esclavos tanto en el ámbito hispanoamericano como en el anglosajón. En el capítulo "Intermediar, representar: Jacinto Ventura de Molina entre esclavos", estudio la dimensión colectiva de la resistencia de los africanos y sus descendientes en Uruguay y la posición fronteriza que Molina ocupó entre los colectivos de afrodescendientes y el Estado.

El trabajo reconstruye el punto de vista de Jacinto Ventura de Molina en la cultura letrada del siglo XIX a través de una perspeciva étnico-racial poco o nada explorada en la historia, la crítica y la teoría de la literatura uruguaya. Creo que su caso permite describir otras posiciones liminares en América Latina y proporcionar herramientas para comprender las posibilidades emancipatorias que la escritura y el accionar colectivo ofrecen a los sujetos subalternos en contextos hostiles como la primera mitad del siglo XIX.

\section{Palabras clave}

ciudad letrada, etnicidad, autobiografía, subalternidad, literatura uruguaya, Jacinto Ventura de Molina 
Índice

Cultura letrada y etNicidad en los manuscritos de Jacinto Ventura de Molina (1817-1840)

Introducción

Capítulo I

Jacinto Ventura de Molina en la ciudad letrada (1766-1837) 18

1. Los años de formación (1766-1782) 21

1.1. Padres africanos: libres y fieles $\quad 21$

1.2. Amo y tutor: el Brigadier José Eusebio de Molina 30

2. La libertad en la Cisplatina (1782-1828) 44

2.1. Esposo, zapatero y militar 45

2.2. Molina y la protección de Federico Lecor, Barón de la Laguna $\quad 50$

2.3. Escribir las Glorias de la Santa Caridad de Montevideo 56

3. Un nuevo escenario: Molina en el Estado-nación (1830-1837) 63

3.1. El defensor de "los ciudadanos de color" 66

3.2. Los límites de la comunidad imaginada 69

\section{Capítulo II}

$\begin{array}{ll}\text { Cultura letrada y etnicidad en el siglo XIX rioplatense } & 77\end{array}$

1. La piedra y la letra: la ciudad letrada como modelo 79

2. Definir una cultura letrada 94

3. Un afrodescendiente libre en una cultura letrada 106

\section{Capítulo III}

$\begin{array}{ll}\text { Escribir "yo": mimesis y autobiografía } & 124\end{array}$

1. Mimesis y aculturación: el otro disciplinado 127

2. La autobiografía de afrodescendientes en Hispanoamérica:
Jacinto Ventura de Molina y Juan Francisco Manzano

3. Escribir "yo" en el contexto anglosajón: una perspectiva comparada 162

\section{CAPÍTULO IV}

Intermediar, representar: Jacinto Ventura de Molina entre esclavos 173

1. La Sociedad de Negros Congos de Gunga y la rebelión de Félix 182

2. El rol de Jacinto Ventura de Molina 191

3. Posiciones fronterizas: representar, intermediar 205

A modo de conclusión.

Cultura letrada y etnicidad en la literatura uruguaya 212

$\begin{array}{lr}\text { Fuentes } & 237\end{array}$

$\begin{array}{ll}\text { Bibliografía } & 238\end{array}$ 


\section{Introducción}

El presente trabajo analiza la trayectoria como letrado de Jacinto Ventura de Molina (1766-c.1841), un afrodescendiente libre que escribió cartas, memoriales, oraciones y documentos jurídicos sobre diversas materias durante la primera mitad del siglo XIX en Montevideo. Es tal vez el único caso de un escritor afrodescendiente en ese período en el Río de la Plata. El objetivo de este trabajo es proporcionar una descripción densa de su acción en un período de grandes transformaciones, ubicado entre fines del siglo XVIII y las primeras décadas del XIX, en el que cae la dominación colonial española, se dan las guerras por la independencia y se instituye el Estado-nación. En tal sentido procuraré exhibir las tramas de significación que explican a Molina, el proceso de aculturación y alfabetización del que fue objeto, la red de relaciones que fue tejiendo en Montevideo, las dificultades de tomar la palabra en una sociedad racista, su lugar en la cultura letrada montevideana, las implicancias de escribir su propia historia y de asumir la representación colectiva de otros afrodescendientes.

Nació el 15 de octubre de 1766 en la ciudad de Rio Grande (Rio Grande do Sul, Brasil). Fue el único hijo de Ventura y Juana de Sacramento, dos negros libres al servicio del militar español José Eusebio de Molina (1707-1782). Nació en esa ciudad, que había sido fundada en 1737 por el Brigadier portugués José da Silva Paes en el marco de las disputas entre España y Portugal sobre los límites imperiales, porque los españoles al mando de José Eusebio de Molina la ocuparon entre 1763 y 1776. Sus primeros años de vida estuvieron marcados por los movimientos de su tutor por Santa Teresa, Maldonado, Colonia del Sacramento, Montevideo y Buenos Aires. Desde muy niño Jacinto Ventura fue el protegido del español, quien hizo las veces de tutor, brindándole toda la educación y la 
instrucción militar que pudo por iniciativa propia o a través de personas de su entorno.

Con 16 años Jacinto Ventura se convierte en un hombre libre, fallecidos sus padres y su tutor. El 27 de julio de 1788 se casa con Rufina Campana, una afrodescendiente porteña que fallece en 1819. Dos años antes, con la ocupación luso-brasileña del territorio de la Banda Oriental, Molina retoma su actividad militar -abandonada por su fidelidad al rey y tras rechazar unirse al artiguismo en 1815- y se vincula al gobierno de Federico Lecor, Barón de la Laguna, y a su entorno en Montevideo. Es precisamente el Emperador de Brasil quien, según Molina, le otorga su título de Licenciado en Reales Derechos, el cual será reconocido por el Estado uruguayo en 1832. En 1827 la Hermandad de la Caridad, una asociación filantrópica de la elite montevideana, le solicita que escriba las Glorias de la Caridad de Montevideo que Molina redacta durante su convalecencia en el Hospital de la Caridad entre 1827 y 1830. Al reconocer su título el Estado uruguayo lo nombra "defensor de negros" y en ese marco defiende a la Sociedad de Negros Congos de Gunga en 1834, entre otras acciones legales que llevó adelante hasta su muerte en Montevideo en 1841.

La sala de materiales especiales de la Biblioteca Nacional de Montevideo (Biblomuseo Arturo Scarone) y no el Archivo Literario, aloja desde los años noventa del siglo XX una colección con el nombre de Jacinto Ventura de Molina. La colección está compuesta por: a) una ilustración sin fechar de Manuel Besnes e Irigoyen; b) un impreso fechado en 1834 firmado por Molina y otros integrantes de la Sociedad de Negros Congos de Gunga; y c) tres gruesos volúmenes de manuscritos (unos mil folios) encuadernados y cosidos (se desconoce si esta encuadernación la hizo el propio Molina o los sucesivos 
coleccionistas que tuvieron en su poder el archivo). No tengo datos sobre la historia del dibujo de Besnes e Irigoyen, ni de cómo llegó a la Biblioteca Nacional. Tampoco sobre el impreso, que es conocido porque Ildefonso Pereda Valdés lo transcribió y publicó en 1941. En cambio, sobre la historia de los manuscritos hay más información.

El único impreso de la colección está encuadernado y en su contratapa algún funcionario de la Biblioteca Nacional o alguno de los coleccionistas que tuvieron el archivo, anotó a lápiz que se trataba de un "rarísimo impreso" que atribuye a la Imprenta de la Caridad y que no aparece en las bibliografías de impresos, el anónimo menciona las de Dardo Estrada (1912) y Horacio Arredondo (1929). También describe el resto de los materiales (el grabado y los manuscritos) e indica que proceden de la Ex-Colección Daniel García Acevedo. ${ }^{1}$ La información disponible en los manuscritos no abunda aunque en la primera página de uno de los tomos se encuentra una descripción hecha por Joaquín de la Sagra y Periz, uno de los protectores de Molina hacia 1830, que hace referencia irónicamente a la cantidad infinita de textos. En el mismo folio se encuentra la siguiente frase: "Esta nota es de puño y letra del Señor Joaquín / Sagra y Piriz. de quien se adquirió esta obra / M Ferreira.”. Hay aquí entonces una primera hipótesis de trabajo sobre la historia de la colección: luego de la muerte de Molina pasó a manos de uno de sus promotores o mecenas, Joaquín de Sagra y Périz, luego este (o sus familiares) la vendió a alguien llamado M. Ferreira y finalmente este último pudo hacer lo mismo con Daniel García Acevedo.

1 Según Zubillaga el Dr. Daniel García Acevedo (1868-1946) fue un "jurisconsulto e historiador" que desempeñó la cátedra de "Historia Americana y Nacional" en Enseñanza Secundaria, autor del Código Rural de 1915 y de diversos trabajos sobre el Derecho Privado: "Su producción historiográfica estuvo, fundamentalmente, orientada al período colonial", además integró el Instituto Histórico y Geográfico del Uruguay y la Junta de Historia Nacional (2003: 180. Nota 4). En un libro de Eduardo Acevedo sobre Artigas, Tomo I de la emblemática colección Archivo Artigas, el historiador hace referencia a tres "bibliotecas particulares", una de ellas la de García Acevedo, en las que consultó libros y manuscritos (1950: 21). Lo que hasta ahora no he podido saber es si esta colección privada fue comprada por el Estado, al menos no se recoge esa información en los portales oficiales del Archivo General de la Nación, la Biblioteca Nacional y el Museo Histórico, por lo que tiendo a pensar que la colección fue vendida a privados. 
No obstante Ferreira no adquirió todo lo que Sagra tenía, una parte mínima de sus escritos y otro impreso se encuentran en el Archivo General de la Nación (AGN) en Montevideo, dentro de la colección de papeles de Joaquín de Sagra y Périz, pertenecientes al Ex Archivo y Museo Histórico Nacional. ${ }^{2}$ Salvo esta carpeta en el Archivo General de la Nación, el grueso de manuscritos de Molina, que pertenecía teóricamente a Daniel García Acevedo, fallecido en 1946, llegaron a manos de un rematador en Montevideo en los años noventa. Según Acree y Borucki, Alberto Britos Serrat tuvo un "papel crucial" en la compra de los manuscritos por parte de la Biblioteca Nacional (2008: 8). En algún momento entre 1994 y 1996, según el relato del historiador y militante afrodescendiente Oscar Montaño, junto con Alberto Britos Serrat, otro intelectual y militante, ambos supieron que los manuscritos serían rematados en Remates Corbo:

Con Alberto Britos Serrat decidimos tomar cartas en el asunto del remate. Nos parecía escandaloso que un material invaluable y desconocido para casi toda la población fuera a rematarse. Decíamos que lo más probable es que terminase en manos privadas que limitaran el acceso al material o que lo comprase un coleccionista extranjero. De inmediato nos dividimos las tareas: Alberto tenía conocimiento del rematador y su función fue interiorizarse de los pormenores y tratar de alargar los plazos. Mi papel fue hablar con García Viera [Director en ese entonces del Archivo General de la Nación] y ponerlo al tanto de la importancia que ese material debía tener para el colectivo afrouruguayo. Él lo entendió de inmediato y se comprometió a realizar todos los contactos posibles. Era el

2 Caja 205. Correspondencia y Misceláneas. Carpeta 7. Papeles de Jacinto Ventura de Molina, 1834-1835. El material que se conserva es: una carta dirigida a Sagra en la que propone la creación del Colegio de los Magos de María Rufina Campana, una institución educativa para afrodescendientes de la que incluso dibujó su fachada y la agregó como adjunto; un poema impreso en hoja suelta posiblemente armado en la Imprenta de la Caridad; y finalmente, un poema manuscrito. 
segundo gobierno de Julio María Sanguinetti, el Ministro de Cultura era Samuel Lichtensztein. García Viera realmente estaba interesado en que los manuscritos pasaran a la órbita oficial. Además García Viera era del Partido Colorado. Con Alberto Britos deducíamos que si alguien podía actuar con efectividad era justamente él. ${ }^{3}$

Britos Serrat con la ayuda de Montaño convencieron a los jerarcas del Partido Colorado de entonces y los manuscritos, por razones que Montaño desconoce, llegaron a la Biblioteca Nacional y fueron destinados a la sala de materiales especiales "Biblomuseo Arturo Scarone".

Al dorso de un poema manuscrito de Jacinto Ventura de Molina alguien escribió, posiblemente Sagra y Périz hacia 1835, que el "tío" Molina era "un moreno que se decía Doctor en Leyes y que todos los antiguos le hacían creer que lo era" (Gortázar, 2008: 144145. Nota 149). Más allá del tratamiento familiar que implica la expresión “tío”, este breve pasaje deja a la posteridad una interpretación que le da sentido al escaso interés que su obra manuscrita suscitó entre la elite letrada: la idea de que se trataba de un loco que "se creía" abogado y todos se lo hacían creer. Una representación similar, que se puede leer explícitamente en el texto que acompaña la litografía de Besnes -escrito tal vez por el propio pintor en el que lo describe como un "Escritor original e infatigable sobre toda materia, en prosa y verso"-, proporciona datos sobre su vida como la fecha y el lugar de nacimiento, su casamiento con María Rufina Campana del cual "No queda prole; mas los

3 Comunicación personal vía e-mail, 28 de agosto de 2014. 
abortos de su fecundo ingenio, aunque inimitables, dejan fundado un nuevo género de literatura que ya lleva su nombre, y lo hace tan famoso, o más, que Dulcinea hizo al Toboso". El texto de Besnes pone en circulación la ironía, la burla directa sobre los "abortos de su fecundo ingenio" que versaban sobre muy diversos temas, y que fundan un "nuevo género de literatura". Finalmente la cita al Quijote al comparar a Rufina con Dulcinea sugiere la locura de Molina. La posible lectura de sus contemporáneos en tono de burla, señalándolo como un loco, se consolidó en la ciudad letrada con un texto de Isidoro de María publicado en una de sus obras más difundidas -Montevideo antiguo- en el que recuerda anécdotas del pasado colonial montevideano. Allí De María incluye un relato sobre Molina junto al de otro hombre -Pepe Onza-, descritos como personajes graciosos a los que los "muchachos callejeros" seguían y molestaban (240).

La primera aparición de un texto de Molina tomado en serio, en este caso como fuente, se produce en 1941, cuando Ildefonso Pereda Valdés incluye la transcripción del impreso sobre los Congos de Gunga en el anexo documental (Documento $\mathrm{N}^{\circ}$ 59) de su Negros esclavos y negros libres. Esquema de una sociedad esclavista y aporte del negro en nuestra formación nacional (1941: 157-160) comentándolo brevemente y sin explicar cómo lo conocía o lo había leído (1965: 96). En 1968 Carlos Rama cita (mal) el documento sin aclarar el origen de su fuente (Pereda) para ejemplificar el progreso de la conciencia de sus derechos de los afro-uruguayos, su nivel cultural y el cambio de la "tradicional autoimagen de su condición social" (65). Para Rama, Molina personifica "el ascenso social y cultural de los afro-uruguayos" (66). Estos dos autores parecen abrir una nueva interpretación, más positiva, de Jacinto Ventura de Molina y de su rol en la sociedad montevideana. Fundamentalmente Rama, porque Ildefonso Pereda Valdés había publicado en 1965 una reedición ampliada de su libro de 1941 y agregó un capítulo central para la crítica literaria de los escritores afrodescendientes "Desarrollo intelectual del negro 
uruguayo". En ese artículo su relato sobre los intelectuales negros no inicia con Jacinto Ventura de Molina sino con los periodistas que fundaron el semanario La Conservación en $1872(1965: 206){ }^{4}$

Después de Pereda y Rama nadie hizo referencia a ninguna otra documentación ni mención alguna a Jacinto Ventura de Molina hasta que Alberto Britos Serrat compiló la Antología de poetas negros uruguayos (1990) en cuya introducción menciona a Jacinto Ventura de Molina como un "licenciado negro en derecho" (8) y en una nota a pie afirma lo siguiente: "El negro (...) dejó tres obras manuscritas inéditas. Una sobre filosofía, otra sobre derecho y la tercera sobre literatura según me ha informado don Manuel Villa, director de la revista "Bahía". Esos manuscritos se conservaron en manos de una familia conocida de Montevideo, quien la habría vendido a un coleccionista" (12). Luego describe el impreso utilizado por Pereda Valdés sin mencionar la fuente. En 1990 Britos aporta un dato central: hay tres tomos de manuscritos e incluso menciona un posible orden. Quiere decir que además de Britos, Manuel Villa había tenido acceso a ellos o al menos alguien le había dicho cómo estaban ordenados.

En 1997 Gustavo Goldman publica un trabajo sobre la fiesta católica de los Reyes Magos en el barrio Sur. Los manuscritos de Molina eran un elemento central para estudiar los antecedentes de esta fiesta en el siglo XIX. Goldman califica a los manuscritos de “complejos" para obtener por ejemplo datos de fechas precisas (2003: 47), cita un documento de Sagra y Périz que está entre los manuscritos de Molina en el que enumera las sociedades con sus reyes y reinas (51), el impreso publicado por Pereda Valdés (74) y una curiosa cita a Molina en la prensa de 1877 (84). También en 1997 Oscar Montaño analiza los papeles de Molina y recupera, entre otros documentos, uno que hace referencia al grupo carabarí, "una extraña nación africana de la cual no teníamos datos de su

4 Sobre este semanario y otro que salió al año siguiente (El Progresista) escribí un artículo (Gortázar, 2006). 
existencia en estos lares" (1997: 67). Finalmente en 2006 el militante e invesigador afrodescendiente Romero Jorge Rodríguez incluye un breve capítulo sobre Molina en su Mbundo malungo a mundele (2006: 50) en el que en su afán de introducirlo en su relato sobre el colectivo en las salas de nación, reduce el caso de Molina a su actuación frente a los Congos de Gunga, comete un error en un dato sobre la rebelión de 1833 (dice que fue en 1803) y afirma que "buena parte de sus manuscritos hacen referencia a esa defensa y brindan a su vez, documentación medular sobre la mencionada revuelta, y de los pueblos venidos a estas tierras en general" (51). En definitiva con los tres tomos de manuscritos ya en la Biblioteca Nacional, los investigadores daban cuenta de la dificultad en el tratamiento de los mismos y comenzaban a citar algunos documentos, superando el aporte inicial de Pereda Valdés.

La historia que sigue es la que protagonicé en 2007 con un ensayo de interpretación, que profundizaba un pequeño capítulo que había adelantado en 2003 y la antología de manuscritos que elaboré junto a un equipo de investigadores (Adriana Pitetta y Juan Manuel Barrios) en 2008. Luego le sucedió el trabajo que llevaron adelante los investigadores William Acree y Alex Borucki (2008). Los cinco hemos intentado dar claves de interpretación y un mayor apoyo docuemental a nuestras hipótesis. Aún así en estos últimos años no hemos podido resistir la tentación editorial, que podríamos calificar como antifoucaultiana, de hacer un "autor" y construirle una "obra". En mi caso cumplí parcialmente con el objetivo de situar su caso en el contexto de la bibliografía sobre el siglo XIX uruguayo, fundamentalmente la primera mitad, que en las últimas dos décadas ha recibido especial atención de los investigadores en literatura uruguaya. 
Además de esta introducción y las conclusiones, este trabajo está dividido en cuatro partes con el fin de ofrecer, como propone el antropólogo Clifford Geertz, una descripción densa de Jacinto Ventura de Molina a partir de sus manuscritos. Para Geertz la antropología no es una ciencia experimental que busca leyes sino una interpretativa que busca significaciones. El antropólogo al hacer trabajo de campo y escribir una etnografía busca y capta líneas de significación que intenta explicar. Por lo tanto lee e interpreta al hombre inserto en unas tramas de significación y su objetivo es "establecer una jerarquía estratificada de estructuras significativas en las que se producen, perciben e interpretan los productos culturales" (22). Hago la analogía con la propuesta de Geertz aunque tengo claro que en la comparación entre los términos se pierde la dimesión del presente, de la observación de la acción del hombre y la perspectiva del actor "en la aldea" (33). En este trabajo intento una descripción densa de una comunidad, un grupo social, una perspectiva del actor, un conjunto de prácticas que ponen en funcionamiento estas "estructuras de significación" pero en papeles. Se trata de escribir las prácticas desde el punto de vista histórico y de reconstruir un contexto con estas tramas de significación en el horizonte. Me propongo poner en juego tres estructuras de significación: a) la trayectoria de Jacinto Ventura de Molina a partir de sus propias palabras, su forma de narrarse a sí mismo y al mundo social; b) la cultura letrada de fines del siglo XVIII y comienzos del siglo XIX, antes de la estampida romántica que iniciará la idea de una literatura nacional en el marco de Estados-nación recientemente inaugurados, considerando las lecturas, las ideologías y las práctica de la escritura; c) los confictos sociales (étnico-raciales) y políticos, siempre en relación a los contenidos de las intervenciones públicas de Jacinto Ventura de Molina, y su vinulación concreta con algunas autoridades (Policía y Juzgados). 
En el primer capítulo “Jacinto Ventura de Molina en la ciudad letrada (1766-1837)” organizo la trayectoria de Molina en un relato de tres partes: los años de formación letrada entre 1766 y 1782, sus primeros años en libertad atravesando el proceso independentista y la ocupación luso-brasileña entre 1782 y 1828, y su desempeño en el nuevo escenario del Estado-nación entre 1830 y 1837. Para ello recurriré a sus manuscritos, es decir, a su propio testimonio tratando de contrastar la perspectiva del actor, siempre marcada por las necesidades del presente -que es signo del discurso autobiográfico-, con otra documentación y con la bibliografía sobre el período. Es un ejercicio de microhistoria en la medida en que, como explica Carlo Ginzburg en El queso y los gusanos (2001 [1976]), en la trayectoria "de un individuo mediocre, carente en sí de relieve y por ello representativo pueden escrutarse, en un microcosmos, las características de todo un estrato social en un determinado período histórico" (21). De este modo Ginzburg analiza la mentalidad campesina en el siglo XVI, es decir, de un sector de las "clases subalternas" a través de la vida de un molinero. Del mismo modo es posible estudiar a los letrados montevideanos, los modos de circulación de los textos, la publicación, la educación formal e informal, las reglas de inclusión/exclusión del grupo a través de la perspectiva de un sujeto marginal que la historia dejó a un lado.

El relato del primer capítulo no es inocente y empieza a delinear alguna preocupaciones teóricas que desarrollo en el segundo capítulo "Cultura letrada y etnicidad en el siglo XIX rioplatense". Aquí discuto el concepto de ciudad letrada de Ángel Rama como modelo teórico para entender al letrado como sujeto y sus relaciones con el poder en América Latina. Propongo a su vez ciertos ajustes al modelo y su sustitución por el concepto de cultura letrada a partir de las distintas críticas que el texto ha recibido desde su publicación en 1984. Asimismo recupero un texto de Rama publicado póstumamente y discuto su concepto de cultura a través de los aportes de la antropología contemporánea. A 
partir de mi propuesta en el último apartado ensayo una reescritura de la trayectoria de Molina para dar entrada a dos propuestas concretas de lectura.

La primera de esas lecturas, en el tercer capítulo "Escribir «yo»: mimesis y autobiografía", explica el resultado de asumir la palabra escrita y construir un "yo" a partir de la experiencia de ser un hombre negro en una sociedad racista, la importancia de la mimesis con la cultura de los blancos como estrategia básica para construir un yo y las implicancias de este dispositivo mimético en el caso de Molina (Ramos, 1996). Este capítulo se complementa con una perspectiva comparada sobre las autobiografías de esclavos tanto en el ámbito hispanoamericano como en el anglosajón. La experiencia individual de Molina no es una experiencia aislada y aunque no abundan los relatos de hombres negros esclavizados o libres, los textos del cubano Juan Francisco Manzano, del inglés Oludah Equiano y del norteamericano Mahommah G. Baquaqua permiten ubicar mejor el caso de Molina y su autoconstrucción como "letrado negro".

La segunda lectura concreta está relacionada con su papel como representante de un colectivo de afrodescendientes, los negros Congos de Gunga, en los primeros años de la República. En el cuarto capítulo, "Intermediar, representar: Jacinto Ventura de Molina entre esclavos", analizo la dimensión colectiva de la resistencia de los africanos y sus descendientes en Uruguay a través del caso de una rebelión de esclavos de la que Molina fue testigo privilegiado. A partir de la documentación existente en el Archivo General de la Nación y de la colección de manuscritos de Molina, se desprende que su posición fronteriza de "letrado negro" le permitió actuar en la defensa de un colectivo que se vio afectado por las medidas tomadas por el gobierno a raíz de la revuelta. La acción de Molina frente al Juzgado y la Policía hizo que se levantara una prohibición de realizar bailes para 1835. Esta posición fronteriza permite comparar la acción de Molina con la de otros sujetos subalternos en América Latina que ocuparon posiciones similares como 
Guamán Poma o el Inca Garcilaso.

En la profundización de estos dos aspectos concretos, el individual y el colectivo, creo haber cumplido con la tarea de describir el punto de vista de Jacinto Ventura de Molina en la cultura letrada del siglo XIX a través de una perspeciva étnico-racial poco o nada explorada en la historia, la crítica y la teoría de la literatura uruguaya. Su caso permite describir otras posiciones liminares en América Latina y proporcionar herramientas para comprender las posibilidades emancipatorias que la escritura y el accionar colectivo ofrecen a los sujetos subalternos en contextos hostiles como la primera mitad del siglo XIX. Espero que este trabajo contribuya en algo a la comprensión de estos problemas.

\section{Sobre las fuentes}

Los papeles de Jacinto Ventura de Molina están semi publicados al momento de elaboración de esta tesis. Existen hoy dos fuentes documentales publicadas el mismo año 2008. La primera es una antología que coordiné junto a un equipo de investigación conformado en 2006 por José Manuel Barrios y Adriana Pitetta. Las citas al libro aparecerán en el cuerpo de este texto como Antología 1 (Al) seguido del número de página. La segunda antología fue publicada por William Acree y Alex Borucki y aparecerá citada en el cuerpo de este texto como Antología 2 (A2). A su vez haré uso de manuscritos y pasajes no publicados en libro aún. En ese caso utilizaré mi propia transcripción paleográfica y su correspondiente adaptación a la ortografía contemporánea. En las referencias a estos manuscritos se indicarán con una $(\mathrm{M})$, el número de tomo $(I, I I, I I I)$ y el número de folio, indicando si es verso (v) o reverso (r).

La ordenación de los tomos implica una forma de interpetar la colección de manuscritos. Por ejemplo, los investigadores Acree y Borucki proponen un orden que 
atribuyen al propio Molina:

(...) el tomo 1 contiene textos teológicos, históricos y literarios; el tomo 2 guarda los escritos históricos y autobiográficos, además de notas de sus contemporáneos y variadas peticiones y memoriales dirigidos a las autoridades; y el tomo 3 posee mayormente escritos autobiográficos y judiciales. (A2, 47-48).

Dado que la colección estuvo en manos de diferentes personas antes de llegar a la Biblioteca Nacional me parece imprudente atribuir este orden al propio Molina. Por otra parte el orden temático me parece que disminuye la diversidad de formas y temas contenidos en los distintos tomos, además de afectar la comprensión de la colección. Por ejemplo, el registro autobiográfico que los investigadores suponen en el tomo 2 , recorre buena parte de los manuscritos contenidos en los tres tomos. Por esa razón la ordenación que propongo es menos detallada y más descriptiva. El Tomo I corresponde a los papeles vinculados a las Glorias de la Caridad, los siguientes dos tomos son Miseceláneas (I y II) porque recoge manuscritos diversos. Sea cual sea el orden cabe destacar que la colección de manuscritos de Jacinto Ventura de Molina todavía no ha sido catalogada por la institución por lo que cualquiera de los dos órdenes propuestos deberán ser sometidos al trabajo técnico de la Biblioteca Nacional.

En el caso de los textos recogidos en las antologías corresponde señalar las diferencias de clasificación. En la primera antología (A1) ordené los textos en función de géneros de discurso: a) Obras retóricas; b) Correspondencia; c) Obra poética. Los investigadores Acree y Borucki (A2) sin embargo optaron por criterios históricos y temáticos: a) Escritos históricos y autobiográficos; b) Los afrodescendientes en los escritos de Molina; c) Peticiones al poder; d) Molina en los escritos de sus contemporáneos; e) "Defensor de los pobres"; f) Escritos políticos y literarios. Ambas clasificaciones implican 
un recorte sobre más de mil páginas manuscritas, interpretaciones de la colección y perspectivas de investigación distintas, que responden también a inscripciones disciplinarias distintas: las letras en el primer caso y la historia en el segundo.

La clasificación propuesta en A2 se ubica entre categorías basadas en la historia y posición de Molina (“defensor de los pobres”, "peticiones al poder”) y la construcción de esferas de la vida que la modernidad ha separado (historia, política, literatura). Este último criterio parece el menos acertado teniendo en cuenta la densidad de los manuscritos de Molina, que conjugan aspectos discursivos (no literarios), históricos, políticos, bíblicos, autobiográficos. Los manuscritos de Molina fueron escritos antes de que existiera un concepto de literatura autónoma o una separación tan rígida entre las esferas de la vida, por eso la clasificación por categorías amplias de géneros discursivos parece la más adecuada. 


\section{CAPÍtULO I}

Jacinto Ventura de Molina en la ciudad letrada (1766-1837)

La ciudad letrada es el escenario porque remite a un espacio (la ciudad) y a un grupo social (los letrados) que sirve al poder del Estado y es, a su vez, dueño de un poder: el dominio de la palabra escrita. La ciudad de Montevideo, fundada a comienzos del siglo XVIII, fue la ciudad letrada-puerto en la que vivió Jacinto Ventura de Molina y en la que produjo casi la totalidad de los manuscritos hoy conservados. Según el historiador Eric Hobsbawm durante la era de la revolución: "[v]ivir cerca de un puerto era vivir cerca del mundo" (Hobsbawm, 17). El mundo que podía verse en el puerto de Montevideo incluía muy particularmente a África. Como sostienen Petit Muñoz, Narancio y Traibel la llegada de cargamentos con esclavos fue más o menos frecuente desde 1743 (45) y en 1791 en una Real Cédula se lo declaraba "único puerto de entrada (...) con respecto a toda la región meridional del continente sudamericano, inclusive Chile y Perú". Estos beneficios se repitieron cada seis años hasta $1809(50)$.

Según datos de un padrón elaborado en 1805, que incluye únicamente el casco de la ciudad, los esclavos y libertos eran unos 3.114 en un total de 9.359 habitantes, que significaban un tercio de la población montevideana (Petit et al: 53). Casi cuatro décadas después, en un censo realizado en 1843, Montevideo había aumentado sensiblemente su población con 31.189 habitantes, de los cuales unos 4.344 eran africanos o descendientes de africanos, algo así como el 14\% de la población total (Pereda: 47). Entre 1786 y 1806, sostiene Borucki, el tráfico de esclavos tuvo su "época de oro" en el Río de la Plata. Entre 1778 y 1810 "la población de Buenos Aires se incrementó en un 34 por ciento, mientras que la población esclava aumentó en 101 por ciento. En Montevideo, la población total 
creció 119 por ciento entre 1791 y 1810, mientras que la población esclava lo hizo en 486 por ciento" (Datos de Ernesto Campagna en Acree y Borucki: 22).

Los esclavos introducidos en el Río de la Plata fueron utilizados para tareas domésticas, en distintos oficios, también en la construcción, en la actividad portuaria y en actividades rurales agropecuarias (Pereda: 92 y Borucki: 24). Para Borucki la esclavitud "fue una entre varias modalidades de provisión de mano de obra" (24) por lo que hay que distinguir a Montevideo de aquellas sociedades cuya riqueza dependía del trabajo esclavo en la plantación extensiva (café, algodón, caña de azúcar) o en la extracción de minerales como las de Estados Unidos, Caribe o Brasil. En base a la distinción entre sociedades esclavistas y sociedades con esclavos planteada por Moses I. Finley (1980: 100), Alex Borucki sostiene que no puede decirse que la montevideana fuera una sociedad esclavista sino con esclavos, y agrega "con muchos esclavos" (2008: 24). Si bien la distinción es pertinente para definir una sociedad no alcanza para describir e interpretar un caso concerto como el de Jacinto Ventura de Molina. Sin embargo, me pregunto si las formas de dominación implícitas en la esclavitud tal como las define Finley -el trabajador en sí mismo como propiedad, el gobierno absoluto de su vida por el propietario y su desarraigo (1980: 97)- no se configuran de un modo similar en ambos tipos de sociedades. Finley advierte sobre los problemas de tomar a amos y esclavos como individuos, dando lugar al relato del caso excepcional, hablando a favor del esclavo o del amo "según la ideología del historiador" (119). En mi opinión este asunto se reduce a un problema de escala, los manuscritos de Jacinto Ventura de Molina ofrecen la posibilidad de estudiar la vida privada y pública de un descendiente de africanos en Montevideo sin la necesidad de generalizar su experiencia al conjunto de la sociedad o hacerlo solamente en aquellos aspectos que fuera posible hacerlo.

El caso de Jacinto Ventura de Molina es el de un afrodescendiente criollo nacido en 
territorio colonial (Rio Grande, 1766), hijo de un esclavo liberado por gracia de su amo (Ventura) y una esclava escapada de territorio portugués (Juana de Sacramento), liberada al ser capturada por los españoles. Por lo tanto fue un hombre negro nacido libre, unido hasta los 16 años a la vida del amo que liberó a su padre (José Eusebio de Molina), quien le enseñó a leer y escribir, siendo su tutor hasta 1782 cuando fallece. Molina vivió buena parte de su vida en Montevideo, aunque visitó varias ciudades de la región, y desde 1817 hasta 1837 produjo una importante cantidad de manuscritos en los que pueden leerse relatos autobiográficos, pequeñas biografías, ensayos teológicos, cartas a figuras públicas, algunos escritos judiciales, poemas y cartas privadas. Sus manuscritos son una fuente interesante para comprender las relaciones amo-esclavo desde dentro, en el escenario de un hogar armonioso, gobernado por un pater familia, un buen amo. Lo que tenemos entonces es la perspectiva del subordinado, inserto en relaciones de servidumbre con un español, un subordinado que utilizará su historia personal, su historia de esclavo fiel, para subsistir en la sociedad montevideana de comienzos del siglo XIX. 


\section{Los años de formación (1766-1782)}

Los años de formación de Jacinto Ventura de Molina estuvieron marcados por un lento proceso de aculturación, que implicó la introducción en el catolicismo y su alfabetización, pero fundamentalemente la separación de un potencial legado cultural que sus padres africanos pudieron transmitirle. Sus primeros 16 años estuvieron ligados a la vida del militar español José Eusebio de Molina y a la relación de servidumbre que sus padres tuvieron con él aún siendo libres. En el marco de una sociedad colonial que pone en el más alto grado al hombre blanco europeo, que detesta las mezclas de sangre y construye meticulosas clasificaciones raciales, los africanos y sus descendientes no tienen otro destino que ser blancos (Fanon: 44).

Por esta razón la mimesis aparece como una estrategia que los sujetos no-europeos desarrollaron en el contexto de la cultura colonial con más frecuencia que otras. Pero no hay necesariamente en esa estrategia una mera actitud pasiva que acompaña el proceso de aculturación al que son sometidos los colonizados no europeos, la mimesis colonial termina provocando la mirada extrañada del colonizador y hasta el temor de que la copia pueda convertirse en una amenaza (Bhabha).

\subsection{Padres africanos: libres y fieles}

Los pasajes de los manuscritos referidos a los padres biológicos de Jacinto Ventura son escasos en relación con los que están dedicados a la historia y la biografía de José Eusebio de Molina. Esto puede explicarse por el uso táctico que hizo Jacinto de la historia de un español blanco en diferentes momentos de su trayectoria. La información sobre sus padres no escapó a estos usos pero fue menos prestigiosa y útil. Desde esta perspectiva 
puede explicarse el desbalance en la cantidad de información sobre sus padres respecto a la de su tutor español. Jacinto Ventura nació y vivió en Río Grande de San Pedro, una villa portuguesa en el actual estado de Rio Grande do Sul (Brasil), ocupada por los españoles desde 1763 hasta 1776. Sus padres formaban parte del grupo de esclavos y libres que estaban al servicio -en una relación de servidumbre- del Teniente José Eusebio de Molina, un oficial que acompañaba la misión de Cevallos en el Río de la Plata. Su padre se llamaba Ventura, un esclavo de origen Mina Dajome (Dahomey, hoy República de Benin) y su madre Juana de Sacramento, una afrodescendiente de origen Benguela (Angola). Ambos llegaron al Río de la Plata vía Brasil, concretamente Bahía y Río de Janeiro respectivamente (Acree y Borucki: 20).

Su padre, de nombre Ventura, fue comprado por José Eusebio de Molina en 1759 y liberado en 1763 a causa de una acción noble en el campo de batalla que le salvó la vida a su amo. El Brigadier compró a Ventura en el Real de San Carlos, a unos pocos quilómetros de Colonia del Sacramento en compañía del apoderado de Cevallos, Don Jacinto Quiroga. Este, según testimonio de Jacinto, “compró un negro barbero nombrado Pedro" y José Eusebio "otro negro hermano de aquel, nombrado Ventura". Pedro era un Mina, de origen africano. Ventura, un "anfibio", nacido en el mar, camino a Bahía donde sería vendido y trasladado, siguiendo uno de los caminos de la trata de esclavos que llegaban al Río de la Plata: Castillo Elmina (África), Bahía (Brasil), Colonia del Sacramento o Montevideo (M, T. II, foto 9572). ${ }^{5}$ La madre de Jacinto, Juana del Sacramento, era según su hijo una “joven morena libre por la gracia de José de Molina" (A1, 95). El español quiso remitirla a Buenos Aires pero Ventura la pidió y se casó con ella. ${ }^{6}$

5 Los textos tomados de los originales manuscritos fueron modificados en su ortografía. En el original: “(...) compró al paso por $1=/=$ Real, en la Colonia, un negro barbero nombrado Pedro, $\mathrm{y}=/=$ Dn, Josef de Molina, otro negro ermano de aquel, nombrado Ventura=/ = aquel de nacion Mina, este amfivio, menor que el otro, el que avia=/=nacido en el trancito de Africa, à la Vadia de todos Santos:”.

6 Según Borucki, Ventura fue comprado por el Teniente Molina en Colonia del Sacramento durante la toma de la ciudad en 1762, y su madre se había pasado a las tropas españolas cuando el Teniente Molina ocupó 
La pareja era de origen africano y Molina así lo recuerda: "benguela mi madre Juana del Sacramento, anfibio mi padre, que no obstante sabía muchas palabras del idioma Mina Dajone, que fueron mi abuela y tío" $(\mathrm{A} 2,58){ }^{7}$ A pesar de su empecinamiento en reforzar la idea de su origen cristiano por la calidad de "anfibio" de su padre, Jacinto era consciente y recuerda el origen étnico de sus padres, tío y abuela paternos. Conviene señalar que en el mismo pasaje Jacinto hace referencia a "la razón que tuvo" el militar español al pedirlo para su educación y el empeño que este puso en que no aprendiera los idiomas africanos de sus padres $(A 2,58)$. Ventura y Juana fueron parte del grupo de sirvientes que tuvo el español durante su pasaje por el Nuevo Mundo. Ventura fue su asistente, barbero y cocinero: “Don José de Molina no comió jamas risotto en su casa, no probó pasta, o dulce hecho de otras manos; nadie tocó su barba, sí solo ese negro; ni careció de otra asistencia sano, o bueno, en tierra, o embarcado, que de su negro Ventura." $(\mathrm{A} 2,58){ }^{9}$

Al describir a su padre Jacinto lo recuerda como alguien "severo" con su madre, "muy joven, bonita y decente"; y con él, por ser "criollo del país". Ambos amaban al militar español porque los defendía de la "acrimonia de aquel altivo etíope"10. Cuando se producía algún conflicto, al parecer violento, el español intervenía: “¿Qué te hizo tu mujer, hombre? No la mortifiques, ten humanidad. Cuidado como me la toques o me lo toques". Según Jacinto la razón de la reacción de su protector era que su padre era "vicioso, jugador

Rio Grande en 1763. La confusión respecto al dato de la compra de Ventura puede no ser necesariamente un error de Borucki o mío dada la confusa redacción de Molina o la posibilidad de que su memoria fallara. En su texto Borucki no consigna el orígen de los datos que proporciona y no surgen de la documentación transcrita en la antología.

7 En Acree y Borucki: "banguela mi madre Juana del Sacramento. Amfibio mi padre, q.e no ostante savia muchas palabras del ydioma Mina dajone q.e fueron mi abuela y tío".

8 En Acree y Borucki: "la rason que tubo".

9 En Acree y Borucki: "D.n Josef de Molina no comió jamas risoto en su casa, no probó pasta, o dulse echo de otras manos, nadie toco su barba, ci solo ese negro. Ni careció de otra acistencia sano, o bueno, en tierra, o enbarcado, que de su negro Ventura." (58)

10 El significado de la palabra "etíope" es originalmente "hombre de Etiopía" y tiene su origen, según Covarrubias, en algunos pasajes de la Biblia y la Antigüedad Clásica (390). Es posible suponer que Molina conozca el término a partir de sus lecturas bíblicas, como sinónimo de "africano". Aunque el origen en el norte de África nada tengan que ver con el origen de su padre. 
y hábil para buscarse dinero" mientras su madre era "económica, reservada y opuesta a la profusión de su marido". Según Jacinto el militar tenía un "amor sin medida” por su madre y por tal motivo "le contaba especies e historias de los sultanes moros, que en sus palacios tienen pena de la vida" $(\mathrm{A} 1,75)$.

Los cuentos que José de Molina le contaba a Juana de Sacramento muestran las asociaciones que los españoles pudieron hacer entre su experiencia o su imaginación sobre los moros y los africanos que ahora convivían con ellos en las colonias americanas. En este caso particular las historias podrían relacionarse también con su origen andaluz, lo cual me lleva a preguntarme si Juana y los demás africanos no serían parte de un paisaje humano familiar para el militar. Pero lo importante del recuerdo de Jacinto es la "intimidad" que el español tenía con su madre y el énfasis en este "amor sin medida" que le prodigaba.

Este pasaje me llevó a proponer, en mi ensayo El licenciado negro (2007), la posibilidad de que Jacinto Ventura fuera hijo del español, lo cual podría explicar la protección y dedicación de Molina para con el niño así como las reprimendas y advertencias a su padre biológico por su comportamiento (23). En un artículo publicado en 2009 William Acree discute mi sugerencia afirmando, en una nota a pie, que "Ni los contemporáneos de Josef de Molina ni los de Jacinto alguna vez escribieron o hablaron sobre él como pardo o mulato" y que su "blanquedad" hubiera sido utilizada por él mismo para "respaldar sus argumentos frente a reyes y oficiales del estado" (2009: 46). Aunque los dos argumentos de Acree fueran válidos la posibilidad de intercambios sexuales entre amos y esclavas estaba también en el horizonte de posibilidades y algunos estudios históricos sobre Montevideo en el período mostraban eso (Islas, 1997 y Bentancur y Aparicio, 2006). Incluso Bentancur lo extiende a todo el territorio americano e incluso señala que algunas de estas esclavas -en Brasil, Jamaica, Barbados y otros- "gozaron de privilegios comparables con los de las esposas legítimas” (Bentancur y Aparicio, 72). 
Pero no es cierto que los contemporáneos no alimentaran la sospecha de que Jacinto Ventura pudiera ser hijo de José Eusebio. El propio Jacinto Ventura narra un viaje a Buenos Aires en 1777 y recuerda que en esa ciudad corría el rumor de que el español "tenía en Río Grande un hijo mulato" (M, I: f 352v). ${ }^{11}$ El rumor llegó a oídos de Catalina Gil, con quien el Brigadier pretendía casarse. Ante el planteo de su prometida el militar español la llevó frente a Jacinto Ventura, cuyo color de piel debió ser una "prueba" irrefutable de que Jacinto no podía ser hijo suyo. Este rumor de los contemporáneos en Buenos Aires podría relativizar la afirmación de Acree sobre el hecho de que nadie describiera a Jacinto Ventura como un "mulato". Pero lo más importante es que ese rumor fuera creíble para las personas que lo hicieron circular. Creo que este indicio hace que la hipótesis sea, al menos, posible como sugería en 2007 , aunque no sea factible verificarla por ningún medio ya que no hay nada en los manuscritos que Jacinto Ventura recordara o quisiera recordar al respecto. ${ }^{12}$

La información que proporciona Jacinto Ventura sobre su madre es más bien escasa. Sabemos por sus innumerables relatos autobiográficos que Juana de Sacramento murió en Maldonado en 1777 y que dos años después su padre se casó por segunda vez “con una negra criolla de Río de Janeiro tan joven y hábil que Don José de Molina dio dos

11 En el original: "[de] quien se dijo en B.s A.s que tenia enel rio grande hun yjo mulato= la S.a D.a Catalina Gil hapalabrada esposa que oy lo [honra] en la eternidad: creyo de modo este discurso que llegando el ha vuenosayres el S.or D.n Josef de Molina conel Ecl.mo [...] D.n Pedro Seballos el año de _1777_mi edad hera diez años hasi que vio ha mi S.or que ya era vrigadier pero [no] husaba las divisias: le pregunto por mi y fueron hal hasien[to] ha vuscarme para desengañarse esta S.a que muerto mi [tutor] haqui berifico el amor de madre con migo en B.s A.s hasta que vine haqui el año de 1799" (M, I: f 352v).

12 Para sostener su argumento Acree recurre a las categorías raciales del siglo XIX cuando afirma que si fuera pardo o mulato sus contemporáneos lo notarían, que utilizaría su "blanquedad" (Acree escribe "whiteness" entre comillas) para "respaldar sus argumentos para reyes y oficiales de estado"; y concluye que, por el contrario, Jacinto "muestra orgullo de ser negro" (2009: 46). Utilizar las categorías raciales del siglo XIX no está mal en un estudio sobre un letrado del siglo XIX siempre y cuando se tome distancia de las mismas. La prueba sobre la posible paternidad del español no residiría en el color de la piel de Jacinto Ventura ni en cómo sus contemporáneos la percibieron y describieron, sino en su información genética, punto que está muy lejos del objetivo de mi investigación y de las posibilidades de la disciplina. Sin embargo, construir un escenario posible en base a la documentación y la bibliografía disponible me parece más importante. Otra consideración merece el hecho de postular un "orgullo de ser negro" en los manuscritos de Jacinto Ventura. Creo que las tácticas y estrategias que este adoptó para legitimarse como letrado, especialmente el uso del color de su piel, no pueden resumirse en "orgullo de ser negro". 
negros jóvenes a cambio de ella" (M, II, f 281r). ${ }^{13}$ En los 11 años que convivió con su madre esta aparentemente no le enseñó nada, ni vivió con ella historias que creyera oportuno contar, excepto que lo protegía de los ataques de su padre.

Se puede decir que, en términos generales, Jacinto Ventura utilizó tácticamente sus recuerdos. Y su padre no escapó a esta lógica general. Por ese motivo los recuerdos de Jacinto sobre su progenitor no refieren solamente a malos tratos. La narración de cómo el esclavo Ventura obtuvo su libertad fue utilizada por Jacinto en reiteradas ocasiones, con pocas variantes y para distintos fines como probar la fidelidad del hombre negro al hombre blanco o las virtudes de su buen amo. El hecho ocurrió durante el sitio de Colonia del Sacramento en la primera campaña militar de reconquista iniciada por Cevallos en 1762. José Eusebio de Molina fue el Capitán de Infantería en este sitio. La anécdota, que tal vez escuchó de labios de su padre o del español, es que la primera divisón de un batallón compuesto por "gente del país, de chuza, sable y cuchillo [¿gauchos tal vez?] se levantó toda [y] atropelló contra el centro a rienda suelta”. Cuando Don José de Molina se topó con los insurrectos recibió "un chuzazo que tomando su vestido (...) lo sacó de la silla [y] lo derribó de espaldas, cabeza abajo por las ancas del caballo”. La acción de Ventura consistió en saltar de su caballo y sostenerlo "librándolo de desnucarse y de los pies del animal”. En el cierre de la narración Jacinto termina esta épica mínima de la siguiente forma: "Don José de Molina al rehacerse en pie, en presencia de toda la división, dio la libertad a su esclavo ordenándole que fuese con su beneplácito y palabra donde gustase", a lo que Ventura respondió que "lo acompañaría toda la vida". Entonces el militar español "le dio 40 pesos y siguió su marcha” (A1, 93-94). En otro manuscrito, fechado en 1836, Jacinto Ventura aporta el dato de que José Eusebio mantuvo firme aquella decisión en 1776, cuando hizo su primer testamento en Santa Teresa, y en 1779 lo volvió a certificar en

13 En el original: “con una negra criolla del Geneyro tan joben, y avil q.e Dn Josef de Molina, dio dos negros, jobenes en canvio de ella" (M, II, f 281r) 
Buenos Aires (A2, 56).

El otorgamiento de la libertad por parte de los amos se encuentra dentro de lo que Moses Finley describe como los derechos absolutos de los amos sobre su propiedad. No se trataba, según Finley, de dar un trato "más humano" a los esclavos sino de decisiones unilaterales que, así como se hacían, podían deshacerse por única voluntad del amo (9394). Según la narración de Jacinto Ventura, su padre no solamente rechazó la libertad otorgada por su acción heroica, sino que "le aseguró" fidelidad para "toda la vida". La fidelidad y la obediencia fueron valores que la iglesia católica inculcó, con mucho éxito, en los africanos y sus descendientes (Bentancur y Aparicio, 66). De hecho fue uno de los valores más resaltados por los amos al otorgar las "libertades por gracia" estudiadas por Bentancur en el período 1790-1820. El autor describe las libertades por gracia como "un acto de desprendimiento con repercusiones patrimoniales" ya sea a través de los testamentos, que afectaban el patrimonio de los sucesores o a través de acuerdos previos, que podían incluir distintos "servicios prestados", que se consagraban a través de cartas de libertad "gratuita" (Bentancour y Aparicio, 65). En esas cartas de libertad la fidelidad como virtud del esclavo predomina junto a referencias al amor o la lealtad (66). A su vez la fidelidad aparece como respuesta "al trato benigno dispensado por el «buen amo»" (66) que podía ser recompensada en el futuro con la libertad. La libertad otorgada a Ventura en 1762 parece una libertad instantánea que, luego de ser rechazada por el esclavo, fue recompensada con dinero. Sin embargo, José Eusebio de Molina confirmó en su testamento el otorgamiento de dicha libertad.

Pero Ventura no alcanzó a gozar de su libertad porque falleció en Montevideo el 17 de julio de 1782, apenas tres meses antes que el militar español. Su muerte afectó al amo, que dedicó "muchos auxilios y asistencia" al moribundo (A1, 53), a tal punto que apresuró su propia muerte $(\mathrm{A} 2,58)$. Antes de morir, según el relato de Jacinto, Ventura le dio un 
consejo: “jamás te acompañes con nadie", paradójicamente le pidió y le mandó como última voluntad acompañar a José Eusebio mientras viviera y le legó 150 pesos (A1, 53). Además del dinero, había recibido como legado de su padre una demostración más de su lealtad al amo, transfiriendo incluso su patenidad. Según el testimonio de Jacinto, su padre le habría dicho además: "mi Señor es más bien tu padre que no yo, sabes y tienes muchos más conocimientos que yo, y todo se lo debes a él" (A1, 53). Con la muerte de su padre Jacinto Ventura perdió a su familia biológica, había perdido a su madre en 1777, y todo posible contacto con su pasado africano, del que había sido despojado a la largo de su vida junto al militar español.

Sus padres fueron servidores leales del español cumpliendo tareas domésticas como el lavado de la ropa, la cocina o el cuidado personal del militar, entre otras. No fueron los únicos sirvientes negros en la casa de José Eusebio de Molina. Según los recuerdos de Jacinto el grupo estaba integrado por: Eusebio, ayuda de cámara y sastre; Juan Mulato, cochero que había sido comprado con su esposa Isabel; Ventura, padre de Jacinto, comprado como barbero, aunque también aprendió cocina con el repostero de Cevallos; los esclavos Eusebio y Juan Mulato, el primero "le fue infiel" y ambos huyeron juntos a España; y por último Antoñuelo, indio libre que también se fue a España (A2, 57-58).

En la región del Río de la Plata fueron muy comunes los grupos de sirvientes como este, e incluso más grandes. De hecho estos sirvientes ocupan un lugar similar al de los esclavos de la casa que existieron en regiones esclavistas como el Caribe o Brasil, en el que la distinción entre estos y los esclavos de la plantación extensiva era muy fuerte. Y aun había una tercera categoría, el esclavo cimarrón, que exisitó en menor escala también en el Río de la Plata. En Cuba, por ejemplo, la revolución de 1959 trajo consigo la exaltación del esclavo cimarrón a través de un nuevo género literario: el testimonio. En las siguientes décadas el género se fue consolidando y delineando sus características principales: un 
intelectual solidario con la causa de los más desfavorecidos que pone su trabajo con la palabra al servicio de sujetos, algunos iletrados, para que estos cuenten su historia de vida a su comunidad nacional y también a la internacional. El libro Biografía de un cimarrón (1966) de Miguel Barnet relata la vida de Esteban Montejo, un esclavo que logró escapar de la plantación y vivió para contarlo. Biografía de un cimarrón no sólo abrió la puerta de la difusión de este nuevo género literario entre la izquierda revolucionaria, sino que permitió exaltar la figura de un hombre negro nuevo, que rechaza la sumisión que le impone la esclavitud y lucha por su libertad.

En ese libro Esteban Montejo describe a quien fuera su antagonista en la plantación, el esclavo de la casa, y lo relata casi al comienzo de la siguiente forma:

Cuando un negrito era lindo y gracioso lo mandaban para adentro. Para la casa de los amos. Ahí lo empezaban a endulzar y... iqué se yo! El caso es que el negrito se tenía que pasar la vida espantando moscas, porque los amos comían mucho. Y al negrito lo ponían en la punta de la mesa mientras ellos comían. Le daban un abanico grande de yarey y largo. Y le decían: “¡Vaya, para que no caigan moscas en la comida!”. Si alguna mosca caía en un plato lo regañaban duro y hasta le daban cuero. Yo nunca hice eso porque a mí no me gustaba emparentarme con los amos. Yo era cimarrón de nacimiento. (Barnet, 14)

Desde la perspectiva de un cimarrón, el esclavo de la casa está endulzado y emparentado con el amo. Esto es precisamente lo que sucede con Jacinto Ventura, quien no fue un esclavo en sentido estricto, pero sirvió a su amo hasta los 16 años. En los hechos su formación estuvo signada por la vida dentro de la casa del amo de su padre y, aunque no 
haya muchas referencias, estuvo rodeado por otros esclavos de la casa. Definido así, es posible interpretar ciertos pasajes en los que Molina habla de su infancia en los que este se autorepresenta como esclavo de la casa. Si bien Jacinto Ventura nunca se autoclasificó como tal en muchos de sus manuscritos se puede leer sobre el entorno doméstico en el que se movía.

Cuando tenía aproximadamente unos setenta años (en 1836) refiriéndose a los hábitos y costumbres que tuvo desde su infancia, cuando aprendió a hablar, menciona un refrán: "Negrito, has lo que tu amo te manda y comerás a la mesa". Una enseñanza que le dio muy buenos resultados en el entorno paternalista y protector que su "buen amo" impuso en su hogar. Su relación de cercanía con el patriarca fue crucial para su desempeño durante las primeras décadas del siglo XIX porque implicó, entre otras cosas, su evangelización y alfabetización. En general no hay manuscritos en los que Jacinto haga referencia a malos tratos que pudieran recibir sus padres o algún integrante del grupo de sirvientes pese a que la violencia física era frecuente en la cultura bárbara que describe Barrán en el primer tomo de su Historia de la sensibilidad (2011: 41). Según uno de sus eslavos predilectos, en el hogar del "buen amo" reinaba la armonía.

\subsection{Amo y tutor: el Brigadier José Eusebio de Molina}

En un prólogo a la edición francesa de la biografía de Simone de Beauvoir escrita por Toril Moi, Pierre Bourdieu afirma que el sistema de enseñanza es una "infraestructura específica de todas las trayectorias intelectuales, casi siempre ausente de las biografías" (1998:189. Énfasis del autor). A pesar de estar pensando en el caso particular de una mujer del siglo $\mathrm{XX}$, es posible afirmar su validez para casos como el de Jacinto Ventura de Molina en los que sin haber un "sistema de enseñanza" en sentido moderno, su formación 
inicial se constituyó en una infraestructura específica. La mayoría de los testimonios de Jacinto Ventura sobre sus primeros años se encuentra en los relatos sobre el español José Eusebio de Molina, a quien debe su educación y fue su tutor hasta el día en que murió. Uno de estos testimonios es el texto "Saludo al Sumo Pontífice Gregorio XVI y moral colección de cartas misivas a los augustos soberanos de España-Portugal y Estado del Uruguay" en el que Jacinto Ventura relata sus primeros años junto a José Eusebio de Molina.

Según su propio relato, Jacinto Ventura comenzó a escribir sus documentos a los tres años junto al secretario de su tutor Manuel Otero, y culminó su formación en 1780 con Mateo Cabral. A los cinco años el Brigadier Molina comenzó a enseñar a Jacinto Ventura a leer, escribir y rezar. A los seis años conocía el catecismo de Astete y como afirma en este manuscrito sufrió: "un dilatado ecsamen, tres beses en el Riogrande: mereci la aprobación y sertificado ami Sòr, del virtuoso Capellan D.n Josef Galeano que a la edad de seys años, y medio, me ynstruyò, comfesò, e yso cumplir con la iglesia, de cuya obligación no me separè asta aquí" (M1, Tomo III: f 273v). En 1774 comenzó a “dibujar por reglas” a cargo del Teniente Coronel de Artillería Don Francisco de Betbezé. ${ }^{14}$ Su formación en este punto se profudizó con D.n Félix Iriarte entre 1780 y $1792 .{ }^{15}$

En el marco de las disputas coloniales, ese mismo año de 1774 Jacinto Ventura comenzó su instrucción militar dado que los niños de Río Grande sirvieron a la artillería trasladando cartuchos y tacos. Al año siguiente vuelve a entrar en acción frente al segundo ataque de los portugueses a la ciudad en 1775, y finalmente durante la toma de 1776. La cuarta acción militar de Jacinto fue durante el sitio de Colonia del Sacramento ese mismo

14 Don Francisco Betbezé aparece en 1787 entre los "poseedores más distinguidos" que tienen su chacra en el arroyo Miguelete y es presentado como "Coronel del Cuerpo de Artillería y jefe de la Provincia" (Pérez Castellano, 1968: 6)

15 Don Félix Iriarte o Idiarte es nombrado por Molina en otro "Memorial Histórico" dirigido a Lecor en 1817. Se refiere a él como un "excelente matemático" que en el período de 1780 a 1792 le enseñó a "dibujar por reglas". No hemos podido encontrar otros datos sobre este militar que los proporcionados por el mismo Molina. 
año. En 1777 Jacinto viaja a Buenos Aires por primera vez y en ese momento: "savia leer, escribir, contar, todo el catecismo de Astete" (M1, Tomo III: f 273v). El militar español estuvo en Buenos Aires para resolver algunos de sus asuntos y fundamentalmente para encontrarse con el virrey quien se retiraría poco después a España y moriría al año siguiente.

También en 1777 Jacinto Ventura se hizo con sus seis tomos del Digesto (compilación de normas del Derecho Romano) con los que aprendió latín de memoria repitiendo su lección cada noche frente a José Eusebio de Molina, el mayorodomo y su padre. El español aprovechaba el momento para tomar candeal o chocolate mientras le daba una explicación "del idioma latino palabra por palabra, por lo que lo leo y entiendo [aunque] traduzco sin hablarlo pues ignoro sus reglas (...) para formar oraciones" (M1, Tomo III: f 273v). ${ }^{16}$ A los 11 años Jacinto Ventura había sido alfabetizado y evangelizado; sabía latín, aritmética y tenía nociones de dibujo que profundizó años más tarde. El trayecto de quienes tenían acceso a la educación se iniciaba en una escuela de primeras letras en la que se enseñaba a leer, a escribir, las cuatro operaciones de la aritmética y la doctrina cristiana (Reyes Abadie, 108). Jacinto Ventura había asistido a la escuela de primeras letras que José Eusebio de Molina creó en Río Grande durante la ocupación española (1763-1775). El maestro Mateo Cabral dirigió esta escuela y poco después -1776obtuvo la licencia otorgada por el Cabildo de Montevideo para ejercer en forma privada el magisterio en primeras letras (Reyes Abadie, 110).

La educación formal continuaba con estudios secundarios y superiores. En los primeros el Maestro de Gramática o Latinidad enseñaba latín, retórica, aritmética,

$\overline{16}$ En el original: “(...) trajo en, 77, de B.s, A.s, esta obra, que entre barias tenia en sus baules archibada en casa del Sòr D.n Vizente Gil: ò de las SS.s Españolas: daba mi leccion de memoria a mi Sòr a la noche, en presencia de mi padre, y el mayordomo, quando S,S.a, tomaba- Candial, ò chocolate: con este motibo S.a, medaba una explicación, del ydioma latino palabra por palabra: por loque no solo lo leo, y entiendo pero lo traduzco cin ablarlo, pues ygnoro sus reglas, y composiciones, para formar oraciones y contestos" (M1, Tomo III: f 273v). 
geometría, astronomía, física experimental y otras. En los segundos Filosofía y Teología. Las opciones por aquel entonces, para los estudios superiores eran el Colegio de San Francisco de Buenos Aires o la Universidad de Córdoba. La educación de Jacinto Ventura no siguió este camino, aunque su educación en diversas materias continuó gracias a los aportes de su tutor o de personas vinculadas a él. Eso sucedió, por ejemplo, con la poesía. Jacinto Ventura se aficionó a la poesía a instancias de Vicente Maturana, un español al que seguramente conoció en el segundo sitio a Colonia de Sacramento en mayo de 1777. En aquella oportunidad Cevallos destruyó los muros de la ciudad y para aquella tarea requirió los servicios de Maturana, por ese entonces alférez de artillería. Este oficial, “afectísimo al Brigadier José de Molina” le enseño poesía entre 1780 y 1782. El español y otros oficiales se divertían con sus composiciones (M, Tomo II, foto 9405). ${ }^{17}$

Casi todas las personas mencionadas por Jacinto Ventura tienen algún nivel de cercanía con el Brigadier José Eusebio de Molina (1707-1782), cuya historia fue narrada incansablemente por Jacinto Ventura y, como consignaba más arriba, utilizada por él tácticamente en una multiplicidad de situaciones a lo largo de toda su trayectoria. Nació en Antequera (a pocos kilómetros de Málaga en Andalucía) entre fines de junio y principios de julio de $1707^{18}$ y fue un "noble de padres plebeyos". Su padre se llamaba Eusebio y su madre María y eran campesinos. Hasta los 26 años tuvo "todos los privilegios y excepciones que [hacen] los colegios a sus alumnos para el sacerdocio". Abandonó su casa y sus estudios para inicar su carrera militar en Italia, dejando atrás a su padre viudo y a su hermana María. En su ausencia Don Eusebio se volvió a casar y tuvo otra hija llamada Francisca (M, T. I, pp. 643-644 de la transcripción). En verdad huía del futuro que su padre

\footnotetext{
17 En el original: “ese mismo oficial afecticimo al Vrigadier Dn Josef de Molina me dio gratuito sus primeros cuadernos de poecia en los años 1780_81_asta 82 aqui divirtiendose con mi Sor y otros oficiales en el uso de mi estudio y compociciones" (M, Tomo II, foto 9405).

18 Supongo este dato considerando que al momento de su muerte -el 15 de octubre de 1782- tenía 75 años, tres meses y unos días $(\mathrm{A} 1,49)$.
} 
había definido para él: ordenarse cura y tener una capellanía (M, T. II, 6562, 6563). ${ }^{19}$

Según Jacinto Ventura fue la carrera militar la que condujo a José Eusebio de su origen o naturaleza plebeya a ser un noble, hecho que destaca para su propio beneficio en 1837. En Italia llegó a Capitán y recibió tres heridas de guerra en sus piernas y en el brazo izquierdo, cosas que Jacinto Ventura leyó en su "libreta de méritos". Al volver a Madrid fue secretario del "grande de España" Marqués de la Mina, que había sido general en Italia (M, T. I, pp. 643-644 de la transcripción). ${ }^{20}$ El Marqués de la Mina fue "tutor, padre y benéfico amigo" de José Eusebio de Molina y lo conoció gracias a Cevallos (M, T. II, foto 6563). ${ }^{21}$ En varios manuscritos Jacinto Ventura recuerda que el español conservaba y valoraba mucho un retrato del Marqués en el que este aparecía "bajo un arco dorado" en Madrid (A2, 68). Su nombre era Don Jaime Miguel de Guzmán Dávalos y Spínola (16891767) y comandó las tropas españolas durante las campañas de Sicilia, Cerdeña e Italia en 1746, donde conoció a José Eusebio de Molina, alcanzando el grado de Teniente General de los Reales Ejérictos así como el grado de Capitán General de Cataluña entre 1749 y 1767.22

En 1759 José Eusebio de Molina llega al Río de la Plata y se integra a la expedición comandada por Pedro de Cevallos quien vino a marcar los límites con el Imperio portugués

19 En el original: “(...) debe saberse como fue noble este S.or yjo de Antequera en la Andalucia de padres plebeyos pero besinos- con casa y exercicio Labrador su padre se llamó [...] Eusevio y su Madre D.a Maria: el S.or D.n Josef de Molina empeso la carrera militar de 26 añ.s en la Ytalia: y tiene desde su ymfancia ha esa edad todos los privilexios y hesenciones q.e [sus]criben los colexios hasus halucnos para el Saserdosio." (M, T. I, pp. 643-644 de la transcripción)

20 En el original: "El R.1 Dro Militar consede el privilexio de noblesa ha todos los yndividuos que octienen Despachos [...] la M A delos Soberanos D.n Josef de Molina llego ha Cap.n en Ytalia, pero haun tubo otro terser metodo por donde la noblesa [...] via de la fidelidad la hacquiere tres heridas resivio haquel [...] en la guerra huna en cada pierna de piedras ympulsadas por la explocion de una bomba: una enel braso ysquierdo q.e [...] paso huna bala de pistola por la ynmediacion del ofisial de caballeria que le yrio y consta todo de la libreta de sus meritos que yo vi: refomado sirvio en Madrid Secretario hal Grande de España Marques dela Mina que fue su Xeneral y de la Yzquierda en Ytalia” (M, T. I, pp. 643-644 de la transcripción).

21 En el original: "remitido al Marquez por el Coronel Dn, Pedro Seballos, en el Momento que lo vio, e yso escribir su Nombre y Apellido" (M, T. II, foto 6563).

22 Era en verdad el segundo Marqués de la Mina. El primero fue su padre, don Pedro José de Guzmán y Dávalos, quien recibió su título nobiliario por su actuación militar de manos de Carlos II en 1681 (Fantoni y Benedí, 2007: 261). 
en 1756 y tenía como base de operaciones a la capital del Virreinato. Desde fines del siglo XVII -si se toma como inicio la fundación por parte de los portugueses de la Colonia del Sacramento en 1680- españoles y portugueses se disputaron el territorio de la Banda Oriental. ${ }^{23}$ El primer registro de la actuación militar de José Eusebio data del sitio a Colonia del Sacramento en 1762. En un apartado sobre la "Orden general para el asalto" contenido en la Relación exacta del sitio de la Colonia del Sacramento, plaza portuguesa en la costa $N$ del Río de la Plata, formada por uno que se halló en el mismo sitio, con todas las reflexiones conducentes a la más cabal inteligencia de sus circunstancias (Rela, 199), se establecen las instrucciones para el Capitán Don José de Molina. Con 50 dragones y 150 "hombres de milicia" se encargó de la caballería "con orden e instrucción reservada”. En el detalle del destacamento aparecen además Vicente Quiñones y Fernando Cosio (subalternos), dos sargentos y dragones (50 hombres) y la Caballería de Buenos Aires (150 hombres) completando un total de 200 hombres.

En 1763, y como parte de la misma expedición, Molina participa en la toma de la ciudad portuguesa de Río Grande de San Pedro enviado por Cevallos con 500 hombres como vanguardia desde el fuerte de San Miguel tomado el 23 de marzo. En la Devassa sobre a entrega da Villa do Rio Grande ás tropas castelhas (1764) es mencionado apenas en una oportunidad por "el capataz de carretas y boyadas de su majestad" Miguel López de Toledo como “comandante do Ryo Grande”. Al parecer Molina llamó en dos oportunidades a Miguel López "para jurar en una causa que borraba los disturbios cometidos en esta villa de Río Grande tanto en los almacenes como en las casas particulares" (Devassa..., 79-84).

Los historiadores de Río Grande, particularmente interesados en demostrar la autonomía de este estado brasileño, interpretan la guerra por la frontera entre los imperios de España y Portugal como un momento fundante del sentimiento local. En la búsqueda de

23 Sobre la historia del territorio de la Banda Oriental antes de su poblamiento ver Verdesio (1996). 
un origen para la identidad riograndense, algunos historiadores establecen que el primer "ellos y nosotros" es esta disputa entre españoles y portugueses. En este marco narrativo Alfredo Varela en su Riograde do sul. Descripçao phisica, histórica e económica (Varela, 28-231), hace referencia a la toma de Río Grande por parte de Zeballos (sic). Luego de que se le entregara el fuerte de San Miguel, a cargo del capitán portugués Joao Alves Ferreira, Cevallos:

(...) hizo seguir al capitán José Molinas (sic) rumbo a la plaza de Río Grande con fuerza para expugnarla. El gobernador portugués Eloy Madureira pasará con la población y fuerzas, casi todos, para el otro lado del canal: el capitán español, llegando a su destino, encontró una defensa débil, cambiando algunos tiros con los últimos soldados en retirada y sobrándole tiempo para abrir fuego inexorablemente sobre las familias fugitivas, que en canoas remaban para el Norte... (39)

Este relato contrasta con la interpretación que tenía Jacinto Ventura de su tutor, tal vez porque el propio José de Molina o su padre Ventura le relataron aquellas historias y omitieron u olvidaron estos detalles, tal vez porque los portugueses en sus informes estaban interesados en enfatizar o agrandar la crueldad de sus enemigos.

En mayo de 1766, antes de que naciera Jacinto Ventura, los portugueses intentaron tomar Río Grande. Como relata Francisco Bauzá en su Historia de la dominación española en el Uruguay, José Eusebio de Molina tenía a sus tropas sublevadas "por falta de pagamento" y con mucha deserción. Tenía a su vez a los portugueses, acampados y fortificados en la sierra de los Tapes. Estos conocían la situación de inestabilidad de las tropas españolas e iniciaron el ataque. El 29 de mayo los portugueses embarcaron 800 
hombres pero equivocaron el rumbo, ingresaron por un pantano que los resintió y permitió que los españoles dispararan contra ellos desde "una batería de tierra y la tartana de guerra San Nicolás” repeliendo el ataque sorpresa (Bauzá, 179-180).

Luego de esta acción quedaron en Río Grande los coroneles José de Molina y Miguel de Tejada a cargo de una tropa de 1.800 hombres. La artillería era comandada por el teniente coronel Francisco Betbezé y la marina por Francisco Javier Morales. Mientras tanto, en Madrid, la diplomacia portuguesa insistía en sus intenciones de paz y neutralidad, y los españoles le creían una y otra vez. En 1775 el comandante general Makedún intentó atacar Río Grande, otra vez sin éxito. Como fruto de aquella "mala política" de los españoles "se presentaron los portugueses con más de 2.000 hombres en $1^{\circ}$ de abril de 1776 al amanecer” recuperando la villa para el Imperio (Bauzá, 229).

En 1767 Pedro de Cevallos regresa a España ante el cese de hostilidades entre Portugal y España, sin que pueda continuar su plan de tomar Santa Catalina corriendo la frontera de los imperios. Cuando la política española cambia en el Atlántico Sur, Cevallos es convocado nuevamente y en 1775 parte hacia Santa Catalina con el fin de avanzar hacia Rio Grande y destruir la Colonia del Sacramento (Lesser, 94-95). La nueva política hacia los portugueses que impulsaba Carlos III se enmarcaba en una reestructuración del imperio que implicó entre otras cosas la creación del Virreinato del Río de la Plata, cuyo primer Virrey será Pedro de Cevallos (Lesser, 97). La camapaña se inicia en la isla de Santa Catalina que le es entregada a Cevallos sin resistencia. Un brigadier portugués -Don José Custodio de Saa y Faría- solicita se les permita huir a Río de Janeiro, y Cevallos autoriza que lo hagan los oficiales a condición de rendirse. Cevallos tiene ahora que conquistar Río Grande. Le había ordenado a Vértiz que ataque Río Grande por el Sur mientras él lo hacía por el norte pero el plan se retrasa dado que el oficio llega a Vértiz un mes después. Debido a las tormentas y vendavales Cevallos termina en Maldonado con parte de su flota 
desagrupada. Allí advierte, según Lesser, que la paz entre los imperios está por llegar: el Rey José I de Portugal morirá pronto, la sobrina de Carlos III, Reina de Portugal toma las riendas del gobierno y propone un cese de hostilidades a su tío. Ante la inminencia de la paz, Cevallos decide atacar Colonia del Sacramento antes que Rio Grande (Lesser, 99102).

El Brigadier Molina participa del segundo sitio a Colonia de Sacramento que se produce a comienzos de 1777. Eran siete mil españoles sitiando a unos setecientos portugueses en Colonia. La entrega de Colonia del Sacramento más que una acción militar fue un trámite que la diplomacia portuguesa había planificado antes de la llegada de Cevallos. Según Lesser, el Marqués de Pombal de Portugal ya había dado instucciones al Virrey de Brasil para que fuera retirando sus tropas y embarcaciones de la Colonia ante el inminente ataque de una nutrida flota castellana. También se instruye al gobernador de Colonia, el coronel de infantería Francisco José da Rocha, para que teatralice una resistencia que no servirá de nada y se rinda rápidamente. Cuando Cevallos llega, la suerte está echada (Lesser, 102-103). La paz entre los imperios es un hecho y Cevallos se queda sin ninguna otra gloria militar que reivindicar. A fines de año Cevallos es nombrado Virrey del Río de la Plata en Buenos Aires, por lo que José Eusebio de Molina viaja a esa ciudad en octubre (y también Jacinto Ventura). En junio de 1778 Cevallos sale para Cádiz en el navío El Serio. Su virreinato duró 240 días y fue sustituido por Juan José de Vértiz y Salcedo (1718-1799) con quien Cevallos había tenido algunos enfrentamientos en su segundo viaje al Río de la Plata. Ese mismo año Cevallos falleció en 1778 en la ciudad de Córdoba (Andalucía, España).

La nueva paz firmada entre los imperios hizo que José Eusebio de Molina se instalara en Montevideo en 1778, en donde permaneció hasta su muerte en 1782. Según Jacinto Ventura ocupó interinamente el cargo de Gobernador de Montevideo en 1779 y fue 
Subinspector del Regimiento de Buenos Aires (1781-1782) designado por el Capitán General Juan José Vertiz. No alcanzó el grado de Brigadier en vida porque murió seis días antes de que llegara a Montevideo la designación del Rey Carlos III (M, Tomo II, foto 9581). ${ }^{24}$ La rivalidad entre Cevallos y Vértiz tendría consecuencias en la relación de José Eusebio de Molina con el nuevo virrey. En su Memorial Histórico y Político del Licenciado Negro Jacinto Ventura de Molina al Alto y Poderoso Señor de las Cámaras del Estado del Uruguay de 1836, Jacinto Ventura narra minuciosamente los últimos meses de su tutor y, entre otras cosas, menciona estos conflictos.

Hacia junio de 1782 se produjeron una serie de "convites" o banquetes en diferente quintas de las afueras de la muralla de Montevideo, de las que Jacinto menciona dos: la “Quinta Nueva” del Doctor Pérez y la de Doña María Blanco $(A 1,49)$ que suponemos al oeste de la muralla. El Virrey Vértiz, que compartía también estos banquetes, quiso hablar con José Eusebio de Molina y aprovechando que este se había retirado a almorzar pidió que se lo siguiera y lo detuvieran antes de llegar a la ciudad para conversar. Cuando el asistente del Virrey lo interceptó pidió a José Eusebio que se detuviera en el paso del Arroyo Seco (A1, 50). Al interceptarlo, afirma Jacinto Ventura, Vértiz le dijo "los dos somos ya viejos y no esperamos más que la muerte ¿hasta cuando ha de durar un rencor entre nosotros?”. El Virrey pretendía tener una relación recíproca de amistad. Al llegar a al Portón de San Pedro en la muralla, José Eusebio de Molina quiso despedirse del Virrey y este "no admitió la despedida" y dijo: "yo quiero que sepan todos que yo gusto que VS me acompañe hasta el Fuerte y no me abandone jamás como se lo he pedido $(\mathrm{A} 1,50){ }^{25}$

24 En el original: "Este fue el Caracter acsoluto del Vrigadier Dn, Josef Eusevio de Molina (...)[Gobernador] Interino de Montevideo en 1779: Subynspector del Regimiento de Bs As - en 1781_82-por Comicion del Cap.n General Dn, Juan Jose de Vertiz: $2^{\circ}$ Inspector General. en cuya graduacion fallecio 6 dias antes que llegase el correo y despacho del Rey Dn, Carlos_ $3^{\circ}$ la elebacion de este empleo, la paz y dispociciones de Dn Josef de Molina prueban la profundidad de la Umildad de este ombre sapientisimo" (M, Tomo II, foto 9581)

25 En Gortázar et al. (2008): "He mandado llamar a VS y le hice detener para advertirle que los dos somos ya viejos y no esperamos más que la muerte ¿hasta cuando ha de durar un rencor entre nosotros?” (...) Dio las gracias a SE que siguió instándole que no sólo se olvidase de cuanto pasó, pero que le diese pruebas 
La razón de tanta insistencia era que José Eusebio de Molina fue el único que tuvo acceso a las instrucciones que Cevallos había recibido para la demarcación de los límites con Portugal. Los enfrentamientos entre Cevallos y Vértiz tuvieron lugar entre 1777 y 1778. El primero ocultó documentación a Vértiz e incluso intentó que no fuera nombrado como sucesor de su virreinato. El historiador José Torre Revello describe así la actitud de Cevallos: “(...) ocultó cuantas disposiciones se le dieron de gobierno a su sucesor, no sólo mientras ocupó el cargo, sino que tuvo la osadía de retornarlas a España y ocultarlas entre sus papeles" (33). Finalmente las negociaciones con los portugueses comenzaron en 1784 sin que Vértiz lograra que José Eusebio de Molina compartiera esa información con él. Según Jacinto Ventura, el militar había dicho en alguna ocasión: "puede disponerse lo que guste, menos que yo escriba papel sobre tal materia" (A1, 51).

La agonía de José Eusebio de Molina terminó el 15 de octubre de 1782 y Jacinto Ventura fue testigo privilegiado porque desde la muerte de su padre biológico en julio, había pasado al dormitorio de su tutor. El español padecía de gota y ciática que había sufrido desde el cruce del "Río Pando" en 1777 (A1, 53). La muerte del padre de Jacinto Ventura, su sirviente más fiel, deprimió al español que "solía decir que en su casa falta[ba] algo que él no sabía encontrar" $(\mathrm{A} 1,55) .{ }^{26}$ Este estado de ánimo hizo que comiera escasamente aunque se creyó mejorado y aceptó salir a un paseo a caballo: “fue y volvió de este último paseo y continuó con el gran entretenimiento de registrar su fusil” y los oficiales al notar estos movimientos no creyeron "que la parca tenía apuntada su saeta y aguardaba la voz poderosa para ejecutar su tiro (A1, 58-59). ${ }^{27}$ Pero el 12 de octubre de

de su amistad, que le visitase y consultase, como yo lo haré con VS. (...) Llegaron al Portón de S.n Pedro y D.n José de Molina empezó a despedirse de SE que no admitió la despedida. (...) el Ecl.mo S.or Vértiz repuso instando, "yo quiero que sepan todos que yo gusto que VS me acompañe hasta el Fuerte y no me abandone jamás como se lo he pedido" (A1, 50)

26 En Gortázar et al. (2008): "El invierno del año 1782 no contenía la activa persona de D.n José de Molina, separándose de casa. Aún a la hora del descanso de la siesta me llamaba e iba a tomar el sol al muelle, a los baluartes de la ciudadela y oprimido su pesar, solía decir que en su casa falta algo que él no sabía encontrar".

27 En Gortázar et al. (2008): “D.n José de Molina se creyó mejorado y D.a Maria Blanco, D.n Francisco 
1782 los signos del deterioro de su salud eran muy claros. Durante la fiesta de la Virgen del Pilar de Zaragoza, José Eusebio de Molina le dijo al Capitán José Pérez: “esta humanidad ya va a acabar" pero fingió que nada ocurría al llegar a su casa (A1: 60).

Ante la certeza de su muerte el español solicitó la presencia del capellán del Regimiento para recibir el viático, según se acostumbraba en el ritual católico. El Padre Vidal, capellán del Regimiento de Infantería junto a Don Juan Miguel Berroeta (Pérez Castellano, 1968: 25), sirvió a Molina en sus últimos días. El militar dialogó con el padre y se preparó para hacer el examen de su vida y el cumplimiento de cada uno de los mandamientos antes de confesarse (A1, 60). Jacinto Ventura acompañó ese examen de conciencia durante dos días:

\begin{abstract}
A pesar de las predicciones, D.n José Eusebio de Molina tuvo tal quietud, que tardó desde el 13 bien temprano, hasta el 14 a las cinco de la tarde. Una o dos horas de Examen, una o dos de confesión. ¡Despejo, reflexión, venid y veréis un mortal que se eleva sobre lo magnífico y heroico en el examen general de toda su vida, lee despacio y pausado, para, sigue, hay punto, hay interrogación, admiración. Tal fue el método del Examen último de D.n José de Molina (A1, 61).
\end{abstract}

Luego de cumplir con el padre Vidal el español dictó su testamento, que Jacinto Ventura no pudo ver hasta dos o tres años después, nombrando como sus albaceas a Pedro Castellano y

Collantes, $2^{\circ}$ Comandante de la fragata "Venus"1, y D.n Gabriel de Guerra motivaron el ejercicio y diversión de D.n José de Molina. Fue con tan afectos SS.s Blanco y Mont, todos a caballo, admirándolo tanto que D.n Gabriel de Guerra le dijo: "Molina Vmd no puede tener la edad que dice", esta era entonces 75 años, 2 meses y 15 días. D.n José de Molina fue y volvió de este último paseo y continuó con el gran entretenimiento de registrar su fusil, que tenía en la culata la bayoneta tan pulida y fina como fuerte, el oído de oro, el punto sutilísimo de plata, el cañón empavonado, las abrazaderas preciosas, de hierro templado la caja cazoleta, excelentemente templado. Notaron los oficiales estos ejercicios, mantenía el caballo puesto, y nadie pudo persuadirse que la parca tenía apuntada su saeta y aguardaba la voz poderosa para ejecutar su tiro" (A1, 58-59). 
Tomás Gil, dos de sus asistentes. A este último le solicitó que sostuviera a Jacinto Ventura "hasta que sea hombre y que no pueda extraviarse" (A1, 62). Finalmente el 15 de octubre a las ocho y media de la noche, José Eusebio de Molina falleció. Minutos antes le habría dicho a Jacinto Ventura: "Jacinto, yo muero, encomiéndame a Dios, mira como vives, porque cualquier cosa que te suceda, se atribuirá a la mala crianza que yo te he dado" (A1, 63-64).

El texto de Jacinto Ventura describe en detalle el funeral de su tutor y permite ver la sensibilidad de este sector frente a la muerte de un superior:

El día 16, a las dos de la tarde o poco antes, condujeron el cadáver de D.n José de Molina al espacioso patio que entonces tenía la Casa de Provisión, con el piso enlozado de piedra ancha, bien delineada, igual y embutida, alfombrado circunferenciado de sillas y rodeado de luces sobre un bufete enlutado. Yacía en una fuerte caja forrada de rico paño negro su mortaja, un hábito de S.n Francisco, cubierta la cabeza con la capilla, ceñido un cordón, los brazos y manos cruzadas y cubiertas con el grande uniforme de brigadier, que dejaba pequeña distancia para observar la humildad de sus pies descalzos. En el momento condujo una compañía las dos banderas del batallón, que cruzadas con dos fusiles estaban cerca de sus pies, enlutadas las pequeñas lanzas y tomadas con igual flámula por el medio; contra sus astas, paseaban dos centinelas: una a la puerta, otra a las banderas con armas al funeral (A1, 68-69).

La muerte del militar español generó cierto revuelo entre los militares de Montevideo. Había alcanzado el grado de Brigadier, el más alto que un español de origen humilde sin ningún abolengo podía tener. El contraste con Cevallos, un hombre de familia noble cuya 
historia se remonta a la invasión de los árabes (siglo VIII), no puede ser más ilustrativo: en 1744 Cevallos ya era Brigadier y en treinta años más sería designado Virrey del Río de la Plata. La trayectoria de uno y otro ilustra el proceso histórico y las tensiones entre la Europa monárquica y la ilustración que inicia el proceso hacia su socavamiento como régimen político. Cierto aire de esa ilustración hizo que Molina gozara del ascenso social a través de la educación y algo de esto se proyectará en Jacinto Ventura, en un momento histórico en el que se desarrollaba el proceso de consolidación de los Estados-nación en América Latina, heredero también de una heterogénea ilustración europea.

Los años de formación de Jacinto Ventura estuvieron a cargo de su tutor y el entorno inmediato de españoles hijos de la ilustración y miembros de la incipiente ciudad letrada colonial fundada en la Banda Oriental a comienzos del siglo XVIII. Esta experiencia es fundante y constituye su "infraestructura específica" como letrado. También le proporcionó una red social que siguió explotando tras la muerte del Brigadier y de la que recibió nuevos conocimientos, trabajos, recomendaciones y todo tipo de favores. El proceso de aculturación del que fue objeto, unido indisolublemente a la colonización española, le proporcionó un marco para interpretar el mundo. En las primeras décadas del siglo XIX ese mundo colonial al que estaba ligado racional y afectivamente comenzó a derrumbarse, situación que lo obligó a adaptarse y encontrar un lugar en el incipiente Estado-nación moderno. 


\section{La libertad en la Cisplatina (1782-1828)}

Es muy poca la información sobre Jacinto Ventura entre 1782 y 1817, año en que fechó sus primeros manuscritos y se inicia la ocupación luso-brasileña en la Provincia Oriental. La última voluntad de su tutor había sido que Tomás Gil, uno de sus albaceas, se hiciera cargo de él hasta que "fuera hombre y no pudiera extraviarse" (A1, 62). Lo cierto es que Jacinto Ventura era un hombre libre y como tal se casó en 1788 con Rufina Campana, una mujer afrodecescendiente, libre "por gracia” de Doña María Sánchez de la Rozuela, primera esposa de Jaime Illa $(A 1,72) .{ }^{28}$ Según Alex Borucki, tras la muerte de su tutor, Jacinto Ventura vivió en Buenos Aires trabajando "como zapatero y como Teniente de un cuerpo de milicia de negros libres" en 1791 y ocho años después regresa a Montevideo sin motivo aparente. Entre 1782 y 1788 Jacinto Ventura vivió en Buenos Aires con Catalina Gil, mujer vinculada sentimentalmente a José Eusebio de Molina, quien según las palabras de Jacinto "verificó el amor de madre conmigo en Buenos Aires" hasta su regreso a Montevideo en $1799(\mathrm{M}, \mathrm{I}, \mathrm{f} 352 \mathrm{v}) .^{29}$

Hacia 1800, según Borucki, estaba en Montevideo al servicio de Teresa Fagiani "viuda de un combatiente de las campañas de Cevallos". Borucki afirma como hipótesis que Jacinto "halla empleado sus contactos con ex-combatientes de Rio Grande para hacerse un lugar en Montevideo" (A2, 22). Esto no es solamente posible. Por ejemplo, Molina recordará en sus manuscritos la relación que tenía con el coronel Miguel de Tejada, quien junto al entonces coronel Josef Eusebio de Molina tomó Rio Grande de San Pedro en

28 El Sr. Illia fue un vecino de Montevideo muy activo políticamente quien volvió a casarse en 1802. Illa colaboró económicamente con la reconquista de Buenos Aires en junio de 1806 e integró la expedición militar contra los ingleses como voluntario con el grado de teniente (Aguerre: 52). El 18 de mayo de 1811 aparece en la Batalla de las Piedras integrando el ejército español con el grado de "Capitán de milicias" y destacado entre los "oficiales" en el parte que Posadas elevó al Comandante del apostadero naval de Montevideo (Puiggrós: 22 y 60).

29 En el original: "berifico el amor de madre con migo en B.s A.s hasta que vine haqui el año de 1799" (M, I, f 352v). 
1763. En 1803 Tejada le pidió a Molina que lo sirviera y este se negó por la enfermedad de su esposa, a quien debió atender en la Villa de Guadalupe, actual ciudad de Canelones, entre 1803 y 1806, año en que se producen las invasiones inglesas en las que Jacinto participó. Aparentemente Molina iba a servirlo o lo sirvió en 1807, pero al año siguiente Tejada falleció (A1: 72-73). Esta trayectoria muestra también que el tutor español le había legado no sólo una serie de conocimientos útiles sino un entramado social que muchas veces lo sostuvo económicamente y lo influyó también en sus posturas políticas e ideológicas pro-realistas y antiartiguistas.

\subsection{Esposo, zapatero y militar}

El 27 de julio de 1788 María Rufina Campana y Jacinto Ventura contrajeron matrimonio. Muy poco más se puede decir. ¿Qué tan privados son los manuscritos de Jacinto Ventura? ¿Hasta dónde es posible leer algo de su intimidad? En ellos no hay muchos datos sobre ese momento ni sobre algún otro aspecto de su "vida privada". En los diferentes momentos de enunciación de los manuscritos, en las omisiones y en los silencios está la clave para comprender el significado de los recuerdos de la vida privada que Jacinto Ventura pone en juego. Por esa razón es válido preguntarse: en qué podían aportar sus habilidades como zapatero en Buenos Aires o los detalles de su matrimonio con Rufina, a la imagen que quería construir de sí mismo como un letrado. En tal sentido Jacinto Ventura se muestra siempre dispuesto a brindar extensas descripciones sobre aquellas ocupaciones que le dieron estatus como la carrera militar o sus conocimientos letrados. ${ }^{30}$

30 Tampoco sus contemporáneos permitieron que su oficio de zapatero pasara inadvertido. Entre los manuscritos se conservó, tal vez el propio Jacinto Ventura lo hizo, un poema insultante firmado bajo el pseudónimo de Panamá: Aparta negro loco y asqueroso / no seas impertinente y majadero / trabaja en tu oficio de zapatero / no seas holgazan y perezoso: / dejate de escrivir temeridades / que no sirve a todos mas que de gracia / un amigo que te ama te lo avisa/ a ver si asi enmiendas tus barbaridades (Manuscritos, Tomo II, f 92v). Posiblemente el prejuicio de su atacante, y de muchos otros ciudadanos, también 
Los primeros años el matrimonio vive en Buenos Aires en donde además de zapatero Jacinto Ventura inicia su carrera militar desde el punto vista formal. Como adelantaba Jacinto Ventura tuvo instrucción militar entre 1774 y 1776 cuando sirvió a la artillería trasladando cartuchos y tacos ante los ataques de los portugueses a Río Grande. En 1776 participa también en las acciones militares del sitio de Colonia del Sacramento que culminan con la victoria española. Como sostiene Borucki la alfabetización a la que Jacinto fue sometido, le permitió obtener "algunas ventajas" y explicaría "el alto rango que tenía en las milicias de negros libres de Buenos Aires y en Montevideo.” (A2, 26). Para el investigador en 1791 Jacinto Ventura aparece entonces como "Teniente de un cuerpo de milicia de negros libres en Buenos Aires" (A2, 22).

Según los investigadores Borucki y Acree, María Rufina nació en Buenos Aires en 1756 y falleció a los 54 años y un mes, el 4 de setiembre de 1819 (M, T. I, f 83 r y M, T. III, f 128r). En los treinta años que duró su matrimonio la pareja no tuvo hijos. La explicación de Jacinto Ventura es que fue atacada violentamente por una maestra que intentaba convencerla de "abandonar la aplicación a aprender en cartilla", es decir, aprender a leer. Esto causó que María Rufina pasara sus últimos quince años "hidrópica” y con "erupciones sanguíneas por la boca" (Manuscritos, Tomo I, f 83 v-f 83 r). En varios pasajes de sus manuscritos Jacinto Ventura hizo referencia a la enfermedad de Rufina (Manuscritos, Tomo I, 167r) y los cuidados que le dedicó. A su vez María Rufina salvó a su esposo de distintas amenazas.

Una de ellas fue, según Borucki, durante las invasiones inglesas y podría explicar que no se conozcan manuscritos anteriores a 1817. Ante la llegada de los invasores en 1807 María Rufina prendió fuego sus papeles “para no incriminarlo ante los ingleses” (A2: 26). Borucki no señala en qué manuscrito es que Molina relata estos hechos. El otro episodio es 
el que se produce en marzo de 1815 cuando las fuerzas artiguistas sitian la ciudad de Montevideo. Un ilustre ciudadano de la Banda Oriental, Tomás García de Zúñiga, pretendía reclutarlo para las fuerzas artiguistas a lo que Jacinto Ventura se negó rotundamente alegando que permanecería fiel a Fernando VII. Por tal motivo García de Zúñiga y sus hombres "se decidieron a darme una muerte ejemplar y se me mandó [a] poner de cabeza en el cepo" (Manuscritos, Tomo II, foto 9523). Algunos oficiales propusieron incluso matarlo "a estocadas, para ejemplo de los demás” (Manuscritos, Tomo II, foto 9362).

Para salvar a su esposo María Rufina recurrió a Francisca Ubarnes/Hubarnez, madre de Tomás, quien le aconsejó que hablara con Juana García de Zúñiga, hermana de Tomás, la única persona en la casa que podía obtener algo de él (Manuscritos, Tomo I, 173r). Fue Juana la que logró, con la ayuda del doctor Francisco García de Zúñiga, liberar a Jacinto Ventura (Manuscritos, Tomo I, 175r). Para ser liberado Molina presentó dos veces un "memorial". En la primera versión afirmaba que "ninguna ley o costumbre alguna obligaba al vasallo a tomar armas en la guerra o fuera de ella, contra su natural Señor, como lo era para mí el Poderoso Señor Rey de España” y relataba los hechos acontecidos. El escrito fue rechazado y se le comunicó a María Rufina que Jacinto Ventura debía redactar otro en el que "no se expusiesen esas circunstancias ni esos nombres" (Manuscritos, Tomo I, 174v). ${ }^{31}$ El problema de la primera versión del escrito no residía, al parecer, en su fidelidad al Rey Fernando VII sino en las circunstancias y los nombres mencionados.

Primero como esclava y luego como mujer libre, María Rufina cumplió tareas

31 En el original: "La Yll.ma S.a D.a Juana Garzia de Zuñiga se encargo y consiguio mi libertad hacosta de dos memoriales porque dictando en el primero que ninguna ley o costumbre de halguna nasion obligaba hal basallo ha tomar armas enla guerra o fuera de ella contra su natural S.or como lo era mi el Poderoso S.or Rey de España, quedandose este S.or coneste escrito dijo ha mi muxer que ysiera otro enque no se espusiesen esas sircunstansias ni esos nombres" (Manuscritos, Tomo I, 174v). 
domésticas para distintas familias. Esto le permitió acceder al ámbito del poder doméstico de sus amas, de las redes o relaciones que ellas pudieran tener. ${ }^{32}$ Tanto Jacinto Ventura como María Rufina supieron aprovechar su cercanía con los “amos” para obtener distintos beneficios. Ambos eran libres, uno desde su nacimiento, la otra "por gracia" de una de sus amas. En tal sentido el episodio con García de Zúñiga en 1815 muestra también las dificultades que presentaba la carrera militar para Jacinto Ventura. Como señala el historiador Reid Andrews para el caso bonaerense, aunque aplicable a la región, la carrera militar servía como camino al ascenso social por lo que a un afrodescendiente "le convenía ingresar en el ejército y poner todos sus talentos en el intento de conseguir el rango de coronel" sin desconocer que debía sortear muchos inconvenientes y que "el acceso a los niveles superiores de la jerarquía le estaría por siempre vedado por su raza". Por tal motivo Andrews concluye que quienes "buscaban un progreso menos espectacular pero más seguro, les convenía adoptar un oficio más confiable y menos riesgoso que el de las armas" (161).

Tal vez la fidelidad al rey y su amor por la patria fueron motivos suficientes para que Molina entrara a la milicia en Buenos Aires, luego de sus experiencias durante la puja militar por el territorio entre españoles y portugueses. Pero también la voluntad de ascenso social debió tener alguna incidencia en su decisión. En los hechos Molina parece continuar con esa carrera militar hasta que en 1815 Tomás García de Zúñiga lo castiga porque no quiere integrar las tropas de Artigas. Fiel a su rey Fernando VII Jacinto Ventura abandonó su grado de Sargento salvado por su esposa como afirmaba antes. Sin embargo, cuando los portugueses llegan a Montevideo y ocupan el territorio de la Banda Oriental en 1817,

32 Según Nancy Amstrong el "contrato sexual", que se consolida en el siglo XIX, divide las esferas en las que actúan hombres y mujeres. En ese reparto al hombre le tocan la economía y la política en la esfera pública, mientras a la mujer le tocan el gobierno del hogar y los sentimientos en la esfera privada. En este relato Molina muestra tanto a Rufina como a las mujeres del patriciado actuando políticamente con eficacia en el ámbito privado y logrando un buen resultado en el ámbito público "de los hombres". 
Molina se presenta ante las autoridades como Sargento de milicias. Lo cual confirma que la carrera militar representaba para Jacinto Ventura una posibilidad de ascenso social y que, como sostiene Andrews, no había llegado a un grado muy superior. Aunque de hecho reclamar su cargo militar se convirtió en una puerta de entrada al entorno del Barón de la Laguna, ya no para ascender en la carrera militar sino para encontrar "un progreso menos espectacular" como letrado, es decir, un oficio más confiable y menos riesgoso como sostiene Andrews.

Pero eso no ocurrió hasta al menos 1823 año en el que Jacinto Ventura de Molina recibe el título de Licenciado en Reales Derechos "por el emperador de Brasil" (A2, 16). Ese mismo año escribe una carta a Lecor, firmada en la Villa de Guadalupe, en la que se presenta todavía como "Sargento Mayor de milicias del Regimiento nombrado el Borbón americano". Es posible afirmar entonces que Jacinto Ventura de Molina desarrolló entre 1791 y 1823, con un intervalo de dos años (1816-1817), una extensa carrera militar. Sin embargo, a partir de 1823, comienza a firmar sus manuscritos como "licenciado negro", dejando de lado la milicia y abriéndose un nuevo horizonte.

En 1819 María Rufina murió por lo que no pudo ser testigo ni aprovechar los avances de su esposo, quien la recordará en muchos de sus manuscritos posteriores. Al igual que con su padre Ventura y con su tutor José Eusebio, Molina recuerda las últimas palabras que María Rufina le dirigió antes de morir: "Siempre que te acuerdes de mí haz de cuenta que le estoy pidiendo a Dios por ti, pues si mi alma fuese capaz de sentimiento, nada otra cosa sentiría si solo dejarte aún de buena edad, en medio de suertes tan peligrosas". María Rufina le aconseja buscar una mujer y casarse "para librarte de las ofensas de Dios y para que te asista" y finalmente, como si fuera una madre protectora, le recuerda "que de algún modo te he criado pues tan jovencito te sujetaste a mi (M, I: 
166v). ${ }^{33}$ Siguiendo su consejo Jacinto Ventura conoció a la esclava Catalina de la Merced, el 20 de marzo de 1820 (A2, 104), a quien había defendido ante los hermanos de la Caridad (A2, 105-108) y con quien quiso contraer matrimonio por esos años (A2, 102105). La nueva relación no impidió que Jacinto Ventura homenajeara a su esposa en varias ocasiones en manuscritos tardíos como la carta dirigida a Joaquín de Sagra y Periz, fechada entre 1834 y 1835 , en el que le propone construir un colegio para negros con el nombre "Colegio de los Magos de María Rufina Campana" (A1, 127). En varias de esas referencias María Rufina aparece como un ejemplo moral para los afrodescendientes.

\subsection{Molina y la protección de Federico Lecor, Barón de la Laguna}

Cuando el Barón y Vizconde de la Laguna llegó a Montevideo el 20 de de mayo de 1817 tenía órdenes precisas del rey de Portugal Juan VI: debía pacificar la Provincia Oriental y desarticular la revolución artiguista. El Rey le daba automáticamente, una vez conquistada la misma, el cargo de Capitán General. Dos días después Lecor nombró a Don Sebastián Pinto de Araujo Correa como Gobernador militar de la Plaza, Intendente de la Real Hacienda y Presidente del Ayuntamiento. El Cabildo, con mayoría simple, votó la anexión a Portugal y encomendó al Vicario Dámaso Antonio Larrañaga y a Jerónimo Pío Bianqui la negociación con las tropas lusitanas. Al poco tiempo de entrar a Montevideo triunfalmente e instalarse, el Barón de la Laguna tuvo noticias del Sargento Mayor de Milicias de Infantería Jacinto Ventura de Molina.

Fueron apenas cuatro días. El entusiasmo de Jacinto Ventura de Molina se

33 En el original: "Siempre que te hacuerdes de mi, has quenta que le estoy pidiendo ha Dios porti, pues si mi halma fuese capaz de sentimiento, nada otra cosa sentiria, si solo dejarte haun de buena edad, en medio de suertes tan peligrosas...busca huna muxer, casate para librarte de las ofensas de Dios, y para que se hasista !O jasinto hacuerdate que de halgun modo te he criado pues tan jobensito te suxetastes ami” (Manuscritos, Tomo I, 166v). 
explicaba por la llegada de un "Ejército Pacificador" europeo y monárquico, que en su opinión venía a restaurar el orden en nombre de Fernando VII. De hecho, como explica Ana Frega, los “españolistas" se dividieron entre quienes se inclinaban por mantener el dominio luso-brasileño y quienes pensaban en la posiblidad de una restitución de estos territorios a la Corona española (Frega, 2009: 44). A su vez, la presencia del ejército de ocupación generó una trama compleja de alianzas y posibilidades, que incluyó por ejemplo el intento de una expedición española para recuperar el Río de la Plata en 1819 (Frega: 41). Pero al parecer nada de esto afectó la adhesión de Molina al gobierno luso-brasileño en la Banda Oriental, que significó para él entrar en contacto otra vez con una monarquía. De hecho, el período de dominación luso-brasileña fue el momento de mayor actividad de Jacinto Ventura de Molina a juzgar por los manuscritos del período y el entusiasmo con el que lo recordó años después.

Existen en la colección de manuscritos muchos documentos escritos en el período y posteriores que hacen referencia a la Cisplatina. Uno de los más interesantes es un manuscrito sin fechar que Molina tituló "Vini, vidi, vinci” (Manuscritos, Tomo III, f 4v9r). ${ }^{34}$ Aunque el texto no tiene una fecha concreta, es presentado por su autor como una “oración fúnebre de un Conde hecha por un autor moreno". Este carácter fúnebre indica que el texto fue escrito a raíz de la noticia de la muerte de Lecor en 1836. Como texto corresponde afirmar que es una pieza retórica típica con un Exordio, tres partes presididas por las palabras de la cita -vine, vi y vencí- y una Conclusión. En la primera parte relata la llegada de Lecor a Montevideo en enero de 1817. En la segunda, la etapa del Congreso Cisplatino y la división interna de los ocupantes tras el regreso de Juan VI a Portugal y la consagración de Pedro I como Emperador de Brasil (entre 1821 y 1824). En la tercera, su

34 En verdad la frase correcta en latín es "Veni, vidi, vici", en español "Vine, vi, vencí", frase atribuida a César en su defensa frente al Senado romano. Jacinto Ventura de Molina toma la frase para relatar la campaña de Lecor durante la Cisplatina. 
éxito como pacificador y su retirada de la Provincia Oriental en 1827.

Es importante señalar, antes de analizar el relato, algunos pasajes de Molina en el "Exordio": la descripción, por ejemplo, de las obras del Barón de la Laguna en su pasaje por Montevideo, su “carácter bondadoso, mérito magno, labores dificultosas de un orden imponderable, prudencia sin afectación, valor inimitable, modestia singular, piedad imponderable, fidelidad al Monarca, afabilidad con sus compañeros de armas y aún mayor con los nacionales americanos". Pero además de los elogios es interesante que Molina se presente en el "Exordio" como un historiador, más específicamente como cronista, basándose en la Doctrina Cristiana de San Agustín y en la Geografia de Estrabón. Del primero cita una frase en latín que luego traduce: "Nada debe dictarse sin testigos por solo idea de pensar y de escribir" (f4v) y del segundo cita también en latín aunque interpretándo su sentido general sin traducción:

\footnotetext{
Y si el fin de una historia es la verdad desentrañada, no sólo tengo el honor de reproducirme sobre la pluma, que como historiador el Excelentísimo Señor Don Carlos Federico Lecor puso en mi mano, mas acaso llevaré su memoria mucho más allá que pudieran otros historiadores (M, III: f 4v)
}

Jacinto Ventura comienza el texto autoimponiéndose la tarea del historiador, no la del biógrafo, desde el lugar del testigo en la concepción de San Agustín y de Estrabón pero también -ya en la primera parte de su discurso- de Cicerón y Quinto Curcio Rufo: "No deben omitirse las relaciones particulares si conducen a la inteligencia, ornato y defensa de la oratoria" (f5r). Esta "relación particular", por momentos megalómana, sobre su relación con Federico Lecor (Barón de la Laguna), escrita en 1836 lo coloca como testigo y 
protagonista privilegiado de ese momento histórico. Pero al igual que con su tutor español José Eusebio de Molina y con su esposa María Rufina, Jacinto Ventura intenta construir también una biografía ejemplar que sirva “(..) para lograr en los morenos la aplicación a buenas costumbres y entre ellas la fidelidad, que es virtud" (M, III: f 6r). En varios pasajes Molina cita el Flos Santorum (1588) de Alonso de Villegas, una antología de vidas de santo que sirvió de modelo para el relato hagiográfico hasta bien entrado el siglo XVII. Aunque en este texto Molina no cita este libro es claro que el relato hagiográfico influyó en su modo de narrar las vidas de Rufina Campana, José Eusebio de Molina y Lecor como ejemplos morales. ${ }^{35}$

En verdad Jacinto Ventura quiere mostrar también que sirviendo a la causa lusobrasileña, y a Lecor especialmente, permanecía fiel a su "fuero de nacimiento" y al servicio de la milicia española. ${ }^{36}$ Me interesa reparar en este hecho no por la invención política de cierta continuidad entre el "Ejército Pacificador" luso-brasileño y la posible restauración del orden monárquico español, sino porque Jacinto se separa de sus padres biológicos, ignora o silencia su origen africano y recurre al concepto de "hidalguía" que tiene un enorme peso en el pensamiento ibérico desde la Edad Media. Esta ideología ponía particular énfasis en la pureza de sangre y en el desprecio por las mezclas que se producían y producirían en América entre indígenas, europeos y africanos. En otra ocasión, dirigiéndose a la "Cámara del Estado", se presenta de este modo: "Jacinto Ventura de Molina, por naturaleza negro libre, y por ejercicio escritor particular de los poderosos señores monarcas de Portugal y el Brasil, por sesión de los poderosos señores reyes de España el año 1817, pues pertenezco a esa nación” (Manuscritos, Tomo III, f230v). Molina

\footnotetext{
35 Para un estudio sobre el relato hagiográfico y en particular de las diferentes ediciones y compilaciones durante los siglos XVI y XVII ver el "Prólogo" a una edición reciente de Vidas de santos de Pedro de Ribadeneyra.

36 En el original: "mis principios ancido militares sostenidos por el fuero de $\mathrm{m}$ nacimiento y cirviendo la milicia de España" (M, III: f 7v).
} 
yuxtapone a su afrodescendencia una genealogía ligada a su tutor español, lo que le permite justificar su presencia y su grado militar en filas españolas.

Una vez posicionado como testigo y justificada ideológica y políticamente su intervención en la ocupación luso-brasileña, Molina prepara el escenario para relatar su primer encuentro con el Barón, de quien recibió su "protección, amparo y beneficencias". Estos son los hechos: Molina escribió una nota a la Junta Regente para reclamar el pago de un incentivo para vestimenta que no cobró. El Mariscal de Campo Don Gaspar de Vigodet, que según Jacinto Ventura había notado la "circunstancia rara" de que un "moreno" escribiera, le aseguró que la carta llegaría. Pero Lecor retuvo la carta "en su gabinete” y el Almirante Gerardo Lobo la leyó "por diversión” a Lecor y otros oficiales del ejército portugués. Jacinto Ventura había sido detenido dos horas antes por el oficial porque supuso que era un "indigente sobrecogido por algún interés o causa maliciosa" por lo que sufrió "los chistes de los soldados". Finalmente, Jacinto Ventura fue interrogado por Lecor. Este le preguntó quién le había dado la carta y Jacinto Ventura respondió que él la había escrito, luego preguntó quién era y respondió “un oficial de milicias en servicio del Rey de España”, a lo que el portugués respondió "Usted es oficial sí” (M, T. III: f 7v). ${ }^{37}$

El diálogo resulta interesante porque Molina reproduce el portugués hablado por Lecor. Si bien es una mera reproducción fonética, como la que utilizaba con el latín, es posible pensar que esa no fuera la primera vez que Jacinto Ventura escuchaba el portugués dado que vivió en la villa portuguesa Rio Grande muchos años. Además tanto su madre como la segunda esposa de su padre Ventura, provenían de Brasil y posiblemente hablaran

\footnotetext{
37 En el original: "Savia por aviso de el Ecl.mo Sor D.n Gaspar de vigodet que SMC retenia en su gavinete aquella carta que leyho por diversión el Ecl.mo Sor D.n Carlos Federico Lecor leyo el sobre escrito de mipliego viniendo alas onse de ver al acmirante Gerardo lobo comm.te de la Escuadra Leyò el sobrescrito- Al Eccl.mo Sor Varon D.n Carlos Federico Lecor=Alos Ecl.mos SS.s generales sus colegas y alos SS.s oficiales del nobilísimo Exercito Portugues recidente enesta ciudad alias la R.1 Union: El oficial suponiendome un yndixente sobrecogido por alugn ynteres o causa malicio me mantu bo arrestado desde las nueba y media: sufri los chistes de los soldados teniendo el Plaser d eoyr primerabez al Ecl.mo Sòr Varon= Queyn le deu a vose esta carta $=$ yo la edictado a VE vose el Sòr queyn e vose un oficial de Milicas en servicio del Rey de España: vose e ficial ci” (Manuscritos, Tomo III, f 7v).
} 
portugués o le transmitieran algunos rudimentos. Pero resulta interesante también que en este primer encuentro Lecor sospechara de la autoría de la carta. En muchos manuscritos Jacinto describe escenas como esta, de rechazo o incredulidad de los interlocutores. Incluso buena parte de los textos que Molina presenta a diferentes autoridades tienen notas en las que se pide alguna aclaración, se rechaza el estilo entreverado e incluso se convierte en objeto de burlas.

Estas situaciones le sirvieron, en algún manuscrito, para hacer énfasis en la sorpresa de sus interlocutores ante un letrado negro. En este caso, según su relato de los hechos que Molina contempló desde la puerta, Lecor leyó la carta y "prorrumpió en llanto" explicándole el motivo al oficial Pintos (Molina hace la transcripción fonética del portugués): "De tanto trabajo que hemos pasado, con sangre y muerte de nuestros hermanos, viniendo a pacificar esta tierra, sólo este preso es quien nos dice que Dios le pague". Entonces Pintos le pregunta si él había escrito el texto y cómo se llamaba. Finalmente le prometió que él mismo le entregaría la carta al Rey. Molina describió este acontecimiento "de prudente piedad que caracterizó" las acciones de Lecor en Montevideo (Manuscritos, Tomo III, f 7v-7r). ${ }^{38}$

Así contaba Jacinto Ventura de Molina en este manuscrito cómo se había ganado los favores del los jefes del ejército de ocupación luso-brasileño. Después de 11 años de ocurrido este hecho, hacia 1828, Molina firma algunos de sus manuscritos como "escritor de cámara" de V.M.I. (Vuestra Merced Ilustrisimo) dirigiéndose en un Memorial Instructivo al Emperador de la América, Pedro I (Tomo II, f 70v.) o firmando así su obra

38 En el original: "bolò SE arriba avrio leyo se entrtubo acmirò y prorrum Pio en llanto loque notado por el Eclenteicimo Sor Pintos que no lo avia Ynterrumpido dentro y dirigiendose à SE dijo ¿qui e istu VE chora? Està suente? Naun, de tanto traballo como temus pasadu, con sangue, ymorte dus nosos yrmauns, viendo à pacificar Terra allega: so este presu e queyn nos diso Deus lle paque, leya: yo esta a la puerta del comedor viendo la esena leyò el Sòr Pintos, me llamò= bose escriviu situ ciseñor beya =unque diz= yo lo escrivi $=$ vose como se chama $=$ Jacinto V. de Molina $=$ esta firma a sua $=$ ci Sòr:= eu bo lebar un reens à SM y le do palabra de entregar porlas mina maun, estas cartas à SM: Tal fue el primer acontecimiento de Prudente Piedad que caracteriso en esta capital al Ecl.mo Sor Varon D.n Carlos Federico Lecor" (Manuscritos, Tomo III, f 7v-7r). 
Glorias de la Caridad. Los favores de Lecor fueron muchos. Entre ellos el título de Doctor en Leyes que Molina afirma haber recibido en 1821 (Tomo III, f 128r) y que Borucki y Acree fechan en 1823. La relación con Lecor le permitió estar en contacto con algunos miembros del "Club del Barón", como se conocía al grupo "hispano-criollo" que apoyó a Lecor en la Banda Oriental (Frega, 2009: 23), de los cuales obtendrá algunos beneficios. Como por ejemplo su relación con la Hermandad de la Caridad, una institución benéfica que atendía a enfermos, presos y naúfragos (Bianchi, 2001: 108) y estaba integrada por algunos católicos masones como Joaquín de la Sagra y Périz (Barrán, 2011: 22). A raíz de su internación en el Hospital de la Caridad, Molina se comprometió, según él a pedido de la institución, a elaborar una extensa obra de más de doscientos folios manuscritos.

\subsection{Escribir las Glorias de la Santa Caridad de Montevideo}

El regreso de Juan VI y su corte a Portugal y la continuación de la corona en el Imperio del Brasil por Pedro Alcantara de Braganza, ahora Pedro I, trajo como consecuencia la división del ejército de ocupación en dos bandos. El primero, en Montevideo y al mando de Alvaro da Costa, optaba por regresar a Portugal con Juan VI y permitir la independencia de la Banda Oriental. El segundo, en la Villa de Guadalupe (actual ciudad de Canelones), al mando de Lecor y a favor de la ocupación, ahora con Pedro I, emperador de Brasil. El bando monárquico de Montevideo se instaló con Lecor en la Villa de Guadalupe. Algunos manuscritos de 1823 fueron firmados por Jacinto Ventura de Molina en el "campamento de Guadalupe", en el que tuvo otra oportunidad para vincularse con Lecor y su entorno (Juan María Pérez, Nicolás Herrera, Juan Durán, Pedro Pérez, entre otros). Es posible que allí conociera a dos miembros de la Hermandad de la 
Caridad: Manuel Otero y Joaquín de Sagra y Périz. ${ }^{39}$

Una parte de la historia de la Hermandad está ligada a la cultura letrada de Montevideo y se explica por la forma en que se financiaba, con los aportes de sus hermanos y con la organización de una lotería. En 1822 Sagra y Périz propuso la compra de una imprenta para abaratar los costos de impresión de los boletos para la lotería. Ese año adquirieron la imprenta de Francisco de Paula y Pérez, armada en base a los restos de otra traída por José Miguel Carrera que había funcionado en Montevideo entre 1817 y 1819 (Fúrlong, 1932: 5). Ese mismo año, hacia diciembre, comenzó a funcionar en el Hospital y en 1825 fue reforzada con tipos y prensas provenientes de la imprenta del Estado, construida en base a la enviada por Carlota, infanta de Portugal en 1810. Se encargó de los boletos de lotería, pero su actividad excedió este fin y hasta 1855 fue la imprenta más importante de Montevideo (Rocca, 2003: 35). Produjo todo tipo de impresos, de los cuáles Furlong logró detectar 162 (1932), y “superó a todas [las imprentas del período], en las ediciones de libros" (Fernández y Medina, 1900: 19).

El gallego Joaquín de Sagra y Périz dirigió esta imprenta entre 1822 y 1846 . Fue un destacado "hermano" con una activa participación política primero en favor de la corona, luego de Lecor y finalmente dentro de la elite dominante del Estado-nación. Sagra y Périz comenzó su carrera militar con los españoles, como subteniente del batallón de Comercio y por ese motivo fue detenido por Alvear en 1814. Fue, además, escribano en el Consulado de Comercio de Montevideo, creado por el Capitán General del Río de la Plata, Mariscal José Gaspar de Vigodet. Durante la Cisplatina fue Secretario de la Cámara de Apelaciones,

39 La Cofradía y Hermandad de San José y la Caridad fue fundada en Montevideo en 1775 y sus estatutos fueron aprobados en 1789 por el rey de España. De 1787 a 1789 fundó el Hospital de la Caridad para atender a los enfermos, los naúfragos y los reos. El Hospital fue luego trasladado a un nuevo edificio que comenzó a construirse en 1825. Funcionó hasta 1843 sin cambiar "en la operativa asistencial y en la gestión" (Bianchi, 2001: 113), hasta que fue incorporado a la Junta Económico-Administrativa de Montevideo en 1855 (Acosta, 2000: 5). El Hospital de la Caridad es el actual Hospital Maciel y continúa en la órbita del Estado. 
presidida por el Barón de la Laguna e integrada por Tomás García de Zúñiga, Francisco Llambí, Nicolás de Herrera y Juan María Pérez. Hacia 1830 participó en una logia política vinculada a Rivera, y desde ese momento será uno de sus más importantes partidarios. Fue miembro del Tribunal de Apelaciones del Estado (1838-1843) y diputado (Ramírez, 1949).

Este español fue uno de los "protectores" de Jacinto Ventura de Molina, lo que explica en parte la cantidad de cartas que le dirigió, algunas incluso íntimas como el poema que dedicó a la esposa, Agustina Zufriategui. En marzo de 1827 la Hermandad, a través de su Hermano mayor Domingo Vásquez, le encargó a Molina la tarea de escribir sobre la Caridad. El resultado fue una colección de textos sumamente compleja y al parecer incompleta, titulada Glorias de la Santa Caridad de Montevideo. Uno de los tres tomos de manuscritos que se conservan en la Biblioteca Nacional reúne buena parte del material que Jacinto Ventura quiso dar "a estampa". El tomo comienza con una breve nota sobre el volumen que, según anotación de un tal M. Ferreira, fue escrita por Sagra y Périz:

Colección preciosa, y mas q.e infinita q.e le han publicado, publican y publicarán en todo el orbe, y q.e sin embargo por la incuria de los tiempos quedara inedita de algunas de las innumerables obras escritas de puño, y letra, y por consiguiente, autografas y originales (exceptu exceptuandi) del Dr. D. Jacinto Ventura de Molina (Manuscritos, Tomo I, f $1 \mathrm{v})$

El comentario resulta por demás irónico, si efectivamente fue escrito por Sagra y Périz, ya que fue él casi el único que tuvo la posiblidad de publicar estos textos. Si efectivamente la ironía es el tono general del pasaje entonces "más que infinita", reforzado por la expresión "innumerables obras", permiten inferir que el estilo de Jacinto Ventura de Molina era 
objeto de burla. Algo que no sólo Sagra y Périz hizo, sino también otros letrados en diferentes momentos.

Si efectivamente el estilo de Molina resulta algo confuso para sus contemporáneos, sin dejar de tomar en cuenta que la burla y otras formas de desprecio son en verdad formas en las que se expresa el racismo, este se hace aún más confuso para quien lee los manuscritos en el siglo XXI. A juzgar por los manuscritos que compondrían las Glorias, reunidos en uno de los tomos casi en su totalidad, y tomando en cuenta que no existen otras versiones del texto, la primera conclusión es que su organización no es clara. Lo cual podría indicar un proceso de escritura no finalizado por Molina, la existencia de una versión completa de este texto en otro archivo, o bien una organización de los manuscritos posterior a la muerte del letrado que no consideró este ni ningún otro aspecto. La tarea de reconstrucción del texto, su ordenamiento y posterior composición o la búsqueda de otros originales manuscritos supera los objetivos de esta investigación.

En las Glorias Molina toca diversos temas vinculados a la historia europea y "de Indias", a la teología, a la historia en general y a la memoria personal. Los textos utilizados como "adornos" de las Glorias provenían de diferentes fuentes: un extenso poema del religioso francés Ducheme (traducido por el español José Francisco de Islas) sobre la historia de España, un cuento árabe titulado "Alimek o la felicidad" y un artículo de la Gaceta Mercantil de Montevideo. En este aspecto el manuscrito se parece a un "cajón de sastre", expresión que utilizó Alfredo Castellanos para describir el Common place book de Dámaso Antonio Larrañaga, y que según la RAE es de uso coloquial y refiere a un "conjunto de cosas diversas y desordenadas" que en este caso se acumulan en un solo texto.

El Common place book, que permanece inédito, es un volumen de manuscritos con más de 600 folios, iniciado en 1807 durante la ocupación de Montevideo por parte de los 
ingleses. Durante años Larrañaga recopiló artículos de la Enciclopedia Británica y de diversas publicaciones europeas: Revista de Edimburgo, Gaceta de Madrid, The Traveller, Month Magazine, El Observador de Cádiz, Semanario Patriótico (Castellanos, XVIXVII). La comparación de ambos textos permite observar las diferencias notorias no solo entre las fuentes -las de Molina exclusivamente en español, las de Larrañaga también en inglés y francés- sino entre capitales culturales distintos: Larrañaga no sólo leía textos de distintas lenguas sino que accedía a materiales como la Enciclopedia Británica o manuales de historia natural que Molina seguramente no conoció. No es posible determinar si Molina conocía este texto de Larrañaga, aunque fuera por comentarios de su propio autor o de personas que tuvieron acceso al mismo. Tampoco es posible determinar si este texto de Larrañaga tuvo alguna circulación, si efectivamente existieron personas que lo leyeron o si era un material de uso personal que mantenía en su intimidad. Lo que sí es posible decir es que hay un "aire de época” en este uso indistinto de materiales diversos (¿un bricolage?) en el que se define un estilo propio.

En uno de los prólogos de las Glorias Molina asegura que la obra tiene "otro adjetivo" por ser escrita por un negro, porque "los señores blancos vuelan como pájaros o nadan como peces" en la escritura, lo hacen "casi naturalmente". Pero la diferencia no es necesariamente natural y no se justifica porque "gracias a Dios somos hombres como ellos, redimidos por la preciosísima sangre de mi Señor Jesucristo”. Por eso Molina concluye con un tono amenazante: "si [los blancos] desean que nos salvemos, nosotros deseamos igualmente que se salven ellos". La religión católica, y fundamentalmente Jesucristo, son el fundamento de la igualdad, aunque las palabras finales del Licenciado parecen una advertencia a los blancos si quieren obtener su salvación (Manuscritos, Tomo I, f 19v). ${ }^{40}$

40 En el original: "La obra se nombra Glorias, y escrita por mi tienen otro hacxetibo porque los SS blancos buelan coo los pajaros ho nadan como los peses= escriben casi naturalmente los negros no, haunque grasias ha Dios somo ombres como ellos redimidos con la Presiosisima sangre de mi S.or Jesucristo: y si los SS blancos desean que nos salbemos nosotros deseamos ygualmente que se salben hellos: lease la vida 
Este alegato por la igualdad de los hombres, que Molina vincula a diferencias en el acceso a la palabra escrita, se explica por una serie de rechazos, cuestionamientos y burlas recibidos que no comenzaron con las Glorias ni terminaron en ellas tampoco. Precisamente las Glorias fueron motivo de una disputa con la Hermandad. En 1828 Molina presentó un escrito en el que adjuntaba la declaración de un indigente español llamado Pedro Gómez, que era atendido en el Hospital de la Hermandad. El escrito sirvió también para preguntar a los hermanos qué había sucedido con las Glorias, por qué no había recibido respuesta de Pedro I o incluso de la Iglesia en Río de Janeiro. Pero, sobre todo, para recordarles la deuda que tenían con él por el trabajo realizado y para preguntar cuándo iba a ser “dada a la estampa" su obra. Pero las Glorias nunca fueron publicadas. En cambio la imprenta de la Caridad publicó en 1826 un informe de la administración de la Hermandad, firmado por Sagra y Périz, que abarcaba la historia de la institución desde sus orígenes. ¿En qué medida Jacinto Ventura no esperaba complementar, discutir o continuar ese informe con la redacción de las Glorias? No hay aparentemente ninguna mención a este asunto en los manuscritos pero la cercanía con Sagra y Périz, su interés en agradarle y obtener favores, podrían explicar en parte la existencia de un texto como las Glorias.

El vínculo de Molina con la Hermandad duró apenas dos años (1827-1828), recurriendo entonces a otros protectores. El peso de los estereotipos coloniales no permitió que, pese a su formación militar y letrada, viviera cómodamente. Pero aunque tuviera muchos protectores y diferentes estrategias para sobrevivir, Molina nunca traicionó dos aspectos de su encuadre ideológico: ser católico y monárquico, o viceversa, porque estas dos características parecían ser dos caras de una misma moneda. La religión revelada y el origen divino de la monarquía son ideas que están unidas en su forma de entender la política. Pero su posicionamiento político-ideológico explica también aspectos centrales estas americas, hafin deque henellas se bendixese el nombre Santo del S.or" (M, I: f 19v). 
como la elección de sus lecturas, o al menos, sus citas a textos. Una buena parte de ellas vinculadas a la Biblia -sobre todo las historias de reyes del Antiguo Testamento- y a la teología, que utiliza además para fustigar las ideas de Rousseau o Diderot. En 1827 pierde los favores de Lecor que se retira del territorio. Según Acree y Borucki, permanece internado en el Hospital de la Caridad entre 1827 y 1830, habiendo ingresado a causa de una "inflamación del muslo derecho" (A2, 17).

Al mismo tiempo que Molina ingresaba al Hospital se consolidaba el proceso hacia la independencia de la Provincia Oriental y la formación de un estado indpendiente y soberano. Estar encerrado en el Hospital durante este proceso y encerrarse en su inscripción religiosa y la defensa de la monarquía española, dejan a Molina "fuera de lugar" respecto a la idea de un estado-nación soberano que empieza a tomar forma en los diferentes grupos de la elite letrada criolla. Sin embargo, estas transformaciones no impidieron que los vínculos de Molina con algunos de los "hombres ilustres" se intensificaran, que siguiera obteniendo beneficios de ellos y que, progresivamente, se adaptara a las nuevas reglas. 


\section{Un nuevo escenario: Molina en el Estado-nación (1830-1837)}

El nuevo orden civilizatorio impuesto y centralizado por el Estado-nación le daba a la escritura "un poder legalizador y normativo de prácticas y sujetos cuya identidad quedase circunscripta al espacio escriturario" (González Stephan, 1996: 19) y organizaba un poder "múltiple, automático y anónimo que controlase sin cesar y discretamente a los individuos" (20). De acuerdo a la argumentación de González Stephan estas operaciones tenían por objetivo "reencuazar la violencia hacia la plusvalía del capital" (22). Para ese proceso de incorporación al sistema-mundo el diseño del cuerpo ciudadano era fundamental y eso se hizo con textos: constituciones, gramáticas y manuales de conducta. Estos textos muestran una ciudadanía excluyente, en los términos de González Stephan "falocéntrica" porque "recae sobre él ciudadano, él senador, él maestro, él letrado, él padre de familia” (31). Pero las mujeres no fueron las únicas excluidas de ese proceso. La voluntad de controlar el territorio y centralizarlo se inició con una constitución y también con un genocio programado dirigido a los charrúas y encabezado por el primer presidente del nuevo Estado, Fructuoso de Rivera: el episodio conocido como Salsipuedes. Una encerrona en la que se intentó eliminar a la etnia, fecha recordada en Montevideo porque en ella murió el hermano del presidente Bernabé Rivera y hubo nueve heridos. El orden necesitaba de la violencia física y de la persuasión mediante textos como parte de una misma pretensión civilizatoria para encausar la barbarie.

El texto constitucional votado el 18 de julio de 1830 en su Sección II, Capítulos I a IV, define la ciudadanía y los motivos para suspenderla. Si bien se sostiene que el cuerpo ciudadano estaba restringido en el siglo XIX, el texto constitucional establecía en su artículo $7^{\circ}$ que eran ciudadanos naturales: "todos los hombres libres, nacidos en cualquier punto del territorio del Estado". Ninguna de las razones para suspender la ciudadanía 
(capítulo III) o para perderla (capítulo IV) comprendían la situación de Jacinto Ventura de Molina. Por lo tanto era un ciudadano con derecho a voto. Sin embargo, Molina tuvo que solicitar su derecho a la ciudadanía y a su fuero militar en una nota en la que se respalda en la constitución, que llama "Ley del Estado" (A2, 193-195), y que posiblemente fue escrita en 1833.

Las mismas contradicciones que tuvieron las elites gobernantes criollas en todos los países hispanoamericanos, signaron los primeros años del Estado-nación en Uruguay, por lo que la esclavitud y los significados que la cuestión étnico-racial tenían en la sociedad montevideana no cambiaron sustantivamente con la Constitución. Los esclavos no eran ciudadanos y los afrodescendientes en general, podían estar comprendidos dentro de las causas de suspensión de la ciudadanía, fundamentalmente la que establecía el artículo $5^{\circ}$ de la sección III: "Por no saber leer ni escribir, los que entren al ejercicio de la ciudadanía desde el año de mil ochocientos cuarenta en adelante". La Constitución establecía en los artículos 131 y 132, de la Sección XI "Disposiciones generales", que "nadie nacerá ya esclavo" y que "queda para siempre prohibido su tráfico e introducción en la República" (art. 131). Esto no limitó el tráfico que continuó bajo el nombre de "introducción de colonos africanos" (Frega et al., 2008: 13).

Un poco antes, fruto de las disputas políticas por el territorio de la Provincia Cisplatina, concretamente el 5 de septiembre de 1825, la elite criolla que buscaba la independencia, o al menos el fin de la dominación luso-brasileña, promulgó la llamada "ley de vientres", que también abolía el tráfico: "Serán libres sin excepción de origen todos los que nacieran libres en la Provincia, desde esta fecha en adelante, quedando prohibido el tráfico de esclavos de país extranjero" (en Beraza, 178). Claro que la dominación lusobrasileña todavía no había finalizado y la ley dictada por la Honorable Sala de Representantes de la Provincia Oriental no tenía todavía el efecto deseado. Es 
precisamente el 20 de enero de 1830 cuando la Asamblea Constituyente y Legislativa, que unos meses después votaría la Constitución, "extiende a todos los puntos del territorio la ley del 5 de septiembre” (Frega, Chagas, Montaño y Stalla, 2008: 13).

En este nuevo escenario Jacinto Ventura de Molina, que ya se había visto afectado por la retirada de las fuerzas luso-brasileñas de Montevideo, no tiene otra opción que adaptarse. La tutela de Joaquín de la Sagra y Périz es central en este período así como sus relaciones con otros miembros del gobierno de la Cisplatina que se adaptaban como él al nuevo escenario. La internación de Molina en el Hospital de la Caridad fue de tres años. En 1830 había escrito seis tomos de las Glorias, pero su arsenal de citas bíblicas y teológicas servían en parte al nuevo Estado que, más allá de declarar como su religión oficial la católica apostólica romana (Sección I, Capítulo III, artículo $5^{\circ}$ ), comenzaba a configurar una república liberal contraria a los principios que Molina había expresado unos pocos años antes en su defensa de la monarquía y en su fuerte prédica contra los filósofos de la Ilustración.

Estas nuevas y viejas relaciones hicieron que el Estado Oriental reconociera a Molina en 1832 como "defensor de negros" y como licenciado en Derechos. Toda su actividad entre 1830 y 1837, fecha en la que se pierde su rastro, Molina centra su actividad en ejercer la profesión de abogado. No será su única actividad porque intentará, hacia 1834, crear una Escuela e Iglesia exclusiva para "negros" a la que quiso bautizar con el nombre de "Colegio de los Magos de María Rufina Campana" (A1, 127-128). También en ese año, sin abandonar su religión y en uso de sus facultades como abogado, defendió con éxito a la Sociedad de Negros Congos de Gunga, asumiendo su representación ante las autoridades para conseguir que se levantara la prohibición a los bailes de negros motivada por un levantamiento de esclavos en 1833. 


\subsection{El defensor de "los ciudadanos de color"}

El 4 de mayo de 1832 el Secretario Miguel Antonio Berro (uno de los redactores de la Constitución) y el Presidente firman un documento, que Molina llama "título", que lo habilita a defender a "los ciudadanos de color". El texto contiene cinco artículos en los que se describe el procedimiento a seguir: primero, se autoriza a los Doctores Sagra y Périz y Florencio Varela para que expidan los “títulos nacionales” que Molina pide; segundo, estos se pueden extender no sólo a sus conocimientos en Leyes, sino a otros "ramos científicos"; tercero, una vez expedidos deben ser reconocidos por la Escribanía del Tribunal Superior de Justicia y por la Contaduría General; cuarto, hecho esto Molina está habilitado a dirigirse al Juez Ordinario Don José María Platero en una causa concreta por "actos vergonzosos irreverentes y escandalosos cometidos por el etíope Manuel Alonso". (A2, 204)

En los Considerandos de la resolución las autoridades hacen referencia a la "grande escases de Letrados en que desgraciadamente se encuentra la República” (A2, 204) por lo que Molina ingresa a la vida nacional como letrado, formando parte de la burocracia estatal. A partir de esta fecha Molina, promovido por Joaquín de la Sagra y Périz, recibirá un sueldo del Estado por su tarea de "Defensor de negros" y desempeñará esta tarea en diferentes causas. Existen entre sus manuscritos, documentos judiciales anteriores a 1832 dado que según su testimonio los portugueses le habrían entregado el título de Doctor entre 1821 y 1823. En 1823 redacta el testamento de María Castro, miembro de la Cofradía de San Benito en la Iglesia de San Francisco y defiende la causa de Pedro Gómez “inmigrante español que murió en el Hospital de la Caridad em 1828” (A2, 213). Como abogado participó también en la separación de bienes de Domingo Lima (sin fecha, posiblemente antes de 1832) y de Teresa Mojica (1834). En 1834 defiende también a la liberta María 
Guardado por robo (A2, 231-233).

Pero su trabajo más importante del período es la defensa legal de la Sociedad de negros Congos de Gunga hacia fines de 1834. Esta sociedad era una de las más importantes y numerosas sociedades de afrodescendientes de Montevideo. Jacinto Ventura de Molina fue "asesor fiscal" de un colectivo compuesto por Antonio de la Rosa Brito (rey o presidente de la Sociedad), Joaquín Martínez y Juan Sosa (Ministros), y Gregorio Juanicó, Miguel Piñeiro y Pedro Obes (Consejeros). Su acción concreta fue solicitar que se levantara la prohibición de los bailes decretada en 1833 para poder organizar la Fiesta de Reyes de enero de 1835. La importancia de este escrito en la trayectoria de Jacinto Ventura de Molina reside en que fue su primer, y tal vez único, manuscrito que tuvo una edición impresa. El hecho de haber sido publicado, apenas una vez, aún cuando la comunidad letrada frenó su acceso a tal derecho, es un hecho significativo en la medida en que, como señala Bourdieu, publicar "es una operación que oficializa, por lo tanto legaliza, porque implica la divulgación, el descubrimiento frente a todos, y la homologación, el consenso de todos sobre la cosa así descubierta" (Bourdieu, 1988: 88).

El impreso fue reproducido por Pereda Valdés en su Negros esclavos y negros libres. Esquema de una sociedad esclavista y aporte del negro en nuestra formación nacional (1941) y en su segunda edición corregida y ampliada de 1965, con el número 59 de su “Anexo documental”, sin citar fuente alguna (Pereda Valdés, 1941: 157-160 y 1965: 249-253). En la copia del impreso que existe en la Biblioteca Nacional se afirma que se trata de un "rarísimo impreso uruguayo de la Imprenta de la Caridad, desconocido por todas las bibliografías" y que, junto a los tres tomos de manuscritos y el dibujo de Besnes Irigoyen, provenían de la Ex-colección Daniel García Acevedo. En su vida social el archivo de Molina sufrió múltiples manipulaciones a partir de la muerte de Sagra y Périz. La existencia de un único ejemplar de este impreso, el hecho de que no figure en las 
bibliografías, es al menos paradójico porque la única prueba de su reconocimiento por parte de la comunidad letrada no estaría del todo clara. De todas formas hay varios manuscritos del archivo vinculados directamente con los Congos de Gunga. El impreso es, en todo caso, una entre varias acciones llevadas adelante por Molina junto al colectivo afrodecendiente. Los Congos de Gunga recurrieron al abogado porque pesaba sobre ellos, y sobre los afrodescendientes montevideanos, la prohibición de realizar bailes en sus casas de nación. Esta prohibición tenía su fundamento en un levantamiento de esclavos y libertos que fue desarticulado la noche del 25 de mayo de 1833.

En Hombres con dueño (1943) Juan Carlos Pedemonte rescató este acontecimiento. Gracias a él tenemos uno de los primeros relatos, sino el primero, sobre esta revuelta. Los principales líderes de la conspiración fueron el negro Félix Laserna (conocido como Santo Colomba) y el "alemán" Guillermo Guitarner. El investigador tuvo acceso a la "pieza procesal" y afirma que el plan de Laserna era fundar una República negra y dominar a los blancos (Pedemonte, 63). ${ }^{41}$ La interpretación de Pedemonte es en parte paradójica ya que si bien reconoce el liderazgo de Laserna, le atribuye a Guitarner una orientación "eficaz” por su "condición de europeo" e incluso sostiene más adelante que en caso de resultar vencedor, "más que República hubiera sido un cacicazgo" de Laserna con la asistencia del europeo (Pedemonte, 65). La "Oración política" con la que Molina defiende a los Congos recurre al levantamiento de Felix Laserna para destacar la fidelidad de los negros a la autoridad de los blancos y fundar una Sociedad para la organización de la nación de los Congos de Gunga. Molina ofrece un relato del encuentro entre el conspirador y los jefes Congos así como la negativa del colectivo a participar de la insurrección. El manejo narrativo de esta insurrección, el conocimiento del miedo de los amos a repetir el caso de

${ }^{41}$ A pasar de no dar con la causa judicial desarrollada en contra de los conspiradores tuve acceso en el AGN (Ex Ministerio de Gobierno y de Interior) a alguna documentación dispersa del Fiscal "en comisión", del departamento de Policía y del Jefe Político. Analizaré este material en el Capítulo IV. 
Haití en Montevideo y el conocimiento de las leyes le permitieron a Molina obtener la autorización de las autoridades y triunfar en el caso.

\subsection{Los límites de la comunidad imaginada}

Desde sus primeros años de vida en la ciudad de Rio Grande Molina pasó por diferentes pruebas para demostrar sus conocimientos. Con apenas seis años afirma Molina "sufrí el ecsamen del Catecismo de Astete" y en tres meses sufrió “otros dos ecsamenes", confesándose tres meses después y comulgando luego. Su tutor, como relataba antes, tomaba la lección a Jacinto Ventura todas las noches. En 1782, el año en que moriría su tutor, el Ministro de Marina Don Bernardo de Alcalá le preguntó a Jacinto Ventura si escribía y quién le había enseñado, dado que estaba prohibido enseñar a los "negros", por lo que increpó a José Eusbio de Molina. En 1817 frente a Lecor y Pintos, los hombres más poderosos del ejército luso-brasileño que llegaba a "pacificar" la Provincia Oriental, también fue interrogado sobre sus capacidades letradas. Se puede afirmar que el período colonial fue para Jacinto Ventura de Molina un momento de mimesis con la cultura europea. La máscara blanca de Molina y su piel negra provocaron el rechazo de los europeos y criollos, o más bien, la perturbación. Jacinto Ventura aparecía como una “excentricidad” o una "excepcionalidad” y esto provocó distintas reacciones de los letrados como la risa, la burla o la indiferencia, todas ellas vinculadas a este carácter ominoso, amenazante, de su máscara blanca.

Durante el período previo a la constitución de un Estado-nación soberano, y a pesar de que Molina gozaba de los favores de los luso-brasileños, esta resistencia también se expresó. En su primer Memorial Histórico, escrito en 1817, Molina ya hacía referencia a las "burlas y soflamas" que recibió por su fuero militar (Manuscritos, Tomo II, f 5r), tal vez 
refiriéndose a los ataques de Tomás García de Zúñiga en 1815, o por su pretensión de emprender una nueva carrera de "licenciado en Reales Derechos". Estos y otros hechos anuncian una cadena de actitudes similares de parte de la elite letrada al iniciarse la vida republicana. En algunos manuscritos posteriores a 1830 aparecen varios indicios de la violencia que otros letrados ejercían sobre Molina. Uno de los más importantes se produce precisamente el año en que su "título" es reconocido por segunda vez, en esta oportunidad por el nuevo Estado-nación.

En la resolución firmada por Berro en mayo de 1832 se decía que debía dirigirse ante el juez Don José María Platero para que trabajara en un expediente contra un "etíope" llamado Manuel Alonso. En diciembre Molina se dirige a la Comisión Permanente del Parlamento para solicitar una prórroga hasta 1833 para que el Alcalde Ordinario, Juan María Pérez, quien había quedado "subdelegado" de Platero, siguiera en su cargo y atendiera la necesidad de Molina de ejercer su profesión. El Doctor Platero había sido sustituido tal vez por razones vinculadas al "tétrico mes de agosto" de ese año (Manuscritos, Tomo II, f 101v), en que Lavalleja y sus seguidores (principalmente de Montevideo) se levantaron contra el Presidente constitucional. ${ }^{42}$ Sagra manda el pedido a Pérez para que se pronuncie sobre el expediente de Molina. El 6 de diciembre Pérez contesta que "la basta erudición (...) su estilo elevado y superabundante" complicaron mucho su "sencilla petición” y confiesa que "no le fue fácil (...) subir a ese prodigioso laberinto" para concluir que el expediente pasara a Don Tomás Sartori, antiguo dueño de una fábrica de zapatos, para que certificara si Molina era o no un zapatero. Luego de eso el expediente debía volver al Juzgado: "para entrar en el detalle de los cinco mil y mas puntos

42 Según Eduardo Acevedo: “A mediados de agosto ya quedaba Rivera dueño de Montevideo y se dictaban numerosos decretos dando de baja a un centenar de jefes y oficiales; imponiendo la pena de muerte a los que no se presentaran en demanda de indulto; destituyendo a numerosos empleados civiles de filiación lavallejista (...)" (Acevedo: 389) 
que abarca el celebre escrito" (M, II: 105v-106r). ${ }^{43}$

La autoridad no puede reprimir las burlas a Molina y desde el comienzo descalifica su erudición, afirma que es basta (tosca), y su estilo "superabundante", al que compara con un laberinto al que preferiría no subirse, porque implicaría, según sus propias metáforas, "meter su hoz en mies ajena", es decir, podar para poder descifrar el contenido del pedido. En el párrafo siguiente Pérez remata su juicio con ironía, recomendando que un zapatero certifique los conocimientos de Molina, antes de resolver sobre los "cinco mil y mas puntos" de su escrito. A pesar del juicio del Alcalde, Sagra y Périz pide que se haga lo que Molina solicita.

Pero ni siquiera su protector, Sagra y Périz, escapa a las burlas que se dirigieron a Molina. En su archivo personal, que conserva el Archivo General de la Nación, guardó algunos textos de Molina que describe como "poesías de Tío Jacinto Ventura Molina: un moreno que se decía Doctor en Leyes y que todos los antiguos le hacían creer que lo era" $(\mathrm{A} 1,144)$. Entre esos textos hay un impreso del que se desconoce procedencia y fecha de publicado (A1, 143) que califica los versos de Molina como "abortados". Esta documentación no sólo confirma la relación de proximidad con Sagra y Périz, quien describe a Molina como "tío" expresión que se utilizaba para demostrar cierta familiaridad con los esclavos, sino una tendencia general a denigrar o menospreciar los trabajos y las habilidades de Jacinto Ventura del que su protector no estuvo exento.

43 En el original: "Ex.mo S.or, El Alcalde Ordinario q.e subscribe en cumplimiento de la superior providencia de VE. del $1^{\circ}$ del corr.te dice q.e la basta erudición del D.or Molina su estilo elevado y superabundante ha complicado de tal suerte su sencilla peticion q.e no le es facil al q.e suscrive subir a ese prodigioso laberinto p.r los escalones q.e ofrecen los cinco puntos, sin esponerse á dar un peligroso salto p.a llegar a la obra prima; y aun mas peligroso p.r q.e seria preciso marchar p.r una senda desconocida p.a meter su hoz en mies ajena.

Por estas poderosas razones juzga juzgando el Alcalde Ordinario (q.e si VE lo tiene a bien) este espediente pase al antiguo director de una fabrica de zapatos Dn Tomas Sartori p.a q.e como Maestro en el arte previamente clasifique ó informe, si el sapientisimo D.or Molina, cuando es tan virtuoso q.e se rebaja á oficial de zapatero, es primo primero ú oficial de obra prima, q.e mutatis mutandis es una misma cosa, y q.e hecha esta clasificacion vuelva este espediente al Jusgado para entrar en el detalle de los cinco mil y mas puntos que abarca el celebre escrito y siguiente esplanacion del benemerito Dor Jacinto Ventura de Molina" (M,II: 105v-106r). 
Un mes antes, también en el proceso que se inicia con la resolución de Berro, Molina tiene un altercado por el cobro de haberes con el Tesorero Ambrosio Mitre, quien en sus textos hace referencia a "su vasta literatura" y los "indigestos trozos de historia que se amontonan en su mollera" (A2, 207) Sagra interviene también en esta oportunidad para que se efectivice el pago que Molina reclama y finalmente en una nota del 15 de noviembre de 1832 un anónimo escribe:

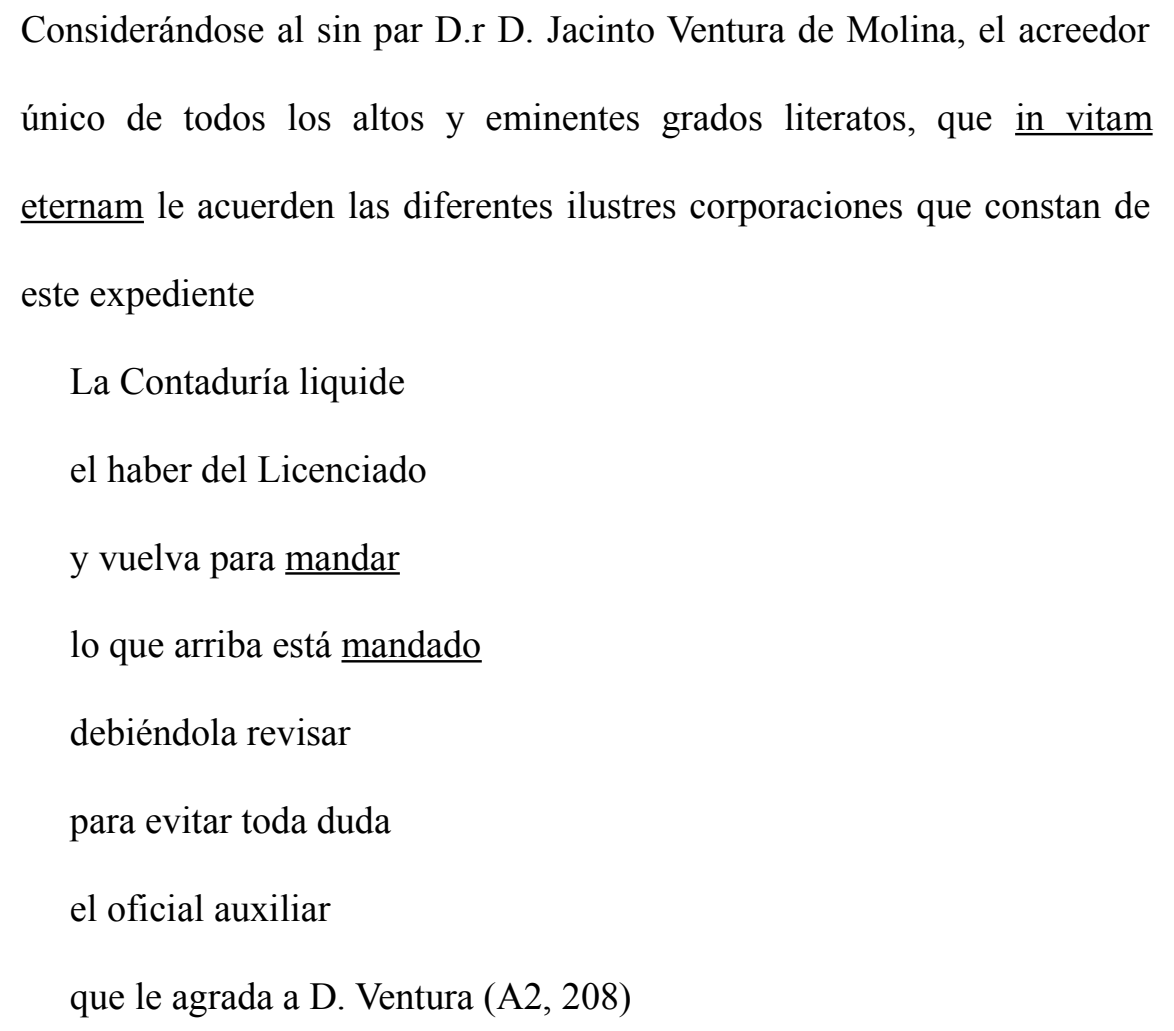

Es notorio que los funcionarios del Estado no tomaban en serio a Jacinto Ventura, a tal punto que la burla llegaba a los expedientes. El texto que cito por ejemplo, otro poema insultante hacia Molina, está firmado por un pseudónimo "Mamerto Lechiguano" y tiene el mismo tono irónico del texto del Tesorero y del Alcalde Ordinario. ${ }^{44}$

44 La palabra no aparece en el Diccionario de autoridades y en el Diccionario del Español del Uruguay aparece el significado de "adicto a la bebida" (Academia Nacional de Letras: 348 ) sin ninguna referencia al momento histórico en que empieza a utilizarse. 
Pero estas burlas e ironías tomaron estado público también. Los investigadores Acree y Borucki encontraron un texto en la prensa montevideana, publicada en La diablada o el robo de la bolsa, en el que un periodista o ciudadano tras un pseudónimo (“Un curioso") satiriza a un ministro del gobierno de Rivera el 17 de marzo de 1832:

(...) debe ser un gran literato pues dice que ha leido cuanto hai escrito desde Beroso, Orfeo, Sanchoniaton y Foie, hasta los legajos del licenciado Jacinto Ventura de Molina: con la fisionomía y expresión del cual tiene cierta semejanza $(\mathrm{A} 2,209)$

El periódico en el que fue publicado el texto se inició y terminó su actividad en marzo de 1832. Entre el 6 y el 21 concretamente, fueron 5 números (Praderio: 45-46). Fue una publicación semanal de sátira política en oposición al gobierno de Rivera, en el que otra vez (ahora públicamente) los papeles de Molina fueron objeto de la burla, dado que el ministro satirizado es capaz de leer "hasta los legajos de Molina" y es comparable físicamente con él, como parte del insulto, es decir, es comparable con un afrodescendiente pobre y algo loco. El texto confirma también que "los legajos" de Molina eran conocidos en Montevideo.

Otro de sus contemporáneos, el pintor y dibujante Juan Manuel Besnes e Irigoyen hizo un retrato de Molina (que se conserva en la Biblioteca Nacional como parte del archivo y que no fue todavía datado) y escribió un texto para identificarlo en el que también se burla de él:

Escritor original e infatigable sobre toda materia, en prosa y verso, Militar, teólogo, jurista, literato, economista, historiador, filósofo, 
MAESTRO DE OBRA PRIMA; Nació libre en la villa de San Pedro del Sud del Río Grande EL 15 DE OCTUBRE DE 1766, hijo de Ventura Molina, criado del Brigadier Español Don José Eusebio de Molina; De su himeneo con MARÍA RUFINA CAMPANA No queda prole; mas los abortos de su fecundo ingenio, aunque inimitables, dejan fundado un nuevo género de literatura que ya lleva su nombre, y lo hace tan famoso, o más, que Dulcinea hizo al Toboso.

Besnes, al igual que los otros letrados, hace referencia a su estilo "original e infatigable sobre toda materia" y se refiere a su obra como "abortos de su fecundo ingenio" e irónicamente concluye que ha fundado "un nuevo género de literatura que lleva su nombre". Finalmente la referencia al personaje de Cervantes hace pensar en la "locura" del Quijote, aspecto que también le fue atribuido a Molina.

El escritor tuvo muchos años como el de 1832, antes y después de la fundación del Estado Oriental, en los que primaron la burla, la negación de sus cualidades como letrado, y otras formas del racismo. En estas condiciones de origen no puede parecer extraño que la elite letrada que configuraría el patrimonio cultural del Estado en sus primeras décadas no prestara atención alguna a los manuscritos de Molina. Un síntoma de eso es Montevideo antiguo. Tradiciones y recuerdos que Isidoro de María publicó entre 1887 y 1895, un texto en el que se reconstruía el pasado colonial de la ciudad, ante un proceso de modernización que iba haciendo desaparecer la materialidad de ese pasado, derribando la muralla y ampliando la ciudad. En ese marco Isidoro de María combinó la memoria personal y familiar, las "tradiciones orales" y algo de documentación, para reconstruir un territorio y una memoria entre personal y colectiva de lo que fue la Montevideo colonial. Cuando en 1888 publica el segundo tomo de esta colección, destaca en uno de sus breves relatos, a 
Jacinto Ventura de Molina junto a Pepe Onza, entre una serie de "tipos de todo linaje" que eran "seguidos y chiflados" y con los que se divertían los "muchachos callejeros" (1957, 240). De María también se burla de sus obras, de sus pretensiones de ser un letrado, aunque proporciona datos interesantes sobre sus protectores

De algún modo el texto de Isidoro de María restituye a fines del siglo XIX aquella actitud generalizada frente a Molina y sus manuscritos. Su descripción lo presenta como un "fuera de lugar", como si se tratara de una copia exagerada del "mejorcito blanco". Este breve relato nos dice más sobre la imaginación racista de Isidoro de María (y posiblemente de la mayoría de los "vecinos" de Montevideo), que sobre los hechos que describe, pero explicita la dificultad de imaginar un letrado afrodescendiente por parte de esa comunidad interpretativa, que lo clasifica como un fenómeno algo excéntrico y sin trascendencia. En estas condiciones era difícil que los manuscritos de Molina se constituyeran en un objeto de estudio serio para algún investigador a principios del siglo $\mathrm{XX}$, sin contar con que el archivo se daba por perdido como lo sugiere De María. El desprecio, la burla, la indiferencia, la desconsideración e incluso la deslegitimación dejaron marcas en los manuscritos de Molina y son observables tanto en sus contemporáneos como en la elite letrada criolla de todo el siglo XIX. Por lo tanto 1832 es un año que marca no sólo los límites de la comunidad imaginada, en la que no había lugar para un "letrado negro", sino también el "espíritu de época" que imprimió en este archivo las condiciones para su olvido.

Entre los más de mil folios con manuscritos de Jacinto Ventura de Molina el más viejo data de 1837 (Manuscritos, Tomo II, f220r). Luego desaparece su rastro y es factible pensar que haya muerto cerca de esa fecha. William Acree, por ejemplo, sostiene que fue en 1841 aunque no presenta ninguna prueba de ello (2010: 59). La historia de Jacinto Ventura de Molina que acabo de relatar es el preámbulo para un análisis de la cultura 
letrada y de las posibilidades de un sujeto subordinado, considerando la clasificación étnico-racial que se instaló en la sociedad colonial montevideana y perduró en la República; burlado e insultado por los prejuicios que esa clasificación sustentó; y también hábil en la búsqueda de beneficios y ventajas. Aunque este relato pueda parecer excepcional o sea presentado por su propio protagonista como algo extravagante, es posible tomar distancia de la sorpresa y explicar el caso desde otra perspectiva. 


\section{CAPÍTULO II}

\section{Cultura letrada y etnicidad en el siglo XIX rioplatense}

En 1997 la Revista de Lengua y Literatura de la Universidad Nacional del Comahue publicó una entrevista de Alejandra Minelli a Antonio Cornejo Polar. Ante la pregunta de si "existen categorías teóricas pensadas desde la realidad latinoamericana", Cornejo Polar hace referencia a la transculturación y también a la última obra de Ángel Rama La ciudad letrada que, según él, “es también en el fondo una categoría teórica, lo que pasa es que de alguna manera somos demasiado tímidos y no nos gusta darle amplitud, categoría, jerarquía teórica a nuestro propio pensamiento" (Minelli, 1997: 154-155). En un texto publicado póstumamente, el autor murió el 18 de mayo de 1997, Cornejo Polar reflexiona sobre las condiciones de producción y reproducción del latinoamericanismo y va un poco más allá de este planteo de la "timidez".

La preocupación de Cornejo Polar era “el excesivo desnivel de la producción crítica en inglés que parece -bajo viejos modelos industriales- tomar como materia prima la literatura hispanoamericana y devolverla en artefactos críticos sofisticados" (1997: 343). Como una de las repercusiones de este hecho Cornejo señalaba que la crítica en inglés utiliza bibliografía en inglés y prescinde o no cita "lo que trabajosamente se hizo en América Latina durante largos años" (343). Una geopolítica del conocimiento desigual, signada por una lógica parecida al modelo industrial, en la que América Latina parece ocupar el lugar de proveedora de materia prima (en este caso literatura), aparece como otra traba al reconocimiento de herramientas teóricas construidas y desarrolladas localmente y en español por teóricos como Ángel Rama o el propio Antonio Cornejo Polar.

Más arriba sostenía que la ciudad letrada es el escenario en el que Jacinto Ventura 
de Molina desarrolló su trayectoria como letrado. No se trata de una elección ingenua o descuidada: la ciudad letrada es algo más que un escenario o un contexto histórico, es un concepto o una red de conceptos teóricos que fue tomando forma en la reflexión de Rama incluso antes de la publicación póstuma del ensayo La ciudad letrada (1984). El concepto es una referencia en el pensamiento sobre la cultura letrada y sobre el proceso histórico de la misma en América Latina. Me parece importante reflexionar sobre sus condiciones de producción, los principales problemas que plantea, así como los aportes de muchos de sus críticos para dar un marco más amplio a las prácticas de Jacinto Ventura de Molina en la Montevideo de las primeras décadas del siglo XIX. A su vez el análisis de este caso particular permite visualizar algunas limitaciones de la teoría de Rama que hacen necesaria una reformulación de algunos de sus términos. 


\section{La piedra y la letra: la ciudad letrada como modelo}

Cuando se publica La ciudad letrada en 1984 ya se había configurado un conjunto de problemas teóricos y críticos respecto a la especificidad de la cultura y la literatura lationamericanas. Una serie de críticos latinoamericanos, entre los que se encontraba Ángel Rama, buscaba construir categorías de interpretación para esa producción específica y de algún modo romper la división internacional del trabajo que nos convertía en proveedores de materia prima para la crítica metropolitana a través de los narradores del boom (Julio Cortázar, Mario Vargas Llosa, Gabriel García Márquez, entre otros). Los escritores latinoamericanos del período vendían su trabajo a editoriales españolas, que por esos años se proponían conquistar un público "hispanohablante" que rondaba los 200 millones de lectores potenciales y son hoy multinacionales con sucursales en varias ciudades latinoamericanas. $^{45}$

Uno de los protagonistas de este movimiento de intelectuales, Antonio Cornejo Polar, lo denominó en 1994 "proyecto epistemológico de los setentas", englobando en esa categoría a un grupo de ensayistas que incluía a Roberto Fernández Retamar, Carlos Rincón, Ana Pizarro, Antonio Candido, entre otros. Para Cornejo-Polar el objetivo de estos teóricos y ensayistas era elaborar una "teoría literaria latinoamericana”, proyecto que desde su perspectiva había fracasado en su intento. Sin embargo afirma "bajo su impulso, la crítica y la historiografía encontraron formas más productivas -y más audaces- de dar razón de una literatura especialmente escurridiza por su condición de multi y transcultural” (Cornejo Polar, 1994: 14). La perspectiva de Cornejo Polar está marcada por la caída del socialismo real, los procesos postdictatoriales y el triunfo autoproclamado del liberalismo

45 Un análisis del fenómeno a partir del caso de la editorial Planeta en Lara Bosch (2002). 
en el terreno ideológico. Pero no es posible pensar el proyecto epistemológico de los años setentas fuera del marco de la Guerra Fría, de la que Rama es objeto durante su pasaje por Estados Unidos y por la que es expulsado en 1983. Según Basile, este contexto signó la figura del letrado ligado al poder que Rama desarrolló en La ciudad letrada y también las ideas de Roberto Fernández Retamar en el Calibán (1971), otro texto fundamental del proyecto epistemológico de los años setentas (1).

La idea de la ciudad letrada se venía gestando en Rama desde los setentas coincidiendo con su salida definitiva de Uruguay. Ya desde finales de los sesentas el crítico había comenzado a proyectarse internacionalmente, sobre todo en el ámbito latinoamericano, dando cursos y conferencias en México, Puerto Rico, Colombia, Venezuela, Chile y Cuba. Cuando se produce el golpe de Estado el 27 de junio de 1973, que inicia la dictadura cívico-militar en Uruguay, Rama se encontraba en Alemania y se instala en Venezuela (Peyrou: 46). Allí comienza el exilio hasta su muerte, a causa de un accidente aéreo, en 1983. En este período de exilio, que lo llevó a vivir en distintas ciudades, Rama escribe dos de sus libros teóricos más importantes: Transculturación narrativa en América Latina (1982) y La ciudad letrada (1984). En las últimas décadas estos dos trabajos han sido revisados desde múltiples puntos de vista, en especial por el latinoamericanismo que se desarrolla en los Estados Unidos, aunque también por los estudios culturales, la historia de las ideas y los intelectuales, entre otros. También la bibliografía póstuma de Rama ha crecido en el período. En 2001 se publica el libro Diario 1974-1983 bajo el cuidado de Rosario Peyrou. Un conjunto de notas privadas interesantes para entender tanto las ideas de Rama como los principales debates y coincidencias con otros en el campo intelectual.

En la entrada del 9 de octubre de 1974 Rama relata aspectos de su estadía en 
Venezuela, particularmente en Maracaibo y en sus barrios periféricos. Rama relata un paseo por un mercado y reflexiona sobre ese "universo popular" en marcado contraste con el saber universitario y el refinamiento "oligárquico" que viven aislados del "torrente vivo" del "universo popular" (Rama, 2001: 51-52). El paseo por el mercado popular y el planteo de estas oposiciones configuran el problema de las relaciones entre la ciudad, los intelectuales y el poder en la cultura. Por esos años ya aparecen publicados algunos trabajos en los que menciona la cuestión, sobre todo "Los procesos de transculturación en la narrativa latinoamericana" en la Revista de literatura hispanoamericana de la Universidad del Zulia (Venezuela).

En otra nota del 11 de marzo de 1980 Rama relata su viaje de Washington a Cambridge para dictar algunas conferencias en la Universidad de Harvard. Por esa fecha la noción de ciudad letrada toma una forma concreta. Rama menciona su diálogo y el aporte de ideas similares de Claudio Vélis o José Luis Romero pero aclara que le sirven "solo de punto de partida" para su concepto que afirma "también podría llamarse la «ciudad escrituraria» porque se construye en torno a la escritura”. Aparece la oposición entre escritura y habla, en el que la primera es un "principio de la suprema hidalguización” pero no hace más que "registrar por escrito una lengua hablada que se organiza gracias a estructuras literarias, de modo que guarda de ella su apertura sonora incesante y al tiempo la constriñe en formas tradicionales precisas y fijas" (137-8). Pero en esta entrada Rama también señala la tarea hegemónica de la ciudad letrada: la representación e interpretación del otro (hay que señalar que Rama coloca del lado de la oralidad al subalterno) tomando su esencia (la voz) y moldeándola a través de estructuras literarias/formas tradicionales precisas y fijas. Estas oposiciones atravesarán todos los capítulos del libro.

Las dos entradas en Diarios marcan el período de formación de la idea. Ya en 1982 
algunas reflexiones sobre la ciudad letrada aparecen en el capítulo II de la primera parte de Transculturación narrativa en América Latina. En el libro Rama explicita uno de los puntos de partida de su reflexión: la "ciudad ideológica” de José Luis Romero a la que "se encomienda la tarea de modelar el espacio circundante desde su concepción centralista y autoritaria" (75). Pero estas ciudades eran incapaces de controlar todo el territorio por lo tanto Rama agrega que "su proyecto de imposición y dominación” centralista se consolida entre fines del siglo XIX y triunfa en el siglo XX. La modernización comandada por Madrid da lugar a otras metrópolis que se imponen "sobre las culturas tradicionales internas" (75). Para Rama la modernización implicaba la imposición de un "rígido sistema jerárquico" sobre la "heteróclita composición cultural de la ciudad", que denomina "patrón aristrocrático" y que modeló históricamente las culturas latinoamericanas. Esa tarea fue encomendada a "una elite intelectual, cuya importancia en la época colonial es desmesurada y, a pesar de los avatares de la vida americana, lo ha seguido siendo hasta nuestros días (75-76).

En estos fragmentos Rama presenta ya uno de los argumentos centrales de la ciudad letrada: el patrón aristocrático de la elite intelectual se repite desde la colonia hasta "nuestros días". Claro que Rama percibirá cambios dentro de ese continuo histórico, que consignará en La ciudad letrada, pero me interesa destacar la primera caracterización de esta elite urbana: “(...) es la «ciudad letrada» la que conserva férreamente la conducción intelectual y artística, la que instumenta el sistema educativo, la que establece el Parnaso de acuerdo a sus valores culturales.” (76) A su vez Rama indica que esta ciudad letrada o escrituraria ha tenido la capacidad de mantener su función homogeneizadora, de flexibilizarse ante los embates de los sectores medios -mezzomúsica, es decir, tangos y boleros-, las culturas populares -teatro criollo- o las revoluciones -novelas de la revolución 
mexicana- "manteniendo sus normas" (76).

Hay suficientes indicios de que no solamente el concepto de transculturación narrativa y el de ciudad letrada fueron pensados en el mismo tiempo histórico sino que forman parte de las mismas preocupaciones teóricas de Rama y están profundamente interrelacionados. La modernización y la transculturación son "misiones" que las elites intelectuales se trazaron desde la ciudad letrada. La aparición de narradores transculturadores en los años cuarentas del siglo XX representa para Rama una tradición crítica frente a la voluntad homoneizadora de estas elites centralistas. Si bien ambos libros deben leerse como parte de un mismo proyecto teórico esto no significa que compartan las mismas virtudes. Según Gorelik (2006) el libro de 1982 ofrece una crítica al rol de la ciudad y al mismo tiempo un panorama complejo "de una cadena discontinua de conflictos, que en cada una de sus estaciones permite asomar la densidad de las diversas instancias del proceso transculturador, esa serie dinámica y creativa de pérdidas, selecciones, incorporaciones y resdescubrimientos desde y sobre las culturas que entran en contacto". Sin embargo, afirma Gorelik, La ciudad letrada supuso un retroceso a posiciones más rudimentarias sobre los conflictos culturales del continente (164-165). El modelo interpretativo que ofrece La ciudad letrada, según Gorelik, es más esquemático aunque surja del mismo campo de problemas que Transculturación narrativa. Cabe señalar que este ensayo es un texto inacabado, que el autor no tuvo oportunidad de corregir o mejorar.

En La ciudad letrada se desarrollan dos componentes teóricos centrales: la espacialización del análisis cultural que pone a la ciudad como "base material" de la actividad simbólica (Remedi: 97$)^{46}$ y un modelo teórico cuyo núcleo central es el letrado y

46 Para Adrián Gorelik los pioneros en las investigaciones sobre la cultura urbana fueron José Luis Romero, Ángel Rama y Richard Morse. En sus trabajos se sintetizaron, según Gorelik, dos tendencias dentro de los 
sus relaciones con el poder. Las ciudades latinoamericanas, con su damero aplicado universalmente en todas las ciudades españolas, fueron producto de la racionalidad y del deseo europeo de orden que no se tenía en el propio continente. De esa forma el territorio del nuevo mundo era una página en blanco en la que se proyecta un diseño racional, creado en las metrópolis y adaptado por los fundadores dadas las características de los territorios en los que las ciudades se construían (21). El diseño de la ciudad proporciona la cosa que representa (la ciudad) y la cosa representada (diseño) con independencia de la realidad. En consecuencia para Rama esto provocó que las ciudades americanas tuvieran una doble vida: la de la ciudad material, con sus "vaivenes de construcción y de destrucción”; y, "por encima de ella", la vida de los signos que "actuan en el nivel simbólico, desde antes de cualquier realización, y también durante y después, pues disponen de una inalterabilidad a la que pocos conciernen los avatares materiales (23).

Más adelante Rama llevará esta doble vida a la relación conflictiva entre ciudad real y ciudad letrada. Pero en este pasaje Rama repite la idea de cómo los planes diseñados en la metrópolis debían ser luego "adaptados" a lo real, dando lugar a una realidad latinoamericana que transformaba los planes. Pero esas ciudades tenían una misión que cumplir en el nuevo mundo:

estudios culturales sobre el imaginario urbano y la imaginación urbana. La que postula que "la realidad territorial y urbana es maleable a las ideas en este vacío sudamericano que la naturaleza y la historia habrían brindado como ofrenda a la voluntad fáustica de la modernización occidental". Para esa tradición la representación "crea realidad urbana y ella refuerza la representación de un ideal de nación" (262) La otra tradición postula "el poder de las representaciones como ilusión o falacia, como representación del poder" que en su versión moderada cuestiona la idea del vacío preexistente y destaca los obstáculos que existieron para la imposición civilizatoria de las ciudades y en su versión radical postula una "nueva verdad 'bárbara"' contra la civilización (262-263). Para Gorelink estos tres fundadores, a pesar de las diferencias, "pusieron en el centro de su trabajo sobre la cultura urbana el papel de los intelectuales y los artistas en la conformación de las matrices de comprensión y de transformación social y, a la vez, ellos mismos escribieron como parte de una tensión proyectual hacia un programa intelectual para las ciudades y sus sociedades" (264). Esta tensión, según Gorelik, desapareció en "buena parte" de los estudios culturales actuales sobre la ciudad. 
Aunque aisladas dentro de la inmensidad espacial y cultural, ajena y hostil, a las ciudades competía dominar y civilizar su contorno, lo que se llamó primero «evangelizar»y después «educar». Aunque el primer verbo fue conjugado por el espíritu religioso y el segundo por el laico y agnóstico, se trataba del mismo esfuerzo de transculturación a partir de la lección europea (27)

Para cumplir con esta tarea transculturadora Rama superpone en el damero un nuevo diseño, el de un grupo concreto que controla la vida simbólica:

En el centro de toda ciudad, según diversos grados que alcanzaban su plenitud en las capitales virreinales, hubo una ciudad letrada que componía el anillo protector del poder y el ejecutor de sus órdenes: una pléyade de religiosos, administradores, educadores, profesionales, escritores y múltiples servidores intelectuales, todos esos que manejaban la pluma, estaban estrechamente asociados a las funciones del poder y componían lo que Georg Friederici ha visto como un país modelo de funcionariado y de burocracia (Rama, 32. Subrayado mío)

Luego de definir la ciudad letrada Rama hace un segundo movimiento: pone en el centro al letrado. Si bien es cierto que sería necesario revisar el modo en que Rama introduce la ciudad como plano material en su análisis del plano simbólico, sin dejar de valorar la importancia que tiene haber establecido la relación entre ambos, lo más interesante del concepto reside en los letrados, el grupo que desde la ciudad intenta hegemonizar sus proyectos culturales. A este grupo le corresponde "enmarcar y dirigir las sociedades 
coloniales" (34) desde distintas posiciones: el púlpito, la cátedra, la administración, el teatro, el ensayo. Su rasgo definitorio es "el ejercicio de la letra, dentro del cual cabía tanto una escritura de compra-venta como una oda religiosa o patriótica" (35).

Los letrados sirvieron al poder pero fueron además dueños de un poder que los hizo necesarios, en ese sentido "enmarcar y dirigir" la sociedad en las que les tocó vivir parece ser, para el autor, una constante que atraviesa la colonia, sigue en los comienzos del siglo XIX y llega a la modernización. La poesía convive con esta "función social” que los lleva a escribir también leyes o "escrituras de compra-venta". El poder del letrado reside entonces en su conocimiento de la escritura, que pone al servicio del poder mediante todo tipo de textos. Como afirmaba en su Diario la escritura definía un espacio social reservado "a una estricta minoría" que fijó "las bases de una reverencia por la escritura que concluyó sacralizándola (43)

La escritura es portadora de un orden que los letrados proyectan sobre la ciudad real y que otra vez obliga a Rama a plantear la idea de una doble vida de las ciudades, esta vez separando la letra de la palabra hablada. Además, Rama establece una ciudad escrituraria cerrada, exclusiva, que sacralizó el poder de la letra. Esta idea de una ciudad escrituraria lo lleva a unir el diseño urbano con lo social y con lo lingüístico, cuya originalidad es notoria. Para Rama la ciudad escrituraria estaba rodeada por dos anillos, opuestos, a "los que pertenecía la mayoría de la población”. El anillo urbano, “donde se distribuía la plebe formada de criollos, ibéricos desclasados, extranjeros, libertos, mulatos, zambos, mestizos y todas las variadas castas derivadas de cruces étnicos" y en donde se contribuyó a "la formación del español americano que por largo tiempo resistieron los letrados". Y un segundo anillo que "ocupaba los suburbios (los barrios indígenas de la ciudad de México)" y "se extendía por la inmensidad de los campos, rigiendo en haciendas, pequeñas aldeas o 
quilombos de negros alzados". Alli se usaban "lenguas indígenas o africanas que establecían el territorio enemigo" (45-46).

De este modo no se trata solamente de un análisis de los letrados sino de sus relaciones internas y de un afuera marcado por grupos subalternos que no tenían acceso a esa ciudad escrituraria y que ocupan también el lugar de la oralidad. La escritura se convertirá entonces en un espacio privilegiado de la lucha por la hegemonía porque "todo intento de rebatir, desafiar o vencer la imposición de la escritura, pasa obligadamente por ella. Podría decirse que la escritura concluye absorbiendo toda la libertad humana, porque sólo en su campo se tiende la batalla de nuevos sectores que disputan posiciones de poder (50). Es interesante hasta dónde lleva Rama su reflexión, convirtiendo la escritura en una herramienta de poder prácticamente ineludible en las luchas por la libertad en América Latina, citando ejemplos tanto de la Colonia (en el siglo XVI y en el siglo XVIII) como de 1969 en Uruguay, mostrando en todos los casos esta disputa por el orden y el control de los $\operatorname{signos}(51)$.

Finalmente al analizar el período independentista Rama destaca el poder de adaptación de la ciudad letrada al ponerse al servicio de los nuevos dueños del poder (los caudillos):

Esta curiosa virtud, diríamos la de ser un «adaptable freno» [a los sectores subalternos], en nada se vio con mayor fuerza que en la reconversión de la ciudad letrada al servicio de los nuevos poderosos surgidos de la élite militar, sustituyendo a los antiguos delegados del monarca. Leyes, edictos, reglamentos y, sobre todo, constituciones, antes de acometer los vastos códigos ordenadores, fueron la tarea central de la 
ciudad letrada en su nuevo servicio a los caudillos que se sustituirían en el período pos-revolucionario (52-53)

Con la excepción de Simón Rodríguez planteada por Rama, los letrados se concentraron en la creación de una lengua nacional estándar que sirviera a los fines de unificar administrativamente el territorio. En los tres primeros capítulos analiza tres siglos de historia, desde la Colonia hasta las revoluciones independentistas y en los siguientes capítulos extiende su análisis al final del siglo XIX y las primeras décadas del siglo XX. Pero su definición de la ciudad letrada y del equipo intelectual que la compone no varía sustancialmente a la que brinda en las primeras páginas. Más adelante volveré sobre algunos de sus argumentos históricos. Pero antes expondré algunas objeciones al concepto de ciudad letrada.

Hay dos críticas fundamentales al modelo de interpretación cultural que Ángel Rama ofrece en La ciudad letrada. La primera objeción está relacionada con la narrativa histórica que propone. En esta crítica se engloban varios tipos de argumento: Rama simplifica la relación entre intelectuales y poder, entre intelectuales y política, no contempla el proceso histórico de las distintas ciudades latinoamericanas, ni la formación específica de sus elites letradas. La segunda objeción refiere al concepto de escritura que maneja y su énfasis en aquellos procesos de dominación que los letrados contribuyen a fortalecer, así como en la rigidez de sus divisiones entre campo/ciudad, oralidad/escritura, oficial/popular. Ambas críticas están entrelazadas y contribuyen en muchos casos a profundizar en algunos aspectos en los que Rama no reparó, tal vez por el carácter de obra inconclusa, por la intención política de dar un mensaje a los intelectuales de izquierda, o por el momento histórico de quiebre en el que escribió. Otros autores contibuyen a 
comprender qué cosas había en el horizonte ideológico de Rama y de los críticos con los que debatía, así como aquellas cuestiones que era imposible visualizar sin alguna distancia histórica como la presente.

Para empezar con el primer grupo de críticas al concepto de ciudad letrada quiero comenzar por Claudia Gilman (2006), quien plantea que una de las grandes omisiones de La ciudad letrada es la propia ciudad. Me interesa su comentario sobre este aspecto

\footnotetext{
(...) Excepto al referirse a la construcción en damero o al analizar el modo de clasificación de las calles y sus nomenclaturas, no encontramos ni descripta ni presente ninguna ciudad latinoamericana concreta o, para usar los términos de Rama, real. (160)
}

Parte de la simplificación de los argumentos a la que se refieren varios autores (Gorelik, 2006 y Aguilar, 2006 por citar dos ejemplos) posiblemente esté relacionada con el interés de Rama por construir un modelo abstracto (en el que no hay lugar para "ninguna ciudad latinoamericana") o una perspectiva de "larga duración" como la planteada por Fernand Braudel (2002). En tal sentido Claudia Gilman repara en "la apretada continuidad, en el marco histórico y respetuoso de la cronología que Rama desea dar a su discurso" que lo lleva a establecer una historia marcada por los “acontecimientos 'mayores': la colonización, las guerras de emancipación, los festejos del Centenario (...)" que no da lugar a las rupturas (158). Este aparente alejamiento de un caso concreto y la voluntad generalizadora de Rama generan la sensación de que el modelo es capaz de servir en un plano general pero no puede profundizar en ninguna sociedad en concreto.

Es necesario consignar aquí una lectura más justa con los argumentos de Rama que, 
sin embargo, no anula esta crítica. La perspectiva de Beatriz Colombi apunta a señalar la utilización de México como "caso testigo" en La ciudad letrada. Este aspecto, según el argumento de Colombi, lo une a la tradición culturalista de autores como Pedro Henríquez Ureña, quien planteaba que México era el "único país en el Nuevo Mundo" en el que podía percibirse una tradición letrada continua y vinculada al poder (181-182). Colombi señala que Rama toma ejemplos letrados de México, Perú y Colombia con "tradiciones virreinales fuertes" y al mismo tiempo "evita la puesta a prueba en otras áreas culturales como el Caribe o el Cono Sur" en la etapa colonial. Por tal motivo, sigue Colombi, México y el Río de la Plata, aparecen como dos polos durante la modernización de fines del siglo XIX, el primero como ejemplo del elitismo y el segundo de democratización de los equipos intelectuales (182). La utilización de estos casos testigos, grandes centros coloniales que fueron luego capitales de sus respectivos Estados-nación, no revierte la tendencia a la larga duración ni a un relato continuo. Siguiendo a Colombi el problema de La ciudad letrada no reside en su grado de abstracción sino en los casos testigo y los momentos históricos que elige para ilustrar sus argumentos.

En palabras de Julio Ramos (1989) el problema es la "narrativa historiográfica" que Rama propone en su libro. Para Ramos la relación que Rama establece entre intelectuales y política en esa narrativa historiográfica presenta dificultades para su análisis de los intelectuales de fines del siglo XIX como José Martí. Por eso afirma:

El concepto de "letrado" históricamente no reduce su territorio semántico a la actividad propia del abogado o agente (escritor) de la ley. Pero en $L a$ ciudad letrada pareciera que esa es la acepción dominante del concepto que así viene a describir la relación entre los intelectuales y la burocracia, 
desde la consolidación del imperio español en América hasta el siglo XX.

Dicho de otro modo, el "letrado" es un intelectual orgánico a la vida pública dominada, desde la colonia, por un culto ciego a la autoridad de la letra (69)

Para Ramos este gesto es de "un historicismo notable" que según sus palabras "soslaya, entre otras cosas, los cambios radicales que sin duda hubo, por lo menos, a fin de siglo", lo que desemboca en una interpretación de las relaciones mutuas entre poder y letrado "en términos de permanencia de relaciones y estructuras en un bloque histórico de más de dos siglos" (70). ${ }^{47}$ Este argumento de Ramos además de tener valor en la lógica interna de su estudio sobre Martí, aporta una crítica sustancial al modo de pensar la ciudad letrada y el letrado. La voluntad teórica de Rama deriva en esta homogeneización del lugar del letrado en la historia.

Como apunta Castro-Gómez la ciudad letrada se proyectó en la historia latinoamericana del siglo XVI al XIX como si fuera "una estructura intemporal y sin fisuras" que ignora las transformaciones que experimentaron los letrados y su función social. Por lo que propone:

(...) diferenciar el concepto de ciudad letrada en base a criterios históricoformales, preguntándonos, por ejemplo, si la naturalización de la letra no estuvo ligada a procesos de racionalización social (en sentido weberiano),

\footnotetext{
${ }^{47}$ El sentido de la palabra "historicismo" en Julio Ramos es negativo. Tal como establece Raymond Williams en Palabras clave (2000) el calificativo se utiliza "en un sentido hostil, para atacar todas las formas de interpretación o predicción mediante la "necesidad histórica" o el descubrimiento de «leyes generales del desarrollo histórico»". Ramos no parece estar afirmando que Rama analice el pasado rastreando "los precedentes de hechos actuales" o que esté haciendo referencia a un "énfasis deliberado" en los contextos de un hecho específico (162), que son las otras dos acepciones del término que ofrece Williams, sino todo lo contrario: Rama homogeneiza dos siglos de historia en los que hay quiebres y transformaciones que no considera. Por tales motivos es razonable pensar que usa la palabra en un sentido negativo.
} 
que en América Latina tuvieron importancia apenas desde 1870; o si, marcando nuevamente diferencias, el modelo escritural no pierde su carácter explicativo a partir de 1930, cuando la representación por el discurso se transforma paulatinamente en la representación por la imagen, tal como lo muestra Jesús Martín-Barbero. (125)

El argumento de Castro-Gómez apunta en un mismo sentido que las críticas de Ramos: no es posible afirmar un modelo abstracto de ciudad letrada sin tener en cuenta "criterios histórico-formales". En definitiva el historicismo de Rama lo llevó a encontrar un espacio homogéneo en diferentes momentos históricos. Pero la ciudad letrada no cumplió siempre el mismo rol en todas las ciudades de América Latina. Incluso tomando esto en cuenta este aspecto debe ser planteado desde mi punto de vista como una tensión en la obra de Rama -una obra inconclusa, no está demás aclararlo- entre la búsqueda de un modelo abstracto y las especificidades históricas. Lo que quiero plantear es que esta tensión es ineludible y debe pesar cada vez que el concepto de ciudad letrada se pone en juego en un análisis concreto.

El segundo grupo de críticas reparan en el lugar de la escritura en el modelo de Rama. La importancia es tal que Rama vacila entre los conceptos "ciudad letrada" y “ciudad escrituraria". El libro de Rama apunta a fundar el poder de los letrados en la escritura y a esta en el corazón de la estrategia dominante de la ciudad letrada. Pero, como sostiene Santiago Castro-Gómez, Rama aborda la escritura desde una perspectiva cognitivo-instrumental con el fin de reforzar su relación con el poder hegemónico. En tal sentido Castro-Gómez propone "trabajar con un concepto representacional de la escritura que incluya, además de la reflexividad cognitiva, también una reflexividad hermenéutica y 
una reflexividad estética". Postular estas tres reflexividades no solamente permite disminuir la "identificación unilateral" que Rama establece entre escritura y poder hegemónico, sino que da a la ciudad letrada la capacidad "para generar espacios de transgresión. [...] ¿por qué no entender esta ciudad como una institución reflexiva, capaz no solo de "vigilar y castigar" sino también de domesticar y transformar sus propias reglas" (129).

Dentro de este grupo de críticas aparecen elementos comunes en varios autores (Verdesio, 1997; Adorno, 1987 y Fernández Bravo, 2006) que señalan el uso de fuentes escritas hegemónicas, pertenecientes al canon, lo cual lleva a Rama a desatender cuestiones de género (¿qué sucede con las letradas?), tradiciones letradas críticas o considerar autores mestizos "que hablaron desde posiciones más ambivalentes, híbridas, y que escribieron menos sumisos al poder que los ejemplos analizados en el libro" (Fernández Bravo, 2006: 185). En ese sentido apuntan los análisis de la materialidad, las imágenes, mapas e iconografías de críticos como Rolena Adorno (1996), Mabel Moraña (2005 [1998]) o Walter Mignolo (1995). En la obra de estos autores se descentra el análisis del objeto -letrado, literario- y se cuestiona la escritura, centro del poder letrado en el análisis de Rama. Para Fernández Bravo todos estos trabajos tienen una deuda con Rama que proviene “más del desvío que de la sucesión” (189). Siguiendo o discutiendo su legado tanto La ciudad letrada como Transculturación... son hitos del pensamiento latinoamericano sobre la cultura a partir de los cuales será necesario pensar nuevos objetos, nuevos problemas y realizarle los ajustes necesarios para ello. 


\section{Definir una cultura letrada}

El modelo de Ángel Rama presenta varios problemas: la homogeneización histórica y social del grupo letrado en función de su relación con el poder, la concepción instrumental de la escritura y cierta rigidez en el planteo de oposiciones campo/ciudad, oral/escrito, letrado/iletrado. Para definir mi propia perspectiva sobre el asunto he recurrido al concepto de "cultura" y particularmente a la noción de cultura letrada. Propongo una articulación entre el concepto de letrado/ciudad letrada y cultura. Mi intención no es proceder frente a la ciudad letrada por desvío o por sucesión, como señala Fernández Bravo, sino heredar su perspectiva y proponer una nueva configuración. El "heredero", en el sentido que lo entiende Jacques Derrida, selecciona, critica y es interpelado por los múltiples "espectros" de un autor. Y esa heterogeneidad de la herencia hace que no se pueda heredar en un sentido unívoco y dogmático. ${ }^{48}$ Por tal motivo mi planteo sobre la ciudad letrada no busca desviarse o suceder linealmente a Rama sino asumir algunos de sus presupuestos, y descartar otros, para proceder a elaborar categorías de análisis distintas a la suyas.

En un texto publicado póstumamente en la revista Cuadernos Hispanoamericanos en 1984, titulado "La literatura en su marco antropológico" (2006: 158-166), Ángel Rama explicita su vuelco teórico de la sociología a la antropología teniendo siempre como eje lo que estas disciplinas aportan "al mejor entendimiento de las literaturas de América Latina" (2006: 162). Al plantear el concepto de cultura letrada me propongo retomar este

48 En este punto sigo la reflexión de Derrida en torno a la herencia de Marx en su pensamiento y en el mundo contemporáneo: "Una herencia nunca se re-úne, no es nunca una consigo misma. Su presunta unidad, si existe, sólo puede consistir en la inyunción de reafirmar eligiendo. Es preciso quiere decir es preciso filtrar, cribar, criticar, hay que escoger entre los varios posibles que habitan la misma inyunción. (...) Si la legibilidad de un legado fuera dada, natural, transparente, unívoca, sino apelara y al mismo tiempo desafiara a la interpretación, aquél nunca podrá ser heredado.” (Derrida, 1995: 30) 
desplazamiento de una sociología de la literatura a una antropología de la literatura que Rama explicitó en este texto desde el punto de vista teórico y que atravesó su producción entre 1975 y $1983 .{ }^{49}$ En los debates sobre La ciudad letrada o Transculturación narrativa... nadie ha reparado en esta propuesta de Rama. En su lugar se ha procedido al desvío o la repetición de sus ideas.

Por tal razón creo oportuno resumir las principales tesis de este "último" artículo de Ángel Rama. Allí el crítico repasa el pensamiento sociológico latinoamericano y traza una genealogía que se inicia con Domingo F. Sarmiento y Eugenio María de Hostos. El primer hito de este pensamiento aplicado a la literatura es, según Rama, la História da literatura brasileira (1888) de Silvio Romero, quien instaló una "marca sociológica [que] dominaría por muchos años el panorama de los estudios literarios, no sólo en el Brasil, sino también en críticos como Alberto Zum Felde o Ricardo Rojas" y que permea en toda la crítica literaria latinoamericana posterior, con otros marcos ideológicos (nacionalismo, social, marxismo) pero como “tesonera marca de fábrica del continente" (Rama, 2006: 160). Rama se siente "heredero" de esta perspectiva crítica y, como heredero, se dispone a buscar salidas a esta influencia central del pensamiento sociológico, muchas veces influído acríticamente por la sociología metropolitana y sus categorías. De hecho su elección de Romero no es inocente, responde a la necesidad de plantear un pensamiento crítico respecto a la importación de teorías europeas, como la influencia determinante del clima en las posibilidades de desarrollo de una cultura planteadas por Hippolyte-Adolphe Taine y Henry Thomas Buckle, que implicaba entre otras cosas negar la existencia de cultura en climas tropicales (como el Brasil) y que fueron repetidas hasta bien entrado el siglo XX

49 "La literatura en su marco antropológico" es la última ponencia que Rama leyó antes de morir el 27 de noviembre de 1983. Fue publicado originalmente en la revista Cuadernos hispanoamericanos en mayo de 1984. La versión que manejo fue publicada por Pablo Rocca (2006) y está basada en una copia mecanografíada de la ponencia (en propiedad de la familia del crítico) que Rama leyó en Madrid en noviembre de 1983 (Rama, 2006: 158). 
por críticos como José Enrique Rodó y Juan Marinello (160).

En este marco de análisis Rama recurre a su experiencia y recuerda que en sus estudios sobre Rubén Darío había notado que ningún latinoamericano mencionaba a Edward Tylor, fundador de la antropología moderna -también a fines del siglo XIX- a quien pertenece la clásica definición de cultura como "un todo complejo" que reúne conocimientos, creencias, arte, moral, derecho, costumbres y "cualesquiera otros hábitos y capacidades adquiridas por el hombre" en sociedad (Tylor: 29). Esta nueva disciplina atendería un "territorio propio, curiosamente encabalgado entre una base material (geografía, arqueología, objetos culturales) y un horizonte especulativo social" (Rama, 2006: 162) en los que resuena el énfasis de Rama en la ciudad como base material de la cultura letrada. Si bien reconoce que la "nueva ciencia" extiende su análisis a las sociedades complejas y modernas (en las que, agrega, "cabe un papel central a la escritura"), Rama prefiere destacar el interés original de la antropología por el estudio de las sociedades ágrafas, y muy particularmente de la lengua en esas sociedades. Este elemento le parece central en su contraposición con el saber sociológico, en especial contra la "tendencia contenidista de la sociología de la literatura", más interesada por los significados de la prosa que por la cuestión de "lo que representa y dice el sonido" en la poesía. Hacia el final de la ponencia Rama destaca el interés de la antropología por el folklore y la lengua, que para él constituyen "la materia prima del discurso literario". Su reflexión final apunta entonces a la singularidad de los mitos latinoamericanos dichos en boca de los sujetos populares y re-escritos por los narradores transculturadores (cita un texto de Augusto Roa Bastos), en contraposición a "la tradicional concepción aristocrática de sus intelectuales, apoyada en el autor y en la producción para el circuito culto". De esta manera Rama dejaba planteado el escenario para la publicación de su próximo libro ( $L a$ 
ciudad letrada) y el conjunto de problemas que dejaba (sin saberlo) como herencia para los estudios latinoamericanos.

Dejé para el final los elementos que Rama destaca de la antropología porque son los que me interesa retomar para mi propia reflexión sobre la cultura letrada. El autor analiza tres aportes de la antropología al estudio de la literatura latinoamericana que tienen que ver con el relativismo, la cultura como estructura o sistema y la cuestión de la producción colectiva implícita en el concepto de cultura. Resumo aquí el primero y el tercero. Sobre el relativismo Rama destaca "la afirmación de la legitimidad, independencia y autosuficiencia de cualquier cultura, que debía medirse de acuerdo a sus propios patrones y no ajustarse a los que regían otras culturas" (163) lo cual le permite el cierre metodológico en América Latina para plantear su autonomía y hace posible el proyecto epistemológico de una teoría literaria específicamente latinoamericana. En la explicación de este punto resuena el concepto de transculturación y su análisis de los procesos de selección e invención que caracterizan las relaciones entre tradiciones europeas (o metropolitanas) y tradiciones internas, procesos que implican pérdidas, selecciones, redescubrimientos e incorporaciones de diferentes elementos a la producción de una cultura latinoamericana singular (Rama, 2007: 45-47). Sobre la cuestión de la construcción colectiva de la cultura, esta amenaza la idea burguesa del autor individual y la introduce en "poderosos pattern colectivos" (165). Si bien Rama destaca en la antropología el análisis horizontal de la sociedad y aquellos aspectos vinculados a la participación en la cultura, señala también que lo hace en detrimento del análisis de la verticalidad, es decir, de la estructura jerárquica de las sociedades, que Rama identifica con la sociología.

Pero el segundo elemento, el concepto de cultura como estructura o sistema, es el más importante del texto y punto de partida para explicar la forma en que pretendo 
articular análisis literario y antropológico. Para Rama la antropología aporta "una visión estructurada de las culturas, subrayando la estricta correlación de sus diversos términos (lengua, creencias, formas sociales, artes) en una dinámica fuertemente interdependiente" (164), sentido que apoya con expresiones como "conjunto indisoluble" (164) o "totalidad" (165). Resuenan en el texto no sólo las lecciones estructuralistas basadas en la teoría del lenguaje de Saussure -“de modo que las modificaciones de cualquiera de los términos repercute en los restantes, acarreando cambios" (165)- sino fundamentalmente su diálogo con las ideas de Antonio Candido. ${ }^{50}$ Tal vez este aspecto de la cultura como sistema o estructura es el que más problemas ha causado a la antropología posterior a este texto de Ángel Rama. En 1986 se publica un libro colectivo, compilado por James Clifford y George Marcus Writing Culture (1986). El texto fue uno de los que abrió un proceso de fuerte crisis de la antropología clásica, aquella que estudiaba las "sociedades primitivas" y tenía un concepto de cultura que consistía en un conjunto de características particulares que un grupo social ubicado en determinado espacio o territorio compartía homogeneamente. ${ }^{51}$ La disciplina no ha salido de este debate, a tal punto que todavía hoy existen algunos antropólogos que descartan el concepto de cultura y otros que lo mantienen aunque con ajustes (Grimson, 2011: 84).

La noción de culturas híbridas propuesta por Néstor García Canclini en 1989

50 Los investigadores se encontraron en Montevideo en 1960 y desde ese momento empiezan a "entablar un diálogo que va a funcionar como un circuito donde uno y otro toman en prestamo las ideas que se amplían, se proyectan, van y vienen, retroalimentan cada un de las obras críticas, se expanden en busca de un proyecto que no admite un anclaje en lo propiamente cultural, sino que es indisociable de lo político como macrotexto, en el que encastra, finalmente, lo educativo y lo institucional" (Rocca, 2006a: 250). Más allá de la discutible afirmación final de la cita, en la que Rocca subsume lo cultural a lo político, es fundamental su lectura en torno a la relación entre las ideas de "sistema" y "suprarregionalidad" de Antonio Candido y el concepto de "transculturación” de Ángel Rama. Ver capítulo VI (262-266).

51 El cuestionamiento de estos presupuestos tiene antecedentes en la antropología social inglesa. Es el caso de Edmund Leach, por ejemplo, que en su libro Sistemas politicos de la Alta Birmania. Estudio sobre la estructura social Kachin (1954) comienza a cuestionar el supuesto de las sociedades unitarias y del equilibrio entre las todas las partes de un sistema para dar lugar a la fragmentación y el conflicto como parte las cuestiones a considerar en el análisis de una sociedad. 
representa una respuesta latinoamericana a los problemas que la postmodernidad le planteó a la antropología. García Canclini propone partir de la "hibridación", en detrimento del mestizaje (racial) o sincretismo (religioso), de tres dimensiones "lo culto, lo popular y lo masivo" que la modernidad ve como una "división en tres pisos", jerarquizada. La hibridación abarca, según él, “diversas mezclas interculturales”. A su vez, García Canclini propone otra hibridación (unas "ciencias sociales nómades") entre las disciplinas que antiguamente estudiaban por separado estas tres dimensiones de la cultura: historia del arte y la literatura (culto), folclor y antropología (popular) y comunicación (masivo). Esto implica una forma de entender la modernización no tanto como una "fuerza ajena y dominante" sino como "intentos de renovación con que diversos sectores se hacen cargo de la heterogeneidad multitemporal de cada nación" (15). Las culturas letradas ("cultas") se hibridan con las populares y masivas pero el modelo que propone García Canclini no está cerrado a las fronteras nacionales ya que le importa especialmente el rol que juega la transnacionalización producida por las nuevas tecnologías de la comunicación en el presente. Si bien García Canclini ignora o desconoce el concepto de transculturación, pese a que utiliza conceptos familiares como mestizaje o sincretismo, su teoría de las culturas híbridas y el rol mediador de las elites modernizadoras apunta en un mismo sentido que las ideas de Rama en Transculturación narrativa, solamente que García Canclini se aleja del modelo jerarquizador que Rama todavía defiende en sus últimos textos.

En un contexto de fuerte cuestionamiento a los fundamentos de la antropología clásica que abre la postmodernidad y con la hibridez entre los tres niveles de análisis que plantea García Canclini, la revisión del concepto de cultura que maneja Rama se hace imprescindible. Un texto reciente del antropólogo Alejandro Grimson resume algunas de las discusiones contemporáneas y propone el de configuración cultural como forma de 
prevenirse de conceptos de cultura como el expuesto por Rama en los ochentas. En primer lugar es necesario señalar que Grimson forma parte de los antropólogos "reformistas" que mantienen el concepto de cultura a falta de uno mejor. Por tal razón aboga por una "diversidad situada" (87-89) que incorpora la heterogeneidad social en su análisis de la cultura como antídoto frente a las totalizaciones de conceptos como "identidad" o "identidad cultural" tanto en las versiones del fundamentalismo y del multiculturalismo (Huntington y su idea del choque de civilizaciones) o de los movimientos sociales que postulan identidades rígidas (como la bibliografía surgida luego de la crisis en Argentina sobre los "nuevos movimientos sociales").

Para Grimson el concepto de cultura debe ser pensado en el marco de "una problematización de aquello que algunos conceptos anteriores daban por supuesto, por ejemplo, la homogeneidad y la territorialidad" (85). Por eso retoma a Ulf Hannerz cuando define la cultura como "las prácticas y los significados adquiridos en la vida social" como modo de señalar el potencial de la diversidad humana y la posibilidad de estudiar "cómo diferentes condiciones pueden conducir a cambios mayores o menores en el tiempo, a fronteras más o menos borrosas, y a distintas variaciones en mayor o menor grado de todo aquellos que consideremos una unidad de población". Por todas estas razones Hannerz propone que el concepto de cultura no sirve para afirmar sino para problematizar "las cuestiones de fronteras y de mixturas, de variaciones internas, de cambio y de estabilidad en el tiempo". Finalmente Grismon concluye que la heterogeneidad de todo grupo social sirve para plantear que las distinciones "no funcionan como absoluto" y que esta es la primera condición para separar el concepto de cultura de cualquier uso político que quiera sostener "diferencias irreductibles o naturales" entre los grupos. Para Grimson "[1]a naturaleza social de la cultura consiste, en el mundo contemporáneo, en hacer evidente (...) 
que las retóricas y las acciones identitarias no son un derivado de ningún conjunto de creencias y prácticas que permitan distinguir objetivamente grupos humanos” (85).

Por otro lado, el análisis de la cultura "debe entrelazarse con el análisis de eventos y procesos sociales y políticos" (85) y en tal sentido rescata la idea de Sherry Ortner de la cultura como comprensión del "mundo imaginativo" en el que operan los actores, las formas de poder y agencia que construyen, y los deseos que movilizan. Por lo tanto, Grimson destaca la construcción de significados sobre la idea de la cultura como sistema:

(...) La cuestión de la fabricación de significados es central para el análisis del poder y sus efectos, precisamente porque la identidad "integra" allí donde la cultura, antes que un sistema integrado, es una combinación peculiar (...) aunque ya no podamos (si alguna vez debimos) distinguir conjuntos consistentes y estáticos, el supuesto fundamental es que la gente siempre busca "hacer sentido" de su vida, que siempre fabrica tramas de significados y que además lo hace de maneras diferentes. (86)

Grimson no hace referencia a una dimensión cultural del conflicto político sino de la forma cultural que adquieren las alianzas, los conflictos y las negociaciones entre los actores en un contexto determinado. Por lo tanto no se trata solamente de analizar el conflicto político entre culturas diferentes sino la posibilidad de que aún en un escenario de disputas los actores puedan compartir una lógica común y pertenecer, total o parcialmente, a "mundos imaginativos” parecidos: “(...) el análisis de la cultura no sólo sirve para contrarrestar sino también para vislumbrar si hay algo compartido entre actores aparentemente disímiles que afirman diferencias ideológicas con sus contrincantes" que muchas veces pueden parecer 
abismales o irreductibles (86).

La problematización de la homogeneidad y la territorialidad como supuestos fundamentales del concepto de cultura clásico, así como la incorporación de una perspectiva social y política en el análisis cultural llevan a Grismon a plantear el concepto de configuración cultural como "marco compartido por actores enfrentados o distintos, de articulaciones complejas de la heterogeneidad social" (172). Introduce entonces cuatro elementos constitutivos de una configuración cultural: son campos de posibilidad dado que en cualquier espacio social hay representaciones, prácticas e instituciones posibles, imposibles y hegemónicas (172); no hay homogeneidad, existe una totalidad conformada por partes diferentes que no sólo tienen relación entre sí sino una específica lógica de interrelación (176); se comparte una "trama simbólica común, lenguajes verbales, sonoros y visuales en los cuales quienes disputan pueden a la vez entenderse y enfrentarse" (176); y finalmente, debe haber algo "compartido", entendiendo "lo compartido" en cualquiera de los sentidos que se le da: como algo mayoritario en la población (aunque no sea homogéneo), como creencias o prácticas relevantes de los sectores populares, como postulaciones de elites sobre "la cultura nacional" o como elementos presentes en distintos escenarios, no necesariamente predominantes o mayoritarios (177).

De esta forma el concepto de configuración cultural ayuda a situar histórica, geopolítica y socialmente una cultura, entendida como una configuración, es decir, como un campo de posibilidades, un espacio social y unos lenguajes compartidos por una sociedad. El concepto de ciudad letrada restringe su campo de acción a un grupo social homogéneo -como si se tratara de una "identidad letrada"- que, como parte del poder, contribuye siempre y en todas las épocas con la dominación y la hegemonía en la sociedad. Los letrados latinoamericanos, afirma Rama, evangelizaron primero, por su contacto 
directo con la conquista y colonización, y educaron después, por su contribución a los sistemas educativos de sus respectivos Estados-nación. Utilizar la noción de configuración cultural, y particularmente de una cultura letrada, no supone abandonar la pretensión de la ciudad letrada de analizar la relación entre escritura y poder -particularmente en el siglo XIX este aspecto es capital para comprender a los letrados- sino abrir el análisis a sujetos, textos y prácticas discursivas (no necesariamente escritas) que estaban fuera del horizonte teórico, ideológico y material de Rama, como los manuscritos de Jacinto Ventura de Molina. Analizar una colección de manuscritos privados pertenecietes a un letrado descendiente de africanos, en el contexto de una configuración cultural específica (letrada, colonial y esclavista), permitirá separar aquellos aspectos que los letrados tienen en común o comparten con Molina de aquellos aspectos que los separan.

En definitiva con el concepto de cultura letrada mantengo el supuesto de la ciudad como infraestructura de la actividad letrada planteado por Rama. Sin embargo es preciso modificar la perspectiva de larga duración, que extiende una misma tarea y un mismo lugar para el letrado durante dos o tres siglos, y el "latinoamericanismo metodológico", que supone una especificidad de la cultura latinoamericana y cierta idea de homogeneidad cultural, que hacen que Rama se centre en los grandes centros coloniales y en las ciudades capitales del Estado-nación. Una perspectiva que rompa con estos supuestos permite incorporar el análisis de regiones y las conexiones entre ciudades como Montevideo y Buenos Aires cuya historia común configura una cultura común. Una perspectiva como la ensayada en parte por Rama en Transculturación narrativa... me parece más productiva, en la medida en que incorpora o intenta incorporar la idea de regiones. También es necesario salir del marco "nacionalista” por una razón histórica: los Estados-nación están en proceso de constitución en el período que abordo en este trabajo, por lo que varias ciudades y elites 
pujan por dominar sus "territorios internos".

Las distintas ciudades letradas (portuarias o "internas") se articulan en un territorio que nada tiene que ver con los límites de los Estados-nación, que se consolidarán a partir de 1870 en la región del Río de la Plata. En un artículo reciente Julio Djenderedjian (2008) analiza el proceso poblacional de la región con tres centros fundados en el siglo XVI: Buenos Aires, Santa Fe y Corrientes, a los que se suma Montevideo a comienzos del siglo XVIII: "sedes de gobierno, desde las que las elites locales (principalmente comerciantes y militares) lucharon por imponer algunos seguridades mínimas en la región. Estos nodos de poder esenciales fueron también centros de comercio" (642). Esto ya plantea la posiblidad de "ciudades letradas", con equipos letrados articulados y en disputa, cuyo "centro" pudo ser Buenos Aires, la capital virreinal, pero que tenían vida propia. Según Julio Djenderedjian (2008) el proceso iniciado luego del Tratado de San Ildefonso en 1777 estuvo signado por la ocupación de tierras en una vasta región que ocupa hoy el territorio de Corrientes, Entre Ríos (Argentina), Uruguay y el estado de Rio Grande (Brasil). Una vez definidos los límites entre los imperios "nuevos poblados empezaron a florecer como hongos" (647). Entre 1778 y 1810 se crearon 23 pueblos o villas como parte de una política de la corona, inspirada en las teorías de los fisiocratas, para la "prosperidad y mejora material de sus súbditos" (648). Este proceso y sus conflictos, que emergieron con la revolución de independencia, muestran cómo se construyeron poderes locales que comienzan a articularse en el territorio, con sus conflictos con la capital virreinal (Buenos Aires). En este marco regional, que Rama sacrifica en favor de una mirada de larga duración, el análisis del caso de Jacinto Ventura de Molina y el de muchos otros letrados y ciudades letradas puede cobrar mayor densidad.

El análisis de un grupo social concreto -los letrados, los intelectuales- es otro 
aspecto heredado de La ciudad letrada aunque no desde la perspectiva de un grupo homogéneo interiormente. Cada ciudad letrada implica un entramado de poder en un grupo social, una serie de relaciones entre sujetos, en las que se tejen afinidades e intereses (individuales y colectivos) así como distintos tipos de conflictos y debates. También es heredado el interés de Rama por las relaciones de ese grupo con el poder (político), análisis que hay que completar con un estudio de las relaciones con sus alteridades históricas, es decir, con grupos subalternos que habitan la ciudad e interactúan con la cultura letrada, precisamente porque esta pretende ser hegemónica y dominante sobre los grupos subalternos. 


\section{Un afrodescendiente libre en una cultura letrada}

El cambio de escenario requiere un nuevo relato, hay que re-situar a Jacinto Ventura de Molina en el marco de una configuración cultural específica, articulada en un momento histórico de cambios y quiebres culturales importantes. En un sentido muy general se puede decir que Molina se formó en una configuración cultural (colonial) y murió en otra (nacional) como muchos otros que compartieron con él una cultura letrada. ${ }^{52}$ Por lo tanto sus manuscritos muestran a un sujeto que habla residualmente desde un imaginario colonial español muy específico, el que promovieron los borbones en el siglo XVIII, en un contexto de reconfiguración de ese imaginario y de transformación hacia un Estado-nación, que buscaba romper con el imaginario anterior.

En este nuevo contexto el primer problema es definir aquellos criterios históricoformales planteados por Castro-Gómez en su crítica a la homogeneización del discurso de Rama. Para este autor la "naturalización de la letra" estuvo ligada a los procesos de "racionalización social" a fines del siglo XIX que terminan con la emergencia de los medios de comunicación hacia 1930, por lo que hay que entender el avance de la cultura letrada en el Río de la Plata en el marco de la Ilustración española del siglo XVIII, marco en el que se formaron tanto José Eusebio de Molina como Jacinto Ventura así como letrados "reconocidos" como Juan Manuel Pérez Castellanos o José Prego de Oliver. Asimismo es imprescindible entender la cultura letrada como un proyecto que durante el período estudiado intenta hegemonizarse desde una débil estructura estatal y en medio de

52 En ambas configuraciones (colonial y nacional) la esclavitud es en parte una línea de continuidad. El fin del colonialismo español no implicó el fin de la esclavitud. En todos los países de América Latina el proceso de abolición de la esclavitud fue complejo e implicó en la mayoría de los casos una liberación gradual de los esclavos. El proceso se inició con una ley de vientres por la que los hijos de esclavos nacían libres y unas décadas más tarde por una ley de abolición definitiva. (Uriarte, 2003).Las relaciones de servidumbre se mantuvieron durante décadas por lo que buena parte de la población afrodescendiente se mantuvo en tareas dómesticas o de servicio a sus ex-amos. 
un proceso de cambio social. Analizando el valor atribuido a la oralidad y la escritura durante los siglos XVIII y XIX, Guillermo Milán afirma que Montevideo "fue una sociedad en la que la comunicación oral ejercía algún tipo de predominio" y que en sus primeros años fue poblada por iletrados casi en su totalidad, una comunidad etnográfica con predomino del face to face en la que lentamente se dio un "proceso global de multiplicación y complejización creciente, delimitándose y desarrollándose diversos dominios de actividad letrados, donde los usos de la lengua escrita se definían en una relación específica con la oralidad” (68). Estar cerca del poder significó para Jacinto Ventura de Molina contribuir en este proceso de ampliación de la palabra escrita, en la voluntad de dominar la oralidad "salvaje", disciplinar al ciudadano y modelar la sociedad que se gestó en la colonia y que el Estado-nación busco centralizar.

Es importante señalar que Jacinto Ventura estuvo muy cerca del poder durante sus años de formación. Como analiza Arturo Bentancur en la etapa fundacional de la burocracia colonial se privilegió y promovió un perfil militar (1993: 20-21) que como muestra el caso de José Eusebio de Molina no cumplía solamente tareas militares sino también múltiples tareas sociales. No está de más recordar que no nos encontramos ante una sociedad moderna en la que las esferas aparecen en una lógica de diferenciación en la que "lo militar" es separable de los demás aspectos de la vida social. Jacinto Ventura de Molina fue educado por un militar y por un entorno de militares que cumplían diversas funciones en la campaña de Cevallos para demarcar las fronteras con el imperio portugués. La cercanía al poder central del período es un dato muy imporante tanto como el marco ilustrado en el que estos militares fueron encuadrados.

En general las ideas-fuerza de la Ilustración: la razón, la naturaleza y la idea del progreso material, penetraron en España y conformaron un largo proceso que abarcó el 
siglo XVIII y buena parte del XIX. Estas ideas estuvieron al servicio de “(...) un proyecto general que trata de obtener el adelanto de la cultura y la reforma de la sociedad. Este es, pues, un rasgo inseparable de la mentalidad ilustrada, su ideal reformista” (Martínez Shaw, 8). Se crean en la metrópolis Academias (la Real Academia de la Lengua es producto de este proceso), Sociedades económicas de amigos del país y Consulados, instituciones con objetivos diferentes, aunque todos tendientes a la reforma material, social y cultural. Estas transformaciones tuvieron un impulso particular, sobre todo en las colonias, a partir del desplazamiento de la Casa de Austria con la muerte de Carlos II y la llegada de los Borbones a la monarquía española con Felipe V. Las ideas de la ilustración fueron apropiadas y difundidas por la monarquía española pero no pusieron en entredicho el fundamento político de la monarquía ni el fundamento religioso que la Iglesia Católica le proveyó.

En un virreinato nuevo como el del Río de la Plata una elite de militares españoles creó su propio "experimento" de la razón, que marcó de un modo profundo a Jacinto Ventura al punto de que durante la crisis de la revolución independentista, el proceso de formación del Estado-nación y los primeros años del nuevo Estado, mantuvo su fe católica, su defensa de la monarquía y su cultura letrada ilustrada, adaptándose a su manera a los cambios. En otras sociedades esclavistas, como la norteamericana, existieron también “experimentos" como el de Molina. Son en parte producto del empirismo reinante en el pensamiento científico y la ideología de la ilustración que proponía un sujeto capaz de reformarse a sí mismo a través de la educación. Los “experimentos” letrados probaban la humanidad de africanos y descendientes de africanos, a través de la imitación de los modelos culturales de occidente, alcanzando así el grado de "hombres" a través de la cultura letrada. 
Es el caso de Phillis Weathley en Boston (EEUU). En 1772 un grupo de distinguidos hombres de la ciudad letrada examinaron a Weathley, una esclava llevada de Senegal a Estados Unidos en 1761. La joven de dieciocho años debía demostrar frente a un tribunal masculino lo que le había enseñado su amo, el sastre John Weathley. El tribunal la reconoció como poeta, sorprendido por su dominio del inglés y del latín, y sus lecturas de Milton, su mayor influencia literaria. Un año después Phillis Weathley publica sus poemas en Londres luego de haber intentado, sin suerte, publicarlos en su país. Si bien Jacinto Ventura de Molina y Phillis Weathley comparten un "espíritu del tiempo", EEUU y el Virreinato del Río de la Plata fueron dos formaciones socio-históricas, dos “estructuras de sentimiento" simultáneas pero muy diferentes. Boston y Montevideo son parte de procesos imperiales distintos, que tienen incluso muchas diferencias internas. Sin embargo, tanto en el caso de Jacinto como en el Phillis los conocimientos adquiridos por los afrodescendientes generaron reacciones similares en los hombres de letras, que dudaron de los conocimientos adquiridos por los afrodescendientes sometiéndolos a prueba insistentemente.

La configuración cultural colonial española no admitía, o no podía admitir, que un afrodescendiente, libre o esclavo, pudiera escribir. En el pensamiento del siglo XVIII la escritura era percibida como límite entre civilización y barbarie. Gibbon por ejemplo, afirmaba: "El uso de letras es la principal circunstancia que distingue a un pueblo civilizado de una horda de salvajes, incapaz de conocimiento y reflexión” (En Olson: 2526). Esto en parte explica, según Henry Louis Gate, el mecanismo por el que el "negro" está excluido de la república de las letras, una noción familiar a la de ciudad letrada. Si la escritura es el signo visible de la razón, los negros deben demostrar que son hombres a través de su destreza en las ciencias y las artes (Gate: 9). Estos pre-conceptos se mantienen 
luego de las luchas por la independencia en la medida en que Molina tuvo siempre que demostrar sus habilidades para formar parte de la cultura letrada (ser un letrado) y fue visto por el resto de los letrados como un loco, un excéntrico o una excepción.

Para terminar de ubicar histórica y territorialmente esta configuración cultural quiero indicar que si bien Jacinto Ventura de Molina escribió en Montevideo entre 1817 y 1837, o al menos eso es lo que indica la documentación actual, sus relatos muestran que transitó por el Virreinato del Río de la Plata, acompañando las misiones militares en defensa de un espacio regional común que incluye ciudades y fortalezas de lo que hoy es la frontera entre Uruguay y Brasil. Pero Jacinto Ventura vivió en la ciudad de Rio Grande, en el actual estado de Rio Grande do Sul en Brasil, en donde estuvo desde su nacimiento en 1766 hasta 1776, y también en Buenos Aires entre 1788 y 1799 aproximadamente. En este transitar por el territorio influyeron mucho los servicios que sus padres daban al militar José Eusebio de Molina, que llevaban a la familia a moverse junto a él en sus expediciones militares, de las que Jacinto Ventura también formó parte. En definitiva introducir el caso en un marco nacional es un aspecto poco relevante para explicar el caso, o al menos es necesario suspender o relativizar este aspecto en la medida en que esta cultura letrada se encuentra en un proceso de cambio o crisis en la que se combinan aspectos de dos configuraciones culturales definidas: la colonial y la nacional.

Otro de los aspectos centrales de este nuevo relato es la ubicación de Jacinto Ventura de Molina en el escenario de los "letrados". En el análisis del concepto de ciudad letrada expuse que las ideas de Rama tendían a homogeneizar al grupo (una "identidad" letrada). Esta perspectiva no permitía entender a los letrados como un grupo con sus relaciones, sus intereses, conflictos y consensos. Además Rama tiende a enfatizar la relación de los letrados con el poder sin analizar otras relaciones, que también son 
constituyentes del grupo, como las que establece con los grupos subalternos.

Si como sostiene el antropólogo David R. Olson (1994) la cultura escrita es "una condición cognitiva y social, la habilidad para participar activamente en una comunidad de lectores que han acordado una serie de principios de lectura, una hermenéutica, si se prefiere, un conjunto de textos considerados como significativos, y un acuerdo activo sobre las interpretaciones válidas o apropiadas de esos textos" (302-303), entonces Molina pertenece a la cultura letrada, y cada equívoco, mala interpretación o sobreinterpretación que él mismo realiza sobre los textos, o es detectada y señalada por los otros, sólo confirma su pertenencia a esa cultura letrada. Sin embargo, hay un aspecto sobre el que Olson no reflexiona y es en qué condiciones los sujetos entran y luego "pertenecen" a la cultura letrada. En su versión la cultura letrada está dividida en "comunidades textuales" y, en sociedades modernas con esferas autónomas (economía, política, ciencia, arte, literatura), las instituciones públicas educativas privilegian "la competencia requerida para la participación en esos dominios privilegiados" (302). Si bien este último razonamiento no se aplica al caso estudiado, porque este mundo de "comunidades textuales" está en formación, sí permite comprender que aún con la fragmentación planteada, Olson piensa en un acceso universal a la cultura letrada. Lo que muestra el caso de Jacinto Ventura de Molina es que, aún con las destrezas necesarias, el acceso a la cultura letrada, a la sociabilidad que ese mundo implica, no es universal, de modo que las relaciones étnicoraciales (entre otras) sitúan a los sujetos en diferentes posiciones dentro de las "comunidades textuales".

Esto no quiere decir que los afrodescendientes hayan ocupado siempre el mismo lugar en todas las épocas o que todos en un mismo momento histórico ocuparan el mismo lugar en la cultura letrada. Los afrodescendientes esclavos y los libres tuvieron varias 
posiciones durante el período estudiado además de ser objeto de las representaciones sociales de los europeos y los criollos. Los esclavos cimarrones, por ejemplo, ocuparon la negatividad de la cultura letrada, es el no-sujeto, el no disciplinado, el afuera y la amenaza (cuando se amotina). Su reverso es el esclavo, el sujeto jurídico (un bien inmueble con derechos, según Petit Muñoz) y disciplinado (por la iglesia o la policía). Aunque un rígido dispositivo colonial controlaba a los esclavos, también estos encontraron espacios propios y hablaron en la cara al poder también. Las relaciones con el sistema judicial en la Banda Oriental, aunque asimétricas, fueron un espacio de intercambio de los esclavos con la cultura letrada. Aún así en su gran mayoría los esclavos no dominaron la cultura letrada ni compartieron espacios de sociabilidad. Los afrodescendientes libres, que en 1803 eran 150 junto a los pardos en un total de 4600 habitantes montevideanos (Pereda Valdés, 1965: 46), desarrollaron diferentes actividades en la ciudad colonial en los que la carrera militar fue una de las formas de "ascenso social” más importantes. También ocuparon algunos lugares en la ciudad letrada, lugares intermedios en los que a veces permanecían en relaciones de servidumbre, valorados al igual que los esclavos de un modo ambiguo. Jacinto Ventura de Molina ocupó un lugar intermedio en la ciudad letrada. Lugar que ocuparon otros en el teatro, por ejemplo, que circularon tanto por Montevideo como por Buenos Aires, como el mulato José Antonio, Josefa Echavarría, el pardo libre Juan Antonio Viera o Luis Ambrosio Morente (Borucki, 2008: 248-249). Borucki incluye a dos letrados Bartolomé Hidalgo y Luciano Lira, ambos identificados como "mulatos” por sus contemporáneos (250).

Por otro lado es importante reconstruir los signficados que se generaban en torno a la cultura letrada a comienzos del siglo XIX. Molina responde al modelo de letrado imperante en la primera mitad del siglo XIX cuyo "rasgo definitorio", como sostenía Rama, era el "ejercicio de la letra" tanto para "una escritura de compra-venta" como para 
una "oda religiosa o patriótica" (35). La revolución artiguista que se desarrolló entre 1811 y 1820 en territorio de la Banda Oriental ocupó la ciudad de Montevideo y esbozó un programa ilustrado con la creación, el 26 de mayo de 1816, de la Biblioteca Pública de Montevideo, que sería la base de la actual Biblioteca Nacional. La "Oración inaugural” de su director, el cura Dámaso Antonio Larrañaga, fue dicha y publicada en el marco de las fiestas mayas en honor a la Junta de Buenos Aires, que en mayo de 1810 inició la independencia del Río de la Plata. El primer acervo lo conformaron cuatro bibliotecas: la del cura Manuel Pérez Castellano, la de José Raimundo Guerra, la del Convento de San Francisco (de los jesuitas) y la del cura Dámaso Antonio Larrañaga. En esa “oración inaugural" Larrañaga esboza uno de los principios del "brazo ilustrado" de la revolución artiguista:

(...) Toda clase de persona tiene un derecho y tiene una libertad de poseer todas las ciencias por nobles que sean. Todos podrán tener acceso a este depósito augusto de ellas. Venid todos, desde el africano más rústico hasta el más culto europeo, todos encontraréis la más humana y obsequiosa acogida: a todos se descubrirán los misterios más recónditos de la política que debe gobernarnos y de la sacrosanta religión que profesamos (39)

¿Estaba pensando Larrañaga en Jacinto Ventura? ¿o era “demasiado real” frente a una "idea" como la libertad de acceso a la Biblioteca? Jacinto Ventura ocupaba un lugar intermedio en la contraposición de Larrañaga entre el "rústico africano" y el "más culto europeo". Es posible que, aún en el marco del proyecto político artiguista, la prédica del 
Vicario, su apelación a la civilización del pueblo a través de la cultura escrita y en particular de la lectura, penetraran en Molina con particular interés. Después de todo, compartían la misma tarea evangelizadora. De ahí, por ejemplo, la propuesta de Jacinto Ventura de crear y dirigir una escuela para negros. ${ }^{53}$

Pero este aspecto de la cultura letrada, la circulación de libros, no se agotó en el proyecto artiguista de una biblioteca pública. Es posible saber algo más a través del registro de tres bibliotecas privadas durante el período 1780-1810: la de Cipriano de Melo (72 libros), María Clara Zabala (45 libros), Francisco Ortega y Monroy (276 libros) que indican una incipiente circulación del libro en Montevideo. Como señala Pablo Rocca, es destacable la preponderancia de temas religiosos y de historia (militar, política y religiosa) en detrimento de la poesía o la ficción. La biblioteca de Joaquín de Sagra y Périz posiblemente visitada alguna vez por Jacinto Ventura, fue inventariada en 1851 (tenía aproximadamente unos 400 ejemplares) y mostraba un viraje hacia temas más técnicos, históricos y filosóficos. Si bien la ficción y la poesía seguían ocupando un lugar menor, el interés por lo religioso decayó en este período (Rocca, 2003: 20-22).

En otro texto afirmaba que Jacinto Ventura fue un exiliado de la ciudad letrada, una situación que planteaba como paradójica y partía del supuesto de que los afrodescendientes en bloque estaban excluidos de la ciudad letrada (Gortázar, 2007: 55-57). Sin embargo Jacinto Ventura de Molina perteneció a la cultura letrada por la fisura que abrió el militar español José Eusebio de Molina en el sistema colonial cuando decidió hacerse cargo de la educación de un afrodescendiente. Pero también se abrió camino por sí solo gracias a distintos benefactores blancos, hombres ilustres de la República que pertenecieron a las

53 En el Archivo General de la Nación (AGN) se conserva un documento en el que el Licenciado fundamenta la creación de la escuela e incluso proyecta su construcción mediante un dibujo. Además realiza el cálculo de ladrillos necesarios así como su costo. AGN. Ex Archivo y Museo histórico nacional. Papeles de Joaquín de Sagra y Périz. Caja 205. Correspondencia y Misceláneas. Carpeta 7. Papeles de Jacinto Ventura de Molina, 1834-1835. 
elites hispano-criollas. Estas elites estaban atravesadas por luchas de fracciones que cambiaron y se relacionaron de muy distintas maneras desde la crisis del sistema colonial hasta la constitución de 1830. El texto constitucional es el resultado de una "unanimidad patricia”, según expresión de Carlos Real de Azúa, que Ana Frega entiende como una tregua y no el punto final de un proceso (Frega, 2009: 44-45). Si bien Jacinto Ventura se mantuvo fiel a Fernando VII en 1815, decisión que lo comprometió seriamente frente a los artiguistas que gobernaron la ciudad hasta 1817 , durante el período posterior su posición política fue haciéndose residual hasta que en 1830 se adapta al nuevo escenario político nacional hasta su muerte.

La marginalidad de sus posiciones políticas, las burlas o los insultos, la protección de algunos blancos no muestran a un "exiliado" de la ciudad letrada, sino a un afrodescendiente luchando por el reconocimiento e interviniendo en las disputas de los letrados, permaneciendo en algunos momentos cerca del poder colonial español y luego de los luso-brasileños. En ese marco el discurso sobre su excepcionalidad como afrodescendiente en la cultura letrada de Jacinto Ventura de Molina se exacerba e intensifica:

Mi color negro y mi estado particular, indigente, exigen para mí la singular gracia del Sacerdocio y merecer en él mi fin feliz. Ejemplar a los de mi color en los principios de mi educación, en los medios de mi comportamiento, estudio y reflexión, y en los efectos, cuando se ignora, que en todo el mundo antiguo, algún negro haya dictado, discurrido, o creado alguna cosa (M, T. III, fs $274 \mathrm{v}$ y $274 \mathrm{r})$. 
En este pasaje, tomado de una carta dirigida al "Sumo Pontífice Gregorio XVI" en 1833, en el que Molina solicita ser ordenado como cura, es posible advertir su interés en erigirse representante de los afrodescendientes como grupo. Después de escribir varias historias ejemplares: la de su padre como fiel esclavo, la de su tutor como buen amo, la de su esposa como santa, la de Lecor como pacificador de la Provincia Oriental, Jacinto Ventura utiliza su propia situación, para él excepcional, como ejemplo de vida. Otro dato que marca las diferencias entre los letrados es la situación económica que Molina califica de "indigencia" en su caso. Esta situación sumada a los prejuicios raciales, si bien no impidieron que Jacinto Ventura escribiera, hicieron su lucha por el reconocimiento más difícil.

Una perspectiva como la de Rama en La ciudad letrada privilegia los textos y autores consagrados por cierta tradición crítica, lo cual impediría situar a Molina en una red de letrados que comparten una cultura común. Lo cierto es que sus contemporáneos tuvieron reacciones ambiguas, se burlaron $\mathrm{y}$ al mismo tiempo lo protegieron $\mathrm{y}$ promocionaron. Uno de los efectos más importantes de su posición problemática en la cultura letrada decimonónica fue que desapareciera de la historia literaria futura. La condición de manuscritos casi sin publicación hace la tarea más compleja e invita a revisar el concepto de escritura (letra impresa) que le interesa a Rama. Mientras Molina fue publicado a partir de 2008, entre fines del siglo XIX y comienzos del siglo XX, la obra de tres de sus contemporáneos fue recuperada. Hacia 1890 aparecen las obras completas de Francisco Acuña de Figueroa (1791-1862) y, unas décadas más tarde, los manuscritos de Dámaso Antonio Larrañaga (1771-1848) y José Manuel Pérez Castellano (1743-1815). En el momento en que se inventaba una tradición letrada propia y se erigían sus precursores, Jacinto Ventura de Molina es invisibilizado. ${ }^{54}$

54 La primera colección amplia de Dámaso Antonio Larrañaga fue Escritos, publicada entre 1922 y 1930 por el Instituto Histórico y Geográfico del Uruguay. Las Observaciones sobre agricultura de José Manuel 
Finalmente hay un último aspecto a señalar relacionado con la dimensión material de la cultura letrada. Los libros y las fotocopias que leemos, los papeles manuscritos que transcribimos, son objetos materiales. Sin embargo, para tendencias teóricas y críticas como el estructuralismo o cierto sector del mismo, los textos son abstracciones independientes de su materialidad (las tapas, la tipografía, los destacados, las promociones, las librerías donde compramos) y también independiente de las prácticas que llevamos adelante con esos objetos (entre otras, la escritura y la lectura). En general naturalizamos el mundo del texto impreso y prescindimos de esta dimensión material. El trabajo de historiadores como Roger Chartier, que han prestado atención a la cultura material de los textos, son de enorme utilidad. Para el historiador las obras, manuscritas o impresas, imponen un sentido a los textos o al menos "los usos que pueden serles atribuidos y las apropiaciones a las que están expuestos", a tal punto que "no existen sino a partir del momento en que se transforman en realidades materiales, en que se inscriben en las páginas de un libro, transmitidos por una voz que lee o relata, o interpretados en el escenario de un teatro" (1994: 20).

Aunque Chartier apunta a los dispositivos materiales del libro, y no tanto a los manuscritos, es interesante rescatar la importancia de la dimensión material de la cultura letrada a menudo descartada por los investigadores de literatura que naturalizan la cultura impresa. El trabajo con manuscritos, tradicionalmente asignado al trabajo historiográfico, la lingüística histórica o a lo sumo a la crítica genética que los toma como un dato complementario del texto ya impreso, me hizo pensar en el concepto de literatura burguesa que todavía sostiene nuestras prácticas (y que Rama denunciaba en su última ponencia de

Pérez Castellano fueron publicadas por primera vez en 1848. Re-editadas luego en 1914 (Barreiro y Ramos) y en 1968 (Biblioteca Artigas). Ese mismo año, la Biblioteca Artigas también publica Crónicas históricas (1787-1814). 
1983) pero que al mismo tiempo no puede ser evitado. Durante un período mi interés se dirigió a construir textos que representaran esos manuscritos (Gortázar, 2008), que le quitaran todo nivel de ambigüedad a los manuscritos y los hicieran familiares a las prácticas del análisis literario. Esto también desembocó en señalar ciertos elementos de las tradiciones críticas uruguayas que siempre privilegiaron y privilegian el texto literario impreso, convertido en el objeto libro, dejando a la historia el trabajo de "exhumar" el pasado a partir de los documentos.

Por tal motivo es fundamental indagar sobre la dimensión material de una cultura letrada en ciernes cuyas prácticas están alejadas de la cultura impresa ya instalada en el presente. Una carta escrita en octubre de 1823 dirigida al Barón de la Laguna brinda un importante dato: Molina reclama unos muebles "pobres" pero "ricos" en papeles y libros, según sus propias palabras. Molina vivía en una casa propiedad de Juan Pérez, un Capitán de guerrillas de Montevideo, a quien se refiere como "su favorecedor". Es de esperar que en esa biblioteca se encontraran textos que cita frecuentemente como la Doctrina Cristiana de San Agustín, una selección de las cartas de Cicerón, la Geografía de Estrabón y el Digesto entre otros libros. También es posible pensar que la biblioteca estuviera formada, en parte, por la herencia de su tutor español.

Desde el punto de vista material Molina perteneció precariamente a la cultura letrada del siglo XIX si se compara su modesta biblioteca y papeles con las bibliotecas antes mencionadas y eso es notorio por el interés que manifiesta por recuperararla en su carta de 1823. Pero no se trata solamente de libros. La escritura, en tanto tecnología, requería de algunos implementos cuyo costo no era fácil de cubrir para un afrodescendiente. A juzgar por la descripción que el propio Jacinto Ventura hace de su escritorio cuando todavía vivía con su tutor: “el comedor de la habitación (...) era también 
la sala y en una gran mesa residía la de mi estudio y prácticas, reglas compás, lápiz, cortaplumas, libros, cuadernos, tintero, salvadera (...)”. Esta gran cantidad de implementos, algunos de los cuales tal vez Molina conservara ya entrado el siglo XIX, tenían un costo y su acceso representaba una limitación para quien quisiera desarrollarse en la cultura letrada. El papel y los implementos necesarios se compraban en las librerías que existían en Montevideo desde fines del siglo XVIII como la de Fernández Cutiellos que "ofrecía a sus clientes materiales de papelería y encuadernación en abundancia, pero también algunos libros: catecismos y unos pocos autores castellanos (Cadalso, Herrera), las epístolas de Cicerón" y otros textos (Rocca, 2003: 37-38). Por eso es importante considerar a los protectores o mecenas que sirvieron de ayuda a Molina en su indigencia a cambio de diferentes servicios, entre los que se encontraba la propia escritura:

[...] Vi aquel día al buen Hermano D.n Pedro Pérez cuya atención, fue y será siempre digna de mi mas expresivo agradecimiento [que] estaba escribiendo y dándome papel y pluma me mandó que escribiese en la misma mesa, escribí un saludo al Yll.mo y Ecl.mo S.or Cap.n General y concluido el S.or D.n Pedro leyó y notó este escrito que aprobó y celebró mucho: SS.a había llegado halas 11 de su estancia ydeconsiguiente me desayuné entonces en la misma mesa haciéndome platos he instancias tan atento y Político S.or: cuya conclusión fue preguntarme en qué estado esta [Vuestra Merced] de dinero, he informado del por menor de mi yndixencia, sacó una moneda de plata y me la dio (M 1, f. 176r).

La escritura lo sentaba en la misma mesa de los blancos y le ofrecía también una buena moneda de cambio para obtener dinero. 
Algo similar ocurrió con los libros que Jacinto Ventura leyó: en algunos casos están vinculados a personas que conoció a través de José Eusebio de Molina o personas a las que él mismo sirvió. En algunos casos esas personas le regalaron libros y también él los usó como moneda de cambio. A los 23 años (hacia 1789) por ejemplo, Molina obtuvo algunos libros de la siguiente manera:

El Estudio Moral que he tenido le debí bien joven hala [Señora] española [Doña] Francisca Ortega mujer del antiguo Comandante del Resguardo de esta ciudad, porque preso su esposo (...) la serví varias veces sino fue todos los días motivando a esta [Señora] a darme en su despedida todos los libros morales y teológicos que aquel Comandante hermano de un oidor de Sevilla tenia (...) El [Poderoso] Ministro Fray Juan Rosas vio estos libros y ha fuerza de instancias consiguió que le vendiese esta obra [para] misas pareciéndome que obra tan preciosa no valía dinero (M 1, f. 108r)

Esta es la primera parte de una larga cita de las Glorias de la Caridad en la que Molina relata el modo en que fue aprendiendo saberes de diferentes "amos". Lo que resulta interesante es que como forma de pago o como regalo, la señora Ortega le diera todos los libros morales y teológicos de su esposo "en su despedida". Así como la ropa ya inutilizada de los amos y que estos regalan a sus esclavos, es parte de los bailes públicos de los negros durante el Corpus Christi, el capital cultural acumulado por Molina para ser letrado (su biblioteca, sus papeles, sus estudios) también se construyó con regalos de sus "amos”. Esto se inscribe en un proceso general en que los amos piadosos, agradecidos por la fidelidad, dejaban en sus testamentos la libertad y algunos bienes para sus esclavos. El relato también 
muestra cómo con ese capital Molina hacía intercambios que lo beneficiaban en su “indigencia". Así por ejemplo continúa explicando cómo un cura que le enseñó "a construir latín palabra por palabra", le regaló un breviario de las oraciones para la misa que luego él regalo a Dámaso Antonio Larrañaga. Continuando con el relato de sus conocimientos que muestra distintos intercambios y usos de su capital cultural, Molina hace referencia al “Doctor en leyes" Don Antonio Escarranea quien

(...) viéndome copiar un expediente que dio por gracia [un] borrador a un maestro botero con quien yo trabajaba, asegurado de que era negro me mando llamar e impuesto de mis conocimientos y gustos que tenia para las ciencias me dijo [si] quería aprender el [Derecho] Político y abogar y vista mi voluntad me dio borradores de todos los métodos de Memoriales y Oraciones políticas, me dio una suma de las leyes y libros donde debía estudiarlas como lo hice comprando los dos libros de Política Indiana (M, T. I, f. $109 \mathrm{v})$

Este pasaje permite ver cómo Molina, siendo un zapatero, consiguió que otro blanco se interesara por su formación, esta vez en leyes, y lo beneficiara intercambiando material bibliográfico. En la misma narración Molina agrega otro dato interesante:

(...) añadiendo el [Señor] Doctor Contreras en [Buenos Aires] varias explicaciones a las reglas que me dio el [Señor] Doctor Escarranea no debe omitir las explicaciones de los Derechos Eclesiásticos sobre [pun]tos positivos y comunes a los dos Derechos traídas por el Eminentísimo [Señor] Cardenal Solís, obra que tenia también mi S.or y 
me regaló después de su muerte la [Señora] [Doña] Catalina Gil, su presunta esposa, el [Real Derecho] militar escrito por el [Señor] D.n Félix Colon que [también] tuvo mi [Señor] y yo vi (M. 1, f. 109 r)

El español José Eusebio de Molina murió antes de poder casarse con Catalina Gil. Esta mujer le regaló a Jacinto Ventura un libro del Cardenal Solís, aunque este agrega que leyó otros libros que "su Señor” tenía. En este pasaje y en otros de sus manuscritos se desprende que este libro pudo ser el único que obtuvo de quien fue su tutor y a quien sirvió durante años. El dato tiene su importancia también porque demuestra que después de la muerte del español, Molina pudo acumular un pequeño capital cultural que le permitió construir una biblioteca como se desprende de la carta de 1823. La sociabilidad letrada hizo que Molina pudiera leer en las bibliotecas privadas de otros letrados, como muestran las citas a textos que pudo leer en la biblioteca de Sagra y Périz. Estos datos muestran que era normal, o al menos lo fue para Jacinto Ventura, la circulación de libros y papeles entre los "miembros" de la ciudad letrada.

Todos los datos expuestos habilitan a pensar que Molina podía ser objeto de burlas o muestras de desprecio pero no por encontrarse fuera de la sociabilidad letrada montevideana sino precisamente por pertenecer a ella, conocer las técnicas, manejar un conjunto similar de lecturas y referencias (en el sistema judicial por ejemplo), frecuentar espacios como la iglesia, el teatro y las librerías (donde se producían tertulias en las que pudo participar) y compartir una cultura material común. Su discurso podía incomodar, perturbar e incluso violentar ese espacio común pero las reacciones incluyeron también el mecenazgo, tal vez a causa de la misma incomodidad o perturbación. También es importante introducir perspectivas como los significados de lo "étnico-racial" o de factores 
socio-económicos en el análisis de la cultura letrada para comprender aspectos centrales del discurso de un letrado (su modo de decir "yo", por ejemplo), sus relaciones al interior del grupo y sus relaciones con otros grupos (particularmente los subalternos).

La teoría expuesta por Ángel Rama en La ciudad letrada sienta las bases para comprender el desarrollo de la cultura letrada en América Latina. Sin embargo, a la distancia, presenta también muchas limitantes para comprender aquellas zonas grises, híbridas, intermedias entre la alta cultura letrada y sus versiones "degradadas". A partir del caso de Jacinto Ventura de Molina he querido presentar algunas objeciones al modelo teórico de Rama, sobre todo a los supuestos de una cultura nacional y al rol de las capitales, así como su relato histórico algo homogéneo, que dificultan el análisis del período histórico en cuestión (1766-1837). A su vez presento la idea de una cultura y una sociabilidad letradas que permiten introducir la variable étnico-racial como una limitante que Molina experimentó en su trayectoria como letrado. Una vez ubicado en este nuevo marco importa ver cuáles son las consecuencias de sus prácticas en esa cultura letrada. 


\section{Capítulo III}

\section{Escribir "yo": mimesis y autobiografía}

En una parte importante de los manuscritos de Jacinto Ventura de Molina hay momentos autobiográficos, o mejor, pasajes en los que utiliza el discurso autobiográfico para ilustrar sus argumentos o despertar distintas reacciones en su interlocutor o en sus "lectores". Se puede decir que una retórica de la autobiografía atraviesa sus textos pero no que Jacinto Ventura eche mano del género autobiográfico y lo maneje con destreza. Con esto quiero decir que no existe entre los manuscritos un texto que se titule "Autobiografía" pero sí diversos pasajes en los que Molina construye un relato de su vida para legitimarse como sujeto ante la comunidad letrada. Para ciertas lecturas teóricas de la autobiografía esto no es un problema. Paul de Man plantea, por ejemplo, que la autobiografía no es un género literario sino "una figura de lectura y de entendimiento que se da, hasta cierto punto, en todo texto" (1991: 113). Como figura de lectura me interesa abordar el modo en que Jacinto Ventura de Molina toma conciencia de sí y de su entorno a través de la escritura de estos pasajes autobiográficos y el uso que les da en cada texto particular. Por otro lado, me parece importante analizar los aspectos comunes a otros afrodescendientes que tomaron la palabra en el mismo período como Oludah Equiano, un esclavo africano que luego de un periplo norteamericano y caribeño se instala en Inglaterra; Mahommah G. Baquaqua, esclavo africano en Estados Unidos, luego de un largo periplo por Brasil y el Caribe; y, por último, Francisco Manzano, esclavo cubano que obtiene su libertad en gran parte por sus destrezas letradas.

En los tres la mimesis con la "cultura blanca", con sus valores y tradiciones culturales, implica un proceso de aculturación o deculturación que implica por un lado 
arrancar a un sujeto de su cultura y por el otro hacer que adquiera una nueva cultura, signada por la esclavitud, sistema en el que se lo consideraba jurídicamente "una cosa con supervivencias crecientes del concepto de persona" (Petit Muñoz, 186). La mimesis es constitutiva del afrodescendiente como sujeto en el mundo colonial. Así lo explicaba Frantz Fanon en su libro Piel negra, máscaras blancas (2009 [1952]) cuando afirmaba que para el negro "sólo hay una puerta de salida y desemboca en el mundo blanco" de la que proviene "la preocupación por llamar la atención del blanco" y la "voluntad de adquirir las propiedades de revestimiento, es decir, la parte de ser o tener que entra en la constitución de un yo" por lo que concluye "el negro tratará de sumarse al santuario blanco por el interior" (71). A partir de una relectura de Fanon, el postcolonialismo de Homi K. Bhabha plantea una nueva interpretación de la mimesis, que recupera estos espacios coloniales como espacios de poder productivos, o que producen subjetividades. De esa forma, Bhabha descarta la negritud de Fanon entendida como una identidad negra definida positivamente y no como un mero negativo del mundo blanco (Fanon la denomina "alienación" del blanco en su mundo blanco y del negro en su mundo negro) para resaltar espacios de "hibridación cultural" como los abiertos en el propio discurso colonial. La mimesis, sea esta entendida negativa o positivamente, constituye un eje de lectura fundamental de los grupos subalternos, y está atada a la discusión sobre la deculturación.

Por último, el concepto de sujeto implícito en teorías como el subalternismo y el postcolonialismo remiten al impacto de las teorías postestructuralistas en múltiples áreas de las ciencias sociales metropolitanas. En el prólogo a Escribir en el aire Antonio Cornejo Polar planteaba la cuestión del sujeto como parte de su revisión del "proyecto epistemológico de los setentas" en el que se encuadran también las últimas obras de Ángel Rama. El autor explicita el fracaso que desde su punto de vista experimentó aquel 
proyecto, que estaba basado en una teoría y práctica del cambio social propia de los sesentas, en el supuesto de una identidad, nacional o latinoamericana, y la reivindicación de una heteróclita pluralidad (1994: 12).

Teniendo este fracaso como eje, Cornejo plantea tres núcleos problemáticos en su nuevo ensayo: el discurso, el sujeto y la representación. Respecto al sujeto Cornejo afirma que el romanticismo, "sentido común de la modernidad" (18), postula un sujeto autoreflexivo y coherente. Por el contrario Cornejo concluye que en sus investigaciones sólo ha encontrado "un sujeto complejo, disperso, múltiple" (19). La conclusión que extrae es que "la condición colonial consiste precisamente en negarle al colonizado su identidad como sujeto" (19), de modo tal que cuando no se reconoce "la hibridez, el abigarramiento, la heterogeneidad" se perpetúa la imagen introyectada del sujeto fuerte, inmodificable y monolítico. Incluso menciona que la cuestión del sujeto heterogéneo tiene sus años en América Latina y se entrecruza "con las inquietudes más o menos sofisticadas de intelectuales metropolitanos" (21). En este texto de 1994, y en otro publicado póstumamente en 1997, Cornejo Polar insiste en la advertencia sobre la relación problemática y asimétrica del latinoamericanismo producido en español con el latinoamericanismo producido en inglés. Es en este marco de diálogos y cortocircuitos en el que inserto mi reflexión sobre la mimesis colonial de Homi K. Bhabha y el subalternismo hindú de Gayatri Spivak. 


\section{Mimesis y aculturación: el otro disciplinado}

En un período de más de tres siglos entre 9 y 15 millones de africanos llegaron a América arrancados de sus lugares de origen (Moreno Fraginals, 13 y Du Bois en Benítez, 68). Para que esto ocurriera murieron, en las diferentes etapas de la trata, unos 150 millones de africanos (Du Bois en Benítez, 68). Más recientemente la UNESCO, a través de su programa "La ruta del esclavo", estima que la trata transatlántica trajo entre 25 y 30 millones de esclavos africanos a América, señalando también que muchos más murieron "en la travesía y en el curso de guerras y razzias conectadas a la trata" (UNESCO). Además de pensar en el "encuentro" colonial entre europeos y pueblos originarios es necesario incorporar este otro "encuentro" con los africanos traídos a la fuerza. Los procesos de contacto entre las culturas han generado una buena cantidad de conceptos como el de aculturación (antropología norteamericana) y transculturación (contraparte de la antropología hispanoamericana). En este trabajo es importante tomar ambos conceptos en cuenta, aunque las características del caso de Jacinto Ventura de Molina me llevan a optar por el concepto de "aculturación”.

El término acculturation apareció hacia fines del siglo XIX en el ámbito de la antropología cultural norteamericana. En 1936 Robert Redfield, Ralph Linton y Melville J. Herskovits integraron un Comité que elaboró un Memorandum a pedido del Social Science Research Council bajo el tema “estudio de la aculturación”. Para el Comité el concepto de aculturación "comprende aquellos fenómenos que ocurren cuando grupos o individuos portadores de diferentes culturas entran en contactos continuos de primera mano, con los cambios subsecuentes en los patrones culturales originales de uno o de ambos grupos." (Redfield et al, 1936: 149). Los autores distinguen el concepto de aculturación del 
concepto de "cambio cultural" del cual la aculturación "es sólo un aspecto" (149); también del concepto de "asimilación" que es "a veces una fase de la aculturación" (149); y por último, del concepto de "difusión" que si bien ocurre en todo el proceso de aculturación es un fenómeno que trasciende el tipo de relación planteado en la definición inicial, por lo que aparece solamente como uno de los aspectos del proceso (150).

Finalmente, los autores analizan los resultados de la aculturación destacando tres fenómenos: la "aceptación" que refiere a la adopción de las pautas de una cultura sobre la otra y la pérdida de los valores de la cultura original; la "adaptación" en la que las culturas se combinan en un mosaico, adaptándose en un todo armónico; y la "reacción", es decir, el movimiento de rechazo entre ambas culturas provocado por la dominación de una sobre otra o por los resultados imprevistos del contacto (152). El concepto de aculturación así planteado fue rechazado por el antropólogo cubano Fernando Ortiz, quien propuso el concepto de transculturación como un proceso que incluye la aculturación como una de sus etapas.

En el segundo capítulo adicional a Contrapunto cubano del tabaco y el azúcar (1963 [1940]) Ortiz comienza definiendo el término aculturación como "un proceso de tránsito de una cultura a otra y sus repercusiones sociales de todo género”. Así como el concepto de aculturación respondía al análisis de comunidades originarias y las barreras raciales en Norteamérica, el concepto transculturación surge del análisis de la "verdadera historia de Cuba" que es "la historia de sus intrincadísimas transculturaciones" (99). Luego de repasar linealmente esa historia de transculturaciones de los diferentes grupos que componen la sociedad cubana -del paleolítico al presente- Ortiz defiende el concepto porque "expresa mejor las diferentes fases del proceso transitivo de una cultura a otra" diferenciándolo de aculturación, que consiste apenas en "adquirir una distinta cultura". 
Para Ortiz "el proceso implica también necesariamente la pérdida o desarraigo de una cultura precedente [deculturación] y, además, significa la consiguiente creación de nuevos fenómenos culturales [neoculturación]"(103). Por lo tanto, Ortiz entiende la aculturación como una etapa del proceso transculturador. El libro de Ortiz fue respaldado por el antropólogo inglés Malinowski, padre de la etnografía moderna, quien prologó el libro y apoyaba esta crítica latinoamericana al concepto de aculturación por razones científicas y también profesionales ya que le permitía criticar el desarrollo teórico de la antropología cultural en Norteamérica en el campo de la cultura.

En su libro Transculturación narrativa en América Latina Rama retoma el concepto de Ortiz para explicar algunos aspectos de la narrativa latinoamericana que surge en los años cuarenta del siglo XX (especialmente la obra de José María Arguedas) pero necesariamente hace algunos ajustes. Uno de los más importantes está relacionado con la "visión geométrica" de Ortiz, según la cual la transculturación se da en tres momentos: deculturación, aculturación, neoculturación. Para Rama esto supone unas culturas internas pasivas que reciben el impacto transculturador y son las que más pierden. El ajuste consiste en prestar atención a los criterios de selectividad e invención que intervienen en los procesos de plasticidad cultural, concepto que toma del sociólogo Vittorio Lanternari (Rama, 2007: 36-37). Estos procesos implican pérdidas, selecciones, redescubrimientos e incorporaciones de distintos elementos culturales cuya riqueza es reducida en la concepción lineal de tres etapas planteada por Ortiz. En esta línea argumenta también que la transculturación supone "un variado esquema de pugnas" en el territorio debido a que quienes distribuyen el impacto modernizador son las ciudades capitales nacionales o regionales (41).

Sin embargo, Rama no descarta la idea de un proceso de síntesis deseable política y 
culturalmente que está implícito en su concepto de transculturación. Lo que ejemplifica en la novela de Arguedas Los ríos profundos (1958) que según Rama "aparece como solución al dilema" de la cultura peruana (el conflicto entre la cultura hispánica o europea y la cultura quechua) que el autor se planteaba en sus estudios etnográficos (267), y que se refuerza con la idea de que todos los elementos, aún los menos "dignos" para la alta cultura, son utilizados "al servicio de un ritmo y de una melodía" (305). Muchos investigadores han cuestionado este trasfondo del concepto de Rama y en especial su búsqueda de sintetizar la heterogeneidad social y cultural latinoamericana (Moraña, 1997; Moreiras, 1997 y Cornejo Polar, 1996 y 1997). Uno de los más críticos fue Antonio Cornejo Polar quien postulaba una "heterogeneidad no dialéctica" (1996), es decir, sin la unidad estética que postulaba Rama. En su última ponencia, a la que hice referencia más arriba, el autor señalaba que "la idea de transculturación se ha convertido cada vez más en la cobertura más sofisticada de la categoría de mestizaje" y que esta es "el emblema mayor de la falaz armonía en la que habría concluido un proceso múltiple de mixturación” (341). En el mismo sentido Mabel Moraña indica la "subyacente ideología del mestizaje como fórmula conciliatoria y niveladora" que reduce lo cultural a lo letrado, reforzando la idea del intelectual como "representador, traductor e intérprete del sustrato de lo popular" (1997: 142). En resumen, en la idea de la transculturación como síntesis de sociedades heterogéneas de Rama subyace la idea de una unidad armónica que corre el peligro de borrar los procesos y los conflictos implícitos en cualquier producto cultural.

Desde un punto de vista marxista y enfocando su análisis en la esclavitud, Manuel Moreno Fraginals propuso en 1977 el concepto de "deculturación” que hace referencia al proceso consciente por el cual "se procede a desarraigar la cultura de un grupo humano para facilitar la expropiación de las riquezas naturales (...) y/o para utilizarlo como fuerza 
de trabajo barato, no calificado". Para Moreno Fraginals este modelo es inherente a la explotación colonial y en América debe ser analizado como "un recurso tecnológico aplicado a la optimización del trabajo". Pese a su aparente esquematismo el autor introduce la cuestión de que no es posible una total deculturación porque algunos aspectos de las culturas originales sirven a los intereses de la clase dominante para mantener su dominio sobre los esclavos pero finalmente opta por un planteo bipolar: "La clase dominante aplica al máximo sus mecanismos de deculturación como herramienta de hegemonía, y la clase dominada se refugia en su cultura como recurso de identidad y supervivencia” (14).

Una vez planteado este conjunto de herramientas teóricas que, la mayoría de las veces, busca explicar procesos sociales, es difícil analizar la trayectoria de un individuo como Jacinto Ventura de Molina en la configuración cultural del Río de la Plata. Sobre todo porque los manuscritos no permiten detectar en Molina qué rasgos de los valores culturales de sus padres pudo haber hibridado. A través de los textos de Molina los padres podrían haber pasado por un proceso similar a la deculturación de Moreno Fraginals o a la aculturación de Redfield, Linton y Herskovits, sobre todo en su versión de la "aceptación". Con esto quiero decir que Molina fue conscientemente separado de sus padres, lo cual puede llevarlo a no ver o no querer mostrar aspectos de los mismos que pudieran mostrar alguna falla en la deculturación a la que fueron sometidos. Lo que sí es posible afirmar es que Jacinto Ventura parece ser un doble disciplinario perfecto de su tutor José Eusebio de Molina, de hecho así se presenta, y que en su trayectoria no hubo un proceso de selección e invención más que al interior de la cultura colonial española.

En varias ocasiones Jacinto Ventura menciona la separación de sus padres que José Eusebio impuso desde el inicio de su vida "me hacía existir inmediato a él apenas empecé a andar, me conducía por la mano, me observaba continuamente de noche y día hasta que 
empecé a hablar, notó así mi memoria y se propuso enseñarme cuanto pudiese, previno y me pidió a mis padres" (M, II: f 208v y 208r).$^{55}$ El buen amo dispone de la vida del niño y apenas comienza a hablar lo "pide a sus padres" y comienza su alfabetización. Según Jacinto Ventura esto ocurrió cuando tenía tres años y de ahí en más José Eusebio no paró de darle lecciones en las más diversas materias. Otros hombres se sumaron a su empresa aculturadora. Pero en este proceso aculturador (la alfabetización) Molina no se convirtió en un mero receptáculo de las enseñanzas de su tutor.

Muy tempranamente Jacinto Ventura experimentó las ventajas de la mimesis no solamente a través de las lecciones que repetía a su amo todas las noches. En 1817 Jacinto Ventura firma un "Memorial Histórico" dirigido al Barón de la Laguna, siendo todavía "Sargento de milicias" en el que utiliza el relato de su vida para solicitar se le reconozcan sus saberes letrados y militares. A los 10 años Jacinto Ventura acompañó a José de Molina al sitio de Colonia del Sacramento. En aquella expedición iba también el Mariscal de campo Marqués de Cajigal y su hijo de 8 años, "ayudante de campo" del padre. Para divertir al niño y que pudiera acompañar a su padre como edecán -“lo que era dificultoso por su genio divertido"- Cevallos, José Eusebio de Molina y el Marqués tuvieron la idea, según Jacinto Ventura, de ponerle un ordenanza "conveniente a su edad" para lo que lo armaron con “espada y porra”. Así Jacinto Ventura fue ordenanza de este niño edecán, lo asistió siempre "a su lado" yendo a caballo o a pie a "llevar algunas ordenes" (M, II: f $4 v) .{ }^{56}$ En esta representación podemos ver la doble mimesis a la que están sometidos los

55 En el original: "me acia eccistir, ynmediato ael, apenas empesè, à andar, me conducia por lamano, me ocserbaba, continuamente, denoche y dia, asta que empese à ablar, notò aci mi memoria, yse propuso enseñarme quanto pudiese, previno, y me pidio à mis padres" (M, II: f 208v y 208r)

56 En el original: "Para allar un modo de divertir a este niño, i hacerle ir àcaballo al lado de su padre, en la graduacion de edecan loque era dificultoso por su genio dibertido el Cap.n Jeneral D.n Pedro Seballos D.n Josef de Molina y el Marquez de Cajigal [acvitraron] formarle una Ordenansa combeniente asu edad y armandome con espada -y porra lo fui antes de capitular la colonia, y asisti a su lado siempre, en la linea, marchabamos a caballo, y apie à llebar algunas ordenes" (M, II: f 4v). 
niños al imitar los puestos militares, el niño español que imita a un ayudante de campo y el afrodescendiente que lo acompaña como "ordenanza", es decir, como subordinado. Sin embargo, Molina le toma el gusto a este "divertimento" de representar un rol que no tiene, que le permite acercarse al mundo de su tutor, el mundo militar de los blancos.

En el mismo texto otro pasaje interesante es el "rapto" que Jacinto Ventura dedica a José Eusebio de Molina. El Nuevo tesoro lexicográfico de la Real Academia Española indica que durante el siglo XVIII y XIX la palabra "rapto" se utilizó como sinónimo de éxtasis, e incluso en el diccionario de 1737 se hace referencia a los raptos como "una de las mayores maravillas que Dios obra en las almas santas" (409). Este significado místico o religioso es el que recupera Molina para describir a su tutor español. Para Jacinto Ventura las acciones de su tutor eran "la tabla rasa" de su instrucción, y si bien no pretende emularlo, prueba de su fidelidad al amo muerto, afirma tener "la felicidad de dirigirme y concluir mi carrera por las reglas y ejemplos del original que me propuse" (M, II: f 5r) ${ }^{57}$ Es decir, Jacinto no pretende igualar ni superar a su maestro, se autopercibe como una copia. Don José de Molina fue su "original” y con esta mínima referencia entra en la escena colonial de la mimesis como estrategia del colonizado/subordinado.

Al verse moldeado por su tutor/amo del que toma su apellido, como era habitual entre los esclavos, Molina queda preso de "la estructura modelo-copia, inherente a la idea de imitación, [que] subyace a toda la premodernidad [afirma Gomá Lanzón] y es la más acabada expresión de su mentalidad” (26). Esta estructura, continúa Gomá, es reemplazada en el siglo XVIII por la idea moderna de un sujeto creador, autónomo y libre. Jacinto Ventura de Molina se ubica en el momento histórico en que se produce la transición entre ambos sujetos. Si bien no es posible ubicar a Molina en una única posición como sujeto, es

57 En el original: "la felicidad de dirijirme, i concluir mi carrera por las reglas, i ejemplos, de el original que me propuse" (M, II: f 5r). 
claro que su entrada al mundo letrado fue dentro del paradigma modelo-copia. Aunque esta idea no debe conducir necesariamente a una idea de copia pasiva. Al menos en eso es posible plantear otra dimensión de la mimesis.

El investigador hindú Homi K. Bhabha, uno de los principales teóricos de los estudios postcoloniales, analiza la mimesis bajo el supuesto de la ambivalencia del discurso colonial, que se construye en base al discurso del mimetismo, "una de las estrategias más elusivas y eficaces del poder y del conocimiento colonial” (1994: 85). Partiendo del análisis del colonialismo inglés en la India, Bhabha hace referencia al mimetismo colonial como "el deseo de un Otro reformado, reconocible, como sujeto de una diferencia que es casi lo mismo, pero no exactamente” (86. Itálica del autor). Esta ambivalencia hace que Bhabha plantee que, para ser eficaz, "el mimetismo debe producir continuamente su deslizamiento, su exceso, su diferencia" por lo que es "el signo de una doble articulación; una compleja estrategia de reforma, regulación y disciplina, que se «apropia» del Otro cuando este visualiza el poder" pero también "el signo de lo inapropiado, una diferencia u obstinación que cohesiona la función estratégica dominante del poder colonial, intensifica su vigilancia, y proyecta una amenaza inmanente tanto sobre el saber "normalizado" como sobre los poderes disciplinarios." (1994: 86).

La copia que el nativo hace de los rituales y los signos del poder imperial es "[c]asi lo mismo, pero no exactamente." Bhabha pone en entredicho la homogeneidad del discurso colonial a partir del mimetismo, esta doble articulación irónica, por la que el discurso del mimetismo disciplina y regula, y al mismo tiempo amenaza, desafía, elude, produce una "presencia parcial" del sujeto colonial. Tras la máscara que crea este "doble disciplinario" no hay una identidad, sino una amenaza, un parecido que recoloca la autoridad colonial, la obliga a extender sus estrategias de dominio. Con "parcial", afirma Bhabha, "quiero decir 
“incompleta" y "virtual" (...) El éxito de la apropiación colonial depende de una proliferación de objetos inapropiados que aseguren su fracaso estratégico, de modo que el mimetismo es a la vez parecido y amenaza (1994: 86). El niño Jacinto Ventura fue un “doble disciplinario" de José de Molina, como si se tratara de una creación suya, a imagen y semejanza, pero que al mismo tiempo abre un espacio de enunciación intermedio (inbetween). No se trata de una ruptura, sino de una amenaza dentro mismo de la formación hegemónica colonial.

Pero el caso de Jacinto Ventura de Molina encaja parcialmente en esta descripción del discurso colonial, no solamente porque las experiencias coloniales son distintas, sino porque explica apenas el período de formación durante la segunda mitad del siglo XVIII y alguna de las burlas que otros letrados (blancos) escriben hacia 1830. Se puede decir que en ambos casos los involucrados están inscritos dentro del mimetismo colonial y que los efectos del mismo se prolongan en la historia literaria uruguaya cuando borran los manuscritos de Molina. Sin embargo, la mimicry de Bhabha no puede dar cuenta del trayecto que Molina inicia dentro de la cultura letrada a partir de su mimetismo inicial. Es a partir de esta inscripción colonial que Jacinto Ventura elabora un discurso propio con el que habla frente al poder, ya no como resistencia, sino como un actor más en esa configuración cultural en tránsito al Estado-nación. Las reflexividades cognitiva, hermenéutica y estética propuestas por Castro-Gómez van consolidando un discurso propio en el que se hace un uso táctico de la imitación al amo blanco, ajustado a objetivos propios o colectivos.

Es necesario señalar que los conceptos de Homi K. Bhabha surgen del análisis del discurso colonial británico del siglo XIX al igual que la reflexión de los Subaltern Studies de Guha (2002) o Spivak (1998). Distintas vertientes del latinoamericanismo, que centran 
sus análisis en la conquista y colonización española entre el siglo XVI y y comienzos del siglo XIX, así como la historia de las ideas sobre América Latina, han cuestionado ciertos aspectos del vocabulario teórico propuesto por los estudios postcoloniales y subalternistas. Precisamente porque sus generalizaciones teóricas prescinden de las reflexiones que, desde fines del siglo XIX, se han desarrollado en América Latina en torno a la situación colonial. Para designar este problema Hugo Achugar se ha referido a esta tendencia como “Commonwealth teórico", un discurso poscolonialista que, o bien ignora la producción latinoamericana, o bien la interpreta como "un conjunto homogéneo derivado de un pasado histórico colonial supuestamente común en lo esencial con India, África y otras regiones del planeta" (381).

A esta identificación de lo latinoamericano a lo poscolonial o a lo subalterno, Achugar contrapone una América Latina como campo de batalla en la que "los distintos sujetos combaten por la construcción de su proyecto en función de sus particulares memorias (...) un espacio en el donde combaten por el poder distintos proyectos nacionales" y donde operan diferentes memorias (381). El Commonwealth teórico apunta a leer lo "latinoamericano" desde la experiencia de la descolonización y la re-colonización a través del Commonwealth, procediendo a la deshistorización del proyecto latinoamericanista: "Olvidaron o no tuvieron en cuenta que la resistencia a las distintas construcciones que sobre ella realizaban tenía que ver con procesos históricos específicos y que el proyecto de configuración o construcción de una América Latina unida tiene una larga, polémica y conflictiva historia” (382).

Si bien es necesario tomar las precauciones del caso es importante analizar qué lugar tiene el mimetismo en los procesos de aculturación, deculturación, transculturación e hibridación latinoamericanos, particularmente en el marco de la colonización y su relación 
con los grupos subalternos. Para empezar es necesario comprender y tomar en cuenta los modos de representar lo que la antropóloga Rita Segato denominó “alteridades históricas”, es decir, "las formas de ser otro producidas por la historia local, en oposición a las «identidades políticas» globales”. A Segato le interesa estudiar estas alteridades históricas en el marco de una "formación nacional":

(...) el hecho de que los procesos de otrificación, racialización y etnicización propios de la construcción de los Estados nacionales emanan de una historia que transcurre dentro de los [sus] confines, y al mismo tiempo plasma el paisaje geográfico y humano de cada país (...) llamo alteridades históricas a los perfiles humanos que resultan de ese proceso y enfatizo su emergencia situada en la localidad, en la región y, sobre todo, en la nación (28)

A los efectos de este trabajo importa resaltar algo que Segato no incorpora a su perspectiva, $\mathrm{y}$ es que ese proceso histórico por el que se nacionaliza a los otros, establece necesariamente puentes con las alteridades tal como se representaron durante el período colonial. En tal sentido es importante explorar cómo la literatura colonial del siglo XVI, que es diferente a la formación de alteridades en la experiencia colonial inglesa que analiza Bhabha, presenta distintas posiciones de sujeto en los procesos de subjetivación colonial. Al mismo tiempo habrá que ser prudente a la hora de extrapolar tanto las experiencias del siglo XVI y XVII al siglo XVIII latinoamericano como las conclusiones que pueden extraerse de los casos de México o Perú al Río de la Plata en los mismos períodos.

Para Rolena Adorno hubo “dos modelos relacionales” la semejanza y la antítesis 
dentro de lo que llama el sujeto colonial, en el que incluye al colonizador y al colonizado. Ambas apostaban a "reconocer, comprender y clasificar la humanidad americana" (Adorno, 1988: 56). Para ello recurre al concepto de focalización en el que aparecen tres elementos: el que ve, la visión que presenta y lo que es visto. Desde esta perspectiva no importa quién ve sino la visión que presenta: "No importa si el que habla es europeo o no; el criterio definitorio de este sujeto es la presentación de una visión europeizante, esto es, una visión que concuerda con los valores de la Europa imperial” (56). En tal sentido Adorno destaca el "espíritu caballeresco" medieval español, masculino y cristiano, que sobrevive en el siglo XVI a través del poema épico y las novelas de caballería, que influye decisivamente en el proceso de construcción de la alteridad histórica en América Latina.

Esta es tal vez una diferencia sustancial con el mimetismo al que se ve sujeto Jacinto Ventura. Si bien ciertos aspectos de la religiosidad cristiana acercan a Jacinto Ventura al relato hagiográfico, la historia de José Eusebio de Molina está marcada por el hombre que se hace a sí mismo por sus méritos, mediante la educación y la tutoría de un noble de España. En los relatos de Jacinto Ventura la pobreza de su tutor y su tránsito hacia la gloria militar no dependen de acciones piadosas, como sí puede plantearse en el caso de los relatos de su esposa María Rufina Campana, sino de la educación brindada por el tutor y su capacidad individual. El mimetismo planteado por Jacinto Ventura con este ejemplo ilustrado es notorio: él mismo, a través de la copia a su tutor, se hará a sí mismo como "licenciado negro". En este ejemplo el discurso caballeresco (masculino y cristiano) no cuadra con esta idea del avance personal del siglo XVIII. Sin embargo, hay otros aspectos de esa cultura caballeresca que sí aparecen y dan continuidad al proceso de representación del otro en las sociedades coloniales.

En primer lugar Adorno aborda las representaciones del otro en el discurso 
caballeresco militar del colonizador. Desde esa perspectiva el sujeto colonizado de los pueblos originarios es comparable a la mujer o al moro, es decir, sujetos inferiores culturalmente (58). En segundo lugar, como consecuencia de esta primera idea, Adorno plantea que el sujeto femenino aparece como una víctima vulnerable que debe someterse a un dispositivo pedagógico para su mejoramiento moral (60). Esta misma mirada hegemónica sobre la mujer, que de algún modo se infantiliza, se proyecta sobre el amerindio. La visión "teológico-jurídica” del padre Francisco de Vitoria, según Adorno, produce esta equivalencia: "Para Vitoria, el amerindio era psicológicamente un niño: adulto en lo físico pero mental y psicológicamente un niño" por lo que le faltaba instrucción y educación para convertirse en un ser racional: "Teóricamente, este concepto cambiaba el modelo de las relaciones entre el europeo y el autóctono americano de «dueño/esclavo» en «tutor/alumno»" (61). La mujer y el niño, vinculados más a la emoción que a la razón, necesitaban instrucción y supervisión. La figura del tutor entonces se hace central y se traslada a las las relaciones colonizador-colonizado.

Según Adorno esta idea de Vitoria influyó mucho en "pensadores y activistas” así como en "muchos misioneros" y es dable pensar, creo, que marca una continuidad en el modo de tratamiento del subalterno. En el contexto rioplatense del siglo XVIII el modelo "tutor/alumno" puede trasladarse al esclavo afrodescendiente. De ahí que sea posible analizar las continuidades del discurso colonial de los siglos XVI y XVII con el del siglo XVIII. El propio discurso jurídico recoge esta visión en la Banda Oriental cuando plantea cierta ambigüedad en el estatuto jurídico del esclavo, como propiedad "con supervivencias crecientes de persona" a la que debe tutelarse en los derechos que va adquiriendo (Petit et al: 181-186), y cuando se establece en la "Real Cédula de 1789", en el apartado "Educación”, que el esclavo debe recibir "instrucción religiosa" (Petit et al: 239). Otra vez 
importa aquí resaltar que José Eusebio de Molina sobrepasó lo que pautaba que establecía el orden jurídico, brindando una buena alfabetización a Jacinto Ventura. Todos estos aspectos seguramente influyeron en el empeño que José Eusebio de Molina puso en la educación de su niño/alumno afrodescendiente, además de las ideas de la ilustración. Y ambas influyeron en la importancia de la mimesis con el mundo "de los blancos".

Hay un último elemento vinculado a la mimesis y a su lugar en la configuración cultural rioplatense que es la fidelidad de los afrodescendientes (libres o esclavos) al hombre blanco y sus instituciones. La fidelidad fue un "valor agregado" para el esclavo como mercancía durante la dominación colonial. Y como afirmaba antes determinó que muchos fueran liberados una vez muerto el amo como forma de pago por esa fidelidad. A partir de esta idea de la fidelidad, es posible establecer una de las líneas de continuidad de ese imaginario colonial en la república independiente. La historia nacional conservó y reprodujo una promesa muy similar a la de Ventura (el padre de Jacinto) entre los “cuadros memorables" de su héroe por excelencia, el General José Gervasio Artigas. En setiembre de 1820, cuando este ingresó al Paraguay derrotado, se reunió con unos pocos soldados fieles y les informó de la situación. El "negro Ansina" se destacó dentro del grupo, porque con firmeza contestó a Artigas: "Mi general, yo lo seguiré aunque sea hasta el fin del mundo". Durante todo el siglo XX se fueron tejiendo y consolidando dos narrativas en torno a "Ansina" (¿dos variantes de un mito?) articuladas en torno a dos nombres diferentes: Manuel Antonio Ledesma y Joaquín Lenzina.

La primera narrativa de Ansina fue oficializada por el Estado en 1943 con la creación de un monumento que hoy se encuentra en el cruce de Avenida Italia y Avelino Miranda en Montevideo. Se trata de un símbolo de fidelidad a Artigas que fue utilizado en aquel contexto histórico para conmemorar el "Día del soldado". La segunda se basó en la 
publicación de un conjunto de poemas atribuidos a Joaquín Lenzina por Daniel y Victor Hammerly en 1951. Los investigadores "trascribieron" los poemas pero nunca pudieron recuperar los manuscritos que legitimaban su "descubrimiento". En 1996 los poemas fueron republicados por Gonzalo Abella, Danilo Antón e Isabel Izquierdo, entre otros, sin cuestionar este hecho. El grupo interpretaba a Ansina desde un nuevo punto de vista. Para Antón, por ejemplo, Lenzina "fue fundador de la literatura oriental y padre de la patria vieja. Guitarrero, arpista, poeta y payador políglota, gestor de ideas y aconteceres junto a Don José, Andresito y tantos otros en los tiempos de los orígenes.” (AA.VV., 1996: 12). Un gesto de apropiación interesante que se enmarca en un replanteo de la "identidad uruguaya" por lo menos polémico (Gortázar, 2005).

Dentro de este marco, con dos polos bien definidos (el modelo de fidelidad y la figura del letrado), la cantidad de variantes de Ansina que se produjeron en todo el siglo XX acercan su figura al mito, un mito disputado por diferentes comunidades interpretativas. Estas disputas tuvieron y tienen que ver con el lugar asignado por el Estado al afrodescendiente en determinados momentos históricos, y con los modos en que los afrodescendientes se apropiaron y apropian del mito y le dan un sentido propio. Esto no ocurrió con el esclavo Ventura, padre de Jacinto Ventura, ni con muchos otros esclavos que pudieron estar en la misma situación. Pero de algún modo con la historia de Ansina se reforzó la idea del afrodescendiente (ya libre en un Estado-nación democrático) como fiel y subalterno (en sentido literal).

Ningún afrodescendiente alcanzó la fuerza que tuvo, tiene y tendrá Ansina en el "fantaseo nacionalista" uruguayo. Utilizo la expresión "fantaseo nacionalista" en el marco de interpretaciones del nacionalismo como las de Benedict Anderson y Stathis Gourgouris. El primero interpretando el nacionalismo como un "artefacto cultural” específico partiendo 
de una definición de la nación como "una comunidad política imaginada como inherentemente limitada y soberana". Lo que supone que "las comunidades no deben distinguirse por su falsedad o legitimidad, sino por el estilo con el que son imaginadas" (23-24). Gourgouris conecta esta reflexión más radicalmente con el psicoanálisis en su libro Dream Nation. En esta perspectiva la nación es una forma histórica porque "no puede hacer más que reemplazar su estado onírico por una interpretación del mismo.” En ese sentido “[s]i una nación sobrevivirá como un sueño o no depende de cuánto tiempo pueda sostener su propia interpretación como un síntoma sensible de su existencia" (1). ${ }^{58}$

En este sentido se puede afirmar que el sentimiento cristiano y colonial de dar la libertad a los esclavos por su fidelidad se corresponde con este sueño de la imaginación nacionalista, lo cual indica a su vez las continuidades de la colonialidad en lo nacional no como mero residuo sino como línea de larga duración que ha estado implicado en la fantasía nacionalista y en sus sucesivas actualizaciones del sueño nacional. Por lo tanto el énfasis de Jacinto Ventura en la fidelidad (ya sea de su padre o de otros esclavos o negros libres) cobra un sentido muy particular, que se formula también en su fidelidad a José Eusebio de Molina y su necesidad de tomarlo como modelo a copiar. De modo tal que es posible plantear que la mimesis y la fidelidad son fenómenos correlativos que estructuran el mundo de los afrodescendientes al menos en el Río de la Plata y que son fenómenos de larga duración cuyo origen común debe ser buscado y analizado en la situación colonial.

58 Traducción propia al siguiente fragmento: "A nation is a historical form because it cannot but replace its dream state with its interpretation [...] Whether a nation will survive as a dream or not depends on how long it can sustain its self-interpretation as a sensible symptom of its existence." (1) 


\section{La autobiografía de afrodescendientes en Hispanoamérica: Jacinto Ventura de} Molina y Juan Francisco Manzano

Al analizar el concepto de escritura de Ángel Rama el filósofo Castro-Gómez plantea tres tipos de reflexividad implicados en la escritura: la cognitiva-instrumental (en la que Rama pone el énfasis), la estética y la hermenéutica. Sobre esta última Castro-Gómez plantea que la escritura provee modelos y patrones que el sujeto utiliza para interpretar la realidad. En tal sentido afirma que "la escritura permitió la autoobservación a una serie de sujetos que no existían durante la Colonia, o que se encontraban en la «penumbra» (Michel de Certau)" (130). Esta observación es un excelente punto de partida para analizar los discursos autobiográficos de Jacinto Ventura de Molina y Juan Francisco Manzano en el espacio geopolítico hispanoamericano para describir los resultados de sus autoobservaciones, las formas de salir de "penumbra" en sus distintos contextos.

La Autobiografía de un esclavo de Juan Francisco Manzano fue publicada inicialmente en 1840 con el título Poems by a slave in the island of Cuba, recently liberated; translated from the spanish by R.R. Madden, M.D. with the history of the early life of the negro poet, written by himself, to wich are prefixed two pieces descriptive of cuban slavery and the slave-traffic, con la autoría de Richard Madden en Londres, fuera de la isla de Cuba, de donde Manzano provenía. El texto llegó a su publicación en español y en Cuba casi un siglo después, en 1937. A pesar de las diferencias notorias desde el punto de vista material de los textos: Molina nunca escribió una "autobiografía" ni su obra fue manipulada, ambos afrodescendientes comparten la experiencia de la esclavitud en el ámbito "hispanoamericano" y la comparación de ambos permitirá comprender los usos del discurso del "yo" en manos de sujetos subalternos. 
Desde fines del siglo XIX, a partir de la reflexión pionera de Wilhelm Dilthey, hasta la actualidad el análisis de la autobiografía ha pasado por diferentes etapas que, según sostiene Loureiro (1991) a partir de James Olney (1991), pueden explicarse en base a tres bloques que componen la palabra: auto-bio-grafía. La primera etapa, desde Dilthey hasta la década de los cincuenta, se centró en el "bios", el problema de la autobiografía como testimonio de un sujeto sobre su vida, como si se tratara de un documento que registraba una perspectiva de la historia. A partir de 1956, Georges Guldorf (1991) cambia el eje hacia el problema del "auto", el "yo" que narra su experiencia y toma conciencia de esa experiencia (Loureiro: 3). Por lo tanto ya no importa la relación entre el texto y la historia sino "la conexión entre el texto y el sujeto, y el problema central consistirá en ver de qué manera un texto representa a un sujeto" (Loureiro: 3). La tercera etapa, la grafé, se centra en "el problema del lenguaje y el problema del sujeto" y, fundamentalmente, en la idea del texto autobiográfico como un "artefacto retórico" (Loureiro: 6).

En el primer capítulo analizaba los pasajes autobiográficos de Jacinto Ventura de Molina, y en general sus manuscritos, como documentos. En parte este primer acercamiento daba como supuesta la idea de una identidad entre el autor, el narrador y el personaje que el texto crea, que es el núcleo de la interpretación de Philippe Lejeune en El pacto autobiográfico (1991). Para Lejeune la distinción entre autor, narrador y personaje es pragmática "es el contrato de lectura que identifica al yo textual con el yo del autor el que da origen y especificidad al género autobiográfico" (en Pozuelo Yvancos, 26). Por lo tanto la autobiografía es el "[r]elato retrospectivo en prosa que una persona real hace de su propia existencia, poniendo énfasis en su vida individual y, en particular, en la historia de su personalidad" (en Pozuelo Yvancos, 27). Durante los años ochentas del siglo XX el postestructuralismo, a través de Paul de Man y Jacques Derrida, de la mano de las teorías 
del sujeto del psicoanálisis de Lacan, han complejizado la lectura de Lejeune.

El argumento de De Man expuesto en su "La autobiografía como desfiguración" ([1979] 1991) apunta a deconstruir la barrera entre ficción y no ficción que definiría a la autobiografía como género. Para De Man la autobiografía no es un género sino "una figura de lectura y de entendimiento que se da, hasta cierto punto, en todo texto" (De Man, 1991: 113). Como señala Pozuelo Yvancos para De Man la figura retórica de la autobiografía es la prosopopeya por lo que cuando un yo dice "yo", en verdad dice otro: "Un sujeto presenta a otro, son dos sujetos reemplazables e intercambiables, pero precisamente porque son dos hay un tropo, un desplazamiento sustitutorio." (Pozuelos, 38) o en palabras de De Man: "la autobiografía es la prosopopeya, "conferir y el despojar de máscaras, del otorgar y deformar rostros, de figuras, de figuración y desfiguración” (De Man, 116).

En este punto Pozuelos introduce la reflexión de Ángel Loureiro (Pozuelos, 39) sobre la relación directa en la retórica clásica entre prosopopeya y apóstrofe, "la figura por la cual se concede al acto del decir tal tropo una consideración apelativa” lo cual llevó al autor a proponer que la autobiografía es siempre "una postulación ética". Estos elementos llevan a Pozuelos a postular a la autobiografía no como una mera re-creación de una personalidad sino a la idea de que es "una creación discursiva (...) una producción, una acción" (39). Todos esto lleva a Pozuelos a plantear una complementariedad entre la propuesta de Lejeune y la crítica postestructuralista: "no tienen por qué contraponer la ficcionalidad que de facto, en tanto construcción discursiva suplantadora de los hechos, se da en todo discurso autobiográfico (en todos los términos antes recorridos) con la hipótesis de autenticidad que de iure (y ése es el pacto) contrae ese discurso con sus lectores en el funcionamiento social.” (43) En esta línea es posible plantear la coexistencia del pacto autobiográfico, que le permite al lector la identificación entre el yo de la enunciación y el 
autor, con la ficcionalización, que atraviesa siempre la configuración de un sujeto.

Es decir, Molina crea una máscara, ficcionaliza su relato de vida, crea un "letrado negro" en sus textos autobiográficos pero al mismo tiempo se establece un pacto de lectura por el que su texto es el texto de un autor y de un personaje, un afrodescendiente libre que vivió durante las primeras décadas del siglo XIX en una Montevideo colonial y escribe "yo". De esta forma el relato de su vida se hace interesante como documento y también como una máscara que muestra lo dicho y lo no dicho por él y por sus contemporáneos, así como las valoraciones sociales que tanto ellos como nosotros hacemos en el presente sobre cuestiones como lo étnico-racial o el valor de la escritura y la lectura. Desde esta perspectiva analizaré los textos de Molina en relación a los textos mencionados, comenzando por los que corresponden al ámbito hispanoamericano que, además, casi coinciden en el tiempo histórico.

El orden colonial y el orden esclavista fueron puestos en cuestión por las revoluciones independentistas que estallaron en el ámbito hispanoamericano hacia $1810^{59} \mathrm{y}$ a partir de allí iniciaron un lento proceso de cambio. Las sociedades coloniales comienzan a proyectar e imaginar un nuevo orden social de corte nacional, soberano y hegemonizado por el Estado. La cuestión de los esclavos africanos o sus descendientes aparece como una paradoja difícil de resolver en el marco de la conformación de un cuerpo ciudadano soberano y libre. De allí las posturas ambiguas de las revoluciones independentistas que no abolieron la esclavitud. En su lugar crearon leyes de "vientres" (que liberaban a los hijos de esclavos nacidos a partir de la fecha de promulgación de las leyes) y endurecieron su postura frente al tráfico de esclavos. Pero en la práctica la esclavitud no fue abolida en varios de los países hispanoamericanos sino hasta 1850 aproximadamente. Aunque en

59 No olvidamos el caso de Haití, que unió la abolición de la esclavitud con la lucha independentista antes de 1810 . 
algunos, como Cuba dentro del espacio hispanoamericano o Brasil, ese proceso se cerró recién a fines del siglo XIX. ${ }^{60}$

En el caso de Manzano es necesario mencionar el contexto de un expediente armado por el escritor y propietario cubano Domingo del Monte para el inglés Richard Madden que incluye varios textos literarios que ficcionalizan un nuevo orden social y en el que la voz propia de los esclavos tiene un lugar central. Aunque el texto sirve a los fines del proyecto de Del Monte, también abre un espacio de enunciación no totalmente controlable por él y que incluso puede resultar amenazante para su proyecto (Ramos, 1996: 64). Muy distinto es el contexto de Jacinto Ventura de Molina, quien nació libre y fue educado por un militar español pobre, que no pertenecía a los "grandes de España" pero alcanzó una posición alta en la milicia y fue producto de la ilustración española. Molina no fue parte de ninguna táctica política liberal antiesclavista, aunque criticó la esclavitud. Era un hombre libre pero permaneció fiel a los principios religiosos y políticos de su tutor blanco (que actuaba como un amo) defendiendo la monarquía en tiempos en los que el proyecto independentista buscaba consolidarse. A pesar de estas diferencias con Manzano, el caso de Molina también desestabiliza el proyecto nacional en la medida en que asumir la letra lo "iguala" con los blancos, que lo rechazan, insultan o ignoran durante buena parte de su vida.

Son muchos los aspectos que acercan y muchos los que alejan a estos dos autores afrodescendientes. Todos ellos vinculados a dos espacios y tiempos coloniales muy distintos a pesar de compartir la dominación española. En Cuba, territorio colonial dedicado a la plantación extensiva de caña de azúcar, se introdujo un número importante de esclavos - en ascenso desde 1792, con más de 300 mil en 1830, y 436 mil en 1841 - cuyo

$60 \quad$ El desajuste entre las ideas liberales y el hecho de la esclavitud en la sociedad brasileña fue estudiado por Roberto Schwarz. Especialmente en el primer capítulo "Las ideas fuera de lugar” (Schwarz, 1981). 
crecimiento estaba directamente relacionado con el aumento de producción de azúcar (Benítez, 1977: 91). La separación entre el esclavo de ingenio y el esclavo de la casa era muy grande y el propio Manzano así lo expresa en su Autobiografía, cuando niega cualquier roce o contacto con otros esclavos. En Montevideo, a pesar de ser uno de los puertos "negreros" más importantes en América Latina, única puerta de entrada formal para el sur, los esclavos que llegaban a Montevideo cumplían tareas domésticas, se empleaban en obras edilicias y oficios artesanales así como en estancias para la actividad pecuaria, trabajos de mucho menor escala que los de la plantación extensiva o la extracción de minerales.

La brutalidad de la esclavitud no se opacó por estas características, pero las relaciones raciales fueron distintas en ambas zonas de Hispanoamérica. Una mayor flexibilidad legal y una proximidad con los amos dada por el trabajo doméstico caracterizaron la esclavitud y las relaciones raciales en el Río de la Plata. Por otra parte, hubo una mayor rigidez en Cuba relacionada no sólo con una implantación colonial que tenía ya tres siglos y que hacia 1830 era uno de las pocas colonias españolas en la región (en el Río de la Plata la colonización comenzó en el siglo XVIII) sino también con la cercanía de Haití y el miedo, siempre latente en la élite blanca, de un levantamiento esclavo e independentista que acabara con sus vidas.

La propuesta teórica sobre la autobiografía que se inicia a partir de Paul de Man, es decir, lo autobiográfico como ficción, como modo de lectura y como forma de conocimiento presentes en todo texto es la que habilita a comparar la Autobiografía de Manzano con aquellos pasajes autobiográficos que se encuentran en los manuscritos de Jacinto Ventura de Molina. En el caso de Molina no hay rastros de un conocimiento del género autobiográfico como se entedía en su época, aunque leyó a San Agustín, por lo que 
podemos suponer que la compulsión por narrar su vida tuvo diferentes objetivos, entre los más importantes legitimarse como letrado. En el caso de Manzano tampoco existe una gran consciencia del género pero por algunas de sus cartas, según Molloy (1996: 59-62), es posible advertir que la experiencia autobiográfica cambió la percepción de sí mismo y de su tutor Domingo del Monte.

La introducción de una reflexión sobre la autobiografía en el ámbito hispanoamericano, que pueda servir como marco de análisis del discurso autobiográfico de Molina y Manzano, tiene un hito en la publicación de Acto de presencia. La escritura autobiográfica en Hispanoamérica (1996 [1991]) de Sylvia Molloy. En la introducción la investigadora plantea que la autobiografía ha sido descuidada por los lectores y los críticos hispanoamericanos, y no porque no existan textos autobiográficos. Según Molloy, existen autobiografías en Hispanoamérica pero no han sido leídas autobiográficamente, "se las contextualiza dentro de los discursos hegemónicos de cada época, se las declara historia o ficción, y rara vez se les adjudica un espacio propio.” (12). Por lo que su trabajo ofrece claves para comprender estos discursos. En primer lugar que la autobiografía es una vida que se re-presenta, una construcción narrativa, un relato "que nos contamos a nosotros mismos, como sujetos, a través de la rememoración" o que nos cuentan o leemos cuando se trata de la vida de otro. Por lo tanto, afirma Molloy, la autobiografía "no depende de los sucesos sino de la articulación de esos sucesos, almacenados en la memoria y reproducidos mediante el recuerdo y su verbalización”. Pero el sujeto que escribe una autobiografía en el ámbito hispanoamericano, afirma Molloy, recurre "al archivo europeo en busca de fragmentos textuales con los que, consciente o inconscientemente, forja su imagen (16). Esta búsqueda en el archivo europeo, que Molloy ubica en lo estrictamente literario, tiene interés en la idea de la mimesis y la aculturación que planteaba más arriba, en la medida en 
que los dos afrodescendientes tuvieron modelos literarios europeos y también distintos hombres blancos europeos que fueron modelos morales. Aunque vivieron su situación desde perspectivas diferentes ya que Molina no vivió los conflictos con la esclavitud que vivió Manzano en Cuba.

La configuración de la relación amo-tutor/esclavo-alumno es muy distinta en ambos y está íntimamente relacionada con el modo en que aprendieron la letra. Tanto en Molina como en Manzano la mimesis con la cultura letrada del hombre blanco es determinante pero las situaciones de partida y los resultados son muy distintos. En los manuscritos de Jacinto Ventura de Molina hay varias escenas pedagógicas en la que el tutor blanco, el Brigadier español José Eusebio de Molina, pone mucho empeño en enseñar todos los aspectos de la cultura letrada española al niño Jacinto Ventura, empeño en el que también colaboran personas de su entorno (Gortázar, 2008: 31-34). Sin embargo en Manzano el acceso a la escritura es más conflictivo. Desarrolla un "dispositivo mimético" (Ramos: 61), una copia en base a residuos (Molloy, 1996: 72), en definitiva una treta del débil (Ludmer,1984: 47-59) que le permite, fuera de la mirada vigilante de su amo, a hurtadillas, adquirir la letra.

Las dos escenas originarias, que marcan el contacto con la escritura, presentan aspectos interesantes. Cuando hacia 1835 Manzano redacta su autobiografía para el grupo de Del Monte y para Richard Madden, aquel era esclavo y había publicado ya un libro de poesías y algunas obras en la prensa de Matanzas. Aún en una posición subordinada entre los letrados de la época, Manzano había accedido a la palabra escrita. Ninguno de sus dos intermediarios (Madden y Del Monte) le enseñó la letra, sino que supieron capitalizar las habilidades que Manzano había adquirido por sí solo. Del Monte fue su "mentor literario" y la persona que lo animó a escribir su autobiografía pero no su tutor. Manzano desarrolló 
algunas tácticas para entrar en el mundo letrado de los blancos. Lo hizo en primer lugar sirviendo a su amo, preparándole la mesa, el sillón y los libros con los que este se entregaba al estudio. A partir de allí, afirma Manzano, "me fui identificando de tal modo con sus costumbres que empecé yo también a darme estudios", comienza a leer y repetir “como el papagayo" (56) pero al no obtener nada útil de esa primera mimesis decidió aprender a escribir ${ }^{61}$ :

(...) compré mi taja pluma y plumas, compré papel muy fino y con algún pedazo de los que mi señor botaba de papel escrito de su letra lo metía entre llana y llana con el fin de acostumbrar el pulso a formar letras iba siguiendo la forma que de la que tenía debajo. Con esta invención antes de un mes ya hacía renglones logrando la forma de [la] letra de mi señor causa por [la] que hay cierta identidad entre su letra y la mía (Manzano:56-57. Énfasis mío) ${ }^{62}$

Copiando la letra de su amo a hurtadillas Manzano intenta romper el cerco que levantaron sus amos en torno a la cultura letrada, que Sylvia Molloy recapitula en su ensayo. Manzano memoriza en sus "cuadernos de la memoria" porque no puede conseguir libros y porque no puede escribir, de hecho precisó un permiso especial para poder publicar, años después, su libro. Como Molina se convierte desde niño en una "eficaz máquina de memoria" e incluso

61 En el original: “(...) biendolo qe. apenas aclaraba cuando puesto en pie le preparaba antes de todo la mesa sillon y libros $\mathrm{p}^{\mathrm{a}}$. entregarse al estudio me fui identificando de tal modo con sus costumbres qe. empese yo tambien a darme estudios (...) tomaba sus libros de retorica me ponia mi leccion de memoria la aprendia como el papagayo y ya creia yo qe. sabia algo pero conosia el poco fruto qe. sacaba de aquello pues nunca abia ocasión de aser uso de ello, entonces determiné darme otro mas util qe. fue el de aprender a escribir" (56-57)

62 En el original: “(...) compre mi taja pluma y plumas compre papel muy fino y con algun pedaso de los qe. mi señor botaba de papel escrito de su letra lo metia entre llana y llana con el fin de acostumbrar el pulso a formar letras iva siguiendo la forma qe. de la qe. tenía debajo con esta imbension antes de un mes ya asia renglones logrando la forma de letra de mi señor causa pr. qe. hay sierta identidad entre su letra y la mia” (Manzano: 57. Énfasis mío) 
cuando crea sus décimas debe memorizarlas. Para Molloy "Manzano está condenado a la oralidad: no en vano lo apodan Pico de oro" (Molloy: 70-71). El residuo y la mimesis a los que recurre sistemáticamente le permiten aprender a escribir: "se enseña a escribir con un sistema tan admirable como el utilizado para aprender a dibujar, recurriendo a un reciclaje de desperdicios igualmente creador. Compra pluma y papel muy fino y, rescatando papeletas estrujadas y anotaciones desechadas por su amo, las alisa, las coloca bajo una hoja transparente, y literalmente las calca (...)" (Molloy: 72). Pero el amo considera que no es útil para un esclavo escribir y se lo prohíbe. Es un pasatiempo y el esclavo tiene que ser productivo.

El crítico Julio Ramos llama “dispositivo mimético” (1996: 60-61) a esta técnica inventada por Manzano, esta "imbension" que no es la mera copia del mundo blanco, que Fanon valoraba negativamente en su estudio sobre la psicología del negro colonizado ${ }^{63}$ :

(...) La facultad mimética del subalterno produce en el amo una ansiedad insoportable: la sospecha de que el "espejeo" no era pasivo, y que la letra calcada trastocaba la estabilidad, los lugares fijos de la jerarquía, la economía de las diferencias que garantizaba los límites del sentido, la identidad misma del poder. (...) El desajuste que opera Manzano en la jerarquía no es simplemente el efecto de una rebelde reinscripción de su diferencia ni de una enfática afirmación de su "otredad" ante el poder. El desajuste tiene más bien que ver con la similaridad que en su consecuencia más extrema imposibilitaría el reconocimiento del "otro" en

63 Afirma Fanon en Pieles negras, máscaras blancas: "Para él [el hombre negro] hay un solo tipo de salida, que da al mundo blanco. De ahí esa permanente preocupación por llamar la atención del blanco, esa voluntad tenaz de adquirir las propiedades del revestimiento, es decir, la parte de ser y de tener que entra en la constitución del yo. [...] el negro intenta ingresar en el santuario blanco por el interior" (Fanon, 2009: 80). 
tanto función diferenciadora de la identidad del amo (1996: 61).

La copia de Manzano perturba el mundo blanco, su letra se parece a la del amo, y podría eliminar o pretender eliminar las distancias entre amo y esclavo. Así la escritura de Manzano se convierte en un peligro para la institución esclavitud. El dispositivo mimético de Manzano, su deseo del mundo letrado blanco, permitieron entre otras cosas que consiguiera su libertad.

El caso de Jacinto Ventura de Molina es diferente. Molina no era un esclavo en sentido estricto, jurídicamente hablando. Había nacido libre porque sus dos padres lo eran. Desde muy temprana edad el hijo de ambos africanos, que se mantuvieron al servicio personal del Brigadier, gozó de ciertos privilegios frente al amo, quien tomó muy en serio la tarea de educarlo, a pesar de la resistencia de algunos de sus contemporáneos. La letra para Jacinto Ventura fue acompañada de un proceso de aculturación que, según su relato, sus propios padres fomentaron. La mimesis hizo que Jacinto Ventura fuera un excelente reproductor de la cultura letrada española. Son muchos los pasajes en los que relata cómo "repetía" la lección, lo cual muestra la centralidad de la mimesis de la cultura blanca como única medida para sus deseos, al igual que Manzano. Al mismo tiempo, en ambos casos, escribir se convirtió también en una forma de subsistencia y de ganar los favores de otros tutores blancos. Todo eso contribuyó a obtener cierta autonomía como letrados: en el caso de Manzano comprando su libertad y en el caso de Molina, consiguiendo mediante la protección de hombres y mujeres blancos, acceso a la lectura, a la compra de papel o a los favores de las élites dirigentes.

A pesar de estar unidos por su mimesis con la cultura blanca dominante, son notorias las diferencias: Manzano, como esclavo, tuvo que robar la letra, copiarla a 
escondidas, tuvo que recurrir a su memoria para retener los textos que leía y los que inventaba; Molina era libre, aunque también atado al servicio de un blanco, pero obtiene un rédito de ese "servicio", esa moneda de cambio es la cultura letrada para la que es entrenado sistemáticamente durante las primeras dos décadas de su vida. La situación jurídica de ambos también es diferente y aunque ambos reciban el rechazo de sus comunidades, la cercanía con el tutor y el hecho de ser libre en el Río de la Plata muestran a Molina en un escenario menos hostil al de Manzano en Cuba compartiendo ambos el espacio doméstico con sus amos.

Pero, una vez aprendida la letra de sus amos por alguna forma de la imitación y asumiendo la cultura dominante, los usos que tanto Molina como Manzano le dieron a ese aprendizaje fueron muy diferentes. Se puede afirmar que en el caso de Manzano fueron otros quienes hicieron uso de su discurso autobiográfico mientras en el caso de Molina su historia de vida, a pesar de que nunca fue articulada como una autobiografía, fue utilizada por él a su gusto y para diferentes fines. En ambos casos escribir sobre sus propias vidas, de algún modo controlarlas al controlar su relato, hizo que cambiara su relación con los otros, principalmente blancos en posiciones dominantes. Si bien hay muchos aspectos interesantes en ambos autores, uno de ellos es la representación del cuerpo que en Molina es casi inexistente y en Manzano es constante y coincidente con el deseo de Del Monte y Madden de mostrar las atrocidades de la esclavitud. La Autobiografía de Manzano fue sometida a múltiples apropiaciones. Su lugar en el canon literario cubano y latinoamericano ha concitado la atención de la crítica y muchos análisis pormenorizados de este hecho. La situación de Molina es diferente dado que sus manuscritos permanecieron casi en su totalidad inéditos y la crítica fue indiferente a ellos hasta hace pocos años.

La Autobiografía de Manzano es un texto elaborado a solicitud de Domingo del Monte, 
quien preparó un dossier sobre la esclavitud en Cuba para Richard Madden, un funcionario inglés llegado a Cuba en 1836 y que

(...) frecuentó muy pronto el grupo de la sección de Educación de la Sociedad Económica, de la que Del Monte, al igual que José de la Luz y Caballero, José Antonio Saco y Nicolás Escobedo, formaban parte. Nombrado ese mismo año Superintendente de Africanos Liberados y Comisionado ante el Tribunal Mixto de Arbitraje en Asuntos de la Trata, cargo creado por el tratado de 1835 entre España e Inglaterra (Macchi, 2007: 64).

Manzano escribió este texto en dos partes, la primera abarcaba sus primeros años de vida hasta que escapa para encontrar amos menos despóticos, la segunda parte abarcaba el período posterior a su escape hasta que obtiene la libertad. Esta segunda parte permanece hasta hoy perdida. Hasta 1937, año en el que la Biblioteca de Cuba publica el texto original, no había otra forma de conocerlo que no fuera a través del texto de Richard Madden, quien lo tradujo al inglés en 1840 (Madden, 1840).

En la publicación en español de 1937 la Biblioteca Nacional de La Habana publicó, además del texto original de la autobiografía, los poemas y algunas cartas de Manzano a Madden que fueron analizadas por Molloy. Basada en dos cartas en las que Manzano hace referencia a su proyecto, la investigadora sostiene que la escritura de la autobiografía provocó un cambio significativo. En la primera carta del 25 de junio de 1835 Manzano se muestra ansioso porque debe escribir un texto para el que no está entrenado. La autobiografía supone salirse de su lugar de poeta epígono del neoclasicismo español para el 
que estaba siendo formado por Del Monte. Pero en una segunda carta fechada el 29 de septiembre de 1835 ya no aparecen "la ansiedad y el desconcierto" sino que "hay decisiones”. La primera y más importante: la de guardarse para sí algunos sucesos para construir una novela, es decir, Manzano selecciona los hechos que quiere hacer públicos y guarda otros para fines propios. La primera carta demostraba sumisión a su tutor, afirma Molloy, la segunda "resistencia". En tres meses Manzano cambia el concepto de lo que puede ser más interesante para su texto “está valorizando otra cosa dentro de sí además del relato de sus desgracias, y esa otra cosa más interesante no se regala” (Molloy: 62). Manzano nunca dio forma visible a esa otra cosa (esos hechos que guardó para escribir una novela cubana) por lo que Molloy, siguiendo una lectura deconstruccionista propone "que esa otra cosa está presente y marca toda la autobiografía, desde el momento en que la resistencia al otro (o sea, la diferenciación con respecto al otro) reemplaza la capitulación ante el otro" (Molloy: 62).

Pero más allá de estas resistencias, el texto de Manzano fue manipulado primero por Del Monte, luego corregido por Suárez y Romero y finalmente traducido por Madden. Molloy compara el texto publicado en 1937 con la traducción de Richard Madden y encuentra diferencias sustanciales. Para empezar es un libro firmado por Richard Madden cuyo título-Poems by a slave in the island of Cuba, recently liberated...- apunta en primer lugar a la poesía de Manzano. Segundo, según Molloy el traductor no respetó el orden en que Manzano elaboró su relato y suprimió aquellos pasajes en los que el esclavo no hablaba tan mal de sus amos, resaltando solamente aquellos que mostraban a sus amos cometiendo actos de arbitrariedad y violencia contra sus esclavos. Sin embargo, a Molloy estas supresiones "realizadas de acuerdo a un marco ideológico bien definido" (Molloy: 66) no le parecen las más interesantes sino aquellos pasajes referidos a los afanes y anhelos 
de Manzano “eliminados por razones que sólo se pueden conjeturar” (Molloy: 66) pero que son decisivos para entenderlo como hombre y como autobiógrafo en sus relaciones con la escritura y los libros por ejemplo (Molloy: 67).

Finalmente, cuando se publican los papeles de Manzano en 1937, este es otra vez apropiado por su prologuista José Luciano Franco, quien interpreta la escena de 1836 en la que Manzano lee su poema "Mis treinta años" en la tertulia de Domingo del Monte. Este hecho inició la campaña por la compra de su libertad. Franco presenta este hecho como un hito “que señala en el camino de la historia la bifurcación de rutas diversas, el comienzo de una era fraternal e igualitaria para todos los cubanos: blancos y negros" (Franco, 1937: 10). El hecho se transforma entonces en el "origen" del acercamiento solidario de letrados blancos y letrados negros, lo que expresa claramente unas páginas más adelante:

El ascenso de Manzano hasta aquel cenáculo, viniendo como venía de las vilezas de la vida esclava, nos parece, al dibujarse el acto en la histórica lejanía del recuerdo, como el primer gesto firme y honrado por la incorporación definitiva del negro a la vida cubana, iniciándose el camino por el cual pronto dejaría de ser un intocable maldito (Franco: 20. Énfasis mío).

Para Franco la entrada al mundo blanco representa un ascenso para Manzano y es una metáfora que se repite cuando interpreta sus poemas como una elevación "al plano de un artista de méritos propios" (Franco: 27). Si Richard Madden consideraba el relato de la vida de Manzano como "representativo" de la vida de todos los esclavos cubanos, Franco construye una víctima, un héroe romántico aislado y silenciado por "la desconsoladora 
barbarie de la discriminación racial y de la explotación del hombre por el hombre" (32). Otra vez la escritura de Manzano es arrancada de sus condiciones de producción y apropiada para fines distintos a los originales. Nada indica, excepto aquella carta enviada a Del Monte, que Manzano pudiera usar su autobiografía libremente, lo cual resulta de las condiciones en las que el texto fue producido.

Los manuscritos de Jacinto Ventura de Molina, producidos entre 1817 y 1837 muestran problemas diferentes en torno a su forma de escribir "yo" y a su relación con otros letrados. En primer lugar Molina era un afrodescendiente libre, su padre y su tutor murieron el mismo año de 1782 cuando tenía 16 años y si bien mantuvo ciertas formas de servidumbre con antiguos amigos de su tutor, hizo su trayectoria como militar, zapatero, escritor y abogado. En 1817, con la ocupación de la Banda Oriental por los luso-brasileños, Molina escribe y consigue los favores de quien comandaba dicha ocupación militar, el Barón de Laguna Federico Lecor. Y precisamente es su historia personal junto al español lo que utiliza para llegar a ese mundo blanco que lo rechazaba. En incontables oportunidades Molina debe probar sus conocimientos letrados y para ello da testimonio, dado que no tiene papeles que prueben sus habilidades. ${ }^{64}$

Entre 1827 y 1830 Molina escribe lo que parece ser su única obra pensada como libro Las Glorias de la Santa Caridad de Montevideo. También en este texto hay muchos pasajes clasificables como "autobiográficos". Me interesa destacar los pasajes en los que Molina confronta con Tomás García de Zúñiga, uno de los hombres más ricos y con mucho poder político de la sociedad montevideana. Al parecer García de Zúñiga acusó a Molina

64 Es el caso de un texto fechado en 1817, titulado "Primer memorial histórico al Barón de la Laguna, Capitán General de las fuerzas de mar y tierra, a Don Juan VI, rey de Portugal y Don Pedro I, emperador de América" (Manuscritos, T. II, f. 1v a 9r), en el que Molina explica cómo era posible que dibujara planos (con reglas) y que escribiera algunas piezas literarias dedicadas al Barón, al Rey de Portugal y al Emperador de Brasil. Allí relata los principales hitos de su trayectoria e introduce una tabla cronológica con los conocimientos que fue adquiriendo. 
de estar loco y por esa razón este pide una indemnización a las autoridades. Más allá de la anécdota, cuyo origen es una pelea entre ambos que data de 1815 en la que Molina se negó a incorporarse al ejército revolucionario, es interesante analizar cómo introduce un pasaje de su autobiografía para defenderse de la acusación. En esta oportunidad recuerda una frase que el militar español le dijo en su lecho de muerte, y que repitió en muchos otros documentos: "Acuérdate que naciste en mi casa y cualquier defecto tuyo se hace atribuir a la mala crianza que te he dado" (Gortázar, 2008: 63-64). De manera que el argumento de Molina era que si él estaba loco también lo había estado su tutor español y esto era un insulto imperdonable. Otra vez Molina pone en juego su historia personal y la identidad con su tutor para solucionar problemas que lo aquejan en el presente. Puede verse el uso táctico que Molina le da a la autobiografía, manipulando hechos e historias que en diferentes situaciones le permiten defenderse e incluso atacar a sus adversarios o bien conseguir algún beneficio de quienes detentan el poder.

Al igual que Manzano el aprendizaje de la letra y la reflexión sobre sí mismo hicieron que Molina se destacara entre sus pares, y sobre todo que fuera consciente de su excepcionalidad. Así lo expresa en las Glorias de la Caridad al asegurar que sus textos tienen "otro adjetivo" por haber sido escritos por un negro. O cuando dirige una carta al papa Gregorio XVI en 1833, afirmando que "se ignora que en todo el mundo antiguo algún negro haya dictado, discurrido o creado alguna cosa" (M, III: f 274 r) ${ }^{65}$ A diferencia de Manzano, que tiene una tertulia de intelectuales que lo anima y lo valora, Molina tendrá que lidiar con lo que su excepcionalidad provoca entre los letrados blancos e incluso tender a la megalomanía, en lo que parece una treta del débil que utiliza para poder sobrevivir a las burlas e insultos, al desprecio, al silencio o a la desidia.

65 $\quad$ En el original: "Quando se ygnora, que en todo el mundo antiguo, algun negro aya dictado, discurrido, ò creado alguna cosa” (M, III: f 274r). 
Los discursos analizados hasta ahora le dan la razón a Frantz Fanon cuando afirmaba que solamente había una puerta de salida para el hombre negro que desembocaba en el mundo blanco (Fanon, 2009: 71), aunque es cierto también que esa puerta de salida tuvo formas diversas y que los resultados no pueden ser evaluados finalmente como una mera copia del mundo blanco. Fanon escribía desde París sobre la situación colonial de Martinica, la isla del Caribe francófono de donde provenía, pero la dispersión de los africanos y sus descendientes por todo el Caribe y la costa atlántica hizo que las experiencias históricas de esos hombres variaran sustancialmente de lugar en lugar.

La afirmación es válida para el siglo XIX, tal vez para la primera mitad, y una parte del siglo XX, porque a partir de la poesía mulata de Nicolás Guillén y la negritude de Aimé Cesaire, los afrodescendientes iniciaron un largo proceso de afirmación de sus propios valores culturales, ya intervenidos por su pasaje y transculturación en América Latina. En las primeras décadas del siglo XIX, dos hombres negros -el uno cubano, el otro uruguayoescribieron sobre sus experiencias y compartieron tácticas miméticas para hacerse de la cultura letrada blanca. Pero los contextos de enunciación (Cuba y Montevideo) hicieron muy distintas sus formas de apropiación: Manzano se la roba a su amo calcándola de trozos de papel tirados a la basura, Molina es educado sistemáticamente por su tutor.

Estos hombres escribieron sobre sí mismos marcados por experiencias disímiles: Manzano por la esclavitud que niega la humanidad al "negro" y Molina por la libertad en una sociedad racista que lo ignora o se burla de él. La suerte de sus escritos fue diversa. La Autobiografia de Manzano estuvo marcada por sucesivas apropiaciones, Manzano no tuvo control sobre su propia historia en el papel ni sobre la autoría de su texto. A pesar de eso quedan algunos rastros en la historia del impacto que tuvo escribir sobre sí mismo. Su texto ingresó al canon de la literatura nacional cubana de la mano de estas apropiaciones. Por el 
contrario Molina tuvo un control absoluto sobre sus papeles, utilizó el discurso autobiográfico con mayor libertad e hizo un uso táctico de sus recuerdos y su pasado. Pero su suerte fue la peor desde el punto de vista de su ingreso al canon literario uruguayo, cuyos historiadores y críticos fueron indiferentes a su escritura.

Los textos comparten una ortografía y una sintaxis que los hace difíciles. Son marcas de formaciones deficitarias, relacionadas con lo étnico-racial y la clase, que originaron correcciones de estilo o exclusiones de las respectivas literaturas nacionales. Algunos autores encuentran en los textos de Manzano "conciencia de su africanidad" (Lewis-Galanes: 91) y en los de Molina una escritura negra que media entre "clases populares y distintos niveles de poder" (Acree y Borucki, 2008: 45 y también Acree, 2010: 49-64). Tanto en Molina como en Manzano la "africanidad" es negada para encajar en el mundo blanco y pertenecer a la cultura letrada. La mediación de Molina lo acerca a las clases populares aunque no debe confundir al analista en la medida en que las representa desde la perspectiva de la cultura dominante. 


\section{Escribir "yo" en el contexto anglosajón: una perspectiva comparada}

El comienzo de una "literatura afroamericana", según Mary Louise Pratt (1997), puede ubicarse a fines del siglo XVIII, cuando un conjunto de ex esclavos entraron "en los circuitos de la cultura europea impresa". La autobiografía de ex esclavos fue el género más utilizado por el movimiento abolicionista y su publicación fue alentada por "intelectuales occidentales disidentes". Estos textos eran, según Pratt, "autodescripciones estructuradas en cierto modo según las instituciones literarias occidentales y las concepciones occidentales de la cultura y el yo, aunque en directa oposición a las ideologías oficiales del colonialismo y la esclavitud" (1997: 184). ${ }^{66}$ A partir de 1807 Inglaterra prohíbe la trata de esclavos, luego de haberse enriquecido como única proveedora de esclavos para América con el tratado de Utrecht en 1713, y se convierte en una de las usinas del abolicionismo y de su literatura, aunque el fenómeno se extiende a Europa en general y los Estados Unidos. Según Costanzo el período de mayor actividad para la publicación de autobiografías fue entre 1830 y 1850 (116). El contraste del espacio anglosajón con el hispanoamericano en la producción de autobiografías de esclavos o ex-esclavos es muy grande y se explica en parte por esta lucha global contra el comercio de esclavos en la que España, Portugal y luego las naciones independientes están directamente involucrados. La prohibición de escribir y las limitaciones para publicar, como indican los dos casos hispanoamericanos analizados, fue otro factor determinante.

Posiblemente el género autobiográfico fuera más eficaz para los lectores metropolitanos que la literatura de viajes, ya que los vejámenes de la trata que allí se

66 En su artículo Susan M. Marren (1993) menciona a Olaudah Equiano como el más destacado de los escritores africanos de Inglaterra en el siglo XVIII. Los otros dos son: Ignatius Sancho (1729-1780), a quien le publicaron una colección de cartas con cinco ediciones entre 1782 y 1803; y Ottabah Cugoano (1757-?) y su Thoughts and sentiments on the evil of slavery en 1787(95 y 104 -nota a pie 3-). 
relataban eran descritos en primera persona. Sin embargo, ambos géneros contribuyeron a la empresa de la "vanguardia capitalista", fundamentalmente británica, que viajó a los países hispanoamericanos en busca de recursos naturales para su explotación (Pratt, 2007: 257). ${ }^{67}$ Estos viajeros tuvieron el interés de acusar a la sociedad hispanoamericana "de atraso, indolencia y, sobre todo, de «incapacidad» para explotar los recursos naturales" (265). El trato brutal hacia los esclavos, la esclavitud misma, chocaban ahora con el “escenario de trabajo y eficiencia" propuesto por la vanguardia capitalista, que implicaba además el trabajo libre y asalariado (270). La lectura de las autobiografías no solamete alentaba la identificación con la causa abolicionista, también promovía las virtudes de la libertad individual tan cara a la ideología liberal. Así Madden toma la autobiografía de un esclavo cubano y la lleva a Londres, la traduce y la hace circular. Pero qué pasa con los esclavos del ámbito anglosajón, cuáles son las similitudes y diferencias con los relatos del ámbito hispanoamericano ya analizados.

Me referiré aquí a dos textos publicados en inglés: The interesting narrative of the life of Oludah Equiano or Gustavus Vassa, the african de Oludah Equiano (publicada en Londres en 1789) y Biography of Mahommah G. Baquaqua. A native of Zoogoo, in the interior of Africa editado por Samuel Moore (publicado en Detroit, EE.UU. en 1854). E1 texto de Baquaqua fue traducido parcialmente al portugués en 1988, casi exclusivamente en aquellos fragmentos relacionados con su pasaje por Brasil, dado que se trata de una publicación de la Revista Brasilera de Historia ${ }^{68}$ El texto de Euquiano, sin embargo, sí es manejado en su edición original, tal como apareció en la última edición en vida del autor

67 Marren (1993) aporta otro elemento sobre el público inglés del siglo XVIII y la tendencia filosófica del "benevolismo" que estaba contra la esclavitud basados en la lástima y la compasión "más que en las clásicas nociones de razón y derecho" (97). Las revistas y este tipo de textos prepararon al público de clase media inglés del siglo XVIII para la "humanización de los negros" que, a lo largo del siglo, irá aceptando el discurso de "los derechos naturales de todo ser humano" (97).

68 Existe una versión completa de sus memorias en el sitio web http://abolition.nypl.org/, el proyecto "The abolition of de slave trade" de la Biblioteca Pública de Nueva York. 
en 1794. Ambos textos presentan similitudes y diferencias con los textos de Manzano y Molina. El texto de Equiano pertenece al siglo XVIII e ingresó al siglo XIX, según su editora contemporánea Shelly Eversley (2004), de mano de los liberales como "la primera justificación para el fin de la esclavitud" (xxiv). El texto de Baquaqua fue publicado en 1854 por Samuel Moore, quien escribió gran parte del texto en tercera persona, alternando con la primera persona del testimonio oral del esclavo, para proporcionar información adicional o aclaratoria. Entre los dos abarcan el período de Jacinto Ventura de Molina y en tal sentido la comparación resulta pertinente y productiva.

El primer contraste que surge de los relatos autobiográficos hispanoamericanos es el silencio sobre el pasado africano y cualquier recuerdo de la trata. En el caso de Molina apenas una mención respecto al origen de su padre, nacido en un barco negrero que venía de Bahía y en el caso de Manzano el silencio absoluto. En las dos autobiografías publicadas en el espacio anglosajón, al tratarse de relatos de ex esclavos de origen africano, la existencia de capítulos introductorios relatando "los usos y costumbres" de las zonas de donde provenían, así como la captura y el viaje hacia América aparecen como momentos fundamentales del discurso. En el caso de Equiano el primer capítulo lo dedica a su lugar de origen y su cultura, el segundo a su captura y posterior traslado, y recién en el tercero inicia su relato como esclavo. La autobiografía de Baquaqua tiene una estructura similar, aunque dedica seis de los siete capítulos a describir la vida antes de la trata. Este desbalance se debe en principio a que el africano no aparece como el autor del texto sino Samuel Moore, como indica en el título descriptivo del relato: "escrito y revisado" por Moore "de las propias palabras" de Baquaqua. En este aspecto estas autobiografías no se diferencian de la literatura de viajes en la medida en que muestran un paisaje (territorio y sociedad) exótico para el lector metropolitano. Otro elemento a tener en cuenta como 
diferencia sustancial es la trayectoria de los dos ex esclavos en el espacio anglosajón. Mientras Manzano y Molina son esclavos de la casa, hombres obligados a servir en tareas domésticas, Equiano y Baquaqua pasan cortos períodos de tiempo en tierra y son marineros o viajeros, escapados (Baquaqua) o que compran su libertad, con el dinero que obtienen de su propio esfuerzo individual (Equiano).

El caso de Baquaqua, como el de la primera versión del texto de Manzano hecha por Madden, plantea la cuestión de la mediación blanca, letrada, en la confección de estos textos autobiográficos. Costanzo (1990) hace referencia a la mediación letrada en la mayoría de los textos autobiográficos. Da cuenta de la interpretación de John Sekora quien argumenta que la presencia de otra persona, un blanco que "ordena la narración”, se aleja de la idea de la creación de un "yo" (117). Según Costanzo, Sekora argumenta que el yo de la autobiografía se crea "en el acto de escribir, no antes" y por lo tanto que exista una base testimonial, como en el caso de Baquaqua, impide que podamos llamar a estos textos autobiografías. Costanzo argumenta que el hecho de la mediación blanca "no quiere decir que el narrador negro mientras escribió o contó su historia de vida no haya sido capaz de forjar su identidad y practicar ser fiel a él mismo dentro de los límites del diseño blanco que lo recluye" (117-118). La experiencia del género testimonial en la literatura latinoamericana ofrece problemas similares a los planteados en el ámbito anglosajón para las autobiografías de esclavos. La presencia de un letrado solidario es fundamental para hacer inteligible a un público mayor la experiencia de un otro (sea este afrodescendiente, mujer, indígena o pobre), cuya historia puede ser además representativa de un colectivo mayor. También en este debate la crítica latinoamericana ha fluctuado entre posiciones favorables y desfavorables a la mediación letrada. ${ }^{69}$ Es posible excluir de este problema las

69 Para ver las diferentes lecturas posibles sobre el testimonio ver Achugar (1994a) y Achugar y Beverly (1992). En esta última Antonio Vera-León plantea, para el caso de Biografía de un cimarrón, que "la 
narraciones de sí mismos que hacen tanto Molina como Manzano (en su versión en español de 1937, no la de Madden) y Olaudah Equiano. Las mediaciones que los hacen inteligibles a la comunidad letrada tienen otras características.

Un aspecto central y común a los relatos autobiográficos es el proceso de aculturación y la miemesis con el mundo blanco a la que son sometidos los ex esclavos y los negros libres (como Molina). Mientras Molina y Manzano son obligados a convertirse al catolicismo, incluso por ley son los amos quienes están obligados, los casos de Equiano y Baquaqua son distintos. En el caso de Baquaqua hay dos situaciones relatadas la primera tiene que ver con su contacto con el catolicismo, cuando él y otros esclavos son obligados por su amo portugués a hacer la señal de la cruz y decir unas palabras "cuyo significado no sabíamos" (1988: 274 y 2001: 45). La segunda es su contacto con el cristianismo, específicamente con el misionero de la Iglesia Bautista Reverendo Judd en Haití, que lo sacó de la bebida y "de todo otro vicio" (2001: 58). En contraste con la imposición de su amo portugués de orar y hacer la señal de la cruz, su "conversión" a la Iglesia Bautista parece una elección tomada libremente. La conversión de Equiano al cristianismo se produce en Londres, cuando otros sirvientes le hacen notar que si no es bautizado no iría al cielo. Por tal motivo pide para ser bautizado (Equiano, 2004: 62) y su amo se lo niega hasta que accede en febrero de 1759 (63). Equiano es formado en la iglesia protestante y cuando en 1775 pasa por Cadiz conoce un cura católico con quien discute de religión. Como en el texto de Baquaqua, Equiano contrasta el catolicismo con su opción religiosa: “él decía que había estado en Inglaterra, y que toda persona allí leía la Biblia, lo cual estaba muy mal” (2004: 210). Otra vez su “conversión” a la religión está relacionada con

posición del trascriptor (...) respecto al relato oral no es la de salvarlo sino la de violentarlo, traduciéndolo a los códigos de la cultura escrita y haciendo que el sujeto oral los adopte como los únicos capaces de narrar autorizadamente (191). Sin plantear la transparencia o inocuidad, otros autores han hecho énfasis en los efectos de la mediación letrada. Al respecto ver Achugar (1994b) y Yúdice (1992). 
intereses individuales y es contrastada en el relato, con la verticalidad del catolicismo español o portugués.

También la educación es una decisión personal de Equiano, quien decide, luego de convertirse al cristianismo, "trabajar para sí mismo" y conseguir dinero para "obtener una buena educación" (78). Sus primeras lecciones las tiene a bordo del barco Atna con el cura del capitán quien "me enseño a escribir, y me dio nociones de aritmética hasta la regla de tres”. Allí también conoció a Daniel Queen, un hombre de unos cuarenta años “con quien comía a bordo del barco, y que le gustaba vestir y atender al capitán”. Con este hombre tuvo una relación muy cercana y le eneseñó “a afeitar y arreglar el pelo un poco, también a leer en la Biblia, expicándome varios pasajes, que yo no comprendía”. Tuvo con él una relación en la que lo amó casi con el afecto de un hijo" (79). A diferencia de Manzano que tuvo que robar la letra, de Molina que no tuvo otra opción que aprender o de Baquaqua que no escribe ni aprende a escribir aunque se adaptó rudimentariamente a las lenguas con las que tuvo contacto (portugués e inglés, al menos), Equiano aprende por una decisión personal y un cálculo de interés: lo ve como parte de su esfuezo individual por ascender socialmente. $^{70}$

Antes de relatar su bautismo en Londres, Equiano coloca una escena de mimetismo en su autobiografía. En el capítulo dos de su autobiografía comienza haciendo referencia al miedo que tenía de los europeos: "ya no los veía como espíritus, sino como hombres superiores a nosotros; y luego tuve el más fuerte deseo de parecerme a ellos: asimilar su

70 Costanzo (1990) relata el caso del esclavo jamaiquino, Archibald Monteith, cuya autobiografía fue publicada en 1864 en Alemania y 1865 en Gran Bretaña, que estuvo como sirviente de la casa durante ocho años hasta que su amo lo envió a la escuela. Según Costanzo fracasó porque "los blancos no infundían en los esclavos el valor de una educación cristiana”. Por suerte, afirma Costanzo, Monteith aprendió a leer gracias a una mujer blanca y recibió por ello las burlas de otros esclavos por querer leer (125). Como en el caso de Molina, la intermediación blanca, movida por la piedad cristiana, es fundamental para la educación. Sin embargo, no parece haber testimonios de otros negros (esclavos o libres) que se hayan burlado de las capacidades de Molina. No ocurre lo mismo con el mundo letrado al que quiso pertenecer. 
espíritu e imitar sus modales", a tal punto que "desee largamente ser capaz de leer y escribir; y para ese propósito tomé cada oportunidad de ganar instrucción" (62. Énfasis mío). Otra vez el relato de Equiano parte de sus intereses y no de una imposición. No es obligado a imitar a los ingleses, él decide imitarlos porque los cree hombres superiores. En el caso de Baquaqua la imitación es también una imposición como en Manzano, aunque la referencia a la señal de la cruz y las palabras que no entiende, es la única que evidencia una escena de imitación colonial.

El caso de Oludah Equiano está relacionado con Manzano y Molina en un aspecto central vinculado con la mimesis colonial. Como dobles disciplinarios son a la vez copia y amenaza (Bhabha) y por lo tanto generan desconfianza del mundo letrado blanco. Equiano ha tomado la palabra y ha escrito la narración de su propia vida. Aún así se cuestiona su autoría e incluso algún contemporáneo sugirió que había sido ayudado por "algún escritor inglés" en la compilación del material o en la corrección del texto, ya que "estaba suficientemente bien escrito" (xxxvi). ${ }^{71}$ Cuál sería la reacción del lector-letrado de fines del siglo XVIII al encontrar en el interior del libro la ilustración de un hombre negro, vestido como ellos, con un manuscrito en la mano. La reacción de desconfianza que tiene su contemporáneo se parece a la que décadas después muchos letrados montevideanos tuvieron con Jacinto Ventura de Molina. La diferencia radica en la burla sistemática de la que fue objeto el montevideano, frente a la desautorización y el trato condescendiente de un crítico. $^{72}$ Frente a la megalomanía del montevideano, Equiano no quiere demostrar

71 Según Shelly Eversley el texto de Equiano tuvo nueve publicaciones entre 1789 y 1794, en las que el autor fue agregando noticias, cartas y reseñas de su libro. En estos anexos es que se publica una nota del Monthly Review de junio de 1789 (página 551) en el que un crítico anónimo inicia la reseña afirmando: "We entertain no doubt of the general authenticity of this very intelligent African's story; though it is not improbable that some English writer has assisted him in the compilement, or, at least, the correction of his book; for it is sufficiently well-written." (xxxvi)

72 Al parecer las burlas fueron frencuentes en la vida de los africanos sometidos a la esclavitud. Según Costanzo en su autobiografía Archibald Monteith relata cómo su casamiento autorizado legalmente y llevado a cabo en una iglesia, siguiendo el ritual cristiano, fue "estropeada por una multitud" que se reía y 
heroísmo o coraje, aún cuando se presenta como único y original, utiliza su propia historia como "emblema para el desarrollo de todos los sujetos modernos" ¿o de todo sujeto moderno? (VII). Por tal motivo, dice su prologuista Reid-Pharr, desprecia la esclavitud pero está más interesado en mostrar la transición que experimentó del mundo antiguo -apegado a la tradición y estático- a "los modos de vivir dinámicos y motivados por el progreso que él creyó eran típicos de las sociedades modernas” (VIII).

No se trata, como en Molina, de un hombre que reclama un trato especial por los méritos alcanzados junto a un tutor que lo cobijó y lo hizo quien es. La historia de Equiano, sugiere Reid-Pharr, "detalla los esfuerzos, las frustraciones, y las concesiones no de un simple esclavo, un marinero, o incluso de un hombre liberado, sino, y fundamentalmente, de un moderno intelectual (negro)" que, a diferencia de Molina, se encuentra en la "más paradójica realidad de que la misma sociedad que lo reprime también lo provee con las herramientas con las que resistir la opresión, las herramientas con las que deberá rehacerse y rehacer la sociedad misma" (XX). El individuo emprendedor del capitalismo que Equiano encarna, no se queja de lo que ha perdido y prueba que el más reprimido de los sujetos -un esclavo- puede verse obligado a cambiar permanentemente, cambiar de ambiente, viajar y adaptarse a las nuevas condiciones rápidamente (XI). En este aspecto reside tal vez una diferencia sustancial con Manzano y Molina, quienes en algunos momentos aprovechan su lugar de víctimas indefensas, de indigentes o de personas sin ninguna ambición.

Tanto Molina como Equiano son autores especialmente ambiguos, sus textos están llenos de tensiones o contradicciones. En Molina al lado de las fórmulas de captatio benevolentiae encontramos sus gestos de grandeza, su insistencia en ser "negro" y su 
pertenencia a la cultura española. Algo similar ocurre con Equiano. Según Marren (1993) su texto "es un registro de su intento por crear (...) un lenguaje en el que él pudiera hablar con autoridad dentro de la cultura inglesa [pero] como un miembro típico del grupo esclavizado" (96). La autobiografía de Equiano vive, según Marren, en esta tensión o contradicción. Siguiendo a Orlando Patterson en su idea de que "desde el punto de vista de un orden social dado" un hombre libre y un esclavo ocupan un mismo lugar "liminal", incluso entre las alianzas políticas, Marren afirma que el texto de Equiano está "marcado por la ambigüedad, la ambivalencia y la contradicción” (96). Este mismo lugar liminal también le corresponde a Molina, aunque sea no un hombre liberado sino un hombre libre, pero colocado en un lugar similar por el color de su piel. Su actuación como abogado del grupo Congos de Gunga hacia 1830 lo muestra en esa frontera entre los blancos y los negros, entre la ciudad letrada y la cultura de los iletrados, porque es quien puede articular la demanda del grupo en el lenguaje jurídico de los blancos.

Por último, quiero destacar un elemento que la editora del texto de Equiano, Shelly Eversley, menciona fugazmente: los abolicionistas norteamericanos utilizaron el texto de Equiano como "la primera justificación para el fin de la esclavitud" (xxiv). Lo cual ayuda a pensar por qué razón el texto de Manzano tuvo la misma suerte y fue sucesivamente recuperado por los cubanos y los latinoamericanistas mientras los textos de Molina permanecieron inéditos y casi completamente desconocidos en Uruguay. Mientras las historias de Equiano y Manzano mostraban el relato de esclavos que alcanzaban su libertad y se convertían en ciudadanos modelo para el pensamiento liberal, Molina ataca la esclavitud desde el punto de vista del catolicismo. Su justificación de la igualdad se basaba en el Nuevo Testamento, como afirmaba en sus Glorias de la Santa Caridad: “(...) aunque gracias a Dios [los negros] somos hombres como ellos redimidos con la Preciosísima 
sangre de mi Señor Jesucristo" (Manuscritos, Tomo I, f 19v). Con una argumentación así, no se podía esperar que los liberales tibiamente abolicionistas de las primeras décadas del siglo XIX uruguayo recuperaran sus textos o apenas los mencionaran en sus argumentaciones. La historia de Equiano sin embargo muestra al individuo que necesita el capitalismo central, emprendedor, que fruto de sus méritos y esfuerzos logra su empresa: su emprendimiento económico y su libertad están ligados indisolublemente ya que trabaja para obtener su libertad y ser un ciudadano libre.

Aunque Jacinto Ventura de Molina no escribió una autobiografía sí utilizó el discurso autobiográfico para distintos fines. En el ámbito hispanoamericano, a diferencia del ámbito anglosajón, las autobiografías no abundan. Apenas Juan Francisco Manzano escribió una autobiografía, publicada y manipulada por un liberal abolicionista como Richard Madden en 1840. Los textos “autobiográficos” de Molina se suman al de Manzano para dar una perspectiva más amplia de la vida de los afrodescendientes en América Latina a través de sus propios testimonios. El caso de Molina presenta características distintas a las de Manzano porque no ha pasado por la esclavitud, aunque se ve envuelto en relaciones de servidumbre que hacen algo ociosas las diferencias entre hombres libres (con la piel negra), esclavos y libertos. Escribir "yo" en estas condiciones acerca las distintas historias de vida, pero muestra también muchas diferencias. Los procesos de aculturación, la incorporación problemática a las nuevas sociedades, las dificultades para acceder a una alfabetización mínima, las diferentes formas del rechazo a la integración se configuran de una manera particular en distintos ámbitos geográficos (latinoamericano y anglosajón).

El lugar fronterizo o liminal de cada uno de estos individuos ofrece distintos niveles de análisis. El tránsito de sociedades africanas a las sociedades occidentales, la conversión 
al cristianismo, la lucha abolicionista, la entrada a la ciudad letrada son algunos de los problemas que presentan estos casos. El pasaje de la enunciación de un "yo" a la representación de un colectivo tiene, desde esta perspectiva, una gran importancia. No se trata del significado que los lectores pudieron dar a un caso individual, como representación de un colectivo (los esclavos, por ejemplo) como puede pasar con el caso de Olaudah Equiano, sino al hecho de que Jacinto Ventura de Molina representó a un colectivo negro frente a las autoridades estatales y este situarse en un lugar intermedio habilita a pensar una nueva dimensión de su trayectoria como letrado. 


\section{CAPÍTULO IV}

\section{Intermediar, representar: Jacinto Ventura de Molina entre esclavos}

En el capítulo XXXII de El siglo de las luces (1962) Alejo Carpentier presenta un diálogo entre cuatro personajes: el Abate Brottier, Sieger, Billaud-Varennes y Esteban, uno de los protagonistas de la novela junto a Sofía y Victor Hugues. Los cuatro hombres, instalados en Sinnamary (Guyana Francesa), discuten los efectos de la revolución francesa en el Caribe, especialmente la libertad de los esclavos proclamada primero en Haití en 1791 y luego por la Convención Nacional de París en 1792. La intervención de Sieger, un cultivador suizo que perdió su mano de obra a raíz de la decisión, minimiza el impacto de la revolución europea en las colonias: "Todo lo que hizo la Revolución Francesa en América fue legalizar una Gran Cimarronada que no cesa desde el siglo XVI. Los negros no los esperaron a ustedes para proclamarse libres un número incalculable de veces" (232). El narrador comenta que Sieger enumera una serie de "sublevaciones negras": los mineros de Buría liderados por el Negro Miguel en Venezuela, la Negra Guiomar coronada reina como esposa del primer monarca africano en América, la Cañada de los negros en la costa de la Veracruz en México, el quilombo de Zumbí en Brasil, el Mahometano Mackandal en Haití, entre otras (232-5). Luego de la enumeración, que sorprende a sus interlocutores, Sieger concluye que la abolición de los revolucionarios franceses "no ha traído nada nuevo a este Continente, como no sea una razón más para seguir en la Gran Cimarronada de siempre" (234).

Mientras la revolución cubana se declaraba marxista-leninista y se unía al bloque socialista en el contexto de la guerra fría, Carpentier planteaba que la idea misma de la Revolución había surgido en América Latina, a partir de estos levantamientos de esclavos 
en distintos puntos del continente. La revolución que los dominados practicaban, una "gran cimarronada", había sido inventada en América Latina y no era una mera copia europea. Como planteé más arriba, la revolución se encargaría de ensalzar al esclavo fugado con Biografía de un cimarrón (1966), que además fundaría un género nuevo: el testimonio. Antes de eso Carpentier había escrito El reino de este mundo (1949) pero desde la perspectiva de Tí Noel, un esclavo que relata la revuelta del cimarrón Mackandal en la primera parte de la novela. El personaje de El siglo de las luces plantea el peligro y el temor que los gobiernos coloniales y los hombres y mujeres blancos veían en los levantamientos de negros, que por otra parte acompañaron la esclavitud hasta su abolición en los distintos Estados-nación durante el siglo XIX. La historia de la esclavitud en el período colonial de los diferentes imperios y durante la fundación de los estados-nación en América Latina, estuvo plagada de actos de resistencia individuales y colectivos como los enumerados por el suizo Sieger. Aquellas huídas o revueltas estaban a veces vinculadas a la organización de "quilombos" en los que los esclavos cimarrones vivían libremente y establecían reglas propias junto a otros grupos sociales (indígenas, hombres blancos y negros libres, bandoleros y otros). Fue un modo de ejercer la libertad que no implicó necesariamente la aislación sino un estar al margen pero en algunos casos vinculado a la ciudad (Reis y dos Santos, 1996).

Uno de los estudios pioneros de las revueltas sociales del siglo XIX y XX es el libro Rebeldes primitivos de Eric Hobsbawm, en el que analiza un conjunto diverso de movimientos sociales y formas "primitivas" o "arcaicas" de lucha, como contraposición a las formas de la lucha política organizada por sindicatos y partidos políticos que surge en el siglo XIX y se desarrolla extensamente durante todo el siglo XX. El libro, publicado en 1959, partía de este supuesto que separaba las luchas en primitivas y modernas, y aunque 
no desconoce su "evolución histórica", plantea que son formas que "han dejado de ser la forma primordial de defensa del hombre contra las arbitrariedades del mundo que le rodea" (14) porque carencen de organización o ideología y son inadaptables a los movimientos sociales modernos. Si bien incluye ejemplos de Colombia y Perú, Hobsbawm desconoce, en esta primera edición inglesa de 1959, las revueltas de esclavos en América Latina. En un "Epílogo" a la edición española, firmado en agosto de 1966, Hobsbawm recoge algunas de las discusiones planteadas por sus críticos.

Según su perspectiva la "rebelión primitiva" o "pre-política", puede no ser meramente un "rechazo del presente" sino un medio para controlarlo, pero su éxito depende "de su capacidad de absorber elementos modernos" (279). Para ejemplificarlo Hobsbawm introduce el caso de la revolución haitiana liderada por Toussaint Louverture, la primera independencia declarada en 1804 en América Latina. Según Hobsbawm si bien la revolución haitiana "recurrió a métodos arcaicos locales útiles" como el vudú, no hubiera sido posible "sin la inspiración de las ideas revolucionarias francesas" (280). Hobsbawm acepta que "la evolución de la conciencia política moderna no sigue una sola línea de desarrollo" (284) pero mantiene su distinción primitivo/moderno, en la medida en que estos movimientos "primitivos" no pueden ni se plantean "una unidad política práctica mayor” más allá de su influencia local. Dos décadas después Ranahit Guha discutió la idea de lo "primitivo" o "pre-político" cuando analiza las revueltas campesinas en la India colonial desde la hisotriografía hindú (Guha, 2002 [1983]: 99-101). Dos años después de Guha, el antropólogo James C. Scott analizará las revueltas campesinas en Malasia y las definirá como formas de "resistencia primitiva", pero sin que "primitivo" signifique “atrasado o destinado a dar lugar a ideologías y tácticas más sofisticadas" como hace Hobsbawm (1985: 273). Lo cierto es que tanto la idea de "resistencia" como las formas del 
subalternismo tuvieron mucho éxito en los años noventa y también sus duras críticas (Ortner, 1995). La gran cimarronada, que Sieger describe algo molesto y que percibe como un único movimiento continental, no desembocó en la gran mayoría de los casos en formas políticas modernas como en Haití pero representa formas de resistencia organizada que fueron moldeando a los sectores populares en los estados-nación y que desembocaron en distintas formas de organización (Juntas de Nación, Sociedades, Gremios, entre otros).

Los quilombos de Brasil, por ejemplo, si bien existieron desde el siglo XVII pervivieron hasta bien entrado el siglo XIX. Apenas en un caso, en la zona conocida como "Baixo Amazonas", algunas comunidades quilombolas sobrevivieron hasta el día de hoy (Funes, 1996: 467-497). En el libro colectivo Liberdade por un fio, los compiladores Reis y dos Santos engloban la experiencia de los quilombos en Brasil bajo la idea de "una historia de la libertad" y así titulan su introducción. Los autores parten de la idea de que “donde hubo esclavitud hubo resistencia" y aclaran que el esclavo negociaba "espacios de autonomía" o se rebelaba individual o colectivamente. Las fugas de esclavos no terminaban necesariamente en la "formación de grupos" e incluso muchos preferían diluirse en la sociedad envolvente (9). El libro se ocupa de estos grupos de esclavos fugados que en la América española se llamaron palenques o cumbes, en la inglesa maroons, en la francesa grand marronage y en Brasil quilombo y mocambo (10). Estas experiencias siempre son o pueden ser rescatadas desde una perspectiva exterior, en general por crónicas de quienes perseguían y reprimían los quilombos.

La historiografía de los quilombos en Brasil, especialmente la experiencia de resistencia de dos siglos en Palmares, comienza en la década de 1930 con los estudios “afro-brasileiros". Basados en los trabajos de Nina Rodrigues a fines del siglo XIX, Arthur Ramos, Edison Carneiro y posteriormente Roger Bastide, realizaron estudios con un 
"sesgo culturalista" e identificaron en los quilombos "un esfuerzo contra-aculturador, una resistancia a la «aculturación» europea a la que eran sometidos" (11). De esta perspectiva se desprende la idea del quilombo como un proyecto restauracionista, es decir, restaurar África en este lado del Atlántico, que proponen autores como Raymond K. Kent o Eugene Genovese. Esta hipótesis supone una organización aislada, alternativa a la sociedad esclavista, en la que serían libres e iguales, tal como lo fueron supuestamente en África. En esta perspectiva subsiste la idea de encontrar "africanismos" o "sobrevivencias" africanas (11).

A finales de la década de 1950 las rebeliones de esclavos ganan popularidad como correlato del ascenso de los movimientos de izquierda y de los movimientos negros. Las obras de Clóvis Moura y posteriormente de Luís Luna, José Alípio Goulart y Décio Freitas, entre otros, inauguran una lectura marxista de los quilombos asociada a la lucha de clases en Brasil que buscaba discutir las ideas de unas relaciones eslavistas armoniosas generalizadas por Gilberto Freyre en los años treinta: "La inclinación predominante de esa historiografía era definir la resistencia negra en los quilombos como una negación del regímen de cautiverio por medio de la creación de una sociedad alternativa libre" (13) retomando así la tesis del aislamiento de la corriente restauracionista. En general los autores marxistas analizaban la incapacidad de estos movimientos para acabar con la esclavitud como un todo, como sistema. La explicación que estos autores daban era que los grupos de esclavos fugados no habían alcanzado "el nivel de conciencia de clase necesario" para combatir la esclavitud ni la capacidad para "descifrar las «leyes» que supuestamente rigen las transformaciones sociales" (13). Esta hipótesis, similar a la sostenida por Hobsbawm por los mismos años, es discutida por los compiladores señalando la incapacidad de analizar el comportamiento político y la lógica de poder del 
esclavo rebelde a partir de los cuales sus acciones pudieran ser analizadas (13).

Finalmente, entre 1980 y 1990, los estudios sobre los quilombos no abandonan la problemática cultural ni la influencia marxista, aunque desisten de la "búsqueda frenética de sobrevivencias africanas" o la "rigidez teleológica del marxismo convencional" buscando renovar los estudios sobre la esclavitud. Deben este impulso a la renovación de la historiografía marxista preocupada por incorporar aspectos simbólicos y rituales de la vida en sociedad. Pero los autores destacan la preocupación por la investigación documental, el descubrimiento de fuentes manuscritas y orales que amplían la visión global de los quilombos en Brasil, apuntando a "la compleja relación entre los fugitivos y los diversos grupos de la sociedad en torno de ellos" (14). Todos los ejemplos incluidos en esta historia de los quilombos en Brasil muestran las continuas interacciones entre los quilombos y las ciudades, es decir, discuten en alguna medida la hipótesis extendida del aislamiento. A su vez la interpretación "africanocentrista” del Quilombo de Palmares, que postula la existencia exclusiva de africanos en estas organizaciones, es discutida en base a hallazgos de cerámica encontrados en donde supuestamente estaba ubicado el asentamiento de Macaco, capital de los Palmares. En cambio las investigaciones arqueológicas podrían indicar una presencia indígena más densa de lo que se consideró históricamente y una “mezcla cultural (...) muy intensa" (Funari, 1996: 46). La conclusión del trabajo arqueológico de Pedro Pablo de Abreu Funari es significativa porque vincula estos hallazgos con su "apropiación por parte de los grupos sociales actuales" (47). Para Funari cuestionar la "negritud" de Palmares a partir de la evidencia arqueológica, proponer el contacto con los indígenas, resulta un problema porque representa un lugar sagrado e intocable para los militantes sociales negros. Los movimientos sociales consideran a Palmares como una "tierra de héroes" y para Funari "excavar héroes es tarea 
particularmente difícil" (47) en la medida en que su trabajo puede ser visto como una profanación de esos lugares sagrados.

Como contracara de lo que ocurre en Brasil o el Caribe, la historiografía y los estudios sobre los afrodescendientes en el Río de la Plata no consignan la existencia de experiencias similares a los quilombos brasileros o cualquier otra forma de la resistencia o insurgencia individual o colectiva. Concretamente la historiografía uruguaya sobre los afrodescendientes hasta 1990 nunca puso en primer plano estos eventos ni los investigó en profundidad, incluso la historiografía de los años sesentas que cambió el enfoque de la historia política (historia de héroes y traidores, de hombres notables) desplazándola hacia la historia social y económica. Apenas un texto de Juan Carlos Pedemonte rescató la historia de un levantamiento de negros esclavos en el libro Hombres con dueño (1943) y, como sostiene Hobsbawm en Rebeldes primitivos, esta agitación es representada como una “extraña reliquia del pasado" más que como un acto de resistencia (12). Recién hacia fines del siglo XX, y como fruto de cierta crisis postdictatorial del relato nacional consensuado, la historiografía militante de los movimientos negros inició una recuperación de actos de resistencia individuales y colectivos para dialogar con la "gran cimarronada" latinoamericana y proponer un contrarrelato respecto al papel dócil y servicial de la comunidad afrodescendiente en Uruguay que proponía el Estado.

En 1996 un artículo de Aníbal Barrios Pintos publicado en el primer tomo de la Historia de la vida privada en el Uruguay hacía referencia a un "proceso criminal" en el que dos esclavas asesinaban a su ama -Celedonia Wilch- por los constantes malos tratos y violencia física. En 2001 el caso fue novelado por Susana Cabrera en Las esclavas del Rincón como un acto de resistencia ante las arbitrariedades del amo. Pero no fue la historia académica la que puso en circulación otros actos de resistencia invidivual y colectiva, sino 
la historia escrita por los militantes afrodescendientes (Borucki, 2006). En 1997 Oscar Montaño, militante y por entonces estudiante de la Licenciatura en Ciencias Históricas de la Facultad de Humanidades y Ciencias de la Educación (Uruguay), publica Umkhonto. Historia del aporte negro-africano en la formación del Uruguay. En esta investigación Montaño analiza un intento de rebelión de esclavos en 1803. Unos veinte esclavos escaparon de Montevideo y, según la documentación de la época, se dirigían al Monte Grande para formar "en lo intrincado de él una Población” (1997: 143). En un artículo publicado por UNESCO, el investigador Danilo Antón sugiere la existencia de quilombos en territorio uruguayo y los vincula a distintos asentamientos indígenas (2005: 239). En marzo de 1803 el Cabildo tomó medidas con una Junta de "negros levantiscos" para evitar "que no se transplanten y propaguen en esta Ciudad (como ya sucedió en Guarico) los levantes y motines [...] en las Colonias Francesas", lo que Ana Frega interpreta como una alusión explícita a la revolución de Haití (Frega, 2013: 51). El texto dice más del miedo que sentía la elite blanca ante la posibilidad de una rebelión como la haitiana que sobre la insurgencia en sí misma. Sin embargo, más allá de las fuentes estudiadas por Montaño o Frega, la investigación histórica y arqueológica no ha aportado mucho más material que permita confirmar la hipótesis de Danilo Antón. ${ }^{73}$

Más recientemente, la historia de los afrodescendendientes escrita por académicos ha incorporado la dimensión de la resistencia, la mayor de las veces individual. Un ejemplo de ello son los historiadores Alex Borucki, Karla Chagas y Natalia Stalla (2004) quienes dedican un capítulo de su Esclavitud $y$ trabajo a las formas de resistencia y

\footnotetext{
73 Algo similar ocurre con otro militante, Romero Rodríguez (2006) quien hace referencia a "verdaderos contingentes de africanos huidos de este país, habitaban en montes y praderas de la Banda Oriental", fenómeno al que denomina "cimarronaje". Afirma también que algunos "se integraron a las tolderías indígenas" (29). El autor no profundiza en esta afirmación y eso se explica en gran medida porque su trabajo sobre la "historia del movimiento afrouruguayo" toma como punto de partida la abolición de la esclavitud hacia la mitad del siglo XIX y no explora la historia colonial.
} 
disciplinamiento utilizadas en las relaciones entre amos y esclavos en la zona fronteriza. En un trabajo posterior de Oscar Montaño (2008), el investigador incluye un capítulo sobre las reacciones de los esclavizados frente a la violencia ejercida sobre ellos en distintos casos judiciales entre 1821 y 1839. En suma, el estudio de cómo la "gran cimarronada" se expresó en el Río de la Plata es un terreno poco explorado. Por el contrario el estudio de las formas de colaboración y resistencia organizada en las cofradías, salas o juntas de nación y sociedades de negros tuvieron más suerte, en parte por su vínculo con el candombe y en parte también porque se trató de formas institucionalizadas de organización que perduraron más en el tiempo. Hacia el final de su vida Jacinto Ventura de Molina asumió la representación de la Sociedad de Negros Congos de Gunga ante las autoridades políticas y judiciales del nuevo Estado-nación. Este sector de su producción permite historiar y analizar un intento de levantamiento de esclavos ocurrido en Montevideo el 25 de mayo de 1833 así como el rol de intermediación y representación que Jacinto Ventura de Molina ofreció a una organización de africanos y sus descendientes. Es también una instancia decisiva en la medida en que Molina pone su conocimiento y destreza en el trato con la ciudad letrada al servicio de un colectivo de afrodescendientes. 


\section{La Sociedad de Negros Congos de Gunga y la rebelión de Félix}

La noche del 25 de mayo de 1833 Luis Lamas, jefe político y de policía de Montevideo, fue informado sobre la desarticulación de una conspiración de esclavos y libertos. Un texto de Juan Carlos Pedemonte "La República negra", capítulo VIII de Hombres con dueño (1943), es uno de los primeros relatos, sino el primero, sobre una revuelta de esclavos en Uruguay. Los principales líderes de la conspiración fueron el negro Félix Laserna -conocido como Santo Colomba- de quien se decía que tenía "alguna ilustración" (63), y el "alemán" Guillermo Guitarner. El investigador, que tuvo acceso a la "pieza procesal"74, afirmaba que el plan de Laserna era fundar "una República negra y someter a los blancos a la situación de vasallaje a que hasta entonces habían estado sometidos los seres de color" (Pedemonte, 63). La interpretación de Pedemonte es en parte paradójica ya que si bien reconoce el liderazgo de Laserna, le atribuye a Guitarner una orientación "eficaz" por su "condición de europeo" (64). Incluso llega a afirmar que sin la intervención del suizo era imposible "que a Félix Laserna, se le fuera a ocurrir que luego de emancipados todos sus desdichados hermanos de raza, se pudiera esclavizar a los blancos y, cosa inaudita, hasta se intentara crear una «República Negra, semejante a la que existía en Santo Domingo»" (64). Y más adelante sostiene que en caso de resultar vencedor, "más que República hubiera sido un cacicazgo" de Laserna con la asistencia del europeo (Pedemonte, 65). Hacia el final del texto Pedemonte califica a Laserna como "un esclavo al que un poco de luz en su cerebro le había permitido concebir una cosa, ciertamente monstruosa, pero inspirada en un afán de liberación para sí y para todos los de

74 A pasar de no dar con la causa judicial desarrollada en contra de los conspiradores tuve acceso a una parte de la documentación dispersa en el AGN (Ex Ministerio de Gobierno y de Interior) del Fiscal "en comisión", del departamento de Policía y del Jefe Político. 
su maltratada raza" (67). Al mismo tiempo que lo denigra en tanto necesitó "un poco de luz" en su cerebro, tiene una actitud paternalista y una sensibilidad que justifica la violencia del esclavizado ante la violencia que se ejerce sobre él.

A tres años de fundado el Estado Oriental del Uruguay, en un clima de guerra civil casi permanente, la conspiración de los esclavos y negros libres movilizaba no solamente el terror a una revolución como la haitiana sino también la amenaza interna y externa (Brasil, Argentina) a la "paz pública”, expresión que el primer presidente Fructuoso Rivera había utilizado en una proclama a los soldados de línea en 1830 (Acevedo, 1933: 382). ${ }^{75} \mathrm{~A}$ fines de mayo de 1832 estaballaba una rebelión indígena en el norte del nuevo Estado que fue aplastada por Fructuso Rivera y su hermano Bernabé, quien murió en acción (Acevedo: 387). El 3 de julio un alzamiento militar en Montevideo promovido por Lavalleja, un caudillo que había conducido la lucha por la independencia en 1825 y ahora disputaba el poder con Rivera, fue desarticulada en agosto, aunque continuó en la campaña hasta setiembre (Acevedo: 389). Al año siguiente Lavalleja vuelve a intentar una revuelta desde Buenos Aires que se inicia en abril de 1833 y que para julio estaba sofocada (Acevedo: 395-396).

En este clima la revuelta de esclavos y negros libres de 1833, aunque no se concretó, desencadenó en Montevideo un operativo de vigilancia que tuvo en vilo a las autoridades durante la noche del 25 de mayo. Tres días después de la conspiración Luis Lamas dirige un informe al Ministro de Gobierno Santiago Vázquez en el que hace un relato detallado de las medidas tomadas. A la salida del teatro Coliseo, en el que se festejaban los 23 años de la revolución argentina de 1810, Lamas fue informado por Matías

75 De hecho el periódico El investigador del 29 de mayo de 1833, cuatro días después del intento de levantamiento, expresaba que eran "diversos y contrarios los rumores que circulaban acerca del caracter político de los conjurados". Los editores tranquilizaban a los ciudadanos afirmando que las autoridades habían desarticulado la revuelta, "demostrando el empeño que se desplega en el mantenimiento del orden y de las instituciones" (300) y que pronto serían informados de todo. 
Tort sobre la conspiración y de inmediato salió a buscar al General de Armas, Manuel Oribe, quien ya estaba enterado de los hechos y había dispuesto el patrullaje de los límites de la ciudad por parte de la Caballería de Extramuros. A su vez, Lamas hizo lo mismo con los celadores, que repartió por distintos puntos de la ciudad para que informaran de cualquier cosa que ocurriera. En el operativo fueron capturados "once negros" y apenas dos fueron puestos "a disposición del Fiscal militar por creerlos comprendidos en la citada conspiración", algunos quedaron retenidos para obtener más información sobre la conspiración y otros habían sido liberados por no estar relacionados con la misma. ${ }^{76}$ Según Pedemonte los dos esclavos capturados primero eran Tomás Liz y Antonio Varela, y antes del amanecer habían sido capturados Félix Laserna y Antonio Rodríguez, conocido por el apodo de "Duplesis" (63).

Desde el día 26 de mayo el Fiscal militar José María Navajas daba diferentes órdenes para apresar a los supuestos implicados. En ese marco se dió un hecho significativo. El celador José Palomino, encargado de detener a Guitarner y Laserna, no sólo no capturó al suizo sino que lo animó a escaparse. El 5 de junio, Palomino fue encarcelado y puesto a disposición de Manuel Oribe. Pero no fueron los únicos que colaboraron o se vieron tentados a hacerlo. Hacia el 16 de julio, según Pedemonte, se supo que los sargentos Teodoro Hermemburg y Biederman habían tenido intención de sumarse a la conspiración que planteaba asesinar a ministros, al comandante de armas y a "otros personajes y sus familias" (66). El primero inmediatamente delató a los conspiradores e incluso participó como espía en la acción y el segundo se unió seducido por los ofrecimientos de los complotados. Finalmente Biederman se arrepintió y ayudó a su compañero, y ambos fueron los que informaron al comandante Tort sobre el inicio de la

\footnotetext{
$76 \quad$ AGN. Ex Ministerio de Gobierno y de Interior. Caja 842. Mayo de 1833.
} 
revuelta (67). Por lo tanto es significativo que todas las miradas vigilantes de la ciudad letrada apuntaran a los afrodescendientes, y si bien las autoridades castigaron al funcionario por no detener al europeo, ninguna de sus medidas represivas fueron dirigidas a extranjeros.

El "Edicto de Policía" del 28 de mayo, firmado por Luis Lamas, lo confirma. El texto establecía seis medidas para la seguridad y la moralidad. Todas ellas apuntaban a la vigilancia de los "morenos esclavos y libres" y apelaban a la "colaboración" en la tarea policial, de amos y dueños de casas de alquiler. El edicto hacía referencia a los males que provocaba la "independencia o falta de sujeción" de los esclavos y por eso estaba dirigido a los propietarios, apelando a su responsabilidad sobre ellos. Por eso plantea que los amos debían encerrar a los esclavos en sus casas a las ocho de la noche (Artículo $1^{\circ}$ ), que debían informar al Jefe de Policía si algún esclavo no vivía en la casa por motivos fundados o debía estar fuera luego de esa hora, para que este extendiera un permiso especial (Articulo $2^{\circ}$ ), que debían informar al Jefe si faltaba algún esclavo en la casa y que los harían responsables por los crímenes que ellos cometieran (Artículo $3^{\circ}$ ). Además de los amos el edicto apunta a los dueños de casas de alquiler a quienes obligaba a informar nombre y ocupación del inquilino si se trataba de "morenos libres o esclavos" (Artículo 4).

El arículo $5^{\circ}$ es el único que está dirigido a los africanos y sus descendientes, especialmente a aquellos que se organizan para los bailes:

Prohibiese absolutamente los bailes de negros en la Capital, y en lo sucesivo se harán en la parte exterior de la Ciudad frente a la Ciudadela hasta las inmediaciones del Cordón, y de ningún modo en lo interior de las casas. 
Finalmente advierte que todos los comisarios deberán dar cumpliento a las medidas establecidas y que el Jefe no tendrá consideración con quienes inflinjan cualquiera de los artículos del Edicto (Artículo $\left.6^{\circ}\right) .{ }^{77}$

El 16 de julio de 1833 el Fiscal militar Navajas pidió "en nombre de la Patria" que los conspiradores fueran fusilados "sustituyendo esta pena por la de horca" (Pedemonte: 67). Sin embargo una tormenta pospuso la condena y también los festejos del tercer aniversario de la Jura de la Constitución. Cuando el 23 de julio la tormenta pasó se iniciaron los festejos que duraron una semana. El propio Jefe de Policía exhortó a los amos en la prensa a conceder licencia a los esclavos de confianza durante la semana. De algún modo las medidas represivas se flexibilizaron acompañando la distensión general que provocaba la fiesta patria. También en el marco de la fiesta la "Comisión" solicitó el indulto para los presos, que fue concedido por el gobierno. Pero Laserna desde la cárcel, conmutada su pena por prisión, alentó otra conspiración que acabó con su muerte al año siguiente.

Las acciones de los conspiradores provocaron la reacción ejemplarizante de las autoridades. El artículo $5^{\circ}$ del Edicto policial prohibía "absolutamente" los "bailes de negros" en Montevideo, obligaba a realizarlos "en extramuros", fuera de las casas que habitualmente se alquilaban o compraban con este fin por las diferentes "naciones". Pero estas medidas no eran para nada nuevas. Durante el período colonial y en la primera mitad del siglo XIX, los "bailes de negros" fueron vigilados por el Estado colonial y la Iglesia. Los letrados dieron cuenta de estos bailes en textos oficiales (informes, decretos, memorias) siempre desde esta mirada vigilante de la que la ciudad letrada era parte

77 AGN. Ex Ministerio de Gobierno y de Interior. Caja 842. Mayo de 1833. El documento es una copia hecha por Pedro R. Díaz. El documento se publicó en la prensa de la época, por ejemplo en $E l$ investigador ( $\left.\mathrm{N}^{\circ} 37\right)$ del 29 de mayo de 1833 (301-302). 
constitutiva. El 8 de marzo de 1805 el Gobernador Ruiz Huidobro solicitó un informe sobre "el modo y forma" en que se realizaban las Juntas de nación a Juan Antonio Martínez, Sargento Mayor de la Plaza. ${ }^{78}$ La preocupación de Ruiz Huidobro por "las malas resultas" de las reuniones de africanos y afrodescendientes motivó el pedido. El informe no se refiere a una junta o una casa en particular sino que relata un fenómeno al parecer generalizado en la ciudad colonial. Según el sargento las Juntas "tienen nombrados de todos empleos asta el de Rey, y en el caso de mudar alguno de estos por el mal Gobierno, hacían junta entre ellos y lo despedían de la nación”. Las autoridades propias eran respetadas y se les hacía honores. Los bailes se realizaban en días festivos y el funcionario destaca que en ellas se recauda dinero por multas o colaboraciones, que son utilizados, entre otras cosas, para comprar la libertad de esclavos pertenecientes a la nación.

Por último el funcionario observa "las malas resultas que puedan tener tales juntas", reiterando las palabras de su superior y aludiendo a una orden real de 1800, "en que manda no seles (sic) permita que se junten muchos, ni traer armas, ni seles (sic) tolere discursos sediciosos". ${ }^{79}$ A partir de este informe el Gobernador Ruiz Huidobro ordena la prohibición de las juntas "por lo inconvenientes y perjuicios q.e de ellas pueden resultar" y establece que los castigos iban de tres a seis meses de prisión, trabajo en "obras públicas” y grilletes. Las reuniones de esclavos y los discursos sediciosos de los que la ciudada letrada da cuenta en este informe y en el acto administrativo del Gobernador, son resultado del temor a que se produjera en territorios coloniales españoles una revolución como la haitíana.

Sin embargo, los informes de la ciudad letrada responden a la necesidad de control sobre estas Juntas. En La música en Uruguay Lauro Ayestarán planteaba dos corrientes de

78 AGN. Escribanía de Gobierno y Hacienda. Expediente $\mathrm{N}^{\circ}$ 167. Citado por Homero Martínez Montero (1941: 409). Las citas a este documento provienen del original en AGN.

79 Se refiere a una real orden del 1 de noviembre de 1800 (Frega et al., 2008: 27). 
la música afro-uruguaya: una secreta, constituida por "la danza ritual africana sólo conocida por los iniciados, sin transcendencia socializadora y [que] desaparece cuando muere el último esclavo llegado del otro continente" y luego una "superficial (...) de rápida y extendida afloración", colorida y pública que se inicia en el siglo XVIII con la participación de los esclavos negros en el Corpus Christi, se organizó luego en las Salas de Nación con diferentes danzas "que se bailaban entre la Navidad y el Día de Reyes alrededor del 1800" y que luego "se transformó en la comparsa de carnaval de las sociedades de negros, desde el 1870 hasta nuestros días" (147). En este libro establece que la primera línea se proyecta en la segunda aportando el tamboril y un paso coreográfico. Son las ceremonias secretas las que están bajo la mirada vigilante de la ciudad letrada y las que despiertan el dispositivo disciplinario del Gobernador.

La literatura de viajes, escrita por funcionarios y emprendedores europeos, publicada en las metropolis, ponen en circulación otras representaciones de la vida de los africanos en las colonias. Los viajeros están menos preocupados por la vigilancia y más interesados en los rasgos exóticos de las colonias. El 6 de enero de 1827 el viajero francés Alcides D’Orbigny, quien viajaba a pedido del Museo de Historia Natural de París, presenció una ceremonia pública como las descritas por Ayestarán, que las salas de nación ofrecían a toda la ciudad en el día de Reyes. El testimonio de D’Orbigny da cuenta de que las distintas naciones elegían sus autoridades y estas se vestían “de la manera más original, con las ropas más brillantes que pudieron encontrar". Luego iniciaban un recorrido junto a sus súbditos: primero a misa, luego un paseo por la ciudad y, finalmente, en la plazoleta del mercado, la ejecución de "bailes guerreros, simulacros de faenas agrarias y las figuras más lascivas" (Tomo I, 65). La literatura de viajes ha diseminado muchos relatos de bailes de negros como los de D’Orbigny, en los que se repiten hasta el cansancio el exotismo, la 
lascivia, los cuerpos y el salvajismo de los negros africanos y sus descendientes.

También en El Lazarillo de los ciegos caminantes (1775-1776) un texto escrito por un funcionario de la corona, Alonso Carrió de la Vandera, inspector del Servicio de Correos entre Montevideo-Buenos Aires y Lima, que se escondió en el pseudónimo de un mestizo Calixto Bustamante Carlos Inca (Concolorcorvo) para eludir la censura y también parodiar o contestar la literatura de viajes. El texto es un híbrido entre el registro del burócrata y el diario de un viajero. Cuando llega a Perú (Cusco más precisamente) el narrador compara a los negros con los indios, abogando a favor de lo segundos. En el capítulo XX describe las “diversiones de los negros bozales” y las califica como "las más bárbaras y groseras que se pueden imaginar". En todo el pasaje animaliza a los afrodescendientes con frases como: "Su canto es un aúllo", los sonidos de su música son "fastidiosos y desagradables", su tambor es tocado "sin orden" y "con el fin de hacer ruido", sus bailes son lascivos porque menean "la barriga y las caderas con mucha deshonestidad" y "con gestos ridículos". Finalmente compara todo esto con "la fiesta que hacen al diablo los brujos en sus sábados" y concluye la comparación con los indios afirmando que "sólo se parecen las diversiones de los negros á las de los indios en que todas principian y finalizan en borracheras" (Concolorcorvo, pp. 175-176).

En un estudio sobre los afrobonaerenses, Reid Andrews define las salas o juntas como "asociaciones étnicas africanas ligeramente organizadas" $"$, que cumplen funciones tales como la compra de libertades de sus miembros, la creación de escuelas propias (en muchos casos frustradas), la realización de prestamos para fomentar iniciativas económicas de los propios esclavos y libertos, y la realización de bailes a puertas cerradas. Estén bajo el nombre de "juntas de negros" o el de "naciones" e incluso "sociedades", las

$80 \quad$ Andrews, p. 171. 
características de las organizaciones montevideanas son similares a las afroargentinas, incluso en la convivencia de dos formas de asociación: las cofradías y las juntas. La primera cofradía montevideana, la Cofradía de San Baltasar fue creada en 1787 en honor al Rey Baltasar, uno de los tres magos que llegaron de Oriente anunciando el nacimiento del Rey de los judíos y que Herodes intentó utilizar para eliminar a Jesús (San Mateo, 2.712). No hay en el Nuevo Testamento ninguna referencia al nombre de ninguno de los magos ni a su color de piel pero las tradiciones populares asociaron a este mago con un moro. Posteriormente, los negros americanos fueron "coloreando" más al Baltasar popular. Por su parte las salas de Nación, juntas o tangos coexisten con estas por lo menos desde comienzos del siglo XIX (Montaño, 220). Existieron prohibiciones a los "bailes de negros" constantemente durante los siglos XVIII y XIX, por distintos motivos, pero uno se destaca fuertemente: el peligro potencial de las reuniones y los discursos sediciosos que allí se pronunciaban. 


\section{El rol de Jacinto Ventura de Molina}

La aparición de Jacinto Ventura de Molina en la historia de la conspiración está vinculada concretamente a la defensa legal de la Sociedad de Negros Congos de Gunga. Los congos eran el grupo mayoritario entre los bantu, a su vez mayoritario entre la población africana y sus descendientes en Uruguay. En un censo realizado en algunas calles entre 1812 y 1814 , en el que se distinguió el lugar de nacimiento o procedencia de los censados, Montaño encuentra más de 4000 africanos y descendientes, de los cuales el grupo mayoritario es congo (2008: 291-293). Según Molina la nación de los Congos de Gunga estaba dividida en seis provincias: Gunga, Guanda, Angola, Munyolo, Basundi y Boma, que pasaron a unirse en esta "sociedad" fundada en 1834 con las siguientes autoridades: Antonio de la Rosa Brito (Rey o Presidente de la Sociedad), Joaquín Martínez y Juan Sosa (Ministros), y Gregorio Juanicó, Miguel Piñeiro y Pedro Obes (Consejeros) y Jacinto Ventura de Molina como "asesor fiscal" (A1: 80).

Cuando en 1834 Jacinto Ventura de Molina asume la defensa legal de la Sociedad de Congos de Gunga hacía ya dos años que el Estado Oriental del Uruguay lo había reconocido como licenciado en derecho y lo había nombrado "defensor de negros" (A2: 119). A diferencia del caso de María Antonia Mandinga en Cuba, estudiado por Julio Ramos en Paradojas de la letra (1996: 37-70), Molina entiende perfectamente los mecanismos legales, los ha estudiado, su palabra está autorizada y legitimada, mientras "no se sabe cómo llega María Antonia a contar su historia" en la corte de Trinidad (Cuba) en 1815 para exigir su libertad ni cómo pudo entrar "en la abigarrada red de la burocracia colonial, entre síndicos y escribanos, pidiendo representación” (39). La palabra del esclavo no tenía un lugar en la justicia colonial, que tardó décadas en legitimar su testimonio 
cuando ya María Antonia había muerto. En ese sentido la alianza entre Jacinto Ventura de Molina y la Sociedad de Negros Congos de Gunga implicó una mediación del primero a favor de los segundos, quienes pudieron superar las barreras de la ciudad letrada y hablar frente al poder para conseguir sus objetivos.

La primera tarea de Molina fue solicitar que las autoridades permitieran la creación de la Sociedad y la reconocieran como asociación. La "Oración política moral" presentada en 1834 ante las autoridades (el Juzgado de la Policía) y parece haber sido pensada para ser dicha, como pieza retórica para una "instancia oratoria” frente al juzgado. Está compuesta por una dedicación a los diputados y senadores en la que adelanta que su argumento central será la fidelidad "de los jefes" congos (A1: 79); una introducción en el que se posiciona como testigo y cuenta los detalles de cómo Félix Laserna intentó incorporar a los Congos de Gunga en la conspiración (79-82); un exordio en el que describe la organización de la Sociedad y reflexiona sobre la importancia de la sociedad civil (82-84); una narración (84-89), con una primera “conclusión”, en la que toma una historia de la Biblia (la Reina Ester) y adelanta en qué lugar funcionará la sociedad, que se sostendrá económicamente mediante un fondo y se encargará de la "decencia del baile nacional, la asistencia de sus dolientes y la sepultura de los que fallezcan" (89); una prueba en la que proporciona algunas historias coloniales que demuestran la fidelidad de los negros hacia los blancos (89-97), y finalmente se introduce una "conclusión” en la que termina afirmando lo útiles que son sus proposiciones para los "infelices negros" (97). Esta “Oración” sigue desprolijamente las reglas de la retórica clásica y es interesante aclarar que a diferencia de otros manuscritos, es notorio que Molina hizo un esfuerzo por

81 El título original es “Oración política moral para la aprobación, establecimiento, [...] de la humilde Sociedad de negros Congos de Gunga de Montevideo, presentada en las Tribunas del Juzgado de Policía, su protector el Licenciado en Derechos negro Jacinto Ventura de Molina (1834)" (A1: 79-97). 
escribirla con mayor prolijidad.

Aunque en este manuscrito Molina asume la primera persona lo hace en representación de un colectivo, la "parte superior más noble y sana de los etíopes que existen en la República, que respeta sumisa a Vuestras Altezas" (A1: 79). La fidelidad de sus defendidos (y la propia) a las instituciones será el eje de todo su discurso. El punto no es menor no solamente porque buscaba desarticular el Edicto policial, que en su primer artículo hacía referencia a la falta de sujeción de los negros, sino por el significado que la fidelidad tiene en esta época en el trato entre amos y esclavos. Una vez hecho el saludo a diputados y senadores Molina hace su introducción en la que narra, como testigo directo, algunos hechos vinculados al complot. Según su relato Félix Laserna se presentó ante la Sociedad a comienzos de 1833 para solicitar su apoyo en la revuelta. En todo el escrito Molina lo llama "Félix Columbio", una combinación de su nombre legal (Félix Laserna) con su apodo (Santo Colomba). Molina fue testigo porque Laserna había convocado a la “Junta de los Jefes". El texto aporta detalles de cada uno de los integrantes de la elite de los congos: Antonio de la Rosa Brito era esclavo de Don Luis Jimenez; Juan Sosa era un negro libre, mayordomo de San Benito de Palermo ${ }^{82}$; Gregorio Juanicó era un pardo criollo portugués, esclavo de Don Francisco Juanicó; y Miguel Piñeiro era un esclavo que sabía

82 Según Pereda Valdés (1965) los afrodescendientes "no crearon cultos independientes de las prácticas cristianas" y rindieron "un culto especial a determinados santos negros, como San Baltasar y San Benito" (97). Más allá de la afirmación categórica, los datos que proporciona Pereda respecto a San Benito de Palermo (1526-1589) son interesantes: hijo de moros convertidos a la religión católica, nació en San Fratello (Messana, Italia) y murió en la ciudad de Palermo. Los congos en Brasil y también en Uruguay rindieron especial culto a este santo: "San Benito fue el santo más popular y de mayor devoción entre los negros uruguayos que San Baltasar, ya que su culto se puede decir que existe desde 1681, cuando se fundó el venerado santuario del Real de San Carlos” destruído en 1705 y reconstruído en 1729 (102). Pereda hace referencia al culto a San Benito en la recién fundada ciudad de Paysandú (1772) y a los franciscanos que fundaron una Hermandad de San Benito hacia 1740. Si bien en esta oportunidad Molina y la Sociedad de Negros Congos de Gunga solicitan poder hacer sus fiestas del 6 de enero, dedicadas a San Baltasar, es imporante señalar, y así lo entiende Molina, que este ministro de la Sociedad era mayordomo de San Benito de Palermo. Esta referencia señalaría que la devoción al santo, que Pereda ubica fundamentalmente en el siglo XVIII, seguía viva hacia 1834, fecha de este documento. 
leer y era ladino ${ }^{83}$, lo que supone que conocía lenguas africanas y el español, si el término se aplica por analogía con el significado que tiene en el área andina o en México aplicado a los indígenas.

La Junta de Jefes, reunida en la hab|itación de Juan Sosa, había convocado a Molina para “escribir asuntos de la Nación” cuando Laserna llegó a la puerta:

Gregorio Juanicó me dijo en secreto lo que trataba Félix, y yo repugné hallarme en un acto que era tan odioso como lo fue para mí la publicidad del día 19 de marzo de 1815. Pero viendo Juanicó que no podía omitirlo hallándome en la pequeña pieza del aposento con todos los nombrados y Félix ya a la puerta de la sala, contestado por Sosa, me pidió que disimulara. Oí, Señor, la proposición innoble y baja de ofrecerles 4000 pesos por la revolución y levantamiento de los etíopes congos, quienes por su viveza y locuacidad genérica, sometieron los mas o todos los esclavos y gentes de su color. Noté en silencio la mordaz erudición con que persuadía el método cruel de la ejecución, las medidas y proporción de las personas innominadas que ayudarían al suceso y varias disertaciones sobre sus acontecimientos (A1: 80-81).

Antes de relatar las reacciones de los jefes congos, Molina describe y califica sus propias reacciones ante el complot adjetivándolo como un acto "odioso", una propuesta "innoble", "baja”, así como la erudición "mordaz" con la que Laserna explicaba los detalles. Luego

83 Magdalena Coll interpreta la categoría "ladino" en oposición al bozal, es decir, aquel esclavo que manejaba bien el español en oposición al que no lo hacía en absoluto. Al citar una causa judicial en la que el Juez llama a un ladino para que hable con un bozal "en su lengua" esto quiere decir que luego podía traducirle al español. Sin embargo Coll insiste únicamente en esta capacidad de hablar bien el español (2010: 43-44). 
Molina relata la reacción del Rey Antonio de la Rosa Brito, que le explicó a Laserna que todos tenían familia en la ciudad y afirmó "si erramos no sólo nosotros, sino ellas quedan perdidas" (81). Al retirarse Laserna, Molina presiona y finalmente Gregorio Juanicó fue "a casa de Félix, a protestarle que de modo alguno, contase con ningún negro Congo" (81). Las acciones de Laserna, que aclara Molina era negro, de "color baso" "44, explican que el Jefe Político Lamas cargara contra los negros destruyendo sus casas de bailes y quitándoles las licencias para la fiesta de San Baltasar (81-82). El culto a San Baltasar sirve a Molina para demostrar la fidelidad de los congos a las instituciones, en este caso a la Iglesia y por su intermedio a la religión católica: "Los políticos sentarán si el entusiasmo de los negros, estos únicos días de enero, tiene algo de supersticioso, violeto, irreligioso, escandaloso, extraño." (82).

En el "exordio" Molina argumenta sobre la idea de sociedad civil como un "principio necesario [escribe en verdad "nesetitate printipium"] para la felicidad y multiplicación del género humano" y como un "contrato en virtud del cual muchos hombres juntos, se obligan a trabajar de concierto en su utilidad común" (82). Luego pasa a describir la composición de la Sociedad, en verdad "la cabeza de esa sociedad sujeta en todo a VE", que toma como ejemplo la organización de los blancos y tiene un presidente, ministros, consejeros y un asesor fiscal. Molina argumenta que la Sociedad solo podrá ser juzgada por el Juez político en la medida en que el negro congo "se asemeja al ciudadano aunque sea esclavo, lo es per actidens set non nativitate", lo que puede traducirse por desgracia o accidente, no por nacimiento (82). Molina también vuelve a representar a sus defendidos como "infelices, destituidos y privados de todo principio de educación,

84 En el diccionario de la RAE de 1770 "baso" remite a "baxo", que aplicado a los colores es el "que tiene menos viveza" (463). En la versión de 1780 hace referencia a un color débil, lánguido, sin vigor (137). Ver Real Academia Española, Nuevo tesoro lexicográfico. 
civilización, cultura, métodos o costumbres para dirigirse y vivir" (84). Este recurso retórico de captar la conmiseración de su interlocutor, que utiliza frecuentemente, intenta preparar el ánimo de las autoridades para aceptar el pedido de creación de la sociedad.

En la "narración" utilizada en la justicia, como establece Cicerón, se exponen los hechos para favorecer al orador (Pozuelos, 1986: 244). En esta parte del discurso Molina busca probar la fidelidad de sus defendidos pero inicia su narración haciendo referencia a sí mismo, otra vez, relatando cómo se dilató en el tiempo que se aceptara su título como licenciado en derechos, debido al "desconcierto general, la laxitud del país y las anarquías domésticas" (A1: 86). Por tal motivo, y tal vez para entretener y moralizar, echa mano a la historia bíblica de la reina Esther en el Antiguo Testamento (Esther en Scío, 1793: 461473). Este texto relata la historia de la Reina Esther, una mujer judía casada con Asuero, rey desde la India hasta Etiopía. La elección de esta historia bíblica por parte de Molina parece muy acertada en la medida en que hace referencia a conspiraciones, traiciones y fidelidades. Una de las virtudes de la Reina Esther fue que junto a Mardocheo, su tío y protector dado que era húerfana, denunció una conspiración contra el Rey que lo salvó de la muerte. Molina resume buena parte de la historia y cita concretamente un pasaje del capítulo XV en el que Esther es representada como una mujer temerosa del Rey que se postra ante él y besa su cetro.

De este modo prepara el terreno para destacar la fidelidad a las instituciones de sus representados. Pero el pasaje elegido por Molina es significativo no solamente por su contendido, especialmente por recurrir al cetro del Rey como ícono del poder en un juzgado del nuevo Estado-nación, sino porque se trata de un texto que es una adición hallada en la Vulgata como lo indica el traductor en 1793 Felipe Scío de San Miguel (Scío, 1793: 471) que no aparece en las ediciones de la Biblia contemporáneas. Lo que indica que 
posiblemente la Vulgata fuera la edición de la Biblia que Molina utilizaba. Antes de cerrar la narración Molina cita algunas normas legales locales que le permiten establecer por un lado, los "únicos" objetivos de la Sociedad: "la decencia del baile nacional, la asistencia de sus dolientes y la sepultura de los que fallezcan"; y por otro, la "inviolable fidelidad" que la Sociedad debe a la autoridad policial.

Finalmente la "prueba" es la parte del discurso más interesante dado que Molina alega que "el gobierno antiguo [refiriéndose a la colonia] miró algunos negros con singularidad noble por sus obras de fidelidad" (A1: 93), punto de partida que le permite desplegar una serie de relatos que posiblemente conoció de primera mano. El primer cuento es el de Ventura, su padre, esclavo de su tutor español José de Molina. Concretamente relata el episodio en el que salvó la vida de su amo, este le dio la libertad y el esclavo decidió seguirlo hasta su muerte. Pero Molina brinda tres historias más: la del negro Marcelo, nombrado "oficial vivo de Infantería" por su ayuda al ejército del Virrey Juan José Vertiz en la expedición de la sierra de 1774, en la que Molina participó. La segunda es la de Mariano, un "negrito joven” propiedad de Francisco de Paula Sans. Mariano salvó el pellejo de su amo en Chuquisaca (actualmente departamento boliviano cuya capital es Sucre) cuando los indígenas habían rodeado su casa, enviados allí por “Tupamaro [es decir, Tupac Amarú] que empezaba a desenvolverse”. El negro engañó a los indios disfrazando a su amo de fraile. Posteriormente Francisco de Paula liberó a su esclavo aunque este lo acompañó hasta su muerte. La tercera es la de Adán, que salvó a un comerciante (Camperos) "del mismo Tupamaro" y fue liberado también. Las pruebas presentadas por Molina son historias familiares, historias que posiblemente escuchó de personas del entorno del español o de otros esclavos y negros libres. Son parte de su doble memoria familiar (negra y española). 
Además de la "Oración” hay al menos dos cartas en la colección de manuscritos que dan cuenta de las acciones de Molina frente a las autoridades: una al Ministro de Estado Lucas José Obes ${ }^{85}$, fechada en abril de 1834; y otra al Fiscal General, posiblemente Alexo Villegas (interino), fechada en agosto de 1834 y firmada por dos integrantes de la Sociedad: Joaquín Martínez (ministro) y Miguel Piñeiro (consejero). Ambas cartas presentan respuestas escuetas u observaciones de las autoridades, lo que prueba que fueron efectivamente enviadas. Son también una prueba de que Molina busca un lugar en la nueva configuración de la ciudad letrada, consigue que sus saberes sean legitimados por el nuevo Estado aunque no consiga escapar de ser puesto "en su lugar" como defensor de esclavos. ${ }^{86}$

La carta al Ministro de Estado está firmada por Molina quien afirma que su objetivo es "civilizar una porción de morenos", los Congos de Gunga (A1: 121). En su punto $1^{\circ}$ Molina concluye que el gobierno colonial tuvo por objetivo "hacer ilusos los negros porque ignorasen el Derecho natural con que nacieron" mientras la del Estado Oriental y los Estados Americanos es "ilustrar a los infelices negros porque su craza ignorancia, no los precipite. Estimulando sus íntimos sentimientos agradecidos a los ciudadanos y SS que en este y más estados favorezcan su ilustración por principios de civilidad moral y religión, tal es el objeto que hoy trata la Legislatura de este Estado" (A1: 123). En definitiva Molina argumenta que la creación de la Sociedad apunta a civilizar a la nación de los Congos de Gunga. En el punto $2^{\circ}$ afirma que la religión es el "principio de civilidad", la única "capaz de desarrollar el amor a la barbarie que les es natural" y quien debe "proponerle métodos rectos para vivir y morir bien" (A1: 123). Hacia el final Molina ataca el edicto de Lamas que prohibe los bailes y argumenta que los negros americanos "conocían solo el tamboril y

85 Molina no lo menciona pero Obes fue quien ocupó ese cargo durante 1833 y 1834.

86 Como sugiere Frantz Fanon el negro está "sobredeterminado desde el exterior" (2009: 115), porque siempre es negro "frente al blanco" (111). Por tal razón tiene "dos sistemas de referencia" el suyo propio y el de la cultura que le fue impuesta (112). Esta idea de los dos sistemas de referencia tendrá su utilidad más adelante. 
el pito" y que el uso europeo "les enseñó los instrumentos y bailes”, y se pregunta "¿y culpan hoy lo inculto de los africanos?" (A1: 125). Molina defiende la posibilidad de que la mezcla de lo africano y lo europeo de por resultado la civilización de los Congos y por tal motivo desafía con su pregunta a las autoridades. Luego remata el manuscrito invitando a "Vuestra Eminencia" a que permita "que la nación Congos de Gunga tenga su casa para bailar con su tambor los domingos y días festivos hasta la oración y de noche con sus chirimías hasta el día siguiente los que puedan" (A1: 125). El 15 de abril de 1834 la carta fue derivada a Pedro de Navas y Diego Bermúdez de Castro para que dictaminaran sobre dos frases algo confusas que denuncian cierto manejo arbitrario de la situación por parte de las autoridades (A1: 128) aunque es posible que el tono general de la carta irritara al Ministro de Estado.

La otra carta, de Martínez y Piñeiro, está firmada por ambos aunque la letra es de Molina. La práctica de asumir la voz del representado era habitual en el discurso jurídico por ejemplo en los pedidos de libertad de esclavos. Además es posible que los jefes congos no supieran escribir. ${ }^{87}$ En la carta Molina recurre a fórmulas ya utilizadas como "infelices negros" al mismo tiempo que busca convencer al Fiscal de que los miembros de la sociedad son católicos: "estamos sostenidos y apoyados en el capítulo $3^{\circ}$ del dogma constitucional" que establece que la religión del Estado es la católica apostólica romana" (A1: 117) y que su único objeto es la gloria de Dios “en la devoción de su Santo Baltasar” (A1: 118). Al final del texto se introducen seis notas sobre las citas que se hacen. La respuesta del fiscal, el 16 de agosto de 1834, fue pasar al "escribano de cámara" para que informe sobre si las citas son correctas o no. No hay ninguna actuación más de las

87 Bentancur sostiene que existieron "asesores" que muchas veces "dotaron a los litigantes de un discurso y de un razonamiento de los que carecían, siendo que la mayor parte de los afroamericanos no sabía escribir" (2006: 36). La defensa legal recaía en la Defensoría de Pobres y Menores que comprendía a esclavos y libertos porque se suponía que eran pobres pero la mayoría de las veces eran estos asesores "con alguna versación jurídica" (37). 
autoridades que suponga que el trámite tuvo algún efecto.

No hay respuestas o comentarios en la "Oración”, se cuestiona el contenido de las cartas por frases ambiguas, no hay indicios de que las autoridades aprobaran la creación de la Sociedad, hacia fines de 1834 Molina publica un impreso en representación de los Congos por lo que es posible pensar que las autoridades dieron el visto bueno. En este nuevo texto los jefes de la nación solicitaron, por intermedio de Molina, que se levante la prohibición de hacer bailes que pesaba sobre los negros de Montevideo y que el Jefe Político Luis Lamas había incluido en el Edicto policial (Artículo $5^{\circ}$ ) después de la conspiración de Laserna. Apenas se conocen dos impresos de Jacinto Ventura de Molina: un poema $^{88}$ y este escrito judicial vinculado a los Congos de Gunga. Es posible que ambos fueran publicados por la Imprenta de la Caridad, aunque ninguno aparece en el catálogo elaborado por Guillermo Furlong y Enrique Arana (1932). El escrito judicial, que logró llegar a la imprenta, puede fecharse en octubre o noviembre de 1834 y es uno de los éxitos de Molina como defensor de negros ya que documenta el pedido de autorización para realizar la fiesta de Reyes del 6 de enero de 1835 que la Sociedad de Negros Congos de Gunga hizo al Jefe Político Luis Lamas, el decreto de Lamas autorizando la fiesta y el beneplácito del párroco de la Inmaculada Concepción de María, Dr. Juan Otaegui. ${ }^{89}$

El impreso comienza haciendo algunas aclaraciones sobre las actividades de la Sociedad. En primer lugar que "no tienen nada de esas asociaciones secretas" como las que alarmaban a Francia. En contraste afirma Molina “nuestras asociaciones son públicas (...) á

${ }_{88}$ El poema impreso al que hago referencia se conserva en el Archivo General de la Nación (AGN). Ex Archivo y Museo Histórico Nacional. Papeles de Joaquín de Sagra y Périz. Caja 205. Correspondencia y Misceláneas. Carpeta 7. Papeles de Jacinto Ventura de Molina, 1834-1835. El texto fue publicado en Gortázar et al. (2008: 143)

89 El texto comenzó a circular gracias a Ildefonso Pereda Valdés, quien lo publicó en un anexo de su libro Negros esclavos y negros libres (1941 y 1965), junto con otros 74 documentos (1965: 249-253) y es citado brevemente como un "documento precioso" en el texto central para extraer algunos datos de las sociedades o naciones (1965: 96). Pereda Valdés no aclara el origen del texto, como lo hace con los otros, ni especifica si se trataba de un impreso o un manuscrito. 
puerta abierta" y su objeto es "religioso, caritativo". Además no son peligrosas ni podrían causar alarma, muy por el contrario "mas bien contribuyen a sostener el orden, la obediencia, y subordinación, pues fomentan la moral, la Religion y Piedad, que son las bases más sólidas de los Tronos, y los Estados". Como en la "Oración" el argumento de Molina apuntaba no solamente a tranquilizar a los blancos sino a desarticular el Artículo $1^{\circ}$ del Edicto Policial de 1833. El documento aporta datos muy interesantes como la enumeración de las seis provincias que componían la nación Conga: Gunga, Guanda, Angola, Munyolo, Basundi y Boma que concluye con un "toda esta nación, estará unida", lo cual significaba que los esclavos y negros libres de esas regiones estarían bajo la influencia de esta Sociedad.

Luego Molina detalla los objetivos y el funcionamiento de la Sociedad en ocho puntos. El primero establece que la fiesta oficial es la de San Baltasar, el 6 de enero; el segundo es que tendrán como único escudo el "Escudo patrio"; el tercero que la nación tiene sala y patio que se utilizarán para los bailes con tambor y chirimías; cuarto que tendrán un Juez de Muertos que sería el propio Molina, quien supongo tendría por tarea certificar las muertes de quienes componen la nación; el quinto punto establece que la sala servirá para velar a los muertos de todas las regiones de la nación $\mathrm{Conga}^{90}$; el sexto punto establece que se redacatará una “constitución social”, algo así como un reglamento; el séptimo punto establece que un policía concurra los días de fiesta; y, por último, se establece que las provincias tendrán sus casas y darán cada mes un aporte económico para la fiesta de San Baltasar que la Sociedad festejará cada año y para las honras de los difuntos.

90 Esta función permaneció en el tiempo ya que Lino Suárez Peña la recoge en un texto suyo de 1933, lo cual indica que siguió siendo una práctica habitual durante el siglo XIX y tal vez comienzos del XX. En La raza negra en el Uruguay (1933) Súarez Peña da testimonio y detalles sobre los velorios en las sociedades posiblemente narrado desde su experiencia personal o por el relato de algunos viejos, como Olivio Durán quien es nombrado como fuente (1933: 23-25). 
El texto de Molina es un acto de subordinación a las instituciones del Estadonación, adoptando incluso su simbolgía (escudo patrio), al mismo tiempo que una afirmación de la autonomía de los Congos, creando los límites de su autoridad, su propia “constitución social", sus impuestos y hasta regulando la participación de la policía. De este modo se resumen las dos posiciones que Molina representa en este acto, por un lado es un letrado legitimado por el Estado-nación y por otro organiza a sus pares con un grado importante de autonomía dentro de ese mismo Estado-nación. En el impreso Molina borra toda referencia monárquica para describir a las autoridades congas pero en su "Oración" habla de su autoridad máxima como Presidente o Régulo. Tal vez la posibilidad de organizar un reino dentro de la nación entusiasmaba a Molina no solo porque le proporcionaba un suplemento que funcionaría como refugio frente al presente cambiante, sino también porque lo hacía frente a las autoridades, quienes pretendían anular aquel pasado colonial para dar paso al nuevo Estado-nación.

El texto de Molina termina haciendo uso de un recurso retórico habitual en sus manuscritos, la "captatio benevolentiae", victimizándose intenta captar la atención de su interlocutor y ponerlo a su favor: "se sirva no apartar los ojos de nuestra triste condición, y fortuna, que piden algun desahogo, y alguna licita diversion (...) y que nos era permitido en tiempo de los gobiernos absolutos, que no nos debían tanto como nos debe la Patria”. Tras la falsa sujeción está también el reclamo de la deuda que la "patria" tiene con los afrodescendientes. El documento no está firmado exclusivamente por Molina sino que incluye a los principales referentes de la Sociedad. Luego del Decreto de Lamas y el texto del Dr. Otaegui, Molina introduce un cierre en el que argumenta que "la instrucción, las letras, y las ciencias" son el único "ayo, ajente, y apoyo de la humanidad" y de allí la importancia de fomentar la literatura "entre los tristes negritos". Al abandonar la voz 
colectiva del escrito Molina asume una perspectiva condescendiente hacia sus defendidos mientras él mismo se ubica como ejemplo de los buenos resultados que la educación tendría en la población negra. ${ }^{91}$

Es imposible medir la eficacia de este grupo de manuscritos de Molina pero en general se puede concluir que la negociación que promovió fue exitosa, dado que el permiso fue concedido por el Jefe Político pocos días después, con la anuencia del párroco de la Inmaculada Concepción de María Dr. Juan Otaegui, como consta en el impreso. Molina encontró el conflicto ideal para su conciencia doble, educado por el amo blanco y también como "esclavo de la casa", pudo negociar. Su táctica fue separar la actitud de la Sociedad de Negros Congos de Gunga de la de Felix Laserna. De ese modo establece un límite de obediencia que Laserna traspasó. Pero al mismo tiempo puede ser leída como una oportunidad que Molina aprovecha para amenazar veladamente a las autoridades. El concepto de "doble articulación" de Alberto Moreiras (2000: 138) plantea la incompatibilidad entre una política hegemónica y el subalternismo. Para Moreiras el esclavo que quiere eliminar a los blancos y establecer una república negra no tiene lugar en una formación hegemónica, es una negatividad irrecuperable, no traducible. De hecho Laserna es colgado por las autoridades ante un nuevo intento de conspiración. Lo que el discurso de Molina hace es precisamente comenzar por crear esa negatividad para luego plantear a la Sociedad de negros Congos como una asociación de negros, esclavos y libres, fieles a los intereses del hombre blanco. Esta operación retórica es ciertamente hegemónica, es decir, que al representar a los congos los representa en los términos del lenguaje oficial, jurídico y político. Para llevar adelante esta operación fue fundamental que Molina fuera un "sujeto fronterizo", habituado a transitar en el mundo de los negros

91 El manuscrito del impreso está en la colección que conserva la Biblioteca Nacional. Tomo II, f. 110v$113 \mathrm{r}$. 
esclavos y libres, aunque distinguiéndose entre ellos por su educación y capacidad de escribir, y el mundo de los amos blancos. Para un sujeto fronterizo como él la historia bíblica de Esther y la del negro Mariano están en el mismo nivel y pueden usarse frente a la autoridad con cierto orgullo. 


\section{Posiciones fronterizas: representar, intermediar}

La participación de Molina como mediador entre el sistema judicial y los afrodescendientes organizados permite abordar la dimensión colectiva de su acción como letrado que es posible rastrear en sus manuscritos hacia 1832, cuando el Estado reconoce su título de abogado y lo nombra "defensor de negros". Para hablar frente a las autoridades los Congos de Gunga necesitan un intermediario calificado y legítimo como Molina, especialmente en un contexto de desconfianza y sospecha provocado por la revuelta de Lasarte. La posición de Molina es fronteriza porque es reconocido por el "mundo blanco" aunque circunscrito a su "mundo negro" (el de las sociedades o naciones), mundo de que él mismo se distancia (por su educación) y del que no está claro que se sienta parte. Esta posición fronteriza le premite representar a los Congos en un sentido doble: por un lado hablar por ellos frente al Juez, apoderarse de sus palabras, ocupar su lugar; por el otro hablar sobre ellos, re-presentarlos, brindar una imagen de ellos a las autoridades. ${ }^{92} \mathrm{~A}$ estas posiciones fronterizas hacía referencia Homi K. Bhabha en The location of culture (1994) como espacios intermedios (in between) en los que se poducen colaboraciones y resistencias, que no pueden ser pensadas a partir de identidades originales o singulares (12). Por eso hablará de la posibilidad de un espacio escindido de la enunciación, uno en el

92 Cabe recordar la reflexión de Gayatri Spivak en torno a la distinción entre vertreten (en el sentido de hablar por otro) y darstellen (en el sentido de re-presentar) que existe en el alemán y que ayuda a comprender la diferencia entre las dos operaciones. Spivak discute la posición de Deleuze sobre la representación ("Ya no existe la representación; no hay nada más que acción"), lo cual implica descartar “demasiado pronto" la teoría abstracta y la práctica (1998: 181). Lo que Spivak sostiene es que se trata como sinónimos ambos sentidos y de ese modo se construye la idea de sujetos oprimidos que "hablan, actúan y conocen directamente por sí mismos" (1998: 183. Itálicas de la autora). Para la autora es conveniente mantener esta distinción para una teoría crítica en la medida en que "la puesta en escena del mundo en tanto representación -es decir: la escena de la escritura (su "Darstellung")- disimula la elección de una necesidad de "héroes", de apoderados paternales y de agentes de poder (su "Vertretung")" (187). Al final del artículo esta distinción cobra sentido cuando Spivak analiza el "sacrificio de la viuda" en India. Spivak analiza un caso concreto en el que una mujer queda atrapada entre la defensa occidental frente a la barbarie del sacrificio y el patriarcado que la obliga a sacrificarse. En esta disputa por el significado la mujer subalterna desaparece para ser representada por otros. 
que el colonizado no es un Otro del colonizador (exótico o parte de la diversidad humana) sino su copia no exactamente fiel e incluso algo inquietante. Estos espacios de enunciación harán posible "la inscripción y articulación de la hibridez cultural" (38). Esta hibridez, que para Bhabha es el punto de partida paradigmático del mundo postcolonial (21), es un espacio abierto al intercambio, la traducción, la negociación, que no puede anclarse en categorías binarias ni demasiado fijas.

En un sentido similiar, y algunos años antes, tanto Néstor García Canclini (1990 [1989]) como Bruno Latour (2012 [1991]) planteaban la hibridez como una crítica a la modernidad. El segundo al cuestionar las divisiones tajantes entre naturaleza y cultura o entre las esferas de la vida (Latour: 29). El primero como una manera de comprender el funcionamiento de la tríada culto-popular-masivo y las disciplinas que la estudian con el fin de explicar algunos fenómenos culturales y artísticos contemporáneos (García Canclini: 14). En ambos casos el período histórico central es más bien contemporáneo, no es la semiosis colonial l3 $^{93}$ ni los procesos de consolidación de los Estados-nación en América Latina. En tal sentido el contexto postcolonial en el que Bhabha se apoya para ilustrar su teoría permite acercar más su reflexión a la posición fronteriza que asume Molina en la defensa de los Negros Congos de Gunga. Desde su perspectiva también los textos de Molina se explican por esta posición in between, son también híbridos de autobiografía, historia, teología. Pero fundamentalmente Molina representa una amenaza para las categorías raciales de la época en la medida en que es un hombre negro que está en condiciones similares, no iguales, de contestar a los letrados blancos sobre, por ejemplo,

93 Walter Mignolo desarrolla el concepto de semiosis colonial como "un dominio de interacciones poblado por distintos sistemas de signos" más allá de la escritura alfabética y agrega que "señala las fracturas, las fronteras, y los silencios que caracterizan las acciones comunicativas y las representaciones en situaciones coloniales, al mismo tiempo que revela la precariedad hermenéutica del sujeto que se da por tarea su conocimiento y/o comprensión". A partir de este concepto, que desarrolla en su libro The Darker Side of the Renaissance (1995), Mignolo amplía el campo de su investigación a la oralidad, los mapas y formas alternativas de registro como los kipus. 
asuntos judiciales.

Aunque los conceptos de in between e hibridez cultural de Homi K. Bhabha resultan prácticos para describir a Molina, en ellos el sujeto todavía aparece borroso o desdibujado, sin agencia. En tal sentido Mignolo intenta rescatar el "potencial epistémico" del pensamiento que surge de estos espacios intersticiales porque

(...) quien es clasificado vive en un doble mundo (una doble conciencia en la expresión del intelectual afro-americano W.E.B. Du Bois o una nueva conciencia mestiza, en la expresión de la intelectual chicana Gloria Anzaldúa, o la conciencia que le nació a Rigoberta Menchú, según su propia expresión): aquel en el cual lo han clasificado y aquel en el cual él o ella se clasificaba antes de que lo clasificaran. La toma de conciencia de esta situación y el esfuerzo por re-clasificarse desde la subalternidad es lo que he descripto como el potencial epistemológico del pensamiento y la epistemología fronteriza (2001: 25)

Esta pertenencia a un mundo doble y el esfuerzo de re-clasificarse desde la subalternidad no genera, según Mignolo, “una realidad híbrida (como la de Tijuana que analiza García Canclini)", sino que posibilita una "conciencia doble"94: la propia y la que conoce de su amo, mientras este último "sólo reconoce su propia y única conciencia monotópica” (2001:

94 En su libro The Souls of Black Folk. Essays and Sketches (1999 [1903]) W.E.B. Du Bois define la doble conciencia de la siguiente forma: "Es una sensación peculiar, esta conciencia doble, este sentido de siempre verse a uno mismo a través de los ojos de otro, de medir la propia alma con el metro de un mundo que la mira con jocoso desprecio y lástima. Uno siempre siente su duplicidad (twoness) -un americano, un negro, dos almas, dos pensamientos, dos esfuerzos irreconciliables; dos ideas en combate en un cuerpo oscuro, cuya fuerza inflexible sólo se mantiene estando violentamente separadas." (3). La traducción al español es de Alessandro Bisogno, tomado de una cita en italiano. La cita del original: "It is a peculiar sensation, this double-consciousness, this sense of always looking at one's self through the eyes of others, of measuring one's soul by the tape of a world that looks on in amused contempt and pity. One ever feels his twoness, an American, a Negro; two souls, two thoughts, two unreconciled strivings; two warring ideals in one dark body, whose dogged strength alone keeps it from being torn asunder." (3). 
25). Cuando Molina se enfrenta a las autoridades para hablar de sus defendidos pone a operar esta doble conciencia como venía haciéndolo para sí mismo desde 1817. Estar en una posición fronteriza requiere de una doble conciencia para poder subsistir, para generar agencia, para hacer su propia historia.

El potencial de este "pensamiento fronterizo" que Mignolo señalaba en 2001 se formaliza un poco más en 2005 y pasa a denominarse una "práctica epistémica descolonial” (2005: 7) cuya genalogía puede rastrearse en América Latina en primer lugar y a partir del siglo XVI. La obra de Felipe Guaman Poma es un ejemplo de cómo abrir las puertas "al pensamiento fronterizo" (7) que pone lenguas y memorias otras a confrontar con Europa (13). Otro tanto ocurre con la "escritura mestiza" del Inca Garcilaso de la Vega quien, según Cornejo Polar, "habla a veces como servidor fiel de su Majestad, a veces como mestizo doblemente noble, a veces simplemente como mestizo, a veces como Inca y a veces como indio" (1994: 94). Tanto la Nueva crónica y buen gobierno (1615) de Guamán Poma como los Comentarios Reales del Inca Garcilaso (1609-1617) hoy siguen siendo publicados y concitan la atención de los investigadores en todas partes del mundo, además de ser prestigiosos textos en la literatura nacional peruana. Incluso Guamán Poma es planteado por Lienhard como producto de la "conflictiva coexistencia multisecular (...) de dos sistemas culturales opuestos ("andino" y "occidental")" (1990: 190) y como un ejemplo, junto a José María Arguedas en el siglo XX, de una literatura alternativa escrita por letrados biculturales "mal asimilados al sector dominante" (1990: 191). La suerte de los manuscritos de Molina en el Río de la Plata fue muy distinta a la que tuvieron estos dos conocidos fronterizos: no construyó las bases para una literatura "alternativa", ni ninguna otra, ni adquirió con el tiempo un lugar prestigioso en su literatura nacional.

La lista de diferencias es múltiple. Para empezar la calidad de los escritos, que hace 
casi imposible cualquier comparación, en la medida en que los mestizos del área andina tenían acceso a una cultura letrada y pudieron formarse como los españoles, lo cual les permitió acceder a muchísimas fuentes impresas y manuscritas. Es necesario aclarar que la distancia del lugar de enunciación y de los momentos históricos en los que las obras fueron escritas también son factores decisivos que marcan diferencias importantes. También lo es la cuestión étnica en la medida en que tanto Guamán Poma como el Inca Garcilaso son mestizos y ladinos mientras Molina es un descendiente directo de africanos, que escribe casi exclusivamente en español y no conoce ninguna lengua africana. Frente a los libros escritos por los autores, incluso los del Inca Garcilaso que fueron autorizados por la Inquisición para ser publicados, los manuscritos de Molina responden a acciones concretas o instancias específicas: cartas a autoridades, memoriales, oraciones, acciones judiciales, salvo las Glorias de la Caridad de Montevideo que fue pensado como libro pero no llegó nunca a la imprenta.

Sin embargo, y a pesar de las enormes diferencias, los tres casos pertenecen a dos mundos: el de los letrados y el de distintos grupos subalternos, que transitan por ellos, traducen o intercambian. En el plano de la escritura hay dos elementos interesantes. En el caso de Guamán Poma y el Inca Garcilaso los autores se nutren de fuentes diversas, impresas, manuscritas pero fundamentalmente de historias vistas u oídas (Quispe-Agnoli, 2004: 236-237 y Miró Quesada, 1976: xxiii-xiv). En estos casos los autores aportan la visión indígena y aspectos fundamentales de las culturas locales. Molina también se nutre de historias de esclavos en su defensa de los Congos, e incluso defiende la transculturación o mezcla de lo africano con lo europeo en los bailes y la música, pero desconoce o parece desconocer cualquier otro elemento africano en la escritura de sus manuscritos. La lingüísta Magdalena Coll afirma que “escribe en un español típico de la época (...) y no hay 
en él ningún rasgo asociado al contacto con lenguas africanas” (2010: 34). Esto no implica encontrar en los tres casos formas similares de responder a las autoridades con fuentes e historias alternativas. En Guamán Poma, afirma Quispe-Agnoli, el linaje familiar es "una fuente de saber y de poder importantísima en la constitución de la competencia del sujeto que se marca como enunciador" en la Nueva Crónica (2004: 242). También en Molina buena parte de su discurso se sostiene sobre el "linaje familiar", solamente que el suyo no es estrictamente familiar o es más bien de su familia política, su tutor español José Eusebio de Molina. Esta herencia letrada de su tutor-amo y su trayectoria como personal de servicio de otros tantos hombres blancos, constituyen la fuente de su legitimidad como "letrado negro" y marcan su doble conciencia.

Al igual que Guamán Poma o el Inca Garcilaso, Molina es un letrado de su época y responde a los canones del período de transición de lo colonial a lo nacional del que fue parte. Como sugería Rama en este período la producción de un letrado incluía tanto una escritura de compra-venta como una oda religiosa o patriótica (1998: 35). Como letrado Molina cumplió con esta regla redactando documentos judiciales y distintos textos dentro de la tendencia estética general del período: la recreación de la cultura greco-latina propuesta por el neoclasicismo. Si bien Molina no sobrevivió al paso del tiempo, ni integró el canon literario nacional, como la obra de Guamán Poma o el Inca Garcilaso, su escritura representa un ejemplo preciso de cómo se entendía la tarea letrada en la Montevideo del período.

Los manuscritos de Molina permiten conocer algo de la historia colectiva de los africanos y sus descendientes en Montevideo, fundamentalmente de sus formas de resistencia y también de colaboración con las autoridades. Cuando el Estado lo reconoce 
como letrado también lo asigna a "su" grupo de pertenencia, aunque en muchas ocasiones Molina se aleje de esa representación e intente mantener distancia de los africanos y sus descendientes o más bien se distinga de ellos por su educación. El entrelugar en el que las autoridades "lo ubican" le permitió ser un intermediador que, además, fue eficaz a juzgar por los resultados de su trabajo para los Congos de Gunga. Le fue muy útil su doble conciencia en la medida en que conoce al amo blanco y a los africanos, sabe las categorías, los miedos y los prejuicios desde los que un negro es mirado y sabe manipularlos para alcanzar sus objetivos. Esto lo ubica también cerca de otros sujetos fronterizos en la historia literaria de América Latina que pese a importantes diferencias, presentan formas de hacer y decir similares. 


\section{A modo de conclusión. Cultura letrada y etnicidad en la literatura uruguaya}

Cuando la literatura era la parte de un todo que era la nación se podía afirmar que esa tradición llamada "literatura uruguaya" era blanca. Y así fue históricamente construida por la crítica literaria que progresivamente fue haciéndose indiferente a los grupos raciales no europeos hasta hacerlos desaparecer. Pero analizando este aspecto en el presente es necesario advertir sobre tres transformaciones, que no agotan para nada la cuestión de lo étnico-racial en Uruguay, pero explican bastante. La primera es la existencia de un movimiento social de afrodescendientes y pueblos originarios que, en las últimas décadas, ha colocado en la agenda pública la cuestión del racismo y también la reivindicación de su rol en la historia nacional muchas veces invisibilizado o folklorizado en los modos en que se representa "lo nacional". La segunda es que el análisis literario y las ciencias sociales en general han incorporado la dimensión étnico-racial en sus estudios sobre la historia, la cultura y, en menor medida, en la literatura. La tercera es que correlativamente el Estado uruguayo ha dado algunos pasos en su reconocimiento de la diversidad cultural de la sociedad revirtiendo la idea de un pais homogéneo desde el punto de vista étnico-racial que dominó las formas de representar lo nacional desde comienzos del siglo XX.95

Parte de esa revisión de la forma histórica "Estado-nación" que las ciencias sociales y las humanidades han impulsado en los últimos años tuvo el efecto de volver a analizar el siglo XIX. En el campo de la cultura y la literatura, en las últimas dos décadas, el siglo XIX uruguayo ha sido abordado desde muy diferentes puntos de vista, mostrando también

95 Como ejemplo de este reconocimiento hay tres hechos importantes: el primero es la aprobación de la ley $\mathrm{N}^{\circ} 18.059$ que establece el 3 de diciembre como el "Día nacional del candombe, la cultura afrouruguaya y la equidad racial" aprobada en noviembre de 2006; el segundo la aprobación de la ley $\mathrm{N}^{\circ} 18.589$, del 18 de septiembre de 2009, que establece el 11 de abril como el Día de la Nación Charrúa y de la Identidad Indígena; y el tercero es la entrada del candombe a la "Lista representativa del Patrimonio Cultural Inmaterial de la Humanidad" de la UNESCO, aprobada por la Comisión Intergubernamental reunida en Aboud Dhabi (Emiratos Árabes Unidos) entre el 28 de septiembre y el 2 de octubre de 2009. 
una correlativa diversificación de teorías y metodologías del análisis literario y cultural que surgieron en la posdictadura. Se han ensayado análisis desde una noción amplia de discurso que comprende productos textuales y no textuales como himnos nacionales, discursos de y sobre los héroes, fiestas populares, discurso femenino, periódicos, monedas, banderas, fechas y conmemoraciones (Achugar, 1998 y 2003). Una perspectiva más específica se ubica en el cruce o articulación entre poesía y política, entendiendo la literatura como "un discurso social más" que contribuyó a una "política de la memoria" (Rocca, 2003: 8-9). También en el contexto de una historia cultural, en la que se privilegia las oposiciones entre lo urbano y lo rural, la oralidad y la escritura (De Torres, 2008: 10). Desde el punto de vista de la filología clásica se ha estudiado el clasicismo como lenguaje, como "un verdadero código, que servía para expresar distintas posturas ideológicas" con la constatación de una abundante utilización de autores "modélicos" como los griegos Homero y Píndaro y los latinos Cicerón, Virgilio, Horacio, Ovidio o Salustio (Introini y Herrera, 2008: 10 e Introini, Herrera y Moreira, 2012). Otros estudios privilegian géneros específicos como el teatro (Irigoyen, 2000) o la narrativa breve (Rossiello, 1990). Finalmente los estudios de género atendieron a la producción textual y cultural de la mujer en el XIX y en particular su conexión con el feminismo (De Torres, 1995; Cánova 1998; Hernández, 1998). A partir de estas profundizaciones se hace necesaria la confección de un “mapa cognitivo" del siglo XIX, y también de los discursos críticos de los últimos años, que englobe todas estas problemáticas y articule lecturas a veces disímiles. En este trabajo agrego una perspectiva concreta y específica, la étnico-racial, cuya presencia marginal en la bibliografía casi siempre supone la exclusión de los afrodescendientes de la cultura escrita. A través de la trayectoria individual de Jacinto Ventura de Molina intenté complejizar este supuesto e introducir una perspectiva distinta que complejice el ya 
fragmentado escenario de los estudios sobre el siglo XIX.

Según Rocca el siglo XIX fue escasamente estudiado por la crítica y la historiografía literarias en Uruguay. Las razones de este desinterés, siguiendo a Rocca, son múltiples y responden a un conjunto de problemas: una identidad nacional inestable y una literatura que no podrá llamarse "nacional" hasta bien entrado el siglo XIX, una perspectiva teórica que le dio importancia exclusivamente a las "bellas letras", de lo que se desprende además una selección de alguna obra u autor válido según los criterios de algún crítico específico (Rocca, 2003: 5-9). A estas razones es necesario agregar otros aspectos, que se derivan de la introducción de la variable étnico-racial en la crítica literaria. La idea de una nación blanca-europea e indiferente a los "problemas" raciales que otros países latinoamericanos tenían, no surgió de la nada. Este imaginario comenzó a gestarse en las primeras décadas del siglo XIX, recibió una fuerte impronta con la modernización de fines del siglo XIX y se consolidó en el centenario de la primera constitución celebrado en 1930 permeando a las generaciones siguientes que terminaron de universalizar una literatura nacional (una tradición inventada) aún más indiferente a la cuestión étnico-racial. Un repaso no exahustivo de algunos textos de la crítica literaria en torno a la cuestión de la literatura nacional, escritos en diferentes momentos y circunstancias, puede ayudar a entender cuál fue el tratamiento de la cuestión étnico-racial en Uruguay.

Tal vez en el siglo XIX la cuestión étnico-racial fue central en el pensamiento postivista y en la construcción del naciente Estado-nación. Durante el siglo XIX la idea de nación estaba unida, en la cabeza de la elite letrada, a la idea de una cultura y principalmente de una literatura nacional. Influido por este aire de época Andres Lamas publicó en 1864 la segunda edición del libro Poesías de Adolfo Berro, un poeta romántico muerto a los 22 años, promesa trunca de una literatura nacional en ciernes. Esa segunda 
edición, la primera fue de 1842, iba precedida de un estudio introductorio en el que Lamas reflexionaba sobre la cuestión de la literatura nacional y sus orígenes. El texto es parte de lo mucho que se escribió sobre el punto en el siglo XIX. Uno de los puntos sensibles para el discurso nacionalista es la cuestión del origen de la nación y de la literatura nacional. Para Lamas esto está relacionado en parte con los pueblos originarios en la medida en que, afirma, el origen de la nación siempre está atado a la presencia de un poeta guerrero o religioso. Pero en el caso de Uruguay, continúa Lamas, la poesía indígena "no existe" porque fue aniquilada por "la espada conquistadora", y si bien el idioma de los pueblos originarios "se habla en gran parte del litoral de nuestros grandes ríos interiores" nuestra historia está ligada indisolublemente a Europa y al adelanto de su civilización (36).

Escrito en un lenguaje racista, que supone la aniquilación total del indígena y su inexistente aporte a la cultura nacional, el texto funda un origen en el que hubo una relación desigual entre dos razas (europea e indígena) excluyendo de este escenario a los esclavos africanos y sus descendientes. Para Lamas los afrodescendientes son un problema presente, y así lo indica su análisis del interés de Adolfo Berro por combatir el "horror" de la esclavitud. Para Lamas, Berro había sido defensor de esclavos en 1839, lo que le dio la posibilidad de tomar contacto con los detalles de la "opresión que pesa sobre esos míseros hombres" (22). Abolida la esclavitud durante la guerra civil entre blancos y colorados (hubo de hecho dos aboliciones, una en 1842 y otra en 1846, destinadas a engrosar los ejércitos de ambos bandos) el asunto de la esclavitud se escribía todavía en presente y no tenía relación alguna con la cuestión de la literatura nacional y sus orígenes. Por el contrario el ideologema del exterminio de los indígenas, con las campañas de Rivera en su primer gobierno, hizo que proliferara por estos años una literatura romántica que celebraba al indígena y que inicia una tradición literaria cuyo punto cúlmine es el Tabaré (1888) de 
Zorilla de San Martín (Rocca, 2003: 150-155).

En 1885, dos décadas después del texto de Lamas, Francisco Bauzá publica Estudios literarios tocando otra vez el tema racial en dos artículos sobre los orígenes de la literatura uruguaya. En "El gaucho" por ejemplo se refiere a ese grupo social como "una raza nueva" (208) que no es otra cosa que la mezcla de españoles y portugueses fugados con los charrúas, de donde provienen sus costumbres y cultura. "El gaucho es el tipo primitivo de la civilización uruguaya (...) triple fusión de la sangre charrúa, española y portuguesa" (224). Luego en "Los poetas de la revolución” Bauzá desarrolla mejor su argumento de la mezcla racial: "no pudieron los conquistadores ni dominar ni despedir a los charrúas, quienes terriblemente adheridos al sentimiento de su libertad propia y de la independencia nacional, lucharon siempre por conservarlas." (68) Frente a esta resistencia charrúa los españoles comenzaron con la introducción de la "sangre hispana" proveniente de las Islas Canarias, Asturias y Galicia. La mezcla de la sangre hispana con la indígena “daba su antiguo tono a la población nacional":

Los españoles mismos, escasos de mujeres, tomaban por suyas a las mujeres charrúas; y nuestros indios, en los combates en que capturaban prisioneros, se abstenían de soltar las mujeres españolas que caían en su poder y con las cuales se unían. En conclusión pues, ya por las portuguesas, gallegas y canarias que se unían a los charrúas, el origen primitivo de nuestra raza recobró sus derechos, y cuando la Revolución estalló, la sociedad uruguaya no conservaba de la España otra cosa que su religión, su lenguaje y la sabia organización de la familia (68-69)

En este escenario de mestizaje, en el que Bauzá excluye todo trazo de violencia, se advierte 
la imposición de los valores del conquistador (religión, lenguaje y ortanización de la familia) a pesar de la mezcla de sangres y colores de piel.

En el ensayo sobre Acuña de Figueroa, Bauzá reitera el argumento de Lamas en 1842 cuando afirmaba que la literatura nacional no era todavía una realidad. Lamas seleccionaba a Adolfo Berro de un pasado histórico "corto" (europeo) y postulaba un proyecto de literatura nacional del que Berro era un potencial representante. Su muerte temprana frustró ese proyecto pero dejó una obra que permitía pensar en un proyecto futuro. Veinte años después Bauzá corre el límite un poco más atrás, en el pasado colonial, en la figura de Acuña de Figueroa como el primer escritor uruguayo aunque sigue sosteniendo la inexistencia de una literatura nacional que sólo ve emerger en la obra de Zorrilla de San Martín y en algunos gauchescos. Otra vez el escenario del origen estaba marcado por cuestiones raciales entre europeos (españoles y portugueses) y pueblos originarios (generalizados bajo el rótulo de charrúas) y otra vez los afrodescendientes son invisibilizados o en todo caso son un "problema" del presente que nada aporta a este debate $^{96}$.

En 1885 los letrados (en particular los montevideanos) comenzaban a inventarse una tradición para la literatura y la cultura letrada uruguaya aunque siguieran viéndola como una tarea inacabada en el presente. Mientras los afrodescendientes, con las mismas herramientas de los letrados blancos, reclamaban su acceso a una ciudadanía plena mediante la prensa, se los excluía de ese pasado. Casi tres décadas después Carlos Roxlo publica su Historia crítica de la literatura uruguaya (1912) y la historia vuelve a repetirse.

96 De hecho Bauzá apenas menciona el "Canto patriótico de los negros" de Acuña de Figueroa sin siquiera considerarlo como parte importante de su obra (12). El poema fue publicado en el diario El Universal de Montevideo en 1830, firmado por "Cinco ciento Neglo de tulo Nacione". Fue luego reproducido en el Parnaso Oriental (Tomo I, 1835) con la firma de su autor. El poema hace un simulacro de la voz de un coro de negros esclavos que celebran la ley de libertad de vientres y es tomado como representación del "habla de los negros" en el Río de la Plata. 
El escenario del origen vuelve a plantearse y el gaucho aparece como una raza nueva, producto de la mezcla del europeo y el indígena: "El toldo charrúa le dio sus hurañeces y la sangre española sus hidalguías" (Roxlo, 1912: 35). Por influencia de las ideas de Hipólito Taine, que postulaba una relación determinante entre ambiente, raza y cultura, Roxlo reflexionó sobre los orígenes de la nación casi en los mismos términos que Bauzá (citándolo de hecho). La "raza" que dio origen a la poesía uruguaya es, para Roxlo, una mezcla, una "amalgama" de dos razas, la charrúa y la europea (española y portuguesa). Los africanos y sus descendientes no son mencionados en este fragmento y otra vez son excluídos en este paisaje de toldos y ranchos de totora del Uruguay de los “orígenes".

Otro momento crucial para el discurso nacionalismo es el período de los Centenarios en el siglo XX, que conmemoraron el nacimiento de la nación y que significativamente se ubican en Uruguay en 1930, es decir, en el nacimiento del Estadonación y no en el período revolucionario como se hizo, por ejemplo, en Argentina. En un estudio reciente sobre los afrodescendientes uruguayos George Reid Andrews analiza los discursos que, antes y después del Centenario, crearon y promovieron en Uruguay la idea de una sociedad europea blanca alejada de los problemas raciales de otros países latinoamericanos (2010: 2-6). Como correlato los discursos sobre la literatura nacional que circularon a raíz del Centenario fueron abandonando el tono racial del siglo XIX. El Centenario fue una oportunidad o una excusa que los letrados montevideanos aprovecharon para realizar distintos balances de una tradición letrada que contaba ya a esa altura con autores reconocidos. La literatura nacional era ya una realidad sobre la que se podía hacer un balance y proyectarla a futuro. En ese marco Alberto Zum Felde publica Proceso intelectual del Uruguay y crítica de su literatura (1930) en tres tomos que abarcan la colonia y el romanticismo (tomo I), la "generación" novecientos (tomo II) y la 
“promoción” del Centenario (tomo III).

En el primer tomo de su Proceso intelectual por ejemplo, Zum Felde introduce a los afrodescendientes en un apartado sobre la formación colonial, pero por los candombes, en algún sentido dentro de la representación hecha por los viajeros europeos y los cronistas:

La diversión de aquella buena gente, era, en ciertos días, los grotescos y lúgubres bailes de negros, que llamaban candombes, en los que al son monótono de los tamboriles y los cantos, vestidos con las viejas prendas de gala de los amos, evocaban ancestrales ritos mágicos de sus selvas, entre las contorsiones de un histrionismo cuyo frenesí llegaba, a menudo, a la epilepsia (39).

En el tercer tomo Zum Felde, analizando a sus contemporáneos, destaca la obra poética de Ildefonso Pereda Valdés, apartándolo de la moda "snob" del africanismo francés:

Mas, sea cual fuere la medida en que esa moda francesa haya podido influir sobre Pereda Valdez (sic) -siempre muy en contacto literario con París- lo cierto es que sus poemas negros tienen arraigo y tradición en la propia vida nacional platense. No puede acusarse al escritor uruguayo de haber adoptado un motivo exótico; al contrario, el motivo del negro es exótico en Francia, pero aquí, en el Plata, es nativo; es tan nativo aquí como el indio o el gaucho (160-161).

En los párrafos siguientes Zum Felde reflexiona sobre el aporte de "la sangre negra" a la población uruguaya, aunque la relega al medio rural y a los "elementos populares", 
afirmando también que hay "mucha sangre europea pura en nuestra población” (161). Asimismo encuentra el origen de la poesía de Pereda Valdés en los poemas "negristas" de Francisco Acuña de Figueroa.

En los años sesentas, otra "promoción" o "generación" en el lenguaje crítico de Zum Felde, toma su lugar en la cultura letrada impulsando una revisión crítica de la tradición cultural y literaria uruguaya consolidada en el Centenario. Se trata de la “generación crítica”, en la terminología de Ángel Rama, o "generación del 45” en la de Emir Rodríguez Monegal. Dos colecciones populares que todavía circulan como material de divulgación -Capítulo Oriental y Enciclopedia Uruguaya- incluyen, abarcando un amplio panorama de disciplinas en el caso de la Enciclopedia (historia, antropología, sociología, música, economía, entre otras), una revisión de la literatura. ${ }^{97}$ Los discursos sobre los origenes literarios del Uruguay presentan un gran nivel de especialización del discurso crítico y han excluido el lenguaje racializador y racista del siglo XIX. Pero no hay en ellos ni un rastro de escritores afrodescendientes ni un párrafo dedicado a la cuestión étnico-racial.

En su texto, Ángel Rama reitera la vieja hipótesis del siglo XIX sobre los pueblos originarios y señala el caracter de pueblo transplantado para Uruguay: "Surgido tardíamente a la vida colonial y en una región carente de alguna alta cultura autóctona, el Uruguay recogerá escasísimos elementos indígenas (palabras, usos) sirviendo de asiento a un pueblo de transplante europeo"(22). Otra vez un escenario fundacional en el que se excluye al afrodescendiente, que curiosamente no es considerado un pueblo transplantado ${ }^{98}$, y que, con o sin razón, desestima el aporte indígena.

\footnotetext{
${ }^{97}$ Se trata de los fascículos 1 y 2 de Capítulo Oriental elaborados por Carlos Real de Azúa y Ruben Cotelo respectivamente; y del Tomo II de la Enciclopedia Uruguaya elaborado por Ángel Rama. Para una revisión crítica de estas colecciones ver Trigo (2003).

${ }^{98}$ Cabe señalar que la expresión "pueblo transplantado" es tomada de la clasificación elaborada por el antropólogo brasileño Darcy Ribeiro en su libro Las américas y la civilización publicado en Montevideo en 1968.
} 
El caso de Capítulo Oriental es más claro en cuanto no menciona la cuestión racial en ningún momento de la primera introducción a cargo de Real de Azúa, que abarca el período de la colonia hasta 1918, aunque plantea hipótesis de lectura interesantes como la idea de una literatura rioplatense (entre puertos) más que dividida en literaturas nacionales. En la segunda introducción a cargo de Ruben Cotelo aparecen tres elementos de distinta importancia. El primero es un recuadro con la foto de Isabelino Gradín y su familia, en la que el afrodescendiente aparece como objeto de la poesía vanguardista de Juan Parra del Riego, un peruano que vivió en Uruguay y escribió el poema "Polirrítmico dinámico a Gradín, jugador de football” (20). El segundo es una mención al negrismo de Pereda Valdés entre los tímidos "ismos" de la vanguardia practicada en Uruguay de "resultados bien modestos" (22). Finalmente, en la contratapa, sin ninguna explicación didáctica aparece una reproducción en blanco y negro de un cuadro de Pedro Figari, un "Candombe" perteneciente a la colección de Margarita Figari de Faget.

Es posible entonces afirmar en general que durante el siglo $\mathrm{XX}$, salvo algunas excepciones, el discurso crítico perpetuó una perspectiva -imaginada en el siglo XIX- casi ciega al aporte de los grupos no europeos a la cultura letrada uruguaya, que consistió en imaginar los orígenes como una fusión de dos "razas" (europea e indígena), en la que los pueblos originarios aportaron apenas palabras o usos, y en la que se excluye al afrodescendiente o se lo recluye a un ámbito no-letrado, folklórico o popular (el candombe). Estos no es en sí mismo un problema. Pero cuando, como correlato de estos discursos críticos, aparecen comunidades letradas de afrodescendientes en distintos momentos históricos desde 1870 la pregunta por el color de la piel en la literatura uruguaya cobra particular importancia.

A partir de la década del noventa del siglo XX los discursos críticos retomaron la 
cuestión étnico-racial pero en un sentido muy diferente al siglo XIX contribuyendo en parte a democratizar el relato del pasado y reescribiendo aquel paisaje humano sin afrodescendientes que proponían los letrados de aquel entonces. Uno de los protagonistas de este cambio fue la propia elite letrada afrodescendiente que a través de Organizaciones Mundo Afro publicó dos libros como parte de su intención de reinterpretar el pasado. Hay muchos otros actores y causas para explicar las transformaciones que se produjeron desde los noventas, que incluyen importantes modificaciones en la interpretación de los pueblos originarios en Uruguay, pero en el contexto de este trabajo me interesa analizar el caso particular de los afrodescendientes. Antes de ingresar a las publicaciones de Mundo Afro es necesario señalar que esta tarea tiene un antecedente en la obra de Ildefonso Pereda Valdés. Su obra ensayística inicia una valoración histórica del lugar de los afrodescendientes en Uruguay junto a la de otros investigadores contemporáneos como Homero Martínez Montero, Eugenio Petit Muñoz y Carlos Rama.

En su libro El negro uruguayo. Pasado y presente (1965), una segunda edición ampliada de Negros esclavos y negros libres (1941), Pereda incluye un apartado sobre el "Desarrollo intelectual del negro uruguayo" en el cual reduce dicho desarrollo a la utilización de la palabra escrita. El dominio del periodismo, la poesía y el ensayo son el parámetro del nivel de integración de los afrodescendientes a las sociedades nacionales. Desde esta perspectiva Pereda brinda un marco americano a la literatura negra (los casos de Norteamérica y Brasil se incluyen en su idea de lo "americano") y establece una clara separación entre los escritores negros del siglo XIX y los del XX. Los primeros desarrollaron un "estilo blanco" acorde a las estéticas dominantes pero ciego a las cuestiones raciales; y los segundos esgrimieron la "negritud" como discurso de afirmación y orgullo de la afrodescendencia. 
El trabajo de Pereda tiene el mérito de ser uno de los primeros textos, sino el primero, sobre la literatura escrita por afrodescendientes en Uruguay. Tiene además un valor testimonial porque el autor menciona en dos oportunidades su lugar como investigador y promotor de esa "literatura negra". Como primer retrospectiva histórica es concluyente en cuanto a la existencia de una tradición literaria elaborada por afrodescendientes que abarca sus publicaciones periódicas, la poesía, la dramaturgia y el ensayo $^{99}$, mencionando también otras expresiones artísticas. ${ }^{100}$ Para Pereda Valdés el precursor de la literatura negra uruguaya es Acuña de Figueroa por su "Canto patriótico". ${ }^{101}$ Luego la caracteriza como una literatura de unos pocos escritores autodidactas, limitados por sus condiciones socio-económicas, poco reconocidos por el campo literario y poco estimulados por el Estado:

El negro uruguayo alcanzó en los últimos años desde 1920 en adelante un desarrollo intelectual apreciable, que si bien no alcanza la plenitud de la literatura cubana, brasileña o estadounidense, se justifica en la realidad de los hechos, por cuanto el escritor negro en el Uruguay no tiene la posiblidad de encontrar editores para sus libros, no han sido premiados en los concursos literarios aunque más no fuera como estímulo y no han encontrado aún el apoyo que necesitan del Estado. Creemos que la evolución de los escritores negros podrá tener mayor desenvolvimiento

\footnotetext{
${ }^{99}$ Los periodicos son La Conservación (1872), La Propaganda (1893-1895), Ecos del Porvenir (1900), La Verdad (19111914), La Vanguardia (1928), y principalmente Nuestra raza (Primera época: San Carlos, 1917, Segunda época: Montevideo, 1933-1948). Pereda no menciona El Progresista (1873) producido por el mismo equipo que La Conservación. Sobre estas dos publicaciones ver Gortázar (2006) y Andrews (2010). De este último hay edición en español (2011). Los poetas son Pilar E. Barrios, Virginia Brindis de Salas, Carlos Cardozo Ferreira, Juan Julio Arrascaeta, Julio Guadalupe, José Suarez, Salvador Iturriaga Cambón, Feliciano A. Barrios, Angélica Duarte, Santos A. Alaniz. Los ensayistas: Marcelino Bottaro, Elemo Cabral y Lino Suárez Peña. En teatro Isabelino José Gares. Para un estudio sobre el teatro de los afrodescendientes en Uruguay ver Cordones Cook.

${ }^{100}$ Los pintores mencionados son Ramón Pereira, Ruben Galloza, Mario Pio Balles, Orosmán Echeverry y Carlos María Martínez. Además menciona al guitarrista Julian García Rondeau.

${ }^{101}$ Este poema que simulaba el habla bozal de los negros es tomado por Pereda como precursor de su propia poesía (209210) así como lo hizo Zum Felde en 1930.
} 
cuando se puedan vencer estas barreras, que si no son de prejuicio y discriminación, son por lo menos de indiferencia por la obra que realizan (213).

Con esta reflexión Pereda cierra su ensayo reiterando su argumento sobre la calidad de la literatura de los afrodescendientes - menos "plena" que los otros ejemplos nacionales que cita- explicando las causas que han lesionado su capacidad de "evolución": a las razones socio-económicas agrega "barreras" vinculadas al prejuicio, la discriminación y la indiferencia. Este último aspecto resulta interesante a la luz de la indiferencia general de la crítica literaria a lo étnico-racial.

En 1990 y 1997 Mundo Afro publica los dos tomos de la Antología de poetas negros uruguayos elaborada por Alberto Britos Serrat e ilustrada por el artista plástico Ruben Gallosa. En el estudio introductorio del primer tomo Britos reitera alguna de las hipótesis de Pereda Valdés (pobreza, autodidactismo, falta de reconocimiento literario y estatal) y agrega otras (etapas del siglo XX, mejor caracterización de la poesía). Mientras el texto de Pereda es un capítulo de un estudio más amplio que no tiene su centro en la literatura, el texto de Britos es una justificación de una selección de artistas negros que el lector puede contrastar inmediatamente en la antología. El texto de Britos tiene otra ventaja comparativa. Pereda había publicado una antología de poesía negra pero su ámbito era iberoamericano (Pereda, 1936). La muestra de Britos cuenta entonces con la ventaja de poder agregar más poetas, además de incluir escritores posteriores a 1936. Al igual que Pereda Valdés (en su ensayo sobre el intelecto negro), la tradición letrada que Britos rescata en el siglo XIX es la prensa y composiciones que no fueron elaboradas por los afrodescendientes como las de Acuña de Figueroa. Sin embargo el caso del primer abogado 
afrodescendiente Jacinto Ventura de Molina es excluído pese a su producción poética y a pesar de que es mencionado en una nota a pie como antecedente de los "profesionales" negros. El grueso de la producción letrada que Britos quiere mostrar pertenece al siglo XX.

La segunda acción de Mundo Afro que me interesa destacar es la publicación en 1996 de otro libro de poemas: Ansina me llaman y Ansina yo soy. Elaborado por un colectivo de autores con el respaldo de la organización, el libro proponía un conjunto de textos que se atribuyeron en 1950 a Joaquín Lenzina o Ansina, el famoso asistente de Artigas en Paraguay. ${ }^{102}$ En uno de los textos introductorios el periodista Danilo Antón afirma:

A los señores eruditos les pido recuerden cómo fue en realidad la historia -Don Joaquín Lenzina, negro, fue fundador de la literatura oriental y padre de la patria vieja. Guitarrero, arpista, poeta y payador políglota, gestor de ideas y aconteceres junto a Don José, Andresito y tantos otros en los tiempos de los orígenes. En vuestros próximos libros, traten de no olvidarlo nuevamente

Este reto, que se propone como una contra-verdad de la historia, representa una voluntad explícita de desafiar el relato del Estado y colocar a Ansina en el Parnaso de los poetas de la patria. Al menos en el campo del discurso el escenario de los orígenes bi-racial se completa con la presencia de un afrodescendiente mediante una operación política que desafía a la nación blanca e interpela a los “eruditos".

\footnotetext{
${ }^{102}$ El libro, y en general el caso de Ansina, presenta una serie de dificultades que analicé en otro texto (2006).
} 
Esta interpelación al saber académico fue una de los tantos estímulos que en lo personal me llevaron a internarme en la literatura escrita por los afrodescendientes en Uruguay y a conocer el caso de Jacinto Ventura de Molina. Me preguntaba por qué estos investigadores, apoyados por una organización de la sociedad civil negra, elegían el caso dudoso de Ansina frente a la contundencia de más de mil folios manuscritos de un abogado afrodescendiente. La historia de Ansina colocaba a los afrodescendientes al lado de Artigas y eso le daba mayor visibilidad al planteo político de estas organizaciones. Si bien Molina era el primer abogado negro en Uruguay, representaba la oposición a Artigas y su perspectiva ideológica, monárquico y católico, no es atractiva para la lucha de estos colectivos frente al racismo en Uruguay.

Sin embargo, el caso de Jacinto Ventura de Molina ofrece una enorme oportunidad para comprender la situación de un hombre negro libre, que vivió sus primeros dieciseis años al servicio del militar español José Eusebio de Molina como si fuera un esclavo de la casa. El "como si" es importante porque si bien el militar lo separó de sus padres, que también eran libres y continuaban a su servicio, e hizo con él lo que quiso como si se tratara de un esclavo de su propiedad, también se dedicó sistemáticamente a su alfabetización y evangelización. Al lado del español Jacinto Ventura aprende a leer y escribir en español, aprende latín, dibujo, aritmética, habla portugués o al menos lo entiende. Su formación fue una tarea colectiva de Eusebio de Molina y de su entorno, lo que le proporcionó una red social que lo contuvo y lo ayudó a ganarse el sustento una vez muerto su tutor y protector. Como hombre libre aprovechó ciertas zonas de su pasado, como su formación militar y letrada, y escondió otras como su oficio de zapatero, que no le reportaban posibilidades de ascenso social o algún beneficio. Los manuscritos de Jacinto Ventura de Molina, su práctica escrituraria, el espacio y la red social en la que desarrolla su 
acción y fundamentalmente sus textos, constituyen objetos privilegiados porque obligan a repensar el campo letrado de la primera mitad del siglo XIX desde la perspectiva de este afrodescendiente y abandonar el supuesto radical de su exclusión para abordar una perspectiva menos rígida.

Pero que conociera las reglas no implicaba que Jacinto Ventura perteneciera a la ciudad letrada como un ciudadano pleno. Siempre necesitó de protectores, de los que dependió en diferentes grados. Al comienzo su vida dependió en buena medida de José Eusebio de Molina, luego de Catalina Gil, con quien vivió en Buenos Aires y tenía una relación sentimental con el militar, de Teresa Fagiani, a su regreso a Montevideo. Muchos años después Joaquín de la Sagra y Périz lo protegió y ayudó desde su entrada al Hospital Caridad de Montevideo en 1828. La existencia de protectores no disminuyo en nada las burlas, insultos, desprecio y desconfianza que la ciudad letrada le ofreció. Esa hostilidad fue la que marcó en sus papeles la impronta del desinterés con la que historiadores y literatos afrontaron sus textos hasta que se perdieron en la memoria letrada.

El proceso de aculturación al que Molina fue sometido funcionó muy bien en distintos niveles. Cuando se convirtió en un hombre libre recordó siempre a su tutor como un buen amo, a quien sirvió como buen sirviente hasta el momento de su muerte. Se mimetizó con él a tal punto que recordó siempre una de sus últimas frases, dichas en su lecho de muerte: “Jacinto, yo muero, encomiéndame a Dios, mira como vives, porque cualquier cosa que te suceda, se atribuirá a la mala crianza que yo te he dado". Los recuerdos de aquel período de su vida estarán vivos en sus manuscritos y serán utilizados para diferentes fines. El escenario de la mimesis colonial convirtió a Molina en una copia casi igual a su tutor y lo colocó como un férreo defensor de la monarquía y de la iglesia de modo tal que cuando las tropas luso-brasileñas ocuparon la Banda Oriental hacia 1817 
pudo sobrevivir como colaborador del Barón de la Laguna durante más de una década. El nuevo escenario nacional, con una elite liberal aunque algo conservadora, obligó a Molina a adaptarse, aunque su capital cultural y su perspectiva estaban todavía atados a aquella formación colonial que lo convirtió en lo que era: un letrado negro. Sus habilidades para sobrevivir son innegables porque es reconocido como abogado por parte del Estado en 1832 e incluso llega a intermediar como tal en distintos casos.

Así se fue construyendo su subjetividad liminar en un entrelugar: entre la esclavitud y la libertad, entre la monarquía y la ilustración, entre españoles y portugueses, entre los esclavos y el Estado. Hacerse fronterizo no puede despegarse del hecho de la autoconciencia que la escritura le proporcionó. Aunque nunca utilizó el género autobiográfico como tal, en muchos de sus manuscritos predomina un tono, otra vez entre público y privado, en el que es notoria esta facultad de autoconciencia de su excepcionalidad, de sus capacidades como letrado inusuales en los afrodescendientes que lo rodeaban. Esto se hace más notorio en el uso táctico de sus recuerdos, en su manipulación para diferentes fines. Sin embargo no fue el único que escribió en este período. En el ámbito anglosajón muchos esclavos hicieron uso de sus relatos y los antiesclavistas tuvieron un rol activo en esta proliferación de discursos autobiográficos publicados con el fin de remarcar las brutalidades de la trata esclavista. En América Latina sin embargo este tipo de textos no prosperaron, salvo el testimonio del esclavo cubano Juan Francisco Manzano, a quien le fue más difícil acceder a la letra, aunque alcanzó a verse publicado y ser algo reconocido como escritor.

A todos los caracteriza un proceso de aculturación, que implicaba una mimesis con la cultura blanca, aunque en el ámbito anglosajón la presencia de lo africano está más marcada, tal vez como forma de constrastar la candidez de la vida antes de la terrible 
irrupción de la trata de esclavos. La experiencia de ser esclavizados permite pensar en la idea de una diáspora africana que atraviesa toda la costa atlántica y el Caribe aunque las experiencias de los esclavos que tomaron la palabra escrita para decir "yo" se configuraron de distintas maneras en virtud de colonizaciones distintas (anglo, francesa, portuguesa o española) y procesos de nacionalización también heterogéneos. Sin embargo hay una posición liminar que ocupan estos letrados negros que los ubica en espacios de transacción entre culturas y lenguas, algo que viene dado por la violencia de la trata y la capacidad de sujeto para adaptarse, no sin violencia, a las presiones estructurales de las sociedades a las que fueron trasladados como esclavos. La pobreza, el desprecio, la burla, la desconfianza fueron la moneda común con la que tuvieron que lidiar a cada momento. Algunos se salvaron individualmente (sobre todo en el ámbito anglosajón), otros precisaron de acciones colectivas (sea por el paternalismo de una elite liberal como el caso de Manzano, o por una Sociedad de Congos como el caso de Molina).

Al final de su vida Molina encontró en el colectivo de los negros Congos de Gunga una forma de sobrevivir ante la pertenencia deficitaria a una sociabilidad letrada mayoritariamente blanca. Así encontró un lugar perfecto para su subjetividad fronteriza, ofreciendo sus servicios como abogado e intermediando con el Estado para que una Sociedad de Negros Congos de Gunga fuera reconocida y para que una vez aceptada, sus compañeros pudieran realizar sus bailes de reyes en 1835, luego de una revuelta de esclavos que provocó su prohibición. Al igual que otros sujetos fronterizos en el mundo andino, Molina echó mano a diferentes recursos para, en su caso particular, probar la fidelidad de los congos a las instituciones: recursos como su historia personal, la historia de otros negros en el período colonial que seguramente oyó de amos y esclavos, el Antiguo Testamento y otros textos. En el caso de Molina su pertenencia a dos mundos le permitió 
poner en juego este capital simbólico y conseguir sus objetivos para la Sociedad de Negros Congos.

Algunas investigaciones realizadas en los años noventa del siglo XX posibilitaron la emergencia de objetos de estudio como los manuscritos de Jacinto Ventura de Molina. En 1998, dos años después de la aparición de la antología poética de Ansina, se publica La fundación por la palabra editado por Hugo Achugar con trabajos de varios investigadores. En su análisis del siglo XIX latinoamericano Hugo Achugar utiliza una noción amplia de discurso que articula con la noción de memoria y con el debate sobre nación y nacionalismo de las últimas décadas (Achugar 1998, 2003). Propone estudiar el nacionalismo como una "formación discursiva" (Foucault) o "comunidad interpretativa" (Fish) que producía un "discurso religante e interpelante" (Althusser) recuperando la perspectiva de La ciudad letrada para este nuevo contexto de análisis:

Esta centralidad de letra, literatura y letrado refuerzan la idea de "la fundación por la palabra" de los Estados-nación de América Latina durante el siglo XIX. Una fundación homogeneizadora, como señala Ramos, en función de una lengua nacional que "olvidaba" o "borraba" toda manifestación lingüística y cultural que no encajara con el proyecto nacional que los letrados se encargaron de imponer mediante la escritura del poder y el poder de la escritura (24)

Aún cuando se da privilegio a la escritura, en el prólogo de La fundación por la palabra ya se configura el problema de la creación de símbolos diversos para inventar la nación que 
exceden la producción letrada. Si bien los trabajos reunidos en La fundación por la palabra se centran en la producción escrita: el Parnaso Oriental de Luciano Lira publicado entre 1835 y 1837 (Achugar), himnos (Poch) escritos de los héroes (D’Alessandro), mujeres letradas (Hernández), la preocupación por aspectos performativos de esa memoria letrada de la nación atraviesa todos los ensayos y se continua en el siguiente trabajo de 2003, Derechos de memoria.

Otro aspecto a destacar es la preocupación por los sujetos excluidos de la ciudad letrada nacional, el borramiento de su propia voz o escritura y su representación desde el poder. El discurso de la mujer (letrada) por ejemplo, se estudia no como resistencia sino como parte del proyecto hegemónico que la domina en tanto no puede sustraerse de la tarea de creación de una ciudadana ideal, disciplinada, para el orden nacional imaginado. Hay una tensión, al menos en La fundación por la palabra, entre aquellos aspectos negativos de la cultura escrita (vigilancia, disciplinamiento, limitación de la ciudadanía) y el hecho de fundar o crear con la escritura, con énfasis en los primeros.

En un sentido similar el trabajo de Pablo Rocca Poesía y política en el siglo XIX (Un problema de fronteras) (2003) con su periodización del siglo XIX, también prepara el escenario para la emergencia de Molina. El investigador propone situar entre 1787 y 1837 la formación del "campo intelectual" en el siglo XIX uruguayo. Plazo que coincide, sin que Rocca haga referencia a esto, con el período de disciplinamiento y posterior actividad letrada de Jacinto Ventura de Molina. En parte el primer capítulo del libro puede interpretarse como un estudio de la configuración de la ciudad letrada en un contexto más acotado (el Río de la Plata y especialmente Montevideo) tomando como eje tres elementos centrales: el texto, el objeto que lo porta (libro, periódico, manuscrito), y la práctica que lo apropia (lectura pública o privada), planteo que Rocca toma del historiador Roger Chartier. 
Su propuesta desbarata en parte el ideologema de la literatura nacional o, al menos, lo recoloca respecto a las lecturas precedentes:

[...] durante todo el ajetreado siglo XIX, la banda oriental del Plata es un territorio en conflicto y, en gran medida, una zona en disputa por parte de los vecinos y hasta por varias potencias ultramarinas. La relación de dependencia con Argentina fue -y es- tan notoria por la cercanía física y las interpolaciones histórico-políticas, por la identidad común lingüística y cultural, por el peso de su mercado económico y simbólico, que sólo en un acto de muy buena voluntad se puede hablar de una literatura o de una cultura propiamente uruguaya entre 1825 y 1851 [...] Y quizá siga sin poder hablarse con seriedad del concepto hasta, por lo menos, la afirmación del Estado impuesta por el militarismo (6)

Más allá del debate sobre lo que sería "una literatura o una cultura propiamente uruguaya" una hipótesis como esta obliga a leer el siglo XIX uruguayo de un modo diferente a como lo ha hecho la crítica y la historia literarias desde Carlos Roxlo en adelante. En el caso de Rocca la hipótesis tiene algunas consecuencias metodológicas y de contenido: primero, la necesidad de una perspectiva regional, que tiende a poner énfasis en las relaciones Montevideo-Buenos Aires; segundo, una cierta tendencia (al menos en el primer capítulo) a considerar el discurso letrado en un sentido amplio que irá paulatinamente enfocándose en la poesía. Pero fundamentalmente la periodización de esta primera mitad del siglo XIX en un primer período que va de 1787 hasta 1820 y un segundo 
hasta el final de la Guerra Grande, cuando ya se configura un campo literario a instancias del romanticismo. ${ }^{103}$

El concepto teórico de ciudad letrada elaborado por Ángel Rama centraba su universo de análisis en la cultura escrita, especialmente en aquellos autores canónicos de distintas literaturas nacionales. Por otra parte el modelo suponía una ciudad letrada capital del estado-nación. El caso de Achugar representa una salida de ese modelo a través de la idea de discurso y la búsqueda de fuentes no necesariamente canónicas. El supuesto de una literatura nacional, que es otro supuesto sobre el que se monta la ciudad letrada, es indirectamente discutido por Rocca quien insta a pensar la "literatura uruguaya" como una literatura regional, al menos hasta la segunda mitad del siglo XIX. Ambas propuestas teóricas e historiográficas fueron un punto de partida para revisar el modelo de La ciudad letrada. Me interesa sustituir la idea de ciudad letrada por la de cultura letrada, un complejo de textos (manuscritos e impresos), habilidades (escritura, lectura) y objetos (libros, papel, plumas) así como un conjunto de reglas para una sociabilidad letrada que implicaba necesariamente compartir y disputar espacios sociales e interpretaciones sobre un conjunto de textos. El concepto de configuración cultural de Alejandro Grimson permite ampliar el marco de interpretación para incluir procesos como los de la transición entre la colonia y el Estado-nación. En esa formación histórica es que Molina aparece como un híbrido formado en el espíritu de la ilustración pero en una configuración colonial, monárquica y católica. Es decir, es un sujeto reformado por la educación, un

\footnotetext{
${ }^{103}$ Hay que señalar que la mayoría de los análisis sobre el siglo XIX, comentados aquí en general, consideran el siglo XIX con un criterio cronológico y por género literario. Rossiello (1990), por ejemplo, selecciona textos narrativos publicados en prensa entre 1830-1880, y toma la fundación del Estado-nación como inicio de la "narrativa breve uruguaya". Por otra parte considera un período de 50 años del siglo $\mathrm{XIX}$ en los que no establece períodos, estéticas y/o debates. Esto es independiente de la importancia del trabajo de Rossiello en la recuperación de textos nunca antes publicados. Otras perspectivas utilizan categorías elaboradas para la historia cultural europea (neoclasicismo, romanticismo y naturalismo) que no siempre funcionan para explicar la literatura del siglo XIX latinoamericano.
} 
“experimento" racional de un grupo de militares españoles en el Río de la Plata, que al mismo tiempo recibe una formación encuadrada ideológicamente en la monarquía y la religión católica. Esta hibridez explica lo incómodo del pensamiento de Molina cuando la configuración cultural Estado-nación empieza a instalarse hacia 1830.

En este período, Molina también propondrá la creación de un “Colegio de los Magos de María Rufina Campana”, una escuela para los afrodescendientes que llevaría el nombre de su esposa muerta. Esta idea tuvo al menos un lector dentro de la elite letrada que fue Joaquín de Sagra y Périz. ${ }^{104}$ Pero es todavía más importante el interés de Molina por sus pares en este período final de su vida y su confianza en el proyecto civilizador y modernizador en el marco de una cultura letrada. La iniciativa puede interpretarse también desde la perspectiva de Rama como esa proyección futura que la ciudad letrada diseña primero en la mente y luego materializa en la ciudad. El propio Molina dibuja un plano, bastante tosco, en el que proyecta esta escuela para los afrodescendientes.

Tanto este Colegio como la acción legal de Molina a favor de la Sociedad de los Congos de Gunga permiten pensar en la configuración de un espacio discursivo de los afrodescendientes en el siglo XIX uruguayo, y más específicamente la posibilidad de una cultura letrada dentro de la configuración nacional que se inaugura con la obra de Jacinto Ventura de Molina y cuarenta años después se consolida con un colectivo de periodistas afrodescendientes en los semanarios La Conservación (1872) y El Progresista (1873). ${ }^{105}$

${ }_{104}$ El documento puede consultarse en esta antología y es parte del archivo de Sagra y Périz que se encuentra en el AGN.

105 El semanario La Conservación se publicó durante cuatro meses (agosto-noviembre de 1872) y El Progresista apenas dos (setiembre y octubre de 1873). Hay una cierta continuidad entre ambos proyectos dado que fueron publicados casi por los mismos redactores (fundamentalmente Andrés Seco y Marcos Padín) posicionándose como únicos "órganos" de la comunidad afrodescendiente montevideana y representantes de sus intereses. Es por eso que, a pesar de algunos cambios, puede decirse que forman parte de un mismo emprendimiento político-cultural realizado por un equipo letrado integrado por afrodescendientes: la educación letrada de sus lectores y la candidatura de José M. Rodríguez como diputado. 
Estos escritores no mencionarán su trabajo, o al menos no lo plantearán como un antecedente, pero inciarán un trayecto que otros colectivos afrodescendientes continuarán durante todo el siglo XX. Tal vez esto se explique por las características de un proyecto letrado-periodístico y político inscripto ya en los problemas del Estado-nación y en el rechazo a la cultura colonial (Gortázar, 2006).

Visto desde el presente, también es posible aventurar otra hipótesis: que la articulación de un relato unitario de esta tradición letrada de los afrodescendientes es un producto reciente de las luchas políticas de organizaciones como Mundo Afro y que una actitud similar era poco probable hacia 1870 . La aparición en la esfera pública de estos periodistas afrodescendientes $-\mathrm{y}$ la de otros letrados negros durante el siglo XIX y XXhabilitaría a pensar en la existencia de una cultura letrada negra, como una formación discursiva específica, con sus propios lectores y su circulación, con una sociabilidad propia vinculada a la historia social, económica y política de este grupo social en la ciudad real. La lucha de Molina por inscribirse en una configuración letrada blanca, en sus formas de sociabilidad, en su cultura material generó burlas, insultos y algunos escasos reconocimientos. La creación de la Sociedad de Negros Congos de Gunga y la propuesta de construir una escuela para afrodescendientes marcan el pasaje a una dimensión colectiva y proyectan hacia el futuro una ficción -en tanto posibilidad, deseo y proyecto- de una cultura letrada negra fundada en instituciones como las Sociedades y en la instrucción letrada de los afrodescendientes. ${ }^{106}$

Estos espacios autónomos de los afrodescendientes en la cultura letrada, no

106 Tomo el concepto de Julio Ramos para explicar el tipo de "ficción jurídica" que proyectan tanto Manzano como la esclava María Antonia Mandinga. Para Ramos la literatura opera como discurso que se instala en los límites del "orden jurídico-simbólico" para proyectar "las condiciones que harían posible la subjetivación de los esclavos: la interpelación de los sujetos en una nueva red de dominación e identificación" (70). En algún sentido, las acciones de Molina apuntan a crear las condiciones para hacer posible un ciudadano negro en una ciudad letrada. 
independiente de los espacios hegemónicos sino vinculados a ellos por la colaboración y la resistencia, formaron parte de los sueños de Jacinto Ventura de Molina cuando el Estadonación empezaba a delimitar su territorio y a organizar su población. Las contradicciones y paradojas que el caso de Molina plantea a una historia de la "literatura nacional", además del color de su piel, cerraron las puertas para su "descubrimiento" y posterior canonización por parte de la crítica literaria, como sí había ocurrido con letrados como Larrañaga o Pérez Castellanos, tan alejados como él de una idea de una literatura y una estética modernas. Aún para los colectivos afrodescendientes más contemporáneos Molina resulta un caso difícil por su distancia de una heroicidad nacional como la del mítico Ansina. Estos grupos llegaron incluso a la contradicción de crear un Ansina letrado de dudosa legitimidad histórica a pesar de tener a su disposición los más de mil folios escritos por un afrodescendiente de carne y hueso. ${ }^{107}$ Con el extrañamiento que supuso sacar a Jacinto Ventura de Molina del marco interpretativo de la nación, con el ejercicio de reconstruir su punto de vista y concentrar el análisis en su lugar de enunciación, espero haber aportado una crítica al relato nacional hegemónico que comenzó a diseñarse en el siglo XIX y haber contribuido en algo a su democratización.

107 El marco interpretativo del Estado-nación hegemónico desde fines del siglo XIX alimentó identidades para la resistencia (Castells, 2003: 37) como la afrodescendiente en Uruguay. Estas identidades muchas veces se vieron atrapadas en las coordenadas que ese mismo relato nacional les imponía. Para el caso la necesidad de buscar un antepasado ilustre que fuera letrado y artiguista para legitimar un lugar prestigioso en el relato nacional. 


\section{Fuentes}

\section{Manuscritos de Jacinto Ventura de Molina}

(M, I) Tomo I. Glorias de la Santa Caridad de Montevideo

(M, II) Tomo II. Miscelánea I

(M, III) Tomo III. Miscelánea II

\section{Antologías de textos de Jacinto Ventura de Molina}

(A1) Gortázar, Alejandro (Coordinador), Adriana Pitetta y José Manuel Barrios. Jacinto Ventura de Molina. Antología de manuscritos (1817-1837). Montevideo: Facultad de Humanidades/CSIC, 2008.

(A2) Acree, William Jr. y Alex Borucki. Editores. Jacinto Ventura de Molina y los caminos de la escritura negra en el Río de la Plata. Montevideo: Linardi y Risso, 2008. 


\section{Bibliografía}

AA. VV. Ansina me llaman y Ansina yo soy... Montevideo: Rosebud, 1996.

AA. VV. "La ciudad letrada: hacia una historia de las élites intelectuales en América

Latina.” Dossier. Prismas. Revista de historia intelectual X 10 (2006). 155-212.

Academia Nacional de Letras. Diccionario del español del Uruguay. Montevideo: Banda

Oriental, 2011.

Acevedo, Eduardo. Obras históricas. Anales históricos del Uruguay. Tomo I. Montevideo:

Barreiro y Ramos, 1933.

—. Artigas. Su obra cívica. Alegato histórico. Montevideo: Ministerio de Instrucción Pública, 1950. Tomo I. Archivo Artigas.

Achugar, Hugo. Compilador. En otras palabras, otras historias. Montevideo: FHCE, 1994a.

—. "Historias paralelas / vidas ejemplares: la historia y la voz del Otro." En otras palabras, otras historias. Comp. Hugo Achugar. Montevideo: FHCE, $1994 b$.

—_. "Representando la heterogeneidad latinoamericana (a propósito de lugares, paisajes y territorios)." Revista Iberoamericana LXII 176-177 (julio-diciembre 1996). 837844.

—. "Leones, cazadores e historiadores, a propósito de las políticas de la memoria y del conocimiento.” Revista Iberoamericana LXIII 180 (julio-setiembre 1997). 379-387.

—. Compilador. La fundación por la palabra. Letra y Nación en América Latina en el siglo XIX. Montevideo: Facultad de Humanidades y Ciencias de la Educación, 1998.

—. Compilador. Derechos de memoria. Nación e Independencia en América Latina. 
Montevideo: Facultad de Humanidades y Ciencias de la Educación, 2003.

Achugar, Hugo y John Beverley. La voz del otro: testimonio, subalternidad y verdad narrativa. Eds. Lima/Pittsburg, Latinoamericana, 1992.

Acree, William Jr. "Jacinto Ventura de Molina. A black letrado in a white world of letters, 1766-1841." Latin American Research Review 44.2 (2009). 37-58.

—. "Black, famous, and out of place: an alternative intellectual in early nineteenthcentury Montevideo.” Rethinking intellectuals in Latin America. Mabel Moraña y Bret Gustafson. Editores. Madrid: Iberoamericana Vervuert, 2010, pp. 49-64. —. Everyday Reading. Print Culture and Collective Identity in the Rio de la Plata, 17801910. Nashville: Vanderbilt UP, 2011.

Acree, William Jr. y Alex Borucki. Editores. Jacinto Ventura de Molina y los caminos de la escritura negra en el Río de la Plata. Montevideo: Linardi y Risso, 2008.

Acosta, Luis. "La mediación del "higienismo" en la génesis del Servicio Social en el Uruguay". Publicado por la Escuela de Trabajo Social de Costa Rica en 2000. http://www.ts.ucr.ac.cr/binarios/pela/pl-000045.pdf. 17 de enero de 2013.

Adorno, Rolena. "La ciudad letrada y los estudios coloniales.” Hispamérica XVI 48 (1987). 3-24.

—. "La estatua de Gonzalo Guerrero en Akumal: íconos culturales y la reactualización del pasado colonial.” Revista Iberoamericana 176-7 (Jul-Dic 1996). 905-923.

—. "El sujeto colonial y la construccion cultural de la alteridad." Revista de Crítica Literaria Latinoamericana 14-28, Historia, Sujeto Social y Discurso Poetico en la Colonia (1988). 55-68.

—_. "Waman Puma: El autor y su obra". Nueva crónica y buen gobierno. Felipe Guamán Poma de Ayala. Edición de John V. Murra, Rolena Adorno y Jorge L. Urioste. 
Madrid: Historia 16, 1987. XVII-XLVII.

Aguerre Core, Fernando. "Lealtad, riqueza y autonomía en el Montevideo de las invasiones inglesas." Humanidades VI 1 (Diciembre 2006). 23-58.

Aguilar, Gonzalo. "Las costuras de la letra" Prismas. Revista de historia intelectual X 10 (2006). 173-176.

Alonso, Rosa, Lucía Sala, Nelson de la Torre y Julio Rodríguez. La oligarquía oriental en la Cisplatina. Montevideo: Pueblos Unidos, 1970.

Altamirano, Carlos. "La lección de escritura." Prismas. Revista de historia intelectual X 10 (2006). 177-180.

Armstrong, Nancy. Deseo y ficción doméstica. Madrid: Editorial Cátedra, 1991.

Anderson, Benedict. Comunidades imaginadas. Reflexiones sobre el origen y la difusión del nacionalismo. Buenos Aires: FCE, 2000. [1991].

Andrews, George Reid. Los afroargentinos de Buenos Aires. Buenos Aires: De la flor, 1989 [1980].

—. Blacnkess in the white nation. A history of Afro-Uruguay. Chapel Hill: North Carolina UP, 2010. [En español: Negros en la Nación Blanca: Historia de los AfroUruguayos. Montevideo: Linardi y Risso, 2011].

Anton, Danilo. "La esclavitud como sistema, la rebelión como derecho". Memorias del Simposio. La ruta del esclavo en el Río de la Plata: su historia y sus consecuencias. Montevideo: UNESCO, 2005. 225-243.

Arredondo, Horacio (hijo). Bibliografia uruguaya. Contribución. Montevideo: El Siglo Ilustrado, 1929.

Augé, Marc. Los no lugares. Espacios del anonimato. Una antropología de la sobremodernidad. Barcelona: Gedisa, 2000 [1992]. 
Ayestarán, Lauro. La música en el Uruguay. Vol. 1. Montevideo: SODRE, 1953.

_. El folklore musical uruguayo. Montevideo: Arca, 1972 [1967].

_. El tamboril y la comparsa. Montevideo: Arca, 1990 [1965].

Balibar, Etienne-Wallerstein, Immanuel. 1997. Race, nation, classe. Les identités ambiguës. Paris: La Découverte. Lotfallah Soliman. Traducción del inglés.

Baquaqua, Mahommah G. "Biografía de Mahommah G. Baquaqua." Revista brasileira de historia 8. 16 (1988) [1854]: 269-284.

—.Biography of Mahommah G. Baquaqua. A native of Zoogoo, in the interior of Africa. En: $\quad$ http://abolition.nypl.org/content/docs/text/bio mahommah_baquaqua.pdf. 2001. 26 de enero de 2014.

Barnet, Miguel. Biografía de un cimarrón. Buenos Aires: CEDAL, 1977.

_. "La novela-testimonio. Socio-literatura". Testimonio y literatura. Edits. Rene Jara y Hernán Vidal. Minneapolis: Institute of the study of ideologies and literature, 1986. Barrán, José Pedro. Historia de la sensibilidad en el Uruguay. Montevideo: Banda Oriental, 2011 [1989-1990].

Barrán, José Pedro y Benjamín Nahum. Bases económicas de la revolución artiguista. Montevideo: Banda Oriental, 1964.

Barrios Pintos, Aníbal. "Historias privadas de la esclavitud: un proceso criminal en tiempo de la Cisplatina.” Historias de la vida privada en el Uruguay. Tomo I. José Pedro Barrán, Gerardo Caetano y Teresa Porzecanski. Compiladores. Montevideo: Taurus, 1996. 173-195.

Basile, Teresa. "El desarme de Calibán en el deshielo tropical”. (original sin publicar) Bauzá, Francisco. Estudios literarios. Montevideo: Bibioteca Artigas, 1953. [1885] —. Historia de la dominación española en el Uruguay. Montevideo: Biblioteca Artigas, 
1965 [1880-1882, 1895-1897].

Benítez, José A. Las antillas: colonización, azúcar e imperialismo. La Habana: Casa de las Américas, 1977.

Bentancur, Arturo Ariel y Fernando Aparicio. Amos y esclavos en el Río de la Plata. Montevideo: Planeta, 2006.

Bentancur, Arturo Ariel. "La primera burocracia montevideana (1724-1814)”. America Latina y España: de la colonia a la constitución de los estados nacionales.Volumen 2. Lucía Sala. Compiladora. Montevideo: Ediciones del quinto Centenario, 1993.15-67.

Bentancur, Arturo, Alex Borucki y Ana Frega (Compiladores). Estudios sobre la cultura afro-rioplatense. Historia y presente. Tres entregas. Montevideo: FHCE, 20042007.

Beraza, Agustín. “Amos y esclavos”. Enciclopedia Uruguaya 9. Montevideo: Editores Reunidos / Arca, 1968. [Cuaderno: “Cantos y bailes negros.” Selección de textos de Isidoro de María y Vicente Rossi].

Beverley, John. Against literature. Minneapolis: University of Minessota Press, 1993.

—. Una modernidad obsoleta: estudios sobre el barroco. Caracas/Los teques, Estado Miranda: A.L.E.M., 1997.

Bhabha, Homi K. 1994. The location of culture. Londres: Routledge.

—. Editor. Nation and narration. London-New York: Routledge, 2000 [1990].

Bianchi, Diana. "Elementos para una tipología de los pobres asistidos en el Hospital de Caridad de Montevideo (1787-1830)". Revista Complutense de Historia de América 27 (2001). 107-129. 
Blanco Acevedo, Pablo. El gobierno colonial en el Uruguay y los orígenes de la nacionalidad. Montevideo: Barreiro y Ramos, 1944 (1929).

Bourdieu, Pierre. ¿Qué significa hablar? Madrid: Ediciones Akal, 1985.

—. Las reglas del arte. Génesis y estructura del campo literario. Barcelona: Anagrama, 2002 [1992].

—_. "La codificación” [1986]. Cosas dichas, Barcelona, Gedisa, 1988, pp. 83-89.

—_. “La ilusión biográfica". Razones Prácticas. Barcelona: Editorial Anagrama, 1997.

—. "Apología de una mujer formal." Capital cultural, escuela y espacio social. Isabel Jiménez. Compilación y traducción. México: Siglo XXI, 1998. 189-194.

Borucki, Alex. "Tensiones raciales en el juego de la representación. Actores afro en Montevideo tras la fundación republicana (1830-1840).” Cultura y sociedad afrorioplatense. Gustavo Goldman. Compilador. Montevideo: Perro andaluz, 2008.

Borucki, Alex, Carla Chagas y Natalia Stalla. Esclavitud y trabajo. Un estudio sobre los afrodescendientes en la frontera uruguaya. 1835-1855. Montevideo: Pulmón ediciones, 2004.

Borucki, Alex. "Entre el aporte a la identidad nacional y la reivindicación de las minorías. Apuntes sobre los afrodescendientes y la esclavitud en la historiografía uruguaya”. História Unisinos 103 (Setembro/Dezembro 2006). 310-320.

Braudel, Fernand. "La larga duración.” Las ambiciones de la Historia. Traducción de María José Furió. Barcelona, Crítica, 2002. 147-177.

Britos Serrat, Alberto. Compilador. Antología de poetas negros uruguayos. Montevideo: Mundo Afro, 1990.

—_. Antología de poetas negros uruguayos. Tomo II. Montevideo: Mundo Afro, 1997. Cabrera, Susana. Las esclavas del Rincón. Montevideo: Fin de Siglo, 2001. 
Caetano, Gerardo. Historia conceptual. Voces y conceptos de la política oriental (17501870). Montevideo: Banda Oriental, 2013.

Castellanos, Alfredo. "Prólogo.” Selección de escritos. Dámaso Antonio Larrañaga. Montevideo: Ministerio de Instrucción Pública y Previsión Social, 1965. Biblioteca Artigas, Vol. 92. VII-XLIII.

Castells, Manuel. La era de la información. Volúmen II. El poder de la identidad. Madrid: Alianza, 2003 [1997].

Castro-Gómez, Santiago. "Los vecindarios de la ciudad letrada. Variaciones filosóficas sobre un tema de Ángel Rama.” Ángel Rama y los estudios latinoamericanos. Mabel Moraña. Editora. Pittsburgh: IILI, 1997. 123-133.

Castro-Gómez, Santiago y Eduardo Mendieta. Teorías sin disciplina (latinoamericanismo, poscolonialidad y globalización en debate). México: Miguel Ángel Porrúa, 1998. En: http://www.ensayistas.org/critica/teoria/castro/

Cavallo, Guglielmo y Roger Chartier. Directores. Historia de la lectura en el mundo occidental. Madrid: Taurus, 1998. [1997].

Chartier, Roger. El orden de los libros. Lectores, autores, bibliotecas en Europa entre los siglos XIV y XVIII. Barcelona: Gedisa, 1994. [1992].

—. Escribir las prácticas. Foucault, de Certeau, Marin. Buenos Aires: Manantial, 1996. Chatterjee, Partha. La nación en tiempo heterogéneo y otros estudios subalternos. Buenos Aires: Siglo XXI, 2008.

Chukwundi Eze, Emmanuel. “El color de la razón: la idea de 'raza' en la antropología de Kant”. Capitalismo y geopolítica del conocimiento. El eurocentrismo y la filosofía de la liberación en el debate intelectual contemporáneo. Walter Mignolo. Compilador. Buenos Aires: Signo, 2001. 
Clifford, James y George Marcus. Editores. Writing Culture. The Poetics and Politics of Ethnography. Berkeley: University of California Press, 1986.

Coll, Magdalena. El habla de los esclavos africanos y sus descendientes en Montevideo en los siglos XVIII y XIX: respresentación y realidad. Montevideo: Banda Oriental, 2010.

Colombi, Beatriz. “Una gesta antiépica.” Prismas. Revista de historia intelectual X 10 (2006). 181-183.

Concolorcorvo. El lazarillo de ciegos caminantes desde Buenos Aires hasta Lima 1773. Barcelona: Biblioteca Ayacucho, 1985.

Cordones-Cook, Juanamaría. ¿Teatro negro uruguayo? Texto y contexto del teatro afrouruguayo de Andrés Castillo. Montevideo: Graffiti, 1996.

—_. "Mestizaje e hibridez: los riesgos de las metáforas. Apuntes." Revista Iberoamericana LXIII 180 (1997). 341-344.

Cornejo Polar, Antonio. La formación de la tradición literaria en el Perú. Lima: CEP, 1989.

—. Escribir en el aire. Ensayos sobre la heterogeneidad socio-cultural en las literaturas andinas. Lima: Horizonte, 1994.

—_. "Una heterogeneidad no dialéctica: Sujeto y discurso migrantes en el Perú moderno." Revista Iberoamericana LXII 176-177. 837-844.

—_. "Mestizaje e hibridez: los riesgos de las metáforas. Apuntes." Revista Iberoamericana LXII 180.341-344.

Corona, Ignacio. “¿Estrategia para salir de “La ciudad letrada”?: la reconversión de la crítica, el posnacionalismo y la generalción MeX.” Revista de crítica literaria latinoamericana XXXIII 65 (2007). 225-239. 
Coronil, Fernando. "Listening to the Subaltern: The Poetics of Neocolonial States."

Poetics Today, Vol. 15, No. 4 (Winter, 1994), pp. 643-658.

Costanzo, Angelo. "The narrative of Archibald Monteith, a Jamaican Slave". Callaloo 13-1 (Winter, 1990. 115-130.

Cotelo, Ruben. "Intoducción 2. Los contemporáneos." Capitulo Oriental. La historia de la literatura uruguaya. Montevideo: CEDAL, 1968.

Covarrubias, Sebastián de. Tesoro de la lengua castellana o española: Madrid, 1611. Versión digital en: http://fondosdigitales.us.es/fondos/libros/765/818/tesoro-de-lalengua-castellana-o-espanola/. 14 de enero de 2014.

De Man, Paul. “La autobiografía como desfiguración.” Anthropos 125 (octubre 1991). 113118. La autobiografía y sus problemas teóricos. Estudios e investigación documental. Loureiro, Ángel G. Compilador. Suplemento.

De María, Isidoro. Montevideo antiguo. Tradiciones y recuerdos. 2 tomos. Montevideo: Ministerio de Instrucción Pública, 1957.

D’Orbigny, Alcides. Viaje a la América Meridional. Buenos Aires: Futuro, 1945.

De Torres, María Inés. ¿La nación tiene cara de mujer? Mujeres y nación en el imaginario letrado del siglo XIX. Montevideo: Arca, 1995.

—. La guerra de las palabras. Escritura y política en el Río de la Plata. Montevideo: Banda Oriental, 2008.

Djenderedjian, Julio. "Roots of Revolution: Frontier Settlement Policy and the Emergence of New Spaces of Power in the Río de la Plata Borderlands, 1777 - 1810.” Hispanic American Historical Review 88:4 (2008). 639-668.

Demasi, Carlos. "Familia y esclavitud en el Montevideo del siglo XVIII." Sociedad y cultura en el Montevideo colonial. Comps. Luis E. Behares y Oribe Cures. 
Montevideo: FHCE/IMM, 1997.

Devassa sobre a entrega da Villa do Rio Grande ás tropas castelhas (1764). Rio Grande: Biblioteca Rio-Grandense, 1937.

Dos Santos, Gislene Aparecida. A invenção do "ser negro" (um percurso das idéias que naturalizaram a inferioridade dos negros). São Paulo: Educ, 2002.

Du Bois, W. E. B. The Souls of Black Folk. University of Virginia Library Electronic Text Center, 1999 [1903]. http://way.net/SoulsOfBlackFolk/SoulsOfBlackFolk.html. Agosto 2014.

Equiano, Oludah. The interesting narrative of the life of Oludah Equiano or Gustavus Vassa, the african. New York: The Modern Library, 2004 [1789].

Estrada, Dardo. Historia y bibliografia de la imprenta en Montevideo. 1810-1865. Montevideo: Librería Cervantes, 1912.

Eversley, Shelly. "A note on the text." The interesting narrative of the life of Oludah Equiano or Gustavus Vassa, the african. New York: The Modern Library, 2004 [1789]. Oludah Equiano. xxiii-xxiv.

Falcao Espalter, Mario. La vigía Lecor. Historia de la dominación portuguesa en el Uruguay. Montevideo: Renacimiento, 1919.

Fanon, Frantz. Piel negra, máscaras blancas. Madrid: Akal, 2009. [1952].

Fantoni y Benedí, Rafael de. “Títulos y grandezas de España concedidos al estamento militar por Carlos II (1665-1700)”. Emblemata, 13 (2007). 257-270.

Fernández Bravo, Álvaro. Compilador. La invención de la Nación. Lecturas de la identidad de Herder a Homi Bhabha. Buenos Aires, Manantial, 2000.

—_. "La provocación de La ciudad letrada." Prismas. Revista de historia intelectual X 10 (2006). 185-189. 
Fernández Labeque, Alicia y Óscar Jorge Villa. Bibliotecas coloniales. Libros, lecturas y bibliotecas en la América Española y la Banda Oriental. Montevideo: Banda Oriental/Biblioteca Nacional, 2012.

Fernández Medina, Benjamín. La imprenta y la prensa en el Uruguay desde 1807 a 1900. Montevideo: Dornaleche y Reyes, 1900.

Fernández Retamar, Roberto. Obras uno. Todo Calibán. La Habana: Letras Cubanas, 2000. Disponible en http://www.cubadebate.cu/wp-content/uploads/2009/05/todo-calibanroberto-fernandez-retamar.pdf. 28 de enero de 2014.

Fiorucci, Flavia e Inés Rojkind. "Reproches y anhelos del antiintelectualismo.” Prismas. Revista de historia intelectual X 10 (2006). 191-193.

Franco, José Luciano. "Juan Francisco Manzano, el poeta esclavo y su tiempo." Autobiografia, cartas y versos de Juan Francisco Manzano. La Habana: Municipio de La Habana, 1937.

Frega, Ana. "Caminos de libertad en tiempos de revolución. Los esclavos en la Provincia Oriental Artiguista, 1815-1820." Unisinos 4. 2 (Julio-Diciembre 2000): 29-57.

—. Karla Chagas, Óscar Montaño y Natalia Stalla. "Breve historia de los afrodescendientes en el Uruguay”. 2008. Población afrodescendiente y desigualdades étnico-raciales en Uruguay. Lucía Scuro Somma. Coordinadora. Motnevideo: PNUD / UNFPA / INE / Parlamento del Uruguay/AECID y UNIFEM. 5-102.

—. Coordinadora. Historia regional e independencia del Uruguay. Proceso histórico y revisión crítica de sus relatos. Montevideo: Banda Oriental, 2009.

—_. "Las caras opuestas de la revolución. Aproximación a sus significados desde la crisis de la monarquía española a la construcción del estado-nación”. Historia 
conceptual. Voces y conceptos de la politica oriental (1750-1870). Gerardo Caetano. Coordinador. Montevideo: Banda Oriental, 2013. 51-70.

Funari, P.P.A. “A arqueologia de Palmares. Sua contribução| para o conhecimento da história da cultura afro-americana". Liberdade por um fio. História dos quilombos no Brasil. João José Reis y Flávio dos Santos Gomes. São Paulo: Companhia das Letras, 1996. 26-51.

Funes, Eurípedes A. “«Nasci nas matas, nunca tive senhor» - História e memória dos mocambos do baixo Amazonas". Liberdade por um fio. História dos quilombos no Brasil. João José Reis y Flávio dos Santos Gomes. São Paulo: Companhia das Letras, 1996. 467-497.

Furlong, Guillermo y Enrique Arana (h). “La «Imprenta de la Caridad» (1822-1855)” Revista del Instituto Histórico y Geográfico IX, 1932. 6-164.

Garavaglia, Juan Carlos y Juan Marchena. América Latina de los orígenes a la independencia. II. La sociedad colonial ibérica en el siglo XVIII. Barcelona: Crítica, 2005.

García Canclini, Néstor. Culturas hibridas. Estrategias para entrar y salir de la modernidad. México DF: Grijalbo, 1996 [1989].

Garcilaso de la Vega, El Inca. Comentarios Reales. Tomos I y II. Prólogo, edición y cronología: Aurelio Miró Quesada. Caracas: Biblioteca Ayacucho, 1976.

Garramuño, Florencia. "El árbol y el bosque: La ciudad letrada y su concepto de poder." Prismas. Revista de historia intelectual X 10 (2006). 195-197.

Gates, Henry Louis Jr. Editor. "Editor's introduction: Writing «Race» and the difference it makes." Critical Inquiry 12.1, «Race», Writing, and Difference (1985): 1-20.

Geertz, Clifford. La interpretación de las culturas. Barcelona: Gedisa, 2005 (1973). 
Gellner, Ernest. 1983. 1997. Naciones y nacionalismo. Madrid: Alianza. Javier Setó. Traducción.

Gilman, Claudia. “América Latina, ciudad, voz y letra.” Prismas. Revista de historia intelectual X 10 (2006). 157-161.

Ginzburg, Carlo. El queso y los gusanos. El cosmos según un molinero del siglo XVI. Barcelona: Península, 2001 [1976].

Goldman, Gustavo. Candombe iSalva Baltazar! La fiesta de Reyes en el barrio sur de Montevideo. Montevideo: Perro Andaluz, 2003 (1996)

Gomá Lanzón, Javier. Imitación y experiencia. Barcelona: Crítica, 2005 [2003].

González Stephan, Beatriz. La historiografia literaria del liberalismo hispanoamericano del siglo XIX. Cuba: Casa de las Américas, 1987.

—. "Economías fundacionales. Diseño del cuerpo ciudadano." Cultura y tercer mundo. 2. Nuevas identidades y ciudadanías. Beatriz González Stephan. Compiladora. Caracas: Nueva Sociedad, 1996.

—. "La aguja subversiva: el desborde de la ciudada letrada." Revista Iberoamericana LXX 206 (Ene-Mar 2004). 159-182.

Gorelik, Adrián. "Posfacio. Transformaciones urbanas y estudios culturales." Miradas sobre Buenos Aires. Historia cultural y crítica urbana. Buenos Aires: Siglo XXI, 2004. 259-279.

_. "Intelectuales y ciudad en América Latina" Prismas. Revista de historia intelectual X 10 (2006). 163-172.

Gortázar, Alejandro. "Del aullido a la escritura.” Derechos de memoria. Nación e Independencia en América Latina. Hugo Achugar. Compilador. Montevideo: Facultad de Humanidades y Ciencias de la Educación, 2003. 189-263. 
__ 'La 'sociedad de color' en el papel. La Conservación y El Progresista dos semanarios de los afro-uruguayos.” Revista Iberoamericana. Cambio cultural y lectura de periódicos en el siglo XIX en América Latina. LXXII 214 (Enero-Marzo 2006). 109-123.

_. El licenciado negro Jacinto Ventura de Molina. Montevideo: Trilce, 2007.

—. "Jacinto Ventura de Molina en la cultura letrada del siglo XIX uruguayo". Jacinto Ventura de Molina. Antología de manuscritos (1817-1837). Alejandro Gortázar (Coord.), Adriana Pitetta y José Manuel Barrios. Montevideo: Facultad de Humanidades/CSIC, 2008. 11-22.

Gourgouris, Stathis. Dream nation. Enlightenment, Colonization and the institution of Modern Greece. Stanford: Stanford UP, 1996.

Grimson, Alejandro. Los límites de la cultura. Crítica de las teorías de la identidad. Buenos Aires: Siglo XXI, 2011.

Guamán Poma de Ayala, Felipe. Nueva crónica y buen gobierno. Edición de John V. Murra, Rolena Adorno y Jorge L. Urioste. Madrid: Historia 16, 1987.

Guha, Ranahit. Las voces de la historia y otros estudios subalternos. Barcelona: Crítica, 2002 [1982, 1983 y 1996].

—. La historia en el término de la historia universal. Juan Rabasseda-Gascón. Traducción. Barcelona: Crítica, 2003 [2002].

Gusdorf, Georges. "Condiciones y límites de la autobiografía." La autobiografía y sus problemas teóricos. Estudios e investigación documental. Suplemento. Ángel G. Loureiro. Compilador. Anthropos 125 (octubre 1991). 9-18.

Hammerly Dupuy, Daniel y Víctor Hammerly Peverini. Artigas en la poesía de América. Tomos 1 y 2. Buenos Aires: Noel, 1951. 
Hernández, María del Carmen. "Tres primeras escritoras latinoamericanas del siglo XIX”. La fundación por la palabra. Hugo Achugar. Compilador. Montevideo: FHCE, 1998. 177-219.

Hobsbawm, Eric. Rebeldes primitivos. Estudio sobre las formas arcaicas de los movimientos sociales en los siglos XIX y XX. Barcelona: Crítica, 2003 [1959].

_. La era de la revolución, 1789-1848. Buenos Aires: Crítica, 2006 [1962].

—. Naciones y nacionalismo desde 1780. Barcelona: Crítica/Grijalbo Mondadori, 1995 [1990].

Introini, Juan y Victoria Herrera. La ninfa en la selva. Literatura uruguaya y tradición clásica. Montevideo: Facultad de Humanidades y Ciencias de la Educación, 2008.

Introini, Juan, Victoria Herrera y L. Augusto Moreira. Viejas liras y nuevos vates. Literatura uruguaya y tradición clásica. Montevideo: Facultad de Humanidades y Ciencias de la Educación, 2012.

Irigoyen, Emilio. La patria en escena. Estética y autoritarismo en Uruguay. Textos, monumentos, representaciones. Montevideo: Trilce, 2000.

Islas, Ariadna. “Cuestiones de género, «cuestión racial», «cuestión social»: pan, ropa sucia y altares en la colonia de Montevideo (1730-1811)." Sociedad y cultura en el Montevideo colonial. Compiladores. Luis E. Behares y Oribe Cures. Montevideo: FHCE/IMM, 1997.

Isola, Ema. La esclavitud en el Uruguay desde sus comienzos hasta su extinción (17431852). Montevideo: Comisión Nacional de Homenaje al sesquicentenario de los hechos históricos de 1825, 1975.

Kuper, Adam. The invention of primitive society. Transformations of an illusion. Londres: Routledge, 1996 (1988). 1-104. 
Lamas, Andrés. Escritos selectos del Dr. D. Andrés Lamas. Pablo Blanco Acevedo.

Prólogo. Montevideo: Arduino Hnos., 1922.

Lamas, Luis. "Edicto de la policía". El investigador 37 (29 de mayo de 1833). 301-302.

Lara Bosch, José Manuel. "Sector editorial: el caso de Planeta." Empresas multinacionales españolas 799 (abr-may 2002). 219-224.

Larrañaga, Dámaso Antonio. Selección de escritos. Montevideo: Ministerio de Instrucción Pública y Previsión Social, 1965. Biblioteca Artigas, Vol. 92.

Latour, Bruno. Nuca fuimos modernos. Ensayos de antropología simétrica. Buenos Aires: Siglo XXI. 1991.

Lejeune, Philippe. “El pacto autobiográfico.” [Primer capítulo de Le pacte autobiographique, 1975] Anthropos 125 (octubre 1991). 47-61. La autobiografía y sus problemas teóricos. Estudios e investigación documental. Loureiro, Ángel G. Compilador y traductor.

Leach, E. R. 1976 (1954). Sistemas políticos de la Alta Birmania. Estudio sobre la estructura social Kachin. Barcelona: Anagrama.

Lesser, Ricardo. La última llamarada. Cevallos, primer virrey del Río de la Plata. Buenos Aires: Biblos, 2005.

Lewis, Marvin A. Afro-Uruguayan Literature: Post-Colonial Perspectives. Lewisburg, PA: Bucknell UP, 2003.

Lewis-Galanes, Adriana. "Literatura afro-hispanoamericana: óptica estética e ideología autoral." Identidad cultural de Iberoamérica en su literatura. Saúl Yurkievich. Coordinador. 1986. 278-293.

Lienhard, Martín. La voz y su huella. Escritura y conflicto étnico-social en América Latina. La Habana: Casa de las Américas, 1990. 
—. O mar e o mato. Histórias da escravidão. Luanda: Kilombelombe, 2005.

Losada, Alejandro. “Articulación, periodización y diferenciación de los procesos literarios em América Latina.” Revista de Crítica Literaria 917 (1983). 7-37.

Loureiro, Ángel G. Compilador. "Problemas teóricos de la autobiografía." La autobiografía y sus problemas teóricos. Estudios e investigación documental. Suplemento. Anthropos 125 (octubre 1991). 2-8.

Ludmer, Josefina. “Tretas del débil." La sartén por el mango, encuentro de escritores latinoamericanos. Patricia E. González y Eliana Ortega. Editoras. República Dominicana: El Huracán, 1984.

Macchi, Fernanda. "Juan Francisco Manzano y el discurso abolicionista: una lectura enmarcada.” Revista Iberoamericana LXXIII 218-219 (enero-junio 2007). 63-77.

Madden, Richard. Poems by a slave in the island of Cuba, recently liberated; translated from the spanish by R.R. Madden, M.D. with the history of the early life of the negro poet, written by himself, to wich are prefixed two pieces descriptive of cuban slavery and the slave-traffic, by R.R.M. Londres: Thomas Ward and Co., 1840.

Mailhe, Alejandra. "Desdoblamientos especulares." Prismas. Revista de historia intelectual X 10 (2006). 199-203.

Manzano, Juan Francisco. Autobiografia, cartas y versos de Juan Francisco Manzano. La Habana: Municipio de La Habana, 1937.

Mariátegui, José Carlos. Siete ensayos de interpretación de la realidad peruana. La Habana: Casa de las Américas, 1963.

Marren, Susan M. "Between Slavery and Freedom: The Transgressive Self in Olaudah Equiano's Autobiography”. PMLA Vol. 108, No. 1 (Jan., 1993). pp. 94-105.

Martínez Shaw, Carlos. "El siglo de las Luces. Las bases intelectuales del reformismo." 
Historia de España. $N^{o} 19$. Madrid: Temas de hoy, 1996.

Martínez Montero, Homero. "La esclavitud en el Uruguay." Revista Nacional 32 41, 45 y 57 (Agosto de 1940, Mayo de 1941, Setiembre de 1941 y Setiembre de 1942).

Martínez Shaw, Carlos. "El siglo de las Luces. Las bases intelectuales del reformismo." Historia de España. $N^{o}$ 19. Madrid: Temas de hoy, 1996.

Mezzadra, Sandro. "El New Deal en la línea del color. El problema de la reforma y el espacio de la democracia en W. E. B. Du Bois". Prismas. Revista de historia intelectual 12 (2008). 33-48.

Mignolo, Walter. "La semiosis colonial: la dialéctica entre representaciones fracturadas y hermenéuticas pluritópicas". Ad-VersuS V 4-6 (diciembre, 1994). 35-50. http://www.adversus.org/indice/nro3/articulos/articulomignolo.htm. Agosto 2014.

—. The Darker Side of the Renaissance: Literacy, Territoriality, and Colonization. Michigan: Michigan UP, 1995.

—. “Occidentalización, imperialismo, globalización: herencias coloniales y teorías poscoloniales.” Revista Iberoamericana 170-171 (1995). 27-40.

—_. "Posoccidentalismo: las epistemologías fronterizas y el dilema de los estudios (latinoamericanos) de área.” Revista Iberoamericana LXII 176-177 (julio-diciembre 1996). 679-696.

—. Compilador. "Introducción." Capitalismo y geopolítica del conocimiento. El eurocentrismo y la filosofía de la liberación en el debate intelectual contemporáneo. Buenos Aires: Signo, 2001. 9-53.

—. El pensamiento des-colonial, desprendimiento y apertura: un manifiesto. Tristestópicos. 2005. http://disciplinas.stoa.usp.br/pluginfile.php/146654/mod_resource/content/1/Walter 
\%20Mignolo $\% 20-\% 20 \mathrm{El} \% 20$ pensamiento $\% 20$ descolonial $\% 20$ \%20desprendimiento\%20y\%20apertura.pdf. Agosto 2014.

Milán, Guillermo. “Letra 'oscura' contra habla ‘transparente': los valores de la palabra oral y la palabra escrita en el Montevideo colonial”. Uruguay: imaginarios culturales. Tomo 1. Hugo Achugar y Mabel Moraña. Editores. Montevideo: Trilce, 2000.

Miller, Marilyn. "Rebeldía narrativa, resistencia poética y expresión "libre” en Juan Francisco Manzano.” Revista Iberoamericana LXXI 211 (Abr-Jun 2005). 417-436.

Minelli, Alejandra. "Entrevista a Cornejo-Polar”. Revista de Lengua y Literatura 17-22 (1997). 153-156.

Miró Quesada, Aurelio. “Prólogo". Comentarios Reales. Tomos. El Inca Garcilaso de la Vega. Prólogo, edición y cronología: Aurelio Miró Quesada. Caracas: Biblioteca Ayacucho, 1976. ix-xli.

Modonesi, Massimo. Subalternidad, antagonismo, autonomía. Marxismo y subjetivación política. Buenos Aires: CLACSO, 2010.

Molloy, Sylvia. Acto de presencia. La escritura autobiográfica en Hispanoamérica. México DF: F.C.E., 1996 [1991].

Montaño, Oscar D., umkhonto. Historia del aporte negro-africano en la formación del Uruguay. Montevideo: Rosebud, 1997.

—. Yeninyanya (UmkhontoII). Historia de los afrouruguayos. Montevideo: Mundo Afro, 2001.

—. Historia afrouruguaya. Tomo I. Montevideo: IMPO, 2008.

Moraña, Mabel. "Ideología de la transculturación.” Ángel Rama y los estudios latinoamericanos. Mabel Moraña. Editora. Pittsburgh: IILI, 1997. 137-145.

—. Viaje al silencio: exploraciones del discurso barroco. Alicante : Biblioteca Virtual 
Miguel de Cervantes, 2005 [1998].

Moreiras, Alberto. “José María Arguedas y el fin de la transculturación.” Ángel Rama y los estudios latinoamericanos. Mabel Moraña. Editora. Pittsburgh: IILI, 1997. 213231.

—. Tercer espacio: literatura y duelo en América Latina. Santiago de Chile: Lom/Arcis, 1999.

—_. "Hegemonía y subalternidad." Nuevas perspectivas desde/sobre América Latina: el desafio de los estudios culturales. Mabel Moraña. Editora. Santiago de Chile: Cuarto Propio, 2000. 135-147.

Moreno Fraginals, Manuel. “Aportes culturales y deculturación.” África en América Latina. Manuel Moreno Fraginals. Relator. Montevideo: Siglo XXI/UNESCO, 1977. 152-184.

Myers, Jorge E. “Las letras del poder: apogeo y catástrofe.” Prismas. Revista de historia intelectual X 10 (2006). 205-208.

Nairn, Tom. Los nuevos nacionalismos en Europa. La desintegración de la Gran Bretaña. Barcelona: Península, 1979 [1977].

Olney, James. “Algunas versiones de la memoria / Algunas versiones del bios: la ontología de la autobiografía." La autobiografía y sus problemas teóricos. Estudios e investigación documental. Suplemento. Ángel G. Loureiro. Compilador. Anthropos 125 (octubre 1991). 33-47.

Olson, David R. El mundo sobre el papel. El impacto de la escritura y la lectura en la estructura del conocimiento. Barcelona: Gedisa, 1998 [1994].

Olson, David R. y Nancy Torrance. Compiladores. Cultura escrita y oralidad. Barcelona: Gedisa, 1998. [1991]. 
Ong, Walter. Oralidad y escritura. Tecnología de la palabra. Buenos Aires: FCE, 1993. [1982]

Ortiz, Fernando. Contrapunto cubano del tabaco y el azúcar. (Advertencia de sus contrastes agrarios, económicos, históricos y sociales, su etnografía y su transculturación). La Habana: Consejo Nacional de Cultura, 1963. [1940]

Ortner, Sherry B. (Jan. 1995) "Resistance and the Problem of Ethnographic Refusal" Comparative Studies in Society and History 37.1.173-193.

Paladino, Clara. "Fiesta y contrapunto: miradas en las celebraciones de la independencia en América." Derechos de memoria. Nación e Independencia en América Latina.

Hugo Achugar. Compilador. Montevideo: Facultad de Humanidades y Ciencias de la Educación, 2003. 123-188.

Pedemonte, Juan Carlos. Hombres con dueño. Crónica de la esclavitud en el Uruguay. Montevideo: Independencia, 1943.

Pelfort, Jorge. 150 años. Abolición de la esclavitud en el Uruguay. Montevideo: De la Plaza, 1996.

Pereda Valdés, Ildefonso. Antología de la poesía negra americana. Santiago de Chile: Ercilla, 1936. [Otra edición: Montevideo: Medina, 1953]

—. El negro rioplatense. Montevideo: Claudio García, 1937.

—. Linea de color. Santiago de Chile: Ercilla, 1938.

—. Negros esclavos y negros libres. Esquema de una sociedad esclavista y aporte del negro en nuestra formación nacional. Montevideo: Ministerio de Instrucción Pública, 1941.

—. Les afroaméricains. Dakar: Ifsan, 1953.

_. El negro en la epopeya artiguista. Montevideo: Barreiro y Ramos, 1964. 
—. Un tipo social que se le olvidó a Sarmiento en Facundo. Santa Fe: 1964.

_. El negro en el Uruguay. Pasado y presente. Montevideo: Revista del Instituto Histórico y Geográfico, 1965.

Pérez Castellano, José Manuel. Selección de escritos. Crónicas históricas (1787-1814). Montevideo: Ministerio de Cultura, 1968.

Perus, Françoise. “¿Qué nos dice hoy La ciudad letrada de Ángel Rama?” Revista Iberoamericana LXXI 211 (Abr-Jun 2005). 363-372.

Petit Muñoz, Eugenio, Edmundo Narancio y José María Traibel Nelcis. La condición jurídica, social, económica y política de los negros durante el coloniaje en la Banda Oriental. Montevideo: 1947.

Peyrou, Rosario. Ángel Rama. Explorador de la cultura. Montevideo: CCE, 2010.

Pizarro, Ana. Coordinación. La literatura latinoamericana como proceso. Buenos Aires: CEDAL, 1985.

Plotkin, Mariano Ben. “Intelectuales en América Latina.” Prismas. Revista de historia intelectual X 10 (2006). 209-212.

Pozuelo Yvancos, José María. "Retórica y narrativa: la narratio”. Epos Vol. II (1986). 231252.

—. De la autobiografía. Teoría y estilos. Barcelona: Crítica, 2006.

Praderio, Antonio. Índice cronológico de la prensa periódica del Uruguay. 1807-1852. Montevideo: Facultad de Humanidades, 1962.

—_. "Prólogo." Obra completa. Bartolomé Hidalgo. Montevideo: Biblioteca Artigas, 1986.

Pratt, Marie Louise, Ojos imperiales. Literatura de viajes y transculturación, Buenos Aires, Universidad Nacional de Quilmes, 1997 [1992]. 
Puiggrós, Ernesto. “La batalla de Las Piedras.” Boletín histórico del ejército 271-274 (1986). 9-66.

Pupo-Walker, Enrique. La vocación literaria del pensamiento histórico en América. Desarrollo de la prosa de ficción: siglos XVI, XVII, XVIII y XIX. Madrid: Gredos, 1982.

Quispe-Agnoli, Rocío. “"Yo y el Otro»: identidad y alteridad en la «Nueva Corónica y Buen Gobierno»”. MLA 1192 (Mar., 2004). 226-251.

—_. "Prácticas indígenas de la resistencia: sujetos de la escritura y el saber en los andes coloniales”. Revista Iberoamericana LXXIII 220 (Julio-Septiembre, 2007). 415436.

Rama, Ángel. “Sesquicentenario de J. M. Pérez Castellano (I). El primer intelectual uruguayo" Marcha XXVII 1272 (Montevideo, 17 de setiembre de 1965).

—_. "Sesquicentenario de J. M. Pérez Castellano (II). En la propiedad se funda una cultura" Marcha XXVII 1273 (Montevideo, 24 de setiembre de 1965).

—_. "180 años de literatura." Enciclopedia Uruguaya. Historia ilustrada de la civilización uruguaya. № II. Ángel Rama. Plan y dirección general. Montevideo: Arca, 1968.

—. Los gauchipoliticos rioplatenses. Literatura y sociedad. Montevideo: Arca, 1998 [1976].

—. Diario 1974-1983. Rosario Peyrou. Prólogo, edición y notas. Montevideo: Trilce, 2001.

—. Transculturación narrativa en América Latina. Buenos Aires: El Andariego, 2007. [1982]

_. La ciudad letrada. Montevideo: Arca, 1998 [1984]. 
—. "Algunas sugerencias de trabajo para una aventura intelectual de integración." La literatura latinoamericana como proceso. Ana Pizarro. Coordinación. Buenos Aires, 1985. 85-97.

—. "La literatura en su marco antropológico." En: Literatura, cultura, sociedad en América Latina. Antología, prólogo y notas .de Pablo Rocca con la colaboración de Verónica Pérez. Montevideo: Trilce, 2006

Rama, Carlos. Los afrouruguayos. Montevideo: El Siglo Ilustrado, 1968.

Ramírez, Arbelio. Una librería de la época colonial. Montevideo: s.e., 1952.

—. Una biblioteca privada de mediados del siglo XIX. Montevideo: s.e., 1949.

Ramos, Julio, Desencuentros con la modernidad en América Latina. Literatura y política en el siglo XIX. México: FCE, 1989.

—. Paradojas de la letra. Caracas: eXcultura, 1996.

Real Academia Española. Diccionario de autoridades [1726-1739]. Consulta on line en http://web.frl.es/DA.html. 18 de enero de 2014.

- Nuevo tesoro lexicográfico de la lengua española. Consulta on line en: http://www.rae.es/recursos/diccionarios/diccionarios-anteriores-1726-1992/nuevotesoro-lexicografico. 23 de agoto de 2014.

Real de Azúa, Carlos. "Introducción 1. De los orígienes al Novecientos.” Capítulo Oriental. La historia de la literatura uruguaya. Montevideo: CEDAL, 1968.

Redfield, Robert, Ralph Linton y Melville J. Herskovits. "Memorandum for the Study of Acculturation.” American Anthropologist 38-1 (Jan. - Mar., 1936). 149-152.

Reid-Pharr, Robert. "Introduction." The interesting narrative of the life of Oludah Equiano or Gustavus Vassa, the african. Oludah Equiano. New York: The Modern Library, 2004 [1789]. VII-LX. 
Reis, João José y Flávio dos Santos Gomes. Liberdade por um fio. História dos quilombos no Brasil. São Paulo: Companhia das Letras, 1996.

Rela, Walter. Enfrentamiento entre España y Portugal por la Banda Oriental: de Manuel Lobo a Pedro de Cevallos 1680-1777. Rivera: Academia Uruguaya de Historia Universidad de Passo Fundo (RS, Brasil), 2006. [Recurso electrónico, 1 disco].

Remedi, Gustavo. “Ciudad letrada: Ángel Rama y la especialización del análisis cultural.” Ángel Rama y los estudios latinoamericanos. Mabel Moraña. Editora. Pittsburgh: ILLI, 1997. 97-122.

Reyes Abadie, Washington y Andrés Vázquez Romero. Crónica General del Uruguay 2. El siglo XVIII. Montevideo: Banda Oriental, 1999 [1998].

Reyes Abadie, Washington. Españoles en el Uruguay. Montevideo: Banda Oriental, 2000.

Ribadeneyra, Pedro de. Vida de santos. Antología del Flos sanctorum. Javier Azpeitia. Selección y prólogo. Madrid: Lengua de Trapo, 2000.

Rocca, Pablo. Poesía y política en el siglo XIX (Un problema de fronteras). Montevideo: Banda Oriental, 2003.

—. Ángel Rama, Emir Rodríguez Monegal y el Brasil: dos caras de un proyecto latinoamericano. Montevideo: Banda Oriental, 2006a.

—_. "Prólogo." Literatura, cultura, sociedad en América Latina. Antología, prólogo y notas de Pablo Rocca con la colaboración de Verónica Pérez. Montevideo: Trilce, 2006b.

Rodríguez, Romero Jorge. Mbundo malungo a mundele. Historia del movimiento afrouruguayo y sus alternativas de desarrollo. Montevideo: Rosebud, 2006.

Rossi, Vicente. Cosas de negros. Los origenes del tango y otros aportes al folklore rioplatense. Rectificaciones históricas. Buenos Aires: Taurus, 2001. [Córdoba: 
Impr. Argentina, 1926].

Rossiello, Leonardo. Compilador. Las otras letras. Literatura uruguaya del siglo XIX. Montevideo: Graffiti, 1994.

Roxlo, Carlos. Historia crítica de la literatura uruguaya. Montevideo: Barreiro y Ramos, 1912.

Said, Edward W. Orientalismo. ([1978] 2002). Barcelona: Debate. María Luisa Fuentes. Traducción.

—. Cultura e imperialismo. ([1993] 1996) Barcelona: Anagrama. Nora Catelli. Traducción.

Sala, Lucía, Nelson de la Torre y Julio C. Rodríguez. Estructura económico-social de la colonia. Montevideo: Pueblo Unidos, 1967.

Schwarz, Roberto. Ao vencedor as batatas. Forma literária e processo social nos inícios do romance brasileiro. San Pablo: Duas Cidades, 1981.

Scío de San Miguel, Felipe. La Biblia Sagrada, a saber: El Antiguo y el Nuevo Testamento, traducidos de la Vulgata Latina en Español. [1793]. https://archive.org/stream/labibliasagrada00socigoog\#page/n2/mode/2up. Agosto de 2014.

Scott, James C. Weapons of the Weak. New Haven: Yale University Press, 1985.

—. Los dominados y el arte de la resistencia. Discursos ocultos. México DF: Era, 2000 [1990].

Scuro Somma, Lucía. Población afrodescendiente y desigualdades étnico-raciales en Uruguay. Motnevideo: PNUD / UNFPA / INE / Parlamento del Uruguay/AECID y UNIFEM, 2008.

Segato, Rita Laura. La nación y sus otros. Raza, etnicidad y diversidad religiosa en 
tiempos de políticas de la identidad. Buenos Aires: Prometeo, 2007.

Skar, Stacey Alba D. Voces híbridas. La literatura de chicanas y latinas en Estados Unidos. Santiago de Chile: Ril, 2001.

Spivak, Gayatri Chakravorti. (1988) 1998 “Puede hablar el subalterno?” Orbis Tertius. Revista de teoría y crítica literaria 6. 175- 235.

Suárez Peña, Lino. Apuntes y datos referentes a la raza negra en los comienzos de su vida en esta parte del Plata. Montevideo: Museo Lavalleja, 1924 [1923].

—. La raza negra en el Uruguay. Novela histórica de su paso por la esclavitud. Época Moderna, 1933.

Torre Revello, José. Juan José de Vértiz y Salcedo. Buenos Aires: Imprenta de la Universidad, 1932.

Torres, Alicia. La Gazeta de Montevideo (1810-1814). Encubrimiento y representación. Montevideo: Rebeca Linke, 2010.

Trigo, Abril. “El proyecto cultural de «Capítulo Oriental»y «Enciclopedia Uruguaya» (Reflexiones sobre las publicaciones en fascículo de los años 60)”, Hispamérica, Maryland, Número 94, 2003, pp. 13-24.

Tylor, Edward B. La cultura primitiva (1871). Madrid: Ayuso, 1977-1981, 2 vols.

UNESCO. "The slave route. Transatlantic slave trade". http://www.unesco.org/new/en/culture/themes/dialogue/the-slave-

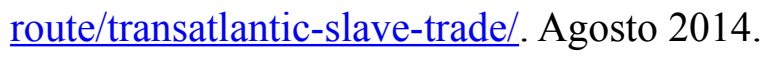

Uriarte, Javier. "Las fechas y la invención del sistema simbólico nacional en América Latina". Derechos de memoria. Nación e independencia en América Latina. Hugo Achugar. Compilador. Montevideo: FHCE, 2003. 341-400.

Varela, Alfredo. Rio grande do sul. Descrição física, histórica e econômica. Pelotas: 
Echenique, 1897.

Vera León, Antonio. "Hacer hablar: La transcripción testimonial.” La voz del otro: testimonio, subalternidad y verdad narrativa. Eds. Hugo Achugar y John Beverley. Lima/Pittsburgh, Latinoamericana, 1992. 181-199.

Verdesio, Gustavo. La invención del Uruguay. La entrada del territorio y sus habitantes a la cultura occidental. Montevideo: Graffiti, 1996.

—. "Revisando un modelo: Ángel Rama y los estudios coloniales." Ángel Rama y los estudios latinoamericanos. Mabel Moraña. Editora. Pittsburgh: ILLI, 1997. 235248.

—. "En busca de la materialidad perdida: un aporte crítico a los proyectos de recuperación de las tradiciones aborígenes propuestos por Kusch, Dussel y Mignolo.” Revista Iberoamericana LXVI 192 (2000). 625-638.

—. "Todo lo que es sólido se disuelve en la academia: sobre los estudios coloniales, la teoría poscolonial, los estudios subalternos y la cultura material" Revista de estudios hispánicos (2001)

Weinberg, Liliana. "El año de la muerte de Ángel Rama.” Revista Iberoamericana LXXI 211 (Abr-Jun 2005). 387-400.

Williams, Raymond. The country and the city. New York: Oxford UP, s.f. [1973]

_. La larga revolución. Buenos Aires: Nueva Visión, 2003. [1961]

_. Marxismo y literatura. Barcelona: Península, 1980. [1977]

—. Palabras clave. Un vocabulario de la cultura y la sociedad. Buenos Aires: Nueva

Visión, 2000. [1976]

—. La política del modernismo: contra los nuevos conformistas. Buenos Aires:

Manantial, 2002. [1989] 
Yúdice, George. "Testimonio y concientización". La voz del otro: testimonio, subalternidad y verdad narrativa. Eds. Hugo Achugar y John Beverley. Lima/Pittsburgh, Latinoamericana, 1992. 208-227.

Zubillaga, Carlos. "Comunidades historiográficas y renovación disciplinaria en Uruguay". Revista Complutense de Historia de América 29 (2003). 179-191.

Zum Felde, Alberto. Proceso intelectual del Uruguay. Montevideo: Nuevo Mundo, 1967 [1930]. 